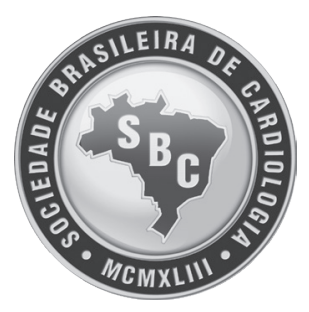

\title{
II Diretriz Brasileira de Transplante Cardíaco
}

\section{Coordenador de Normatizações e Diretrizes da SBC}

\author{
Jadelson Pinheiro de Andrade
}

\section{Autores}

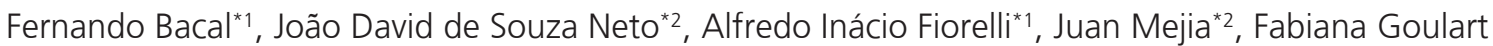
Marcondes-Braga ${ }^{* * 1}$, Sandrigo Mangini ${ }^{\star * 1}$, José de Lima Oliveira $\mathrm{Jr}^{\star * 1}$, Dirceu Rodrigues de Almeida ${ }^{3}$, Estela Azeka', Jarbas Jakson Dinkhuysen", Maria da Consolação Vieira Moreira ${ }^{5}$, João Manoel Rossi Neto4, Reinaldo Bulgarelli Bestetti ${ }^{6}$, Juliana Rolim Fernandes², Fátima das Dores Cruz ${ }^{1}$, Lucinei Paz Ferreira', Helenice Moreira da Costa' ${ }^{1}$ Ana Augusta Maria Pereira ${ }^{4}$, Nicolas Panajotopoulos'1, Luiz Alberto Benvenuti', Lídia Zytynski Moura7 $^{7}$ Glauber Gean Vasconcelos², João Nelson Rodrigues Branco ${ }^{3}$, Claudio Leo Gelape ${ }^{5}$, Ricardo Barreira Uchoa $^{2}$, Silvia Moreira Ayub-Ferreira ${ }^{1}$, Luis Fernando Aranha Camargo ${ }^{3-8}$, Alexandre Siciliano Colafranceschi ${ }^{9}$, Solange Bordignon ${ }^{10}$, Reginaldo Cipullo ${ }^{4}$, Estela Suzana Kleiman Horowitz ${ }^{10}$, Klébia Castelo Branco ${ }^{2}$, Marcelo Jatene ${ }^{1}$, Sergio Lopes Veiga ${ }^{7}$, Cesar Augusto Guimarães Marcelino ${ }^{4}$, Guaracy Fernandes Teixeira Filho ${ }^{10}$, José Henrique Vila11, Marcelo Westerlund Montera ${ }^{12-13}$

*Coordenadores da II Diretriz Brasileira de Transplante Cardíaco **Comissão de Redação e planejamento

\section{INSTITUIÇõES}

${ }^{1}$ Instituto do Coração do Hospital das Clínicas da Faculdade de Medicina da Universidade de São Paulo; ${ }^{2}$ Hospital de Messejana Dr. Carlos Alberto Studart Gomes, Ceará; ${ }^{3}$ Escola Paulista de Medicina, Universidade Federal de São Paulo; ${ }^{4}$ Instituto Dante Pazzanese de Cardiologia, São Paulo; ${ }^{5}$ Hospital das Clínicas da Universidade Federal de Minas Gerais; ${ }^{6}$ Faculdade de Medicina de São José do Rio Preto; ${ }^{7}$ Santa Casa de Misericórdia de Curitiba, Pontifícia Universidade Católica do Paraná; ${ }^{8}$ Hospital Israelita Albert Einstein; ${ }^{9}$ nnstituto Nacional de Cardiologia,

Rio de Janeiro; ${ }^{10}$ nstituto de Cardiologia, Fundação Universitária do Rio Grande do Sul; ${ }^{11}$ Real e Benemérita Sociedade de Beneficência Portuguesa, São Paulo; ${ }^{12}$ Hospital Pró-Cardíaco do Rio de Janeiro; ${ }^{13}$ Santa Casa do Rio de Janeiro

Esta diretriz deverá ser citada como: Bacal F, Souza-Neto JD, Fiorelli AI, Mejia J, Marcondes-Braga FG, Mangini S, et al. II Diretriz Brasileira de Transplante Cardíaco. Arq Bras Cardiol.2009;94(1 supl.1):e16-e73 
Declaração obrigatória de conflito de interesses

Nos últimos três anos, o autor/colaborador da diretriz:

\begin{tabular}{|c|c|c|c|c|c|c|c|}
\hline Nome do médico & $\begin{array}{l}\text { Participou de } \\
\text { estudos clínicos } \\
\text { e/ou experimentais } \\
\text { subvencionados } \\
\text { pela indústria } \\
\text { farmacêutica ou } \\
\text { de equipamentos } \\
\text { relacionados à } \\
\text { diretriz em questão }\end{array}$ & $\begin{array}{l}\text { Foi palestrante } \\
\text { em eventos } \\
\text { ou atividades } \\
\text { patrocinadas } \\
\text { pela indústria } \\
\text { relacionados } \\
\text { à diretriz em } \\
\text { questão }\end{array}$ & $\begin{array}{l}\text { Foi (é) membro } \\
\text { do conselho } \\
\text { consultivo } \\
\text { ou diretivo } \\
\text { da indústria } \\
\text { farmacêutica ou } \\
\text { de equipamentos }\end{array}$ & $\begin{array}{l}\text { Participou } \\
\text { de comitês } \\
\text { normativos } \\
\text { de estudos } \\
\text { científicos } \\
\text { patrocinados } \\
\text { pela indústria }\end{array}$ & $\begin{array}{l}\text { Recebeu } \\
\text { auxílio } \\
\text { pessoal ou } \\
\text { institucional } \\
\text { da indústria }\end{array}$ & $\begin{array}{c}\text { Elaborou } \\
\text { textos } \\
\text { científicos em } \\
\text { periódicos } \\
\text { patrocinados } \\
\text { pela indústria }\end{array}$ & $\begin{array}{c}\text { Tem } \\
\text { ações da } \\
\text { indústria }\end{array}$ \\
\hline Alexandre Siciliano Colafranceschi & Não & Não & Não & Não & Não & Não & Não \\
\hline Alfredo Inacio Fiorelli & Não & Não & Não & Não & Não & Não & Não \\
\hline Ana Augusta Maria Pereira & Não & Não & Não & Não & Não & Não & Não \\
\hline $\begin{array}{l}\text { Cesar Augusto Guimarães } \\
\text { Marcelino }\end{array}$ & Não & Não & Não & Não & Não & Não & Não \\
\hline Claudio Gelape & Não & Não & Não & Não & Não & Não & Não \\
\hline Dirceu Rodrigues de Almeida & Não & Não & Pfizer; Ache; Baldacci & Não & Não & Pfizer; Baldacci & Não \\
\hline Estela Azeka & Não & Não & Norvartis & Não & não & Não & Não \\
\hline Estela Suzana Kleiman Horowitz & Não & Não & Não & Não & Não & Não & Não \\
\hline Fabiana Goulart Marcondes Braga & Não & Não & Não & Não & Não & Não & Não \\
\hline Fátima das Dores Cruz & Não & Não & Não & Não & Não & Não & Não \\
\hline Fernando Bacal & Novartis & Não & Novartis & Não & Não & Não & Não \\
\hline Glauber Gean de Vasconcelos & Não & Não & Não & Não & Não & Não & Não \\
\hline Guaracy Fernandes Teixeira Filho & Não & Não & Nâo & Não & Não & Não & Não \\
\hline Helenice Moreira da Costa & Não & Não & Nâo & Não & Não & Não & Não \\
\hline Jarbas Jakson Dinkhuysen & Não & Não & Não & Não & Não & Não & Não \\
\hline João David de Souza Neto & Não & Merck Serono & Não & Não & Não & Não & Não \\
\hline João Manoel Rossi & Não & Não & Não & Não & Não & Não & Não \\
\hline João Nelson Rodrigues Branco & Não & Não & Não & Não & Não & Não & Não \\
\hline José de Lima Oliveira Junior & Não & Não & Não & Não & Não & Não & Não \\
\hline José Henrique Vila & Não & Não & Não & Não & Não & Não & Não \\
\hline Juan Mejia & Não & Não & Nâo & Não & Não & Não & Não \\
\hline Juliana Rolim Fernandes & Não & Não & Não & Não & Não & Não & Não \\
\hline Klébia Castello Branco & Não & Não & Não & Não & Não & Não & Não \\
\hline Lidia Zytynski Moura & Nâo & Não & Nâo & Não & Novartis & Não & Não \\
\hline Lucinei Paz Ferreira & Não & Não & Não & Não & Não & Não & Não \\
\hline Luiz Alberto Benvenuti & Não & Não & Não & Não & Não & Não & Não \\
\hline Luis Fernando Aranha Camargo & Não & Não & Não & Não & Não & Não & Não \\
\hline Maria da Consolação V. Moreira & Não & Não & Nâo & Não & Não & Não & Não \\
\hline Marcelo Jatene & Não & Não & Nâo & Não & Não & Não & Não \\
\hline Marcelo Montera & Jansen; Pfizer; Altana & Merck; Biolab; Pfizer & Merck & Não & St Jude & Não & Não \\
\hline Nicolas Panajotopoulos & Não & Não & Não & Não & Não & Não & Não \\
\hline Reginaldo Cipullo & Não & Não & Não & Não & Não & Não & Não \\
\hline Reinaldo Bestetti & Não & Não & Não & Não & Saint Jude & Não & Não \\
\hline Ricardo Barreira Uchoa & Não & Não & Não & Não & Não & Não & Não \\
\hline Sandrigo Mangini & Não & Não & Não & Não & Não & Não & Não \\
\hline Sérgio Lopes Veiga & Não & Não & Não & Não & Novartis & Não & Não \\
\hline Silvia Moreira Ayub Ferreira & AMGEN & Não & Não & Não & Não & Não & Não \\
\hline Solange Bordignon & Não & Não & Não & Não & Novartis & Não & Não \\
\hline
\end{tabular}




\section{SUMÁRIO}

I. Introdução

página e16

\section{Avaliação do receptor}

A) Indicações e contraindicações para transplante cardíaco ................................................................ página e16

B) Preparo do candidato ao transplante cardíaco .......................................................................... página e17

i. Exames de avaliação, seleção e acompanhamento dos candidatos ambulatoriais ......................................... página e17

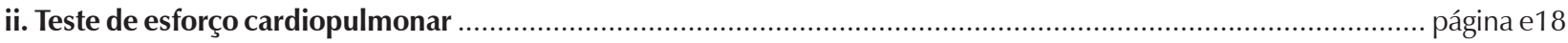

iii. Escore prognóstico - Heart Failure Survival Score (HFSS) e Seattle Heart Failure Model (SHFM) ......................... página e18

iv. Tratamento e manutenção de pacientes ambulatoriais na lista de espera ..................................................... página e19

C) Tratamento e manutenção do receptor internado: farmacológico e não farmacológico ................................ página e19

i. Medidas de controle da congestão em pacientes com insuficiência cardíaca crônica descompensada ................ página e20

D) Manejo de drogas vasoativas e dispositivos de assistência

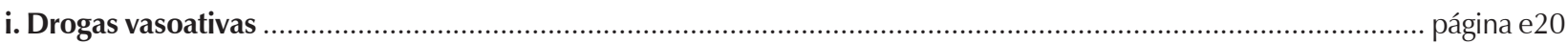

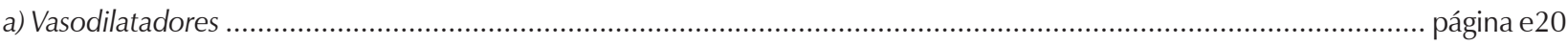

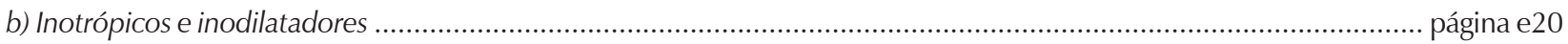

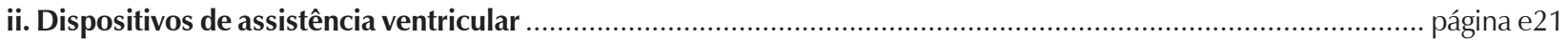

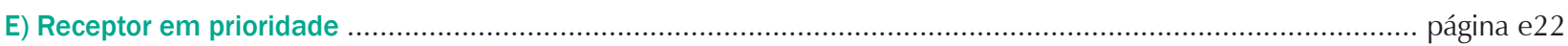

F) Receptor limítrofe

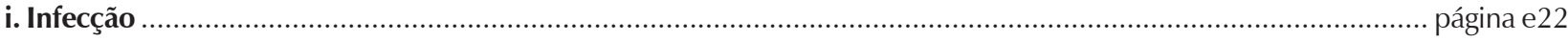

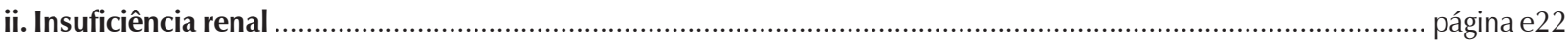

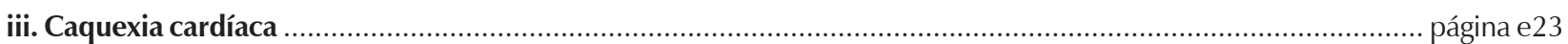

G) Avaliação hemodinâmica pulmonar ....................................................................................... página e2

H) Avaliação multiprofissional do candidato ao transplante cardíaco

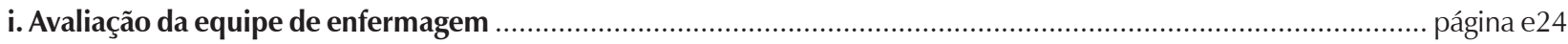

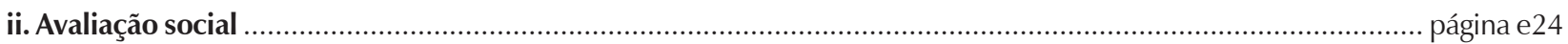

iii. Avaliação nutricional do candidato ao transplante cardíaco …..................................................................... página e25

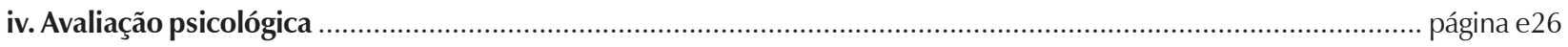

III. Imunología

A) Avaliação imunológica pré e pós-transplante cardíaco …............................................................... página e26

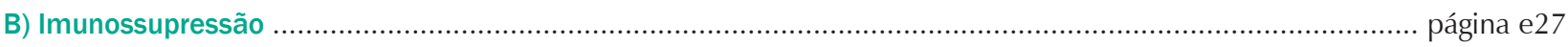

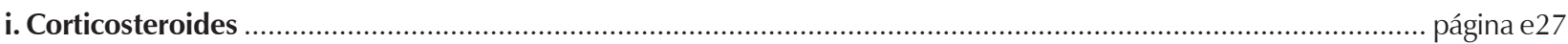

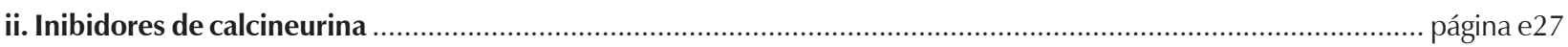

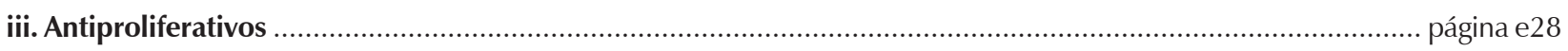

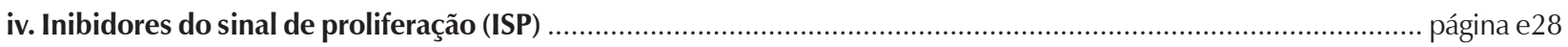

C) Diagnóstico da rejeição aguda celular, humoral e a biópsia endomiocárdica ............................................ página e29

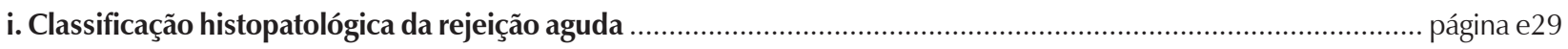

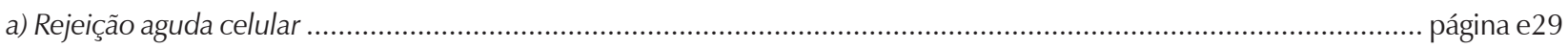

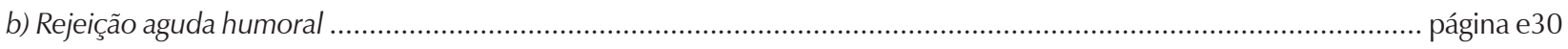

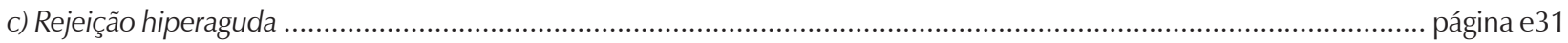

ii. Outros achados significativos da biópsia endomiocárdica, distintos da rejeição ............................................. página e 31

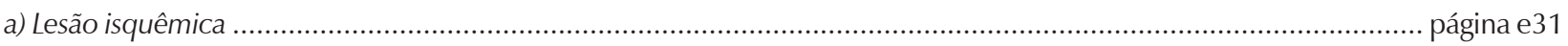

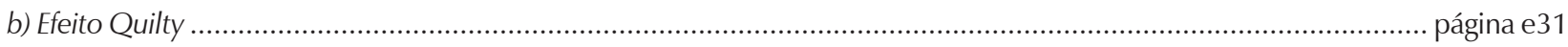

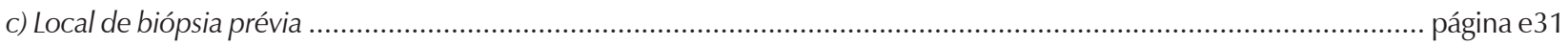

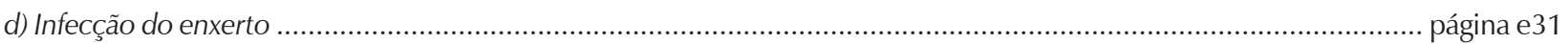

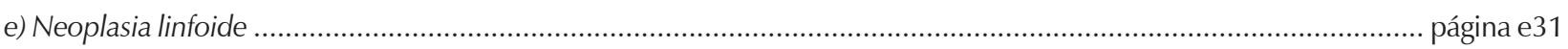


D) Tratamento da rejeição aguda celular e humoral

página e31

i. Rejeição aguda celular

. página e32

ii. Rejeição humoral

página e32

E) Terapias de indução e terapias de resgate

página e33

i. Anticorpos monoclonais

página e33

ii. Anticorpos policlonais

. página e34

iii. Ciclofosfamida

página e34

iv. Plasmaférese

página e34

v. Metotrexate

página e34

vi. Imunoglobulina

. página e35

vii. Rituximab

página e35

F) Seguimento pós-transplante cardíaco - avaliação de rejeição

página e35

i. Biópsia endomiocárdica

página e35

ii. Cintilografia miocárdica

página e35

iii. Ressonância magnética cardíaca

página e35

G) Doença vascular do enxerto

página e35

i. Diagnóstico

página e36

ii. Prevenção e tratamento

página e36

IV. Aspectos cirúrgicos do transplante cardíaco

A) Captação e preservação do enxerto

página e37

i. Técnica de retirada do enxerto

página e37

ii. Preservação do coração

página e38

B) Transplante ortotópico: técnica clássica x bicaval

página e38

i. Anuloplastia valvar tricúspide profilática

. página e38

C) Transplante heterotópico

página e38

D) Aspectos anestésicos e monitoração perioperatória

página e39

i. Técnicas de ventilação

. página e40

ii. Suporte hemodinâmico

página e40

E) Disfunção aguda do enxerto

i. Disfunção aguda do ventrículo esquerdo (VE)

página e41

página e41

ii. Disfunção aguda do ventrículo direito (VD)

página e42

F) Uso de hemoderivados e controle de sangramento no perioperatório do transplante cardíaco

i. Risco de sangramento em transplante cardíaco

página e43

ii. Reversão de terapias anticoagulante e antiagregante plaquetária

página e43

a) Antagonistas da vitamina K (Varfarina)

página e43

b) Heparinas

página 43

c) Antiagregantes plaquetários

página e44

iii. Uso de hemoderivados e controle de sangramento pós-operatório

. página e44

\section{Complicações pós-transplante}

A) Condutas em complicações infecciosas pós-transplante cardíaco ........................................................ página e 45

i. Introdução

página e45

ii. Profilaxia

página e45

a) Profilaxia para infecções de sítio cirúrgico

página e45

b) Profilaxia para toxoplasmose

. página e46

c) Profilaxia para Pneumocystis jirovecii (carinii)

página e46

d) Profilaxia para citomegalovírus (CMV) 


\section{Diretrizes}

\section{iii. Diagnóstico e tratamento}

a) Infecção pelo citomegalovírus

b) Toxoplasmose

c) Pneumocystis jirovecii (carinii)

iv. Imunização em adultos

B) Reativação da Doença de Chagas

i. Profilaxia

ii. Diagnóstico

iii. Tratamento

C) Neoplasias após transplante cardíaco

D) Retransplante cardíaco

E) Comorbidades - prevenção e tratamento

i. Diabetes melito

ii. Hipertensão arterial sistêmica

iii. Dislipidemias

iv. Insuficiência renal

v. Osteoporose .

vi. Depressão

F) Orientações equipe multiprofissional

i. Dieta

ii. Aderência

iii. Reinserção social

iv. Atividade física

v. Atividade sexual

VI. Transplante cardíaco em críanças

A) Indicações e contraindicações

B) Acompanhamento ambulatorial pré e pós-transplante cardíaco pediátrico

i. Acompanhamento ambulatorial pré-transplante cardíaco

ii. Acompanhamento ambulatorial pós-transplante cardíaco

C) Rejeição

i. Diagnóstico

ii. Tratamento

iii. Imunossupressão

D) Técnicas cirúrgicas - particularidades na criança

i. Técnica cirúrgica

E) 0 doador para crianças

VII. O papel das centrais de captação e avaliação do doador

A) Estratégias para confirmação do potencial doador

i. Critérios de morte encefálica

ii. Exames de avaliação

a) Angiografia cerebral .

b) Eletroencefalograma

c) Doppler transcraniano

d) Cintilografia cerebral (tecnécio 99 m Tc hexametazime)

B) Manutenção do doador

C) Atuação das organizações de procura de órgãos (OPO) e alocação de órgãos página e47

página e47

página e47

página e47

página e48

página e48

página e48

página e48

página e49

página e49

página e50

página e50

página e50

. página e51

página e51

página e52

página e52

página e53

página e53

página e53

página e53

página e53

página e53

página e53

página e53

página e53

página e55

página e55

página e56

página e57

página e57

página e57

página e58

página e59

página e59

página e59

página e60

página e60

página e60

página e60

página e60

página e60

página e60

. página e60

página e60

página e62 
D) Abordagem multidisciplinar do potencial doador

página e62

i. Identificação de potencial doador

página e63

ii. Avaliação do potencial doador página e63

iii. Entrevista familiar página e63

iv. Retirada de órgãos e tecidos página e63

v. Entrega do corpo a família página e63

VIII. Organização do centro transplantador
A) Critérios para habilitação e estrutura do centro transplantador
página e63
B) Aspectos éticos do transplante cardíaco página e64
C) Papel da secretaria de saúde na organização do sistema de transplante cardíaco página e64 


\section{Diretrizes}

\section{Introdução}

O transplante cardíaco persiste sendo o tratamento de escolha para a insuficiência cardíaca refratária, apesar da grande melhora na expectativa de vida com o tratamento clínico. Vários avanços nessa área foram observados na última década, com a incorporação de novas técnicas cirúrgicas, novos imunossupressores, novos métodos diagnósticos e abordagens nos pós-operatórios precoce e tardio. O Brasil tem ocupado cada vez mais espaço no campo dos transplantes, com destaque na América Latina, e acima de tudo como país referência no transplante cardíaco na doença de Chagas, guiando condutas que são incorporadas no mundo todo.

A elaboração de uma Diretriz é uma das principais atribuições de uma sociedade médica, orientando e fornecendo elementos para que os médicos possam tomar suas decisões e condutas, embasadas em documento atualizado, seguindo o maior rigor científico, representando condutas de especialistas com larga experiência na área, juntamente com as evidências nacionais e/ou internacionais publicadas até o momento.

Esta é a II Diretriz Brasileira em Transplante Cardíaco, finalizada exatos 10 anos após a primeira Diretriz, publicada nos Arquivos Brasileiros de Cardiologia. O critério para elaboração deste documento iniciou-se com a definição de 4 coordenadores, 2 clínicos e 2 cirurgiões, representantes dos principais centros transplantadores. Após essa definição, consultou-se a Associação Brasileira de Transplante de Orgãos (ABTO), sobre os centros que se mantinham atuantes, tendo realizado pelo menos 10 transplantes nos últimos 5 anos. Foram convidados, portanto, os representantes dessas respectivas instituições, compondo um seleto grupo de profissionais com ampla experiência para elaboração deste importante documento.

Acreditamos que esta Diretriz servirá de consulta para equipes multiprofissionais que atendem pacientes em avaliação ou já em seguimento após transplante, bem como ajudará como orientação para hospitais e serviços que pretendem iniciar seus respectivos programas.

Conceitos que vão desde o processo de seleção de potenciais receptores, até os cuidados em todas as fases após o transplante foram incorporados neste documento, sendo, portanto, um guia prático, atualizado e completo, elaborado por profissionais experientes do grupo de estudos de insuficiência cardíaca (GEIC) da Sociedade Brasileira de Cardiologia.

Seguem as classes de recomendação e níveis de evidência utilizados por esta diretriz.

\section{Classes de Recomendação}

Classe I - Consenso sobre a indicação do procedimento/ tratamento.

Classe Ila - Evidências favorecem a indicação do procedimento/tratamento.

Classe Ilb - Evidências não favorecem a indicação do procedimento/tratamento.

Classe III - Não indicado o procedimento/tratamento.

\section{Níveis de Evidência}

A - Dados obtidos a partir de estudos randomizados ou metanálises de grandes estudos randomizados;

$B$ - Dados obtidos de um único ensaio clínico randomizado ou vários estudos não randomizados;

C - Dados obtidos de estudos que incluíram uma série de casos e dados obtidos do consenso e de opiniões de especialistas.

\section{Avaliação do receptor}

\section{A) Indicações e contraindicações para transplante cardíaco}

O transplante cardíaco é reconhecido como o melhor tratamento para a insuficiência cardíaca (IC) refratária, mesmo na ausência de estudos randomizado-controlados. Quando uma criteriosa seleção é utilizada para a escolha do doador e do receptor, há um significante aumento na sobrevida, na capacidade de exercício, no retorno ao trabalho e na qualidade de vida ${ }^{1}$.

Pacientes portadores de IC avançada, classes funcionais III ou IV, com sintomas graves sem alternativa de tratamento clínico e com pior prognóstico têm indicação para transplante cardíaco ${ }^{2-4}$. O tratamento clínico deve ter otimização farmacológica e não farmacológica máximas ${ }^{5}$.

Também na IC aguda, devemos promover a remoção de fatores reversíveis, como doença coronária de tratamento cirúrgico, insuficiência mitral passível de correção ou cirurgia de defeitos congênitos ${ }^{5}$. Alguns critérios de indicações e contraindicações têm mudado nos últimos anos, principalmente com relação à idade, teste cardiopulmonar (TCP), resistência vascular pulmonar (RVP), obesidade, câncer, diabetes melito (DM), doença de Chagas, insuficiência renal, doença vascular periférica (DVP), e abuso de drogas ${ }^{4,6}$. As indicações para transplante cardíaco estão resumidas na Tabela 1.

A avaliação da RVP e o TCP devem ser realizados em candidatos a transplante cardíaco ${ }^{4}$. $\mathrm{Na}$ impossibilidade de realizar o TCP, o teste de caminhada de 6 minutos é uma alternativa válida. Quando à distância percorrida é menor do que 300 metros, há associação com maior mortalidade.

Nos intolerantes ao betabloqueador (BB), o ponto de corte do pico de $\mathrm{VO}_{2}$ é $14 \mathrm{ml} / \mathrm{Kg} / \mathrm{min}$. Nos tolerantes, o $\mathrm{VO}_{2}$ é $12 \mathrm{ml} /$ $\mathrm{Kg} /$ min. Nos últimos anos, novas publicações confirmaram que o uso equivalente de ventilação do dióxido de carbono $\left(\mathrm{VE} / \mathrm{VCO}_{2}\right)$ slope $>35$ é um parâmetro de mau prognóstico e por este motivo pode ser usado para indicação de transplante cardíaco ${ }^{1,4,8-10}$.

Portadores de neoplasia que têm baixo grau de malignidade podem ser aceitos. Em tumores com resposta à quimioterapia e ausência de metástase, o transplante cardíaco deve ser considerado com permissão do oncologista ${ }^{4}$.

A presença de DM pode ser um grande problema no transplante cardíaco devido às complicações decorrentes da imunossupressão. Portadores de DM com lesões de órgãos-alvo têm contraindicação relativa. Diabéticos sem lesão de órgãos-alvo têm bons resultados, ao passo que 
Tabela 1 - Indicações de transplante cardíaco

\begin{tabular}{|c|c|c|}
\hline $\begin{array}{l}\text { Classe de } \\
\text { Recomendação }\end{array}$ & Indicações & $\begin{array}{l}\text { Nível de } \\
\text { Evidência }\end{array}$ \\
\hline \multirow{5}{*}{ Classe I } & $\begin{array}{c}\text { IC refratária na dependência de drogas } \\
\text { inotrópicas e/ou de suporte circulatório } \\
\text { e/ou ventilação mecânica; }\end{array}$ & C \\
\hline & $\mathrm{VO}_{2}$ pico $\leq 10 \mathrm{ml} / \mathrm{Kg} / \mathrm{min} ;$ & C \\
\hline & $\begin{array}{l}\text { Doença isquêmica com angina refratária } \\
\text { sem possibilidade de revascularização; }\end{array}$ & C \\
\hline & Arritmia ventricular refratária; & C \\
\hline & Classe funcional III/IV persistente. & C \\
\hline \multirow{4}{*}{ Classe Ila } & $\begin{array}{l}\text { Teste da caminhada dos } 6 \text { minutos < } \\
\qquad 300 \text { metros; }\end{array}$ & C \\
\hline & $\begin{array}{l}\text { Uso de } \mathrm{BB} \text { com } \mathrm{VO}_{2} \text { pico } \leq 12 \mathrm{ml} / \mathrm{Kg} / \\
\mathrm{min} ;\end{array}$ & C \\
\hline & $\begin{array}{l}\text { Sem uso de BB com VO }{ }_{2} \text { pico } \leq 14 \mathrm{ml} / \\
\mathrm{Kg} / \mathrm{min} ;\end{array}$ & C \\
\hline & $\begin{array}{l}\text { Teste cardiopulmonar com relação VE/ } \\
\mathrm{VCO}_{2}>35 \text { e VO}_{2} \text { pico } \leq 14 \mathrm{ml} / \mathrm{Kg} / \mathrm{min}\end{array}$ & C \\
\hline \multirow[b]{2}{*}{ Classe III } & Presença de disfunção sistólica isolada; & C \\
\hline & $\begin{array}{l}\text { Classe funcional III ou IV sem } \\
\text { otimização terapêutica. }\end{array}$ & C \\
\hline
\end{tabular}

DM não controlada $(\mathrm{HbAc}>7,5)$ deve ter contraindicação relativa $^{1,4,11}$.

A insuficiência renal deve ser avaliada de acordo com o clearance de creatinina ou creatinina sérica como parâmetros de seleção. Clearance da creatinina $<30 \mathrm{ml} / \mathrm{min} / 1,73 \mathrm{~m}^{2}$ é contraindicação relativa. Nesse caso, pode-se considerar o transplante combinado rim/coração ${ }^{12}$.

Doença cerebrovascular grave e sintomática é contraindicação. Doença vascular periférica é considerada uma contraindicação relativa quando limita a reabilitação e não há condições de revascularização ${ }^{12}$.

Pacientes com dependência química e tabagismo devem ter abstinência superior a 6 meses e acompanhamento da equipe multidisciplinar para indicação de transplante cardíaco.

A doença de Chagas deixou de ser uma controvérsia devido aos seus bons resultados, com baixa incidência de reativação e sobrevida superior às outras etiologias ${ }^{13}$.

As avaliações psicológica, social, de enfermagem, nutricional, odontológica e de fisioterapia são obrigatórias, buscandose identificar fatores de risco que possam comprometer a evolução do tratamento. O transplante cardíaco pressupõe um tratamento multidisciplinar ${ }^{3,4,14}$. As contraindicações estão resumidas nas Tabelas 2 e 3 .

\section{B) Preparo do candidato ao transplante cardíaco}

\section{i. Exames de avaliação, seleção e acompanhamento dos candidatos ambulatoriais}

A seleção dos candidatos ao transplante cardíaco envolve o uso de variáveis prognósticas no sentido de
Tabela 2 - Contraindicações absolutas para transplante cardíaco

\begin{tabular}{|c|c|}
\hline \multirow{5}{*}{ Absolutas } & $\begin{array}{c}\text { Resistência vascular pulmonar fixa > } 5 \text { Wood, mesmo após } \\
\text { provas farmacológicas; }\end{array}$ \\
\hline & Doenças cerebrovascular e/ou vascular periférica graves; \\
\hline & Insuficiência hepática irreversível, doença pulmonar grave; \\
\hline & $\begin{array}{l}\text { Incompatibilidade ABO na prova cruzada prospectiva entre } \\
\text { receptor e doador; }\end{array}$ \\
\hline & $\begin{array}{c}\text { Doença psiquiátrica grave, dependência química e não } \\
\text { aderência às recomendações da equipe. }\end{array}$ \\
\hline Tabela 3 - & traindicações relativas para transplante cardíaco \\
\hline \multirow{14}{*}{ Relativas } & Idade maior do que 70 anos; \\
\hline & $\begin{array}{c}\text { Diabetes insulino-dependente com lesões graves de } \\
\text { órgãos-alvo; }\end{array}$ \\
\hline & Comorbidades com baixa expectativa de vida; \\
\hline & Obesidade mórbida; \\
\hline & Infecção sistêmica ativa; \\
\hline & Úlcera péptica em atividade; \\
\hline & Embolia pulmonar com menos de três semanas; \\
\hline & Neoplasia com liberação do oncologista; \\
\hline & Diabetes melito de difícil controle; \\
\hline & Insuficiência renal com clearance abaixo de $30 \mathrm{~m} / / \mathrm{min} / 1,73 \mathrm{~m}^{2}$; \\
\hline & Amloidose/sarcoidose/hemocromatose; \\
\hline & Hepatite B ou C; \\
\hline & Síndrome de imunodeficiência adquirida; \\
\hline & Painel linfocitário > $10 \%$. \\
\hline
\end{tabular}

identificar pacientes com IC avançada, combinadas com as contraindicações e comorbidades, as quais podem acarretar desfechos desfavoráveis, como redução da sobrevida após transplante ou alto risco perioperatório. Esse processo de seleção requer equipe multidisciplinar com profundo conhecimento do prognóstico e manejo dos pacientes com IC avançada ${ }^{4}$.

A avaliação, estratificação de risco e inclusão dos pacientes ambulatoriais na fila de espera é um procedimento crítico e requer conhecimento dos marcadores prognósticos de sobrevida. Até o momento, não existe um critério clínico perfeito para identificar os pacientes de maior risco de morte, que deveriam ser colocados na fila de espera do transplante. Mais de 100 fatores prognósticos de sobrevida foram identificados, na tentativa de se otimizar a seleção dos candidatos, tais como: etiologia da IC, reduzida fração ejeção do ventrículo esquerdo (FEVE), classe funcional da IC (NYHA), frequência cardíaca de repouso, pressão arterial média, persistência de terceira bulha, distúrbio de condução intraventricular no ECG de repouso, reduzida concentração de sódio sérico, níveis elevados de catecolaminas séricas, peptídeos natriuréticos (BNP e NT-pró BNP), troponina, elevada pressão capilar pulmonar, reduzido índice cardíaco, pressão arterial pulmonar, resistência vascular pulmonar, baixo 


\section{Diretrizes}

pico de consumo de oxigênio $\left(\mathrm{VO}_{2}\right)$ durante o exercício, dentre outros.

A Tabela 4 resume a rotina de avaliação basal e periódica de pacientes ambulatoriais inscritos na fila de transplante cardíaco ${ }^{4}$.

Embora a seleção dos doadores não se baseie nos antígenos leucocitários humanos (HLA), o exame deve ser feito para análise retrospectiva. A reatividade contra painel (PRA) é feita para rastrear anticorpos pré-formados antiHLA e avaliar necessidade de prova cruzada prospectiva e possibilidade de rejeição humoral após o transplante. Um estudo de PRA é considerado positivo quando é maior do que $10 \%$ utilizando as técnicas clássicas de CDC e ELISA, ou qualquer valor quando utilizada a técnica de Luminex, devendo-se, nestas situações, recomendar prova cruzada antes do transplante. O PRA deve ser repetido em pacientes após a utilização de hemoderivados. Em nossa realidade, todos os pacientes devem receber tratamento profilático antiparasitário antes da realização de transplante cardíaco. Isso ocorre devido ao risco de superinfecção após o uso de agentes imunossupressores.

\section{ii. Teste de esforço cardiopulmonar}

Após tratamento máximo da IC, a medida do $\mathrm{VO}_{2}$ pico durante o exercício fornece uma avaliação objetiva da capacidade funcional, e constitui uma medida indireta da reserva cardiovascular. $\mathrm{O}$ valor do $\mathrm{VO}_{2}$ pico na indicação de transplante cardíaco foi estudado em 114 pacientes, os quais foram prospectivamente classificados em três grupos: grupo um: $\mathrm{VO}_{2}$ pico $<14 \mathrm{ml} / \mathrm{kg} / \mathrm{min}$, estes foram aceitos como candidatos a transplantes; grupo dois: $\mathrm{VO}_{2}$ pico $>14 \mathrm{ml} / \mathrm{kg} / \mathrm{min}$, cujo transplante foi adiado; grupo três: $\mathrm{VO}_{2}$ pico $<14 \mathrm{ml} / \mathrm{kg} / \mathrm{min}$, recusados para transplantes por causas não cardíacas. A melhor sobrevida em um ano foi observada entre os pacientes com $\mathrm{VO}_{2}$ pico $>14 \mathrm{ml} /$ $\mathrm{Kg} / \mathrm{min}$ e a pior entre os pacientes com $\mathrm{VO}_{2}$ pico $<10 \mathrm{ml}$ $\mathrm{kg} / \mathrm{min}$ (47\% em um ano) e, portanto, é consensual que este último grupo seja aceito para transplante cardíaco, a menos que haja contraindicação ${ }^{15}$.

Entretanto, a utilização do $\mathrm{VO}_{2}$ pico como valor absoluto tem limitações, visto que a capacidade ao esforço sofre influência da idade, do sexo e da superfície corporal. Outra forma de se analisar esse fator prognóstico tem sido a análise do percentual do valor predito para peso, idade e sexo. $\mathrm{VO}_{2}$ pico inferior a $50 \%$ do predito tem alta sensibilidade como fator de risco de morte súbita ou de descompensações recorrentes da IC. Recentes estudos demonstraram superioridade da eficácia ventilatória ( $\mathrm{VE} / \mathrm{VCO}_{2}$ slope) em relação ao $\mathrm{VO}_{2}$ pico no prognóstico de pacientes com IC $\mathrm{I}^{8,10}$.

iii. Escore prognóstico - Heart Failure Survival Score (HFSS) e Seattle Heart Failure Model (SHFM)

Esses modelos têm sido utilizados frequentemente para cálculo de previsão de sobrevida em pacientes com IC crônica.

O Heart Failure Survival Score (HFSS) pode também orientar a necessidade de transplante em pacientes ambulatoriais com longos períodos de espera. Esse modelo estatístico continua
Tabela 4 - Recomendações para avaliação e seleção do receptor de transplante cardíaco

\begin{tabular}{|c|c|c|}
\hline Teste & Basal & Repetir \\
\hline Anamnese e exame físico completos; & $x$ & \multirow{2}{*}{ Quinzena } \\
\hline Acompanhamento. & $x$ & \\
\hline \multicolumn{3}{|l|}{ Imunocompatibilidade } \\
\hline $\mathrm{ABO}$ & $x$ & \\
\hline PRA (ver texto); & $x$ & \\
\hline Tipagem HLA tecidual; & $x$ & \\
\hline \multicolumn{3}{|l|}{ Avaliação da gravidade da IC } \\
\hline Teste cardiopulmonar; & $x$ & \\
\hline Ecodopplercardiograma; & $x$ & \\
\hline Avaliação hemodinâmica pulmonar; & $x$ & Anual \\
\hline ECG de repouso. & $X$ & \\
\hline \multicolumn{3}{|l|}{ Avaliação funcional de múltiplos órgãos } \\
\hline Bioquímica de sangue, PFH, PFR, PFT, lipidograma; & $x$ & \\
\hline Urinálise; & $x$ & \\
\hline TFG; & $x$ & \\
\hline Proteinúria de 24 horas; & $x$ & \\
\hline PFP e gasometria; & $X$ & \\
\hline Radiografia de tórax (PA e perfil); & $X$ & \\
\hline Ultrassom abdominal total; & $x$ & \\
\hline Doppler carotídeo (se indicado ou em > 50 anos); & $X$ & \\
\hline Exame odontológico; & $x$ & \\
\hline Exame oftalmológico (se diabético). & $X$ & \\
\hline \multicolumn{3}{|l|}{ Sorologia para infecções e vacinação } \\
\hline HbsAg, Anti-Hbc,Anti-Hbs, Anti-HCV; & $x$ & \\
\hline HIV, HTLV; & $x$ & \\
\hline CMV, Toxoplasmose, EBV, Varicela; & $x$ & \\
\hline Vacina antigripal (anual); & $x$ & \\
\hline Vacina antipneumocócica; & $x$ & \\
\hline Vacina anti-hepatite B (três doses); & $x$ & \\
\hline Anti-Hbs (imunidade); & $X$ & \\
\hline Profilaxia de verminose. & $x$ & \\
\hline \multicolumn{3}{|l|}{ Rastreamento de neoplasia } \\
\hline Pesquisa de sangue oculto nas fezes (três amostras); & $x$ & \\
\hline Colonoscopia (se indicada e acima de 50 anos); & $x$ & \\
\hline Mamografia (se indicada ou idade $>40$ anos) & $x$ & \\
\hline $\begin{array}{l}\text { Citologia cérvico-vaginal (se indicado, idade } \geq 18 \\
\text { anos, sexualmente ativa); }\end{array}$ & $x$ & \\
\hline PSA (se indicado e homens $>45$ anos). & $X$ & \\
\hline \multicolumn{3}{|l|}{ Consultas especializadas } \\
\hline Avaliação nutricional, social e enfermagem; & $x$ & \\
\hline Psicologia e Psiquiatria/Nutrologia (se indicadas); & $X$ & \\
\hline Outras especialidades (se indicadas). & & \\
\hline
\end{tabular}

$P R A$ - reatividade contra painel de anticorpos; HLA - antígeno leucocitário humano; PFH - provas de função hepática; PFR - provas de função renal; PFTprovas de função tireoidiana; TFG - taxa de filtração glomerular; PFP - prova de função pulmonar. 
sendo muito útil para discriminar mortalidade nesse grupo de pacientes. Qualquer paciente incluído na lista com escore inicial classificado como de alto risco, e que após o tratamento clínico otimizado tenha seu status alterado para intermediário ou baixo risco, mesmo assim, mantém alta mortalidade. Sendo assim, esses pacientes só podem ser retirados da lista se ocorrer melhora clínica considerável. O único grupo que mantém sobrevida igual ou melhor do que o transplante é o que é incluído na lista com escore inicial baixo e se mantêm nesse status ${ }^{16-18}$.

\section{Escore HFSS}

((1(se DAC) ou 0 (não DAC)) x 0,6931 + (1(atraso de condução intraventricular) e 0 (sem atraso)) x 0,6083 + (FEVE (\%)) $x-0,0464+(F C) \times 0,0216+$ (concentração de sódio) $\mathrm{x}-0,0470+$ (PA média) $-0,0255+\left(\mathrm{VO}_{2}\right.$ pico $) \mathrm{x}-0,05456$

O estudo COCPIT ${ }^{19}$ definiu os pacientes em três perfis de risco utilizando o HFSS:

- Baixo risco (HFSS maior ou igual a 8,10) - Sobrevida em um ano - $93 \%$

- Médio risco (HFSS entre 7,2-8,09) - Sobrevida em um ano $-72 \%$

- Alto risco (HFSS menor ou igual a 7,19) - Sobrevida em um ano $-43 \%$

O Seattle Heart Failure Model avalia o risco de mortalidade considerando o benefício das medicações e dos procedimentos terapêuticos. Inclui no seu cálculo características clínicas (idade, sexo, classe funcional, peso, fração de ejeção de ventrículo esquerdo, pressão sistólica sistêmica), de medicações (inibidores da enzima de conversão da angiotensina - IECA, betabloqueadores - BB, bloqueadores dos receptores de angiotensina - BRA, estatina, alopurinol, antagonista da aldosterona, diuréticos com detalhamento dos tipos), laboratóriais (hemoglobina, linfócitos, ácido úrico, colesterol total, sódio sérico), de ressincronização e/ ou de cardiodesfibrilador. Dentre suas limitações, deve ser destacado que o Seattle Heart Failure Model foi desenvolvido e validado em pacientes de estudos clínicos, observacionais e em registros, não podendo ser generalizado para pacientes hospitalizados e com múltiplas comorbidades. Como a classe funcional da NYHA, sua utilização deve ser pontual, devendo ser recalculado periodicamente estimando o impacto das intervenções acrescidas ${ }^{20}$.

\section{iv. Tratamento e manutenção de pacientes ambulatoriais} na lista de espera

O fato de um paciente ser selecionado, inscrito e ativado na lista de transplante cardíaco não significa que o transplante será realizado. A seleção de um candidato é dinâmica e requer reavaliação contínua. Melhora clínica bem como aparecimento de comorbidades importantes podem adiar ou contraindicar o procedimento.

O tratamento clínico deve estar adequado e otimizado ${ }^{5}$. As Tabelas 5 e 6 resumem as recomendações do tratamento farmacológico e não farmacológico.
C) Tratamento e manutenção do receptor internado -

farmacológico e não farmacológico

Para pacientes em lista de transplante de coração, o tempo de espera pode ser longo e a condição clínica pode deteriorar, necessitando internação hospitalar e mudanças na

Tabela 5 - Recomendações para tratamento farmacológico de pacientes ambulatoriais com IC compensada candidatos ao transplante cardíaco

\begin{tabular}{|c|c|c|}
\hline $\begin{array}{l}\text { Classe de } \\
\text { Recomendação }\end{array}$ & Indicações & $\begin{array}{l}\text { Nível de } \\
\text { Evidência }\end{array}$ \\
\hline \multirow{6}{*}{ Classe I } & $\begin{array}{c}\text { Antagonistas neuro-hormonais (IECA, } \\
\text { BRA e BB) que se mostraram efetivos nos } \\
\text { estudos clínicos de IC e FEVE < } 45 \% \text {, nas } \\
\text { doses máximas toleradas; }\end{array}$ & A \\
\hline & $\begin{array}{l}\text { Espironolactona em pacientes com IC em } \\
\text { CF III / IV e FEVE baixa; }\end{array}$ & $B$ \\
\hline & $\begin{array}{l}\text { Combinação de hidralazina e nitrato em } \\
\text { pacientes com IC e FEVE baixa, com } \\
\text { contraindicações ao uso de IECA ou BRA; }\end{array}$ & B \\
\hline & $\begin{array}{l}\text { Diuréticos de alça em pacientes com } \\
\text { IC grave e retenção hídrica. Nos casos } \\
\text { de resistência aos diuréticos, investigar } \\
\text { e excluir fatores precipitantes e iniciar } \\
\text { tratamento específico; }\end{array}$ & C \\
\hline & $\begin{array}{l}\text { Anticoagulação com varfarina para os } \\
\text { pacientes com IC, FEVE baixa e história } \\
\text { de tromboembolismo, FA ou trombo } \\
\text { intracavitário; }\end{array}$ & A \\
\hline & $\begin{array}{c}\text { Digoxina em pacientes com } \mathrm{FE}<45 \% \text {, } \\
\text { ritmo sinusal ou } \mathrm{FA} \text {, sintomáticos com } \\
\text { terapia otimizada. }\end{array}$ & $B$ \\
\hline \multirow{2}{*}{ Classe Ila } & $\begin{array}{c}\text { Acrescentar BRA às doses máximas } \\
\text { toleradas de IECA e BB, em pacientes que } \\
\text { persistam sintomáticos apesar da terapia } \\
\text { padrão; }\end{array}$ & B \\
\hline & $\begin{array}{l}\text { Acrescentar hidralazina e nitrato em } \\
\text { pacientes afrodescendentes com sintomas } \\
\text { persistentes em uso da terapêutica } \\
\text { padrão. }\end{array}$ & B \\
\hline
\end{tabular}

IECA - Inibidores da enzima de conversão da angiotensina; BRA - bloqueadores dos receptores de angiotensina; $B B$ - betabloqueador; $C F$ - classe funcional; FEVE - fração de ejeção do ventrículo esquerdo; FA - fibrilação atrial.

Tabela 6 - Recomendações para o tratamento de pacientes candidatos ao transplante cardíaco

\begin{tabular}{lcc}
\hline $\begin{array}{c}\text { Classe de } \\
\text { Recomendação }\end{array}$ & Indicações & $\begin{array}{c}\text { Nível de } \\
\text { Evidência }\end{array}$ \\
\hline \multirow{2}{*}{ Classe I } & Restrição hidrossalina; & $\mathrm{C}$ \\
\cline { 2 - 3 } & $\begin{array}{c}\text { Acompanhamento por uma equipe } \\
\text { multidisciplinar; }\end{array}$ & $\mathrm{C}$ \\
\cline { 2 - 3 } & $\begin{array}{c}\text { CPAP na síndrome de apneia obstrutiva } \\
\text { do sono. }\end{array}$ & $\mathrm{C}$ \\
\hline Classe lla & $\begin{array}{c}\text { Exercícios físicos sob supervisão em } \\
\text { pacientes estáveis. }\end{array}$ & $\mathrm{C}$ \\
\hline
\end{tabular}

CPAP - pressão aérea pulmonar contínua. 


\section{Diretrizes}

terapia farmacológica, com a introdução de medicamentos endovenosos, ou de suporte mecânico circulatório com dispositivos de assistência ventricular, elevando sua condição para prioridade. Os pacientes internados devem ser mantidos no melhor estado de volemia possível, com estabilidade hemodinâmica para preservação de órgãos-alvo (cérebro, rim, fígado) e com exames laboratoriais o mais próximo possível do valor normal.

\section{i. Medidas de controle da congestão em pacientes com} insuficiência cardíaca crônica descompensada

Todas as medidas necessárias para alcançar o melhor estado volêmico devem ser tomadas, incluindo diuréticos intravenosos, ultrafiltração ou diálise. A dificuldade de controlar ou evitar a retenção de líquidos pode ser considerada critério de falha terapêutica, ou resistência aos diuréticos (falha em induzir diurese clinicamente suficiente, mesmo em uso de altas doses de diuréticos de alça), exigindo alternativas para o tratamento da congestão.

É importante lembrar que a desidratação excessiva pode levar à hipotensão, nova ativação do sistema neuro-hormonal e piora da função renal. A resistência ao diurético deve ser tratada com aumento da dose ou da frequência dos diuréticos de alça, mudança para diurético de alça com melhor biodisponibilidade, adição de um tiazídico ou administração endovenosa (in bolus ou infusão contínua) de diurético de alça e/ou uso de drogas inodilatadoras como dopamina, dobutamina, levosimendana ou milrinona. Ultrafiltração é uma técnica promissora que pode ser de muita ajuda nos pacientes resistentes (Tabela 7) $)^{2,5,21-23}$.

D) Manejo de drogas vasoativas e dispositivos de assistência

\section{i. Drogas vasoativas}

a) Vasodilatadores

As drogas vasodilatadoras para uso intravenoso na

Tabela 7 - Recomendações do uso de diuréticos e/ou hemodiálise ou ultrafiltração na IC em paciente internado em lista de transplante cardíaco

\begin{tabular}{lcc}
\hline $\begin{array}{l}\text { Classe de } \\
\text { recomendação }\end{array}$ & Indicações & $\begin{array}{c}\text { Nível de } \\
\text { Evidência }\end{array}$ \\
\hline Classe I & $\begin{array}{c}\text { Diuréticos intravenosos para controle de } \\
\text { sintomas de congestão em pacientes } \\
\text { com IC aguda; }\end{array}$ & C \\
\cline { 2 - 3 } & $\begin{array}{c}\text { Associação de diurético tiazídico ao } \\
\text { diurético de alça em pacientes com } \\
\text { tratamento clínico otimizado que } \\
\text { mantém sinais de congestão. }\end{array}$ & $\mathrm{C}$ \\
\hline Classe Ila & $\begin{array}{c}\text { Ultrafiltração ou diálise para redução } \\
\text { da sobrecarga de volume e da } \\
\text { hiponatremia. }\end{array}$ & B \\
\hline Classe III & Diuréticos em pacientes sem sinais de \\
hipervolemia. & $\mathrm{C}$ \\
\hline
\end{tabular}

insuficiência cardíaca disponíveis no Brasil são nitroprussiato de sódio, nitroglicerina e nesiritide.

Essas drogas têm utilização preferencial nas situações de pressões de enchimento ventricular elevadas, aumentos significativos na RVP e na resistência vascular sistêmica (RVS), além das situações de sobrecarga aguda de volume secundária a lesões valvares regurgitantes (insuficiência mitral e aórtica $)^{24}$. Para serem usadas isoladamente, é necessário que a pressão arterial sistólica sistêmica esteja adequada (ideal $\geq 85 \mathrm{mmHg}$ ) para evitar que haja redução da pressão de perfusão orgânica (Tabela 8).

\section{b) Inotrópicos e inodilatadores}

Em pacientes com baixo débito cardíaco, com ou sem congestão, o emprego de terapia inotrópica pode ser necessário para melhorar a perfusão tecidual e preservação de função de órgãos vitais ${ }^{25}$.

Esses agentes são mais apropriados para terapia em pacientes com rápida deterioração hemodinâmica, bem como em pacientes com IC crônica e níveis basais elevados de escórias nitrogenadas e que não alcançaram diurese satisfatória, apesar do uso de diuréticos de alça e vasodilatadores. São também eficazes em suporte hemodinâmico temporário em pacientes à espera de transplante cardíaco.

Tais agentes são divididos em três grupos: agonistas betaadrenérgicos (noradrenalina, dopamina e dobutamina), inibidores da fosfodiesterase III (milrinona) e sensibilizadores de cálcio (levosimendana). As recomendações para seu uso encontram-se na Tabela 9.

O choque cardiogênico representa uma situação especial acompanhada de alta mortalidade e é caracterizado por persistente ( $>30$ minutos) e marcada hipotensão (PA sistólica $<90$ mmHg ou queda na PA média > 30 mmHg), levando à hipoperfusão tecidual induzida por falência miocárdica, após correção da pré-carga. Quando monitorizado invasivamente, a pressão de oclusão pulmonar é $>18 \mathrm{mmHg}$ e o índice cardíaco é $<2,2 \mathrm{I} / \mathrm{min} / \mathrm{m}^{2}$ (classe IV de Forrester). O tratamento medicamentoso inicial do choque cardiogênico se baseia no uso de inotrópicos e diuréticos venosos, o primeiro para melhorar o desempenho cardíaco e o segundo para reduzir a congestão pulmonar. Entretanto, quando esses

Tabela 8 - Indicação de vasodilatadores por via intravenosa na IC em paciente internado em lista de transplante cardíaco

\begin{tabular}{lcc}
\hline $\begin{array}{l}\text { Classe de } \\
\text { recomendação }\end{array}$ & Indicações & $\begin{array}{c}\text { Nível de } \\
\text { Evidência }\end{array}$ \\
\hline & $\begin{array}{c}\text { Nitroglicerina em pacientes sem } \\
\text { hipotensão; }\end{array}$ & B \\
\cline { 2 - 3 } Classe I & $\begin{array}{c}\text { Nitroprussiato em pacientes em uso de } \\
\text { monitoração hemodinâmica invasiva } \\
\text { e resistência vascular sistêmica } \\
\text { aumentada, associado ou não a } \\
\text { inotrópicos. }\end{array}$ & B \\
\cline { 2 - 3 } Classe Ilb & $\begin{array}{c}\text { Nesiritide para tratamento da IC } \\
\text { descompensada em pacientes sem } \\
\text { hipotensão. }\end{array}$ & B \\
\hline
\end{tabular}


Tabela 9 - Recomendações do uso de inotrópicos na IC em paciente internado candidato ao transplante cardíaco

\begin{tabular}{|c|c|c|}
\hline $\begin{array}{l}\text { Classe de } \\
\text { recomendação }\end{array}$ & Indicações & $\begin{array}{l}\text { Nível de } \\
\text { Evidência }\end{array}$ \\
\hline \multirow{3}{*}{ Classe I } & $\begin{array}{c}\text { Dobutamina para pacientes em } \\
\text { choque cardiogênico, para suporte } \\
\text { hemodinâmico, independentemente da } \\
\text { etiologia da cardiomiopatia; }\end{array}$ & B \\
\hline & $\begin{array}{l}\text { Milrinone para pacientes com sinais de } \\
\text { baixo débito, sem choque cardiogênico, } \\
\text { etiologia não isquêmica, em uso de } \\
\text { betabloqueador; }\end{array}$ & B \\
\hline & $\begin{array}{l}\text { Dobutamina e/ou milrinone para suporte } \\
\text { hemodinâmico para pacientes em baixo } \\
\text { débito e em situação de prioridade. }\end{array}$ & C \\
\hline Classe lla & $\begin{array}{l}\text { Levosimendana para pacientes } \\
\text { com sinais de baixo débito, sem } \\
\text { choque cardiogênico, e em uso de } \\
\text { betabloqueador. }\end{array}$ & B \\
\hline \multirow[t]{2}{*}{ Classe Ilb } & $\begin{array}{l}\text { Dobutamina, milrinone ou levosimendana } \\
\text { para melhora dos sintomas de pacientes } \\
\text { em baixo débito sem hipotensão arterial; }\end{array}$ & $B$ \\
\hline & $\begin{array}{l}\text { Associação de Levosimendana na } \\
\text { tentativa de retirada de Dobutamina. }\end{array}$ & C \\
\hline \multirow[b]{2}{*}{ Classe III } & $\begin{array}{c}\text { Dobutamina, milrinone ou levosimendana } \\
\text { para pacientes sem sinais de baixo } \\
\text { débito; }\end{array}$ & $B$ \\
\hline & $\begin{array}{c}\text { Dobutamina, milrinone ou levosimendana } \\
\text { em infusão intermitente ambulatorial } \\
\text { para pacientes com frequentes } \\
\text { descompensações. }\end{array}$ & $B$ \\
\hline
\end{tabular}

falham, o uso, em associação ou em substituição, de reposição volêmica e de vasopressores faz-se necessário (Tabela 10).

\section{ii. Dispositivos de assistência ventricular (DAV)}

O número de transplantes de coração realizados no mundo permanece estático e a terapia medicamentosa sozinha para a IC terminal continua a ter resultados desanimadores ${ }^{26}$. O suporte mecânico circulatório (SMC) vem expandindo o tratamento da IC avançada.

Os DAV são propulsores sanguíneos que substituem o trabalho mecânico ventricular (esquerdo e/ou direito), garantindo o débito cardíaco necessário para propiciar condições favoráveis à recuperação miocárdica ou à substituição do coração ${ }^{27-29}$.

Os DAV podem ser classificados de várias maneiras: bombas centrífugas, deslocamento do volume (pneumático ou pulsátil) ou de fluxo axial. Podem ser implantáveis ou extracorpóreos, usados como ponte para transplante (para manutenção da estabilidade clínica enquanto se aguarda o transplante), como ponte para recuperação (naqueles em que se espera a recuperação da função ventricular), como ponte para uma próxima decisão (quando colocado na descompensação aguda para estabilização, mas ainda não se tem a próxima estratégia planejada) ou como terapia final (para pacientes que não têm indicação de transplante ou que não exista recuperação da função ventricular).
Tabela 10 - Reposição volêmica em pacientes internados em lista de transplante

\begin{tabular}{lcc}
\hline $\begin{array}{c}\text { Classe de } \\
\text { recomendação }\end{array}$ & \multicolumn{1}{c}{ Indicações } & $\begin{array}{c}\text { Nível de } \\
\text { Evidência }\end{array}$ \\
\hline \multirow{2}{*}{ Classe I } & $\begin{array}{c}\text { Reposição volêmica nos pacientes } \\
\text { comprovadamente hipovolêmicos; }\end{array}$ & C \\
\cline { 2 - 3 } & $\begin{array}{c}\text { Valores baixos de PVC e/ou POAP } \\
\text { associados a hipofluxo tecidual, indicam } \\
\text { infusão hídrica imediata. }\end{array}$ & C \\
\hline Classe Ila & $\begin{array}{c}\text { Medidas dinâmicas para avaliação da } \\
\text { responsividade cardiovascular a volume; }\end{array}$ & C \\
\cline { 2 - 3 } & $\begin{array}{c}\text { Prova de volume com infusão rápida } \\
\text { de 250 ml de cristaloide na suspeita de } \\
\text { hipovolemia. }\end{array}$ & C \\
\hline Classe Ilb & $\begin{array}{l}\text { Avaliação do DC para orientação } \\
\text { da reposição volêmica quando há } \\
\text { suspeita de sobrecarga volêmica e/ou } \\
\text { manutenção da hipoperfusão após a } \\
\text { ressuscitação inicial. }\end{array}$ & $\mathrm{C}$ \\
\hline
\end{tabular}

PVC - pressão venosa central; POAP - pressão de oclusão da arteira pulmonar; $D C$ - débito cardíaco.

Devido à pequena experiência brasileira e aos muitos DAV disponíveis, esta diretriz não pode cobrir todos os pontos específicos encontrados na seleção e manejo dos pacientes. Porém, baseando-se na literatura atual, os dispositivos pulsáteis implantáveis devem ser usados com área de superfície corporal $>1,5 \mathrm{~m}^{2} \mathrm{e}$, nos menores, o uso de dispositivos extracorpóreos ou bombas pulsáteis devem ser considerados. Pacientes com creatinina sérica $>3,0 \mathrm{mg} / \mathrm{dl}$ são de alto risco e o uso de DAV deve ser considerado apenas se a insuficiência renal for aguda e com probabilidade de recuperação. Ventilação mecânica sem insuficiência pulmonar prévia ou infiltrado inflamatório é fator de risco, mas não deve ser considerada contraindicação absoluta.

Todos os pacientes avaliados para DAV devem ter função hepática e testes de coagulação mensurados. Níveis de TGO/ TGP > 3x o valor normal são de risco, e na presença de insuficiência ventricular direita, suporte biventricular deve ser a primeira opção. Pacientes com INR espontâneo > 3,5 têm risco aumentado de complicações hemorrágicas.

As complicações existem assim como nas cirurgias cardíacas. As principais são hemorragias, infecções, mau funcionamento do dispositivo (principalmente os de primeira geração) e sensibilização ao HLA (anticorpos aos antígenos leucocitários). As recomendações para o uso de DAV estão resumidas na Tabela 11 .

O balão intra-aórtico de contrapulsação (BIA), embora não descomprima o ventrículo esquerdo, notadamente é o tipo de suporte circulatório mais utilizado e atua como adjuvante no tratamento do infarto agudo do miocárdio (IAM) complicado por choque cardiogênico (auxiliando a recanalização mecânica ou química, ou o tratamento da IC, muitas vezes secundária à complicações mecânicas) ${ }^{30}$.

O SMC é atualmente um tratamento frequente e aceitável para a IC tanto em curto quanto em longo prazo. A recuperação miocárdica vem sendo estudada e o mecanismo exato desta recuperação em longo prazo permanece por ser 


\section{Diretrizes}

Tabela 11 - Recomendações para uso de dispositivos de assistência ventricular

\begin{tabular}{|c|c|c|}
\hline $\begin{array}{l}\text { Classe de } \\
\text { Recomendação }\end{array}$ & Indicações & $\begin{array}{l}\text { Nível de } \\
\text { Evidência }\end{array}$ \\
\hline \multirow{2}{*}{ Classe I } & $\begin{array}{l}\text { Deterioração progressiva do quadro } \\
\text { clínico com necessidade de doses } \\
\text { incrementais de inotrópicos e diuréticos; }\end{array}$ & C \\
\hline & $\begin{array}{l}\text { BIA em pacientes com choque } \\
\text { cardiogênico não responsivo à } \\
\text { terapêutica farmacológica otimizada. }\end{array}$ & B \\
\hline \multirow{3}{*}{ Classe lla } & $\begin{array}{l}\text { Choque cardiogênico refratário ao } \\
\text { tratamento clínico e/ou BIA em pacientes } \\
\text { com possibilidade de recuperação; }\end{array}$ & B \\
\hline & $\begin{array}{l}\text { Como terapia final eletiva em não } \\
\text { candidatos a transplante cardiaco que } \\
\text { estão dependentes de inotrópicos; }\end{array}$ & $B$ \\
\hline & $\begin{array}{l}\text { Dificuldade de desmame da circulação } \\
\text { extracorpórea (pós-cardiotomia) } \\
\text { em pacientes com possibilidade de } \\
\text { recuperação. }\end{array}$ & $B$ \\
\hline \multirow{2}{*}{ Classe III } & Disfunção multiorgânica irreversível. & C \\
\hline & Coagulopatia refratária. & C \\
\hline
\end{tabular}

BIA - balão intra-aórtico.

elucidado, assim como o remodelamento do coração dilatado. Parte da avaliação para SMC deve incluir o potencial para a recuperação miocárdica ${ }^{31}$.

\section{E) Receptor em prioridade}

Os pacientes com maior probabilidade de morte na fila de espera para transplante cardíaco têm prioridade para serem submetidos ao procedimento operatório. Nessa condição clínica, estão os pacientes que necessitam de assistência circulatória mecânica, de suporte inotrópico ou sob ventilação mecânica.

A assistência circulatória mecânica com ventrículo artificial está indicada naqueles que têm expectativa de vida menor do que uma semana. Prioridade para transplante cardíaco deve ser dada aos pacientes que estão em uso de ventrículo artificial por um tempo menor do que um mês, ou aos pacientes que estão usando esse aparelho por mais de 30 dias, porém com complicações relacionadas ao dispositivo ${ }^{32}$.

O uso de BIA provê assistência circulatória mecânica por alguns dias. Esse dispositivo pode ser usado em pacientes que permanecem em choque cardiogênico, com evidências de falência de múltiplos órgãos, a despeito do uso de agentes inotrópicos ${ }^{33}$.

O uso de aminas vasoativas, principalmente dobutamina, está indicado nos pacientes com dificuldade para a manutenção da perfusão tecidual, apresentando hipotensão arterial sistêmica euvolêmica (na ausência de uso concomitante de betabloqueador), oligúria e sinais de hipoperfusão cerebral ${ }^{34}$. São também considerados prioritários os pacientes que estão recebendo múltiplos agentes inotrópicos para a manutenção da estabilidade hemodinâmica ${ }^{32}$.

A ventilação mecânica deve ser usada em pacientes que apresentam insuficiência respiratória secundária ao edema pulmonar subjacente ou à presença de lesões do sistema nervoso central. É, portanto, imperiosa, a exclusão de doença pulmonar concomitante, preferencialmente pela utilização de métodos de imagem ${ }^{5}$.

O aumento do número de pacientes graves tem levado ao aumento dos chamados receptores limítrofes e em prioridade ${ }^{14}$. Os critérios para esses receptores estão resumidos na Tabela 12. Alguns casos não contemplados pelos critérios clássicos podem ser discutidos e aprovados pela câmara técnica como angina ou arritmia ventricular refratárias.

\section{F) Receptor limítrofe}

\section{i. Infecção}

Infecções bacterianas não tratadas com antibióticos contraindicam a realização de transplante cardíaco. Contudo, pacientes com infecções sistêmicas, porém tratadas nas últimas 48 horas com antibióticos, e evidências laboratoriais indicativas de controle do processo infeccioso, podem ser submetidos ao transplante cardíaco. Especial atenção deve ser dada à embolia pulmonar recente, pelo risco de infecção secundária após a realização de transplante cardíaco $^{35}$. Receptores portadores de hepatite $\mathrm{C}$ devem ser submetidos à mensuração da carga viral, podendo ser submetidos ao transplante cardíaco na ausência de tal agente infeccioso.

\section{ii. Insuficiência renal}

Insuficiência renal, definida como níveis de creatinina plasmática $>2 \mathrm{mg} / \mathrm{dl}$, é frequentemente encontrada em pacientes com IC candidatos a transplante cardíaco. Na grande maioria das vezes, ocorre recuperação da função renal após o procedimento operatório, pois a disfunção renal é secundária à isquemia renal crônica consequente à baixa perfusão renal. Contudo, como a maioria dos pacientes submetidos ao transplante cardíaco fará uso de inibidores da calcineurina no período pós-operatório imediato, a função renal poderá ser comprometida pelo uso destas drogas.

Embora não exista um valor de corte claramente definido, a maioria dos serviços de transplante cardíaco exclui do programa os pacientes que apresentam valores de creatinina $>3 \mathrm{mg} / \mathrm{dl}$. Os pacientes que apresentam valores de creatinina elevados, porém abaixo desse nível, devem ser submetidos ao rastreamento de doença renal glomerular (proteinúria de 24 horas), doença renal arterial (ultrassom de artéria renal) ou doença parenquimatosa (ultrassom renal para avaliação de cronicidade e tamanho renal). Na presença de doença renal

\section{Tabela 12 - Critérios de prioridade para o transplante cardíaco}

\begin{tabular}{l}
\hline Dependência de inotrópicos / vasopressores; \\
\hline Balão intra-aórtico; \\
\hline Dispositivos de assistência ventricular; \\
\hline Ventilação mecânica; \\
\hline Determinação da câmara técnica. \\
\hline
\end{tabular}


estrutural, a conduta deverá ser estabelecida individualmente, levando-se em consideração a experiência do serviço e os recursos institucionais disponíveis ${ }^{4}$.

\section{iii. Caquexia cardíaca}

A caquexia cardíaca, definida como índice de massa corporal $<21 \mathrm{~kg} / \mathrm{m}^{2}$ em homens e $<19 \mathrm{~kg} / \mathrm{m}^{2}$ em mulheres, é frequentemente encontrada em pacientes com IC avançada e é variável de predição de prognóstico adverso. Pacientes com essa condição clínica, portanto, devem ser diligentemente tratados para a reversão da caquexia antes do transplante cardíaco. Caso o paciente não tenha condições de se alimentar de forma adequada em virtude da doença cardíaca, deve-se prontamente instituir terapia nutricional, incluindo nutrição enteral ou parenteral a fim de facilitar a cicatrização após o transplante cardíaco e, no período perioperatório ${ }^{35}$, reduzir a probabilidade de eventos desfavoráveis. É, portanto, extremamente necessário que o candidato seja submetido ao transplante cardíaco em condições nutricionais adequadas.

\section{G) Avaliação hemodinâmica pulmonar}

Hipertensão pulmonar (HP) é frequentemente observada em pacientes com IC e está associada a aumento da mortalidade após transplante cardíaco. Entretanto, a HP é uma das variáveis que provoca controvérsia na avaliação de candidatos a transplante cardíaco ${ }^{36}$. Fatores que agravam a HP deveriam ser considerados e excluídos, tais como apneia do sono obstrutiva, insuficiência mitral grave, estenose de veias pulmonares, doença pulmonar intrínseca ou tromboembolismo pulmonar.

O cateter de artéria pulmonar tem sido usado para avaliação hemodinâmica pulmonar de candidatos a transplante cardíaco com o objetivo de: avaliar o grau de HP; determinar pressões de enchimento; medir débito cardíaco e avaliar potencial de reversibilidade da HP pelo uso de agentes vasodilatadores, tais como nitroprussiato, óxido nítrico, milrinona, sildenafil, dentre outros (Tabela 13). Os parâmetros mais usados para avaliar a HP estão mostrados na Tabela $14{ }^{37}$.

O aumento reversível da RVP tem um componente reativo e um fixo. O transplante reduz o componente reativo, mas não o fixo e, com isso, a RVP não se normaliza totalmente logo após o transplante cardíaco. A RVP pode se normalizar em 30 dias, porém uma grave dilatação ventricular direita pode permanecer por até um ano ${ }^{38,39}$. A resistência vascular pulmonar $>3 \mathrm{uW}$ tem sido considerada como um fator de risco independente de morte após transplante cardíaco, mas não há um consenso quanto ao ponto de corte abaixo do qual a disfunção de ventrículo direito não ocorra ${ }^{36}$. Pressão sistólica da artéria pulmonar $($ PSAP) $>50 \mathrm{mmHg}$ e gradiente transpulmonar $(\mathrm{GTP})>15$ $\mathrm{mmHg}$ são também preditores de eventos adversos após transplante cardíaco, independentemente da RVP40. Há consenso de que a combinação dessas variáveis aumenta ainda mais esse risco ${ }^{39}$

A avaliação hemodinâmica pulmonar em candidatos a transplante cardíaco deveria ser realizada conforme as recomendações descritas na Tabela 15. Se RVP basal > $5 \mathrm{uW}$, iniciar vasodilatador até que PAS $<85 \mathrm{mmHg}$. A meta é reduzir a RVP para < 3uW (resposta total). Em alguns casos, a associação de inotrópicos é necessária. Em pacientes internados, se uma resposta parcial ocorre, mas a RVP permanece $>3 \mathrm{uW}$, o paciente deve permanecer com monitoração hemodinâmica contínua e com infusão de vasodilatadores (associados ou não a inotrópicos) para que novas medidas sejam realizadas nas próximas 48 horas. $\mathrm{O}$ menor valor medido de RVP deve ser considerado.

Tabela 13 - Fármacos vasodilatadores usados no teste de reversibilidade da RVP

\begin{tabular}{|c|c|c|c|}
\hline Agente & Via de Administração & Dose & Efeitos Colaterais \\
\hline Oxigênio 100\% & Máscara facial & - & - \\
\hline \multirow{3}{*}{ Nitratos } & Sublingual & $0,8 \mathrm{mg}$ & Hipotensão, cefaleia. \\
\hline & Oral & $0,5 \mathrm{mg}$. & Hipotensão, cefaleia. \\
\hline & Intravenoso & $10-20 \mathrm{ug} / \mathrm{kg} / \mathrm{min}$ & Hipotensão, cefaleia. \\
\hline Nitroprussiato de sódio & Intravenoso & $1 \mathrm{ug} / \mathrm{kg} / \mathrm{min}$ & Hipotensão, cefaleia. \\
\hline Sildenafil & Oral ou sublingual & $20-100 \mathrm{mg}$ & Hipotensão, flushing, cefaleia. \\
\hline Prostaciclina & Intravenoso & $2,0-10 \mathrm{ug} / \mathrm{kg} / \mathrm{min}$ & Tremores, flushing, tontura e hipotensão. \\
\hline Óxido nítrico inalatório & Máscara facial & $20-80$ ppm. & Metahemoglobinemia. \\
\hline Prostaglandina E1 & Intravenoso & $0,01-0,3 \mathrm{ug} / \mathrm{kg} / \mathrm{min}$ & Tremores, flushing, náuseas, vômitos, tontura e hipotensão. \\
\hline Adenosina & Intravenoso & 100 ug/kg/min. & Inotropismo negativo. \\
\hline Milrinona & Intravenoso & $0,375-0,75 \mathrm{ug} / \mathrm{kg} / \mathrm{min}$ & Hipotensão. \\
\hline Neseritide & Intravenoso & $\begin{array}{l}2,0 \mathrm{ug} / \mathrm{kg} / \mathrm{min} \text { em bolus seguida } \\
\text { por infusão de } 0,01 \mathrm{ug} / \mathrm{kg} / \mathrm{min} \text {. }\end{array}$ & Hipotensão. \\
\hline Hidralazina & Oral & $10-100$ mg dividido em 2 doses. & Cefaleia, edema periférico, lupus-like síndrome. \\
\hline
\end{tabular}

RVP - resistência vascular pulmonar. 


\section{Diretrizes}

Tabela 14 - Valores hemodinâmicos pulmonares normais e na hipertensão pulmonar

\begin{tabular}{lccc}
\hline & $\begin{array}{c}\text { GTP } \\
(\mathrm{mmHg})\end{array}$ & RVP $(\mathrm{uW})$ & $\begin{array}{c}\text { PSAP } \\
(\mathrm{mmHg})\end{array}$ \\
\hline Normal & $5-7$ & $<1$ & $<30$ \\
\hline $\begin{array}{l}\text { Hipertensão pulmonar } \\
\text { leve a moderada }\end{array}$ & $7-15$ & $<2,5$ & $31-49$ \\
\hline $\begin{array}{l}\text { Hipertensão pulmonar } \\
\text { reversível }\end{array}$ & - & $\begin{array}{l}\text { RVP }<3 \text { após } \\
\text { vasodilatoador }\end{array}$ & - \\
\hline $\begin{array}{l}\text { Hipertensão pulmonar } \\
\text { grave }\end{array}$ & $\geq 16$ & $>5$. & $>50-60$ \\
\hline
\end{tabular}

GTP - gradiente transpulmonar; RVP - resistência vascular pulmonar; PSAP pressão sistólica da artéria pulmonar.

Tabela 15 - Recomendações para avaliação hemodinâmica pulmonar com cateter de artéria pulmonar

\begin{tabular}{lcc}
\hline $\begin{array}{l}\text { Classe de } \\
\text { Recomendação }\end{array}$ & Indicações & $\begin{array}{c}\text { Nível de } \\
\text { Evidência }\end{array}$ \\
\hline & $\begin{array}{c}\text { Para todos os candidatos em preparo } \\
\text { para transplante cardíaco e anualmente } \\
\text { até o transplante; }\end{array}$ & $\mathrm{C}$ \\
\cline { 2 - 3 } Classe I & $\begin{array}{c}\text { Administração de vasodilatador quando } \\
\text { PSAP } \geq 50 \text { e GTP } \geq 15 \text { ou RVP }>3 \text { até }\end{array}$ & $\mathrm{C}$ \\
& PAS $<85$ mmHg. & $\mathrm{C}$ \\
\hline Classe lla & $\begin{array}{c}\text { Monitoração hemodinâmica contínua } \\
\text { e realização de medidas de RVP } \\
\text { com terapia otimizada de diuréticos, } \\
\text { inotrópicos e agentes vasoativos } \\
\text { pulmonares. }\end{array}$ & \\
\hline
\end{tabular}

PSAP - pressão sistólica da artéria pulmonar; GTP - gradiente transpulmonar; $R V P$ - resistência vascular pulmonar.

Alguns pacientes podem requerer terapia médica prolongada até que uma aceitável redução da RVP seja obtida. O uso de BIA e/ou DAV deve ser considerado para a reversibilidade da RVP quando o ventrículo esquerdo não pode ser efetivamente descomprimido por terapia médica. A hipertensão pulmonar com elevada RVP é contraindicação relativa ao transplante cardíaco ortotópico quando a RVP > 5 uW ou índice de RVP $>6$ ou GTP $>16-20 \mathrm{mmHg}$. Se existe PSAP > 60 mmHg em conjunto com qualquer uma dessas três variáveis, o risco de disfunção de ventrículo direito e morte precoce aumenta. Se a RVP é reduzida para $<3 \mathrm{uW}$ com vasodilatador, mas a PAS cai para $<85 \mathrm{mmHg}$, o paciente permanece com alto risco de disfunção de ventrículo direito e de morte após o transplante cardíaco ${ }^{4,41}$.

H) Avaliação multiprofissional do candidato ao transplante cardíaco

\section{i. Avaliação da equipe de Enfermagem}

A complexidade e especificidade do transplante cardíaco exigem do enfermeiro assistência específica com qualidade e domínio técnico científico, avaliando de forma objetiva e direcionada as necessidades do paciente e seus familiares, com acompanhamento individualizado, sistematizado, e orientações para o autocuidado no processo de educação ${ }^{42-44}$, englobando histórico de enfermagem, exame físico, aspectos gerais (condições de autocuidado e administração da imunossupressão e medicamentos, adesão ao tratamento - história pregressa, cuidador, infraestrutura básica e higiene domiciliar - visita domiciliar, hábitos de higiene/saúde do paciente/família, dependência química e tabagismo - abstinência total por 6 meses $^{4}$, doenças prévias e associadas).

Cabem ainda ao grupo de enfermagem, as orientações quanto à fila de transplante e acesso à lista de espera; seleção de doadores e critérios de compatibilidade; pré-transplante, pós-operatório e riscos cirúrgicos; imunossupressores e seus efeitos colaterais; riscos de rejeição, infecção, hipertensão arterial e nefrotoxicidade; vacinação (contraindicada vacina de vírus vivo em paciente em fila como prioridade); planejamento familiar e uso de contraceptivos; reativação da doença de Chagas e orientações quanto a lesões de pele, infecção dentária ou alterações clínicas.

O enfermeiro deve possibilitar ao paciente e à família o esclarecimento de dúvidas, avaliando fatores que poderão contraindicar ou comprometer o protocolo de transplante (Tabela 16) $42,43,45$.

\section{ii. Avaliação social}

É a ferramenta de conhecimento e intervenção estrutural das questões sociais presentes no cotidiano do paciente. Esse instrumento é realizado por meio de entrevista e, tem por objetivo configurar o quadro social em que o paciente se encontra inserido, identificando fatores de ordem socioeconômica e cultural, que possam ser considerados de risco médico para o paciente após a realização do transplante cardíaco. Além disso, apresenta a capacidade de facilitar, interferir ou obstruir o acompanhamento integral proposto pelo programa.

A avaliação social é fundamentada em 04 categorias $^{46}$ :

a) Aceitabilidade - Capacidade de aceitação/adesão pelo paciente/cuidador;

b) Dinâmica familiar - Identificação de cuidador familiar informal/formal que participe da assunção dos cuidados;

Tabela 16 - Recomendações da equipe de enfermagem ao paciente em fila de transplante cardíaco

\begin{tabular}{lcc}
\hline $\begin{array}{c}\text { Classe de } \\
\text { Recomendação }\end{array}$ & Indicações & $\begin{array}{c}\text { Nível de } \\
\text { Evidência }\end{array}$ \\
\hline & $\begin{array}{c}\text { Implementação de atividades de } \\
\text { educação e ensino ao paciente e familia } \\
\text { em todas as fases do processo de } \\
\text { transplante; }\end{array}$ & $\mathrm{C}$ \\
\cline { 2 - 3 } Classe I & $\begin{array}{c}\text { Identificação ou risco de complicações } \\
\text { no processo de transplante; }\end{array}$ & $\mathrm{C}$ \\
\cline { 2 - 3 } & $\begin{array}{c}\text { Condições para o autocuidado, } \\
\text { e autoadministração de }\end{array}$ & $\mathrm{C}$ \\
\hline
\end{tabular}


c) Acesso - Deslocamento ao hospital no prazo de tempo de até duas horas e acesso aos meios de comunicação;

d) Condição socioeconômica - Análise das variáveis: renda, escolaridade, habitação e profissão do paciente/provedor.

A avaliação social se constitui em um parecer social, resultado de um estudo fundamentado, conclusivo e indicativo ${ }^{47}$ e apresenta proposta de intervenção às variáveis dificultadoras ao adequado acompanhamento do programa de transplante à equipe médica (Tabela 17) .

Tabela 17 - Recomendações de indicadores sociais para avaliação social em programa de transplante

\begin{tabular}{lcc}
\hline $\begin{array}{l}\text { Classe de } \\
\text { Recomendação }\end{array}$ & Indicações & $\begin{array}{c}\text { Nível de } \\
\text { Evidência }\end{array}$ \\
\hline \multirow{2}{*}{ Classe I } & Aceitabilidade; & $\mathrm{C}$ \\
\cline { 2 - 3 } & Dinâmica familiar; & $\mathrm{C}$ \\
\hline Classe Ila & Condição socioeconômica. & $\mathrm{C}$ \\
\hline
\end{tabular}

iii. Avaliação nutricional do candidato ao transplante cardíaco

A IC pode ser vista como um estado catabólico complexo que resulta em um prognóstico não favorável. Um dos principais sinais e sintomas da IC é a perda de peso gradual, afetando os músculos, tecidos gordurosos, ossos e o próprio coração, chegando, em estágios finais, a um quadro conhecido como caquexia cardíaca, definida pela perda involuntária de peso, sem edema, de mais de $6 \%$ do peso corpóreo total no período de 6 meses, que é a causa do aumento da mortalidade ${ }^{48}$.

A desnutrição resulta em alterações na composição corpórea e na homeostase de diversos sistemas, como ativação dos sistemas inflamatórios e endócrinos, que ocasionam a lipólise, enfraquecimento muscular, falta de apetite e alterações na perfusão intestinal ${ }^{49}$. Está frequentemente presente em pacientes com IC grave aguardando transplante cardíaco e pode aumentar as complicações e a mortalidade no período pós-operatório ${ }^{50}$.

A avaliação do estado nutricional tem como objetivo identificar os distúrbios nutricionais presentes e planejar a intervenção terapêutica nutricional adequada, de forma a auxiliar na recuperação e/ou manutenção do estado de saúde do indivíduo. Não existe uma técnica ideal que, exclusivamente, indique o diagnóstico nutricional com precisão. A avaliação deve ser feita de forma subjetiva e objetiva por meio de indicadores antropométricos, bioquímicos e de consumo alimentar utilizados de forma integrada ${ }^{51-55}$.

Dentre os indicadores antropométricos, a aferição das pregas cutâneas tricipital, bicipital, subescapular, suprailíaca, a circunferência do braço e a circunferência muscular do braço são os melhores índices a serem utilizados em pacientes com IC grave, uma vez que são melhores índices na presença de edemas.
Os parâmetros bioquímicos, tais como albumina, transferrina e pré-albumina devem ser analisados com cautela, pois podem estar diminuídos em processos de inflamação, infecção e aumento de catabolismo.

O consumo alimentar pode ser avaliado por métodos prospectivos e retrospectivos, importantes para verificação da alimentação habitual.

Dentre os métodos subjetivos, deve-se utilizar a avaliação nutricional subjetiva global e exame físico com análise dos sinais físicos indicadores de desnutrição energético-protéica e carências específicas de nutrientes.

Além da avaliação nutricional, recomenda-se realizar o acompanhamento dos pacientes com IC que apresentam comorbidades (Tabela 18), tais como diabetes, hiperlipidemia, doença renal, alcoolismo, caquexia cardíaca e obesidade, que necessitam orientações dietéticas específicas ${ }^{\mathbf{2 , 4 8 , 5 6}}$.

\section{a) Recomendações nutricionais}

A terapia nutricional em pacientes com IC tem como objetivos $^{49,57-59}$ : preservar a composição corporal e/ou limitar os efeitos do catabolismo; manter o estado funcional e a qualidade de vida; atingir as necessidades nutricionais; identificar o quadro de caquexia cardíaca para cessar ou reverter perda de peso; contribuir para a diminuição de medicação e a redução da progressão da doença; contribuir para minimizar as descompensações e internações; evitar a sobrecarga de fluídos e controlar edemas.

As características da terapia nutricional encontram-se apresentadas nas Tabelas 19 e $20^{60}$. Merece destaque a importância da restrição de líquidos (água, chás, sucos, refrigerantes, leites, iogurtes, caldos, sopas, gelatinas, sorvetes) que deve ser individualizada, considerando-se o estado volêmico e a gravidade da doença. A restrição pode variar desde 1,5 - 2 litros para pacientes estáveis sem sinais de descompensação recente até $700 \mathrm{ml}-1$ litro para pacientes mais graves que necessitam de internações frequentes.

A recuperação do estado nutricional em pacientes com IC grave é tarefa difícil. Na maioria das vezes, a recuperação completa só ocorre após a realização do transplante cardíaco.

Tabela 18 - Comorbidades e suas implicações em pacientes com IC grave

\begin{tabular}{lcc}
\hline $\begin{array}{l}\text { Classe de } \\
\text { Recomendação }\end{array}$ & Parâmetros & $\begin{array}{c}\text { Nível de } \\
\text { Evidência }\end{array}$ \\
\hline & Terapia nutricional especializada; & $\mathrm{C}$ \\
\cline { 2 - 3 } Classe I & $\begin{array}{c}\text { Orientação para perda de peso para } \\
\text { pacientes com IMC }>30 \mathrm{~kg} / \mathrm{m}^{2} \text { ou } \\
\text { percentual de peso corpóreo }>140 \%, \\
\text { devido ao pior prognóstico associado no } \\
\text { pós-transplante; }\end{array}$ & $\mathrm{C}$ \\
\cline { 2 - 3 } & $\begin{array}{c}\text { Evitar orientação de perda de peso } \\
\text { de forma generalizada na IC grave ou } \\
\text { moderada, devido à perda de peso não } \\
\text { intencional frequente. }\end{array}$ & $\mathrm{C}$ \\
\hline
\end{tabular}

IMC - índice de massa corporal. 


\section{Diretrizes}

\section{Tabela 19 - Características da terapia nutricional}

\begin{tabular}{|c|c|}
\hline Características & \\
\hline \multirow{3}{*}{ Energia } & $20-25 \mathrm{kcal} / \mathrm{kg}$ peso/dia calorias para pacientes críticos; \\
\hline & $\begin{array}{c}25-30 \mathrm{kcal} / \mathrm{kg} \text { peso/dia/kg para pacientes estáveis e de } \\
\text { ambulatório; }\end{array}$ \\
\hline & $\begin{array}{c}\text { Acima de } 30 \mathrm{kcal} / \mathrm{kg} \text { peso para pacientes com caquexia: } \\
\text { evitar a síndrome da superalimentação (importância da } \\
\text { monitoração da glicemia e de eletrólitos). }\end{array}$ \\
\hline \multirow[b]{2}{*}{ Proteínas } & 1,0-,5 g de proteínas/kg/dia: para pacientes críticos; \\
\hline & $\begin{array}{l}\text { 1,5-2,0 g de proteínas/kg de peso/dia: pacientes com } \\
\text { caquexia (atentar em pacientes com insuficiência renal). }\end{array}$ \\
\hline Sódio & $\begin{array}{l}\text { A ingestão de sal entre 2,0-2,4 g/dia (“dieta restrita") e } \\
\text { 3,0-4,0 g/dia ("dieta moderada"). }\end{array}$ \\
\hline $\begin{array}{l}\text { Restrição de } \\
\text { líquidos }\end{array}$ & Deve ser feita de forma individualizada. \\
\hline Potássio & $\begin{array}{l}\text { Preconiza-se a ingestão de } 3500 \text { mg/dia ( } 90 \text { mEq). Em } \\
\text { casos de baixa ingestão, deve-se suplementar por via } \\
\text { medicamentosa. }\end{array}$ \\
\hline $\begin{array}{l}\text { Características } \\
\text { gerais }\end{array}$ & $\begin{array}{l}\text { Avaliar consistência da dieta, oferecer dieta fracionada e } \\
\text { de fácil mastigação e digestão. }\end{array}$ \\
\hline $\begin{array}{l}\text { Suplementos } \\
\text { orais, dietas } \\
\text { enterais e } \\
\text { parenterais }\end{array}$ & $\begin{array}{l}\text { Devem ser considerados na incapacidade do paciente } \\
\text { atingir suas necessidades calóricas e protéicas. }\end{array}$ \\
\hline
\end{tabular}

Tabela 20 - Recomendações para restrição hidrossalina em pacientes com IC

\begin{tabular}{lcc}
\hline $\begin{array}{l}\text { Classe de } \\
\text { Recomendação }\end{array}$ & Indicações & $\begin{array}{c}\text { Nível de } \\
\text { Evidência }\end{array}$ \\
\hline & $\begin{array}{c}\text { Restrição de sódio em pacientes com IC } \\
\text { sintomática para prevenir a retenção hídrica; }\end{array}$ & $\mathrm{C}$ \\
\cline { 2 - 3 } Classe Ila & $\begin{array}{c}\text { Orientação quanto ao conteúdo de sódio } \\
\text { nos alimentos; }\end{array}$ & $\mathrm{C}$ \\
\cline { 2 - 3 } & $\begin{array}{c}\text { Restrição de líquidos em pacientes com } \\
\text { IC grave, especialmente na presença de } \\
\text { hiponatremia. }\end{array}$ & $\mathrm{C}$ \\
\hline Classe IIb & $\begin{array}{c}\text { Restrição de líquidos em todos os pacientes } \\
\text { com sintomas leves ou moderados parece } \\
\text { não conferir benefícios clínicos. }\end{array}$ & $\mathrm{C}$ \\
\hline
\end{tabular}

\section{iv. Avaliação psicológica}

Há considerável divergência nos critérios de seleção psicossocial em candidatos a transplante cardíaco. A utilização isolada do DSM IV - Diagnostic and Statistical Manual possibilita o diagnóstico de um número limitado de casos, nos quais há clara evidência de distúrbios mentais do Eixo I e II que repercutem de forma negativa e direta sobre a adesão, as modificações necessárias de estilo de vida e a disciplina imposta pelo protocolo de tratamento, especialmente, quando as dificuldades apresentadas não podem ser atenuadas pelo suporte familiar e pela rede de apoio social, e que, portanto, determinam a exclusão do paciente do procedimento (Tabelas 21 e 22) (11-63. $^{6}$.
Tabela 21 - Recomendações para avaliação psicológica do candidato ao transplante cardíaco

\begin{tabular}{lcc}
\hline $\begin{array}{l}\text { Classe de } \\
\text { Recomendação }\end{array}$ & Indicações & $\begin{array}{c}\text { Nível de } \\
\text { Evidência }\end{array}$ \\
\hline Classe I & Avaliação psicológica especializada. & $\mathrm{C}$ \\
\hline
\end{tabular}

\section{Tabela 22 - Critérios de avaliação psicológica do candidato ao} transplante cardíaco

\begin{tabular}{lc}
\hline & $\begin{array}{c}\text { A condição psicológica do paciente é compativel com } \\
\text { a situação clínica. Observam-se recursos psicológicos } \\
\text { defensivos adaptativos que mantém a esperança e } \\
\text { permitem suportar o sofrimento físico e subjetivo. Boa } \\
\text { estrutura familiar e rede de apoio social; }\end{array}$ \\
\cline { 2 - 3 } Indicações & $\begin{array}{c}\text { A condição psicológica do paciente é reativa à presença } \\
\text { e à gravidade da doença. Não há evidências, no } \\
\text { histórico do paciente, de reações inadaptadas frente a } \\
\text { estressores psicossociais. Boa estrutura familiar e rede } \\
\text { de apoio social. }\end{array}$ \\
\hline relativas & $\begin{array}{c}\text { Falhas na adesão ao tratamento associadas a } \\
\text { condições previstas no Eixo II do DSM IV (distúrbios } \\
\text { de desenvolvimento e de personalidade) incluindo-se a } \\
\text { categoria - personalidade tipo D (distresse), acrescidas } \\
\text { de falta de suporte familiar e social. }\end{array}$ \\
\hline Contraindicações & $\begin{array}{c}\text { Dependência química (abstinência inferior a seis meses } \\
\text { e fatores de risco para comportamento de recidiva); } \\
\text { ideação suicida corrente; tentativas de suicídio } \\
\text { pregressas associadas a distúrbios mentais do Eixo } \\
\text { I e/ou II do DSM IV. Retardo mental impeditivo para } \\
\text { compreensão mínima do tratamento vinculado à falta e/ } \\
\text { ou à negligência de cuidadores. }\end{array}$ \\
\hline
\end{tabular}

DSM IV - Diagnostic and Statistical Manual.

O abuso alcoólico situa-se entre um dos motivos mais frequentes para contraindicação de candidatos. Considerase como fator de risco em tais casos, mesmo na vigência de abstinência, a negação de qualquer vínculo de dependência (incluindo de pessoas) por parte do paciente ${ }^{64}$. Depressão e ansiedade merecem diagnóstico diferencial, em virtude da debilidade que caracteriza a fase de insuficiência cardíaca terminal e as fantasias pelo fato de vir a possuir o coração de outra pessoa ${ }^{64,65}$. Desesperança é um fator de risco associado à mortalidade na fase de espera pelo enxerto ${ }^{64}$.

A personalidade tipo $D$ é outro fator associado à mortalidade no pós-operatório tardio. Define-se por traço de afetividade negativa, na qual a hostilidade mantém alto nível de estresse e conduz a condições negativas de adaptação ${ }^{63,66}$. Recomenda-se o uso de instrumentos de avaliação consagrados no campo da psicologia clínica para determinação de recursos psicológicos defensivos adaptativos à situação ${ }^{64}$.

\section{Imunologia}

\section{A) Avaliação imunológica pré e pós-transplante cardíaco}

A presença de anticorpos circulantes contra os antígenos HLA (human leukocyte antigen) é um fator de risco para rejeição e perda do enxerto após o transplante cardíaco. 
Para a detecção dos anticorpos pré-formados, o soro de um potencial receptor é testado contra um painel de antígenos HLA representativos. O percentual de reatividade determina o PRA e define o grau de sensibilização do paciente. Vários estudos mostraram uma forte correlação entre os níveis de PRA e a frequência de rejeição humoral e a perda do enxerto ${ }^{67,68}$. Assim, há muitos anos, a avaliação do PRA para os pacientes em lista de espera tornou-se praticamente imperativa (Tabela 23).

Para os pacientes sensibilizados, a maioria dos centros adotou a estratégia de transplantar somente após prova cruzada (crossmatch) prospectiva negativa. Na realização do crossmatch, o soro do receptor é testado contra os linfócitos do doador utilizando a técnica da linfocitotoxidade dependente do complemento (CDC), podendo assim detectar a presença de anticorpos específicos contra os antígenos do doador (DSA - donor specific antibodies).

Considerando que a realização do crossmatch requer entre 5-6 horas, somente raros pacientes, em local próximo ao doador, podem usufruir deste procedimento. Além disso, o crossmatch por CDC pode não detectar DSA de baixo título devido a sua limitada sensibilidade ${ }^{69}$.

Recentemente, foi desenvolvida uma nova técnica (Luminex), baseada na citometria de fluxo (altamente sensível), a qual, através do uso de antígenos HLA purificados, permite a detecção e caracterização dos anticorpos presentes no soro do receptor. Uma vez definida a especificidade dos anticorpos, sabe-se contra quais antígenos HLA estes são dirigidos. Assim, quando um doador é disponível, e após sua tipificação HLA, pode-se predizer o êxito do crossmatch prospectivo: na ausência de anticorpos específicos para os antígenos incompatíveis do doador, o crossmatch será negativo. Tal processo constitui o crossmatch virtual.

A literatura internacional sobre a aplicação clínica do crossmatch virtual é incipiente, mas os resultados são altamente encorajadores, mostrando um novo caminho para solucionar os graves problemas inerentes à sensibilização para os pacientes candidatos a transplante de coração ${ }^{70-72}$. Classicamente, as técnicas por CDC e ELISA definem paciente sensibilizado quando PRA acima de 10\%, sendo desejado nesta situação o crossmatch prospectivo (Tabela 23).

A produção de DSA no pós-transplante é associada com o desenvolvimento de rejeição mediada por anticorpo (AMR - antibody mediated rejection), tanto aguda quanto crônica (doença vascular do enxerto) ${ }^{73}$.

\section{Tabela 23 - Recomendações para avaliação imunológica no transplante cardíaco}

\begin{tabular}{lcc}
\hline $\begin{array}{l}\text { Classe de } \\
\text { Recomendação }\end{array}$ & Indicação & $\begin{array}{c}\text { Nível de } \\
\text { evidência }\end{array}$ \\
\hline Classe I & PRA para pacientes em lista de espera. & $\mathrm{B}$ \\
\hline & $\begin{array}{c}\text { Crossmatch virtual para pacientes } \\
\text { sensibilizados; }\end{array}$ & $\mathrm{C}$ \\
\cline { 2 - 3 } Classe Ila & PRA para monitoramento imunológico \\
& pós-transplante. & $\mathrm{C}$ \\
\hline
\end{tabular}

PRA - reatividade contra painel de anticorpos.
O mais comum mecanismo de AMR aguda é a resposta anamnéstica que tem origem na exposição antigênica prévia (gravidez, transfusão, transplante prévio, dispositivo de assistênca circulatória) e aparece durante a primeira semana ou, no máximo, em até 30 dias após o transplante. A produção de altos títulos de anticorpos é rápida e associada à disfunção do enxerto exigindo diagnóstico imediato e tratamento agressivo. A produção de anticorpos de novo é mais lenta (geralmente 100 dias após o transplante) e a rejeição menos grave.

A demonstração de DSA circulantes, juntamente com os achados clínicos, histológicos e imunopatológicos, é recomendada para um diagnóstico rápido e preciso da $\mathrm{AMR}^{74}$. O uso da técnica Luminex com sua alta sensibilidade é ideal para esse propósito, considerando que a maioria dos DSA está fixada no enxerto ${ }^{75}$.

Em conclusão, a detecção e caracterização dos anticorpos no pré e pós-transplante cardíaco são extremamente úteis na prevenção, no diagnóstico, monitoramento e tratamento da AMR.

\section{B) Imunossupressão}

O sucesso dos transplantes foi possível graças à utilização dos imunossupressores e melhores resultados, no longo prazo, serão atingidos com o desenvolvimento de novas estratégias e novos agentes. Segundo registro mais recente de transplante cardíaco $^{76}$, o esquema tríplice incluindo corticosteroide, inibidor de calcineurina e antiproliferativo continua sendo utilizado de maneira rotineira na grande maioria dos serviços. Mais recentemente, estratégias incluindo inibidores do sinal de proliferação (ISP) têm sido propostas.

\section{i. Corticosteroides}

Exercem potente efeito imunossupressor e anti-inflamatório, atuando na regulação de genes que afetam a função de leucócitos, citocinas, moléculas de adesão e fatores de crescimento. São utilizados em altas doses nas fases iniciais e nos episódios de rejeição aguda. Devido aos seus inúmeros efeitos colaterais, em especial, metabólicos e cardiovasculares, sua retirada tem sido preconizada a partir do $6^{0}$ mês póstransplante ${ }^{77}$, principalmente nos pacientes com histórico favorável de rejeições.

\section{ii. Inibidores de calcineurina}

Ciclosporina e tacrolimus. Associados a proteínas específicas do citosol formam complexos chamados imunofilinas que se ligam à enzima calcineurina, bloqueando sua atuação, consequentemente inibindo a síntese de IL-2 pela célula $T^{78}$. São utilizados como imunossupressores de manutenção devendo ser administrados em jejum ou duas horas após ingesta alimentar. Apresentam metabolismo hepático via citocromo P450 (CYP-3A), por isso, inúmeras drogas podem alterar seus níveis séricos, mediante inibição ou indução enzimática (Tabela 24). Os níveis séricos de ambas as drogas devem ser monitorados e ajustados conforme perfil de rejeição e fase do transplante. A coleta no vale é a mais utilizada e largamente difundida 


\section{Diretrizes}

Tabela 24 - Interações medicamentosas com inibidores de calcineurina

\begin{tabular}{lc}
\hline Indutores enzimáticos & Inibidores enzimáticos \\
\hline $\begin{array}{l}\text { Drogas que diminuem o nível sérico } \\
\text { dos inibidores de calcineurina }\end{array}$ & $\begin{array}{c}\text { Drogas que aumentam o nível } \\
\text { sérico dos inibidores de calcineurina }\end{array}$ \\
\hline & Diltiazem \\
Rifampicina & Verapamil \\
Isoniazida & Eritromicina \\
Fenobarbital & Cetoconazol \\
Fenitoína & Itraconazol \\
Carbamazepina & Nifedipina \\
& Metilprednisolona \\
\hline
\end{tabular}

para ambas as drogas; mais recentemente, foi sugerida a utilização da coleta de ciclosporina duas horas após a ingesta (C2), entretanto, meta-análise de estudos comparando as estratégias não demonstrou diferença ${ }^{79}$. Os efeitos colaterais estão na Tabela 25. O tacrolimus parece apresentar menor incidência de hipertensão, efeitos tróficos, dislipidemia e maior incidência de diabetes ${ }^{80,81}$. Estudos comparando as duas drogas demonstraram resultados semelhantes de sobrevida ${ }^{80,81}$, incluindo incidência de rejeição e doença vascular do enxerto. Em trabalhos mais recentes, foi demonstrada menor incidência de rejeição com tacrolimus em comparação à ciclosporina ${ }^{82,83}$. Nas situações de rejeição moderada a grave frequentes ou persistentes (resistentes a corticosteroide), é preconizada a conversão da ciclosporina por tacrolimus ${ }^{84}$. Em mulheres e crianças, devido aos efeitos tróficos da ciclosporina, há uma tendência à utilização de tacrolimus como primeira opção.

\section{iii. Antiproliferativos}

Azatioprina e micofenolato. A azatioprina é uma pródroga que se converte em 6-mercaptopurina, e atua através da incorporação aos ribonucleotídeos das células, inibindo a síntese de DNA e RNA. Dentre os efeitos colaterais, destacam-se a mielossupressão, a hepatotoxicidade, a alergia, a pancreatite e as neoplasias. O micofenolato mofetil é convertido em ácido micofenólico e atua inibindo não competitivamente a enzima inosina monofosfato desidrogenase na via de novo da síntese de purinas, promovendo redução da proliferação de linfócitos de maneira mais seletiva. Seus efeitos colaterais incluem sintomas gastrointestinais e mielossupressão ${ }^{85}$. O micofenolato sódico

\section{Tabela 25 - Efeitos colaterais dos inibidores de calcineurina}

\begin{tabular}{lr}
\hline Metabólicos & $\begin{array}{r}\text { Diabetes, dislipidemia, insuficiência renal, hipercalemia, } \\
\text { hipomagnesemia, hiperuricemia, hiperbilirubinemia. }\end{array}$ \\
\hline Tróficos & Hiperplasia gengival, hipertricose. \\
\hline Vasculares & $\begin{array}{r}\text { Vasoconstrição periférica, hipertensão arterial, } \\
\text { distrofia simpática reflexa, síndrome álgica óssea. }\end{array}$ \\
\hline Neurológicos & $\begin{array}{r}\text { Tremor, convulsão, cefaleia, } \\
\text { depressão, neuropatia periférica. }\end{array}$ \\
\hline Neoplásicos & Pele e linfoproliferativas. \\
\hline
\end{tabular}

(apresentação entérica do micofenolato mofetil) minimiza os sintomas gastrointestinais e apresenta perfil de segurança e eficácia semelhante ao micofenolato mofetil ${ }^{86}$. A monitoração dos níveis de azatioprina não é recomendada (busca-se manter o número de leucócitos acima de 3000-4000), já o controle do micofenolato através da dosagem de ácido micofenólico tem sido sugerido e mais estudos para validação definitiva do método são aguardados ${ }^{87}$. Estudos comparando azatioprina e micofenolato no transplante cardíaco revelam superioridade do micofenolato em relação à rejeição e à sobrevida $^{88,89}$ e mais recentemente uma possível redução de doença vascular do enxerto e neoplasias ${ }^{90,91}$, enquanto sintomas gastrointestinais, infecções por citomegalovírus, herpes simplex e herpes zoster favorecem a azatioprina ${ }^{92}$. Com base nesses resultados, o micofenolato passou a ser o antiproliferativo de escolha no transplante cardíaco em associação aos inibidores de calcineurina e corticosteroides. Além disso, em situações de rejeição grave ou persistente de pacientes que já utilizavam azatioprina cronicamente, a conversão por micofenolato tem sido orientada. Em pacientes chagásicos, dois estudos nacionais em transplante cardíaco demonstraram elevada incidência de reativação da doença de Chagas com micofenolato mofetil ${ }^{93,94}$, trazendo à tona a discussão sobre a possibilidade de utilização de azatioprina ou doses mais baixas de micofenolato nesta população.

\section{iv. Inibidores do sinal de proliferação (ISP)}

Everolimus e sirolimus. Estruturalmente o everolimus difere do sirolimus pela presença de um grupo hidroxetil extra na posição 40, proporcionando uma meia-vida mais curta e um menor tempo para atingir o nível sérico. Formam um complexo intracelular com a enzima FKBP12, inibindo a atividade da enzima mTOR (mammalian target of rapamycin) e interferindo em inúmeros mecanismos celulares de crescimento e proliferação tanto do sistema imune como de outros tecidos (como a musculatura lisa vascular). O sirolimus deve ser ingerido com 4 horas de diferença em relação à ciclosporina (o everolimus não apresenta esta particularidade $)^{95}$; ambas as drogas devem ser monitorizadas com nível sérico no vale e o perfil de metabolismo é hepático ${ }^{96}$, semelhante ao dos inibidores de calcineurina com suas já demonstradas interações medicamentosas. Estudos com ambas as drogas demonstram: redução na incidência ${ }^{97,98}$ e diminuição da progressão da doença vascular do enxerto ${ }^{99}$; melhora ou preservação da função renal nos esquemas de retirada ou redução de ciclosporina; redução de neoplasias e de infecções virais ${ }^{100,101}$.

Em contrapartida, em esquemas de associação com ciclosporina (em dose habitual) está relacionada à piora da função renal ${ }^{97}$; na suspensão da ciclosporina (visando melhora da função renal) pode aumentar a incidência de rejeições ${ }^{102}$; sua utilização precoce no transplante está relacionada a complicações na cicatrização da ferida operatória ${ }^{103}$ (principalmente o sirolimus) e aumento na incidência de infecções bacterianas ${ }^{101}$. Contudo, recentemente se publicou estudo não randomizado que não mostrou tais complicações, mesmo utilizando doses mais elevadas do medicamento ${ }^{104}$. 
Outros efeitos adversos incluem proteinúria, dislipidemia, plaquetopenia, edema, hipertensão, acne, pneumonite intersticial ${ }^{105}$. Por ser uma classe relativamente recente de imunossupressores, apesar dos resultados favoráveis principalmente em relação à redução de doença vascular do enxerto, infecções virais e neoplasias, questões ainda necessitam de respostas antes de se estabelecer seu papel definitivo no transplante cardíaco.

As doses apropriadas dos imunossupressores estão listadas na Tabela 26, enquanto que as recomendações para seu uso estão nas Tabelas 27 (corticosteroides), 28 (inibidores da calcineurina), 29 (antiproliferativos) e na 30 (inibidores do sinal de proliferação).

C) Diagnóstico de rejeição aguda celular, humoral e a biópsia endomiocárdica

A biópsia endomiocárdica, considerada "padrão-ouro" para o diagnóstico de rejeição aguda, deve ser fixada em solução de formol tamponado a 10\%, em temperatura ambiente e manuseada com cuidado. Deve conter ao menos três fragmentos distintos (preferencialmente 4 ou mais), cada um deles constituído ao menos em $50 \%$ por miocárdio. Cortes histológicos sequenciais (ao menos três níveis) devem ser corados pela hematoxilina-eosina e é aconselhável que níveis intermediários sejam guardados para eventuais colorações específicas ou imuno-histoquímica. A coleta de fragmentos congelados para imunofluorescência, utilizando material a fresco, é facultativa a depender da experiência do serviço ${ }^{106,107}$.

\section{i. Classificação histopatológica da rejeição aguda}

A rejeição aguda pode ser do tipo celular, humoral (mediada por anticorpos) ou mista. É descrita ainda a rejeição hiperaguda, que ocorre imediatamente ou nas primeiras horas após o transplante.

\section{a) Rejeição aguda celular}

A rejeição aguda celular, classificada por vários anos

\section{Tabela 26 - Drogas imunossupressoras}

\begin{tabular}{|c|c|c|c|c|}
\hline Drogas & Via & Dose inicial & Manutenção & Nível sérico \\
\hline Prednisona & Oral & $1 \mathrm{mg} / \mathrm{Kg}$ & Retirada em 6 meses & Não se aplica \\
\hline Metilprednisolona & Venosa & $\begin{array}{c}500-1000 \text { mg, dose decrescente até } \\
\text { terceiro PO }\end{array}$ & $\begin{array}{l}\text { Tratamento de rejeição } \\
\text { aguda por 3-5 dias }\end{array}$ & Não se aplica \\
\hline \multirow{2}{*}{ Ciclosporina } & Oral & 3-8 mg/Kg/dia ; & \multirow{2}{*}{$\begin{array}{l}\text { Guiada por sintomas, } \\
\text { rejeição e nível sérico }\end{array}$} & $\begin{array}{l}\text { C0: 350-450 (inicial); } \\
\text { 250-350 (3 a } 6 \text { meses); }\end{array}$ \\
\hline & Venosa & $\begin{array}{l}1-2 \mathrm{mg} / \mathrm{Kg} / \mathrm{dia} \\
\text { (1/3 dose oral) }\end{array}$ & & $\begin{array}{l}200-300 \text { (6 a } 12 \text { meses); } \\
100-200 \text { (acima de } 1 \text { ano) }\end{array}$ \\
\hline \multirow{2}{*}{ Tacrolimus } & Oral & 0,05-0,1mg/Kg/dia; & \multirow{2}{*}{$\begin{array}{l}\text { Guiada por sintomas, } \\
\text { rejeição e nível sérico }\end{array}$} & \multirow{2}{*}{$\begin{array}{l}\text { Vale: } 10-15 \mathrm{ng} / \mathrm{ml} \text { (inicial); } \\
\text { 5-10 ng/ml (pós } 6 \text { meses) }\end{array}$} \\
\hline & Venosa & $0,01-0,02 \mathrm{mg} / \mathrm{Kg} / \mathrm{dia}$ & & \\
\hline \multirow{2}{*}{ Azatioprina } & Oral & 1,5-2,5 mg/kg/dia; & \multirow{2}{*}{$\begin{array}{l}1,5-2,5 \mathrm{mg} / \mathrm{kg} / \mathrm{dia} \text { manter } \\
\text { leucócitos acima de } 4000\end{array}$} & \multirow{2}{*}{$\begin{array}{l}\text { Não utilizado rotineiramente } \\
\text { (manter leucócitos acima de 4000) }\end{array}$} \\
\hline & Venosa & Semelhante a oral & & \\
\hline \multirow{2}{*}{$\begin{array}{l}\text { Micofenolato } \\
\text { Mofetil }\end{array}$} & Oral & $1 \mathrm{~g} 12 / 12$ horas & \multirow{2}{*}{$500-1,5 \mathrm{~g}$ 12/12 horas } & \multirow{2}{*}{ MPA $2,5-5 \mathrm{mcg} / \mathrm{ml}$} \\
\hline & Venosa & Semelhante a oral & & \\
\hline $\begin{array}{l}\text { Micofenolato } \\
\text { Sódico }\end{array}$ & Oral & 720 mg $12 / 12$ horas & $360-1080 \mathrm{~g} 12 / 12$ horas & MPA $2,5-5 \mathrm{mcg} / \mathrm{ml}$ \\
\hline Sirolimus & Oral & Ataque de $6 \mathrm{mg}$ & $\begin{array}{c}2 \mathrm{mg} / \mathrm{dia} \text { - } 1 \mathrm{x} / \mathrm{dia} \text { (ajuste por nível } \\
\text { sérico) }\end{array}$ & Vale: $5-15 \mathrm{ng} / \mathrm{ml}$ \\
\hline Everolimus & Oral & $0,5-1,5 \mathrm{mg} / \mathrm{dia}$ & $0,5-1,5 \mathrm{mg} / \mathrm{dia}-12 / 12$ horas & Vale: $3-8 \mathrm{ng} / \mathrm{ml}$ \\
\hline
\end{tabular}

Tabela 27 - Recomendações para o uso de corticosteroides no transplante cardíaco

\begin{tabular}{lcc}
\hline $\begin{array}{l}\text { Classe de } \\
\text { Recomendação }\end{array}$ & Indicações & $\begin{array}{c}\text { Nível de } \\
\text { Evidência }\end{array}$ \\
\hline & $\begin{array}{c}\text { Doses elevadas nas fases precoces e } \\
\text { nos episódios de rejeição aguda; }\end{array}$ & C \\
\cline { 2 - 3 } Classe I & $\begin{array}{c}\text { Considerar a suspensão em torno } \\
\text { do sexto mês de transplante visando } \\
\text { redução de efeitos colaterais } \\
\text { metabólicos e cardiovasculares nos } \\
\text { pacientes com histórico favorável de } \\
\text { rejeições. }\end{array}$ & B \\
\hline
\end{tabular}

Tabela 28 - Recomendações para o uso de inibidores de calcineurina no transplante cardíaco

\begin{tabular}{lcc}
\hline $\begin{array}{l}\text { Classe de } \\
\text { Recomendação }\end{array}$ & Indicações & $\begin{array}{c}\text { Nível de } \\
\text { Evidência }\end{array}$ \\
\hline & $\begin{array}{c}\text { Como imunossupressão de manutenção } \\
\text { associado aos antiproliferativo e } \\
\text { corticosteroide; }\end{array}$ & $\mathrm{A}$ \\
\cline { 2 - 3 } Classe I & $\begin{array}{c}\text { Conversão de ciclosporina para } \\
\text { tacrolimus em situações de rejeição } \\
\text { grave ou persistente, ou na presença de } \\
\text { efeitos adversos. }\end{array}$ & $\mathrm{C}$ \\
\hline
\end{tabular}




\section{Diretrizes}

Tabela 29 - Recomendações para o uso de antiproliferativos no transplante cardíaco

\begin{tabular}{lcc}
\hline $\begin{array}{l}\text { Classe de } \\
\text { Recomendação }\end{array}$ & Indicações & $\begin{array}{c}\text { Nível de } \\
\text { Evidência }\end{array}$ \\
\hline & $\begin{array}{c}\text { Micofenolato como imunossupressão de } \\
\text { manutenção associado ao inibidor de } \\
\text { calcineurina e corticosteroide; }\end{array}$ & A \\
\cline { 2 - 3 } Classe I & $\begin{array}{c}\text { Conversão de azatioprina para } \\
\text { micofenolato em situações de rejeição } \\
\text { grave ou persistente e prevenção de } \\
\text { doença vascular do enxerto. }\end{array}$ & B \\
\hline Classe Ilb & $\begin{array}{l}\text { Utilização de azatioprina como } \\
\text { imunossupressão de manutenção em } \\
\text { pacientes chagásicos visando redução } \\
\text { da incidência de reativação da doença } \\
\text { de Chagas. }\end{array}$ & C \\
\hline
\end{tabular}

hemorragia, vasculite e necrose dos cardiomiócitos. O caráter "agressivo" do infiltrado inflamatório é muitas vezes definido pela distorção arquitetural da região envolvida, com firme adesão das células inflamatórias ao sarcolema dos cardiomiócitos, que passam a apresentar bordas irregulares, como se "corroídas" por tais células.

\section{b) Rejeição aguda humoral}

A rejeição aguda humoral (mediada por anticorpos), atualmente reconhecida como entidade clínica, tende a ocorrer em pacientes previamente alosensibilizados e está associada à pior evolução clínica e ao desenvolvimento da doença vascular do enxerto ${ }^{74}$. Entretanto, muitas dúvidas permanecem quanto aos critérios diagnósticos, à avaliação evolutiva e ao tratamento desse tipo de rejeição.

Tabela 30 - Recomendações para o uso de inibidores do sinal de proliferação no transplante cardíaco

\begin{tabular}{|c|c|c|}
\hline Classe de Recomendação & Indicações & Nível de Evidência \\
\hline \multirow{5}{*}{ Classe lla } & $\begin{array}{l}\text { Como imunossupressão de manutenção em associação à ciclosporina visando redução de } \\
\text { doença vascular do enxerto; }\end{array}$ & B \\
\hline & $\begin{array}{l}\text { Como imunossupressão de manutenção em associação à dose baixa de ciclosporina após } \\
\text { a cicatrização da ferida operatória, sem antiproliferativo, visando redução de incidência de } \\
\text { rejeição e doença vascular do enxerto; }\end{array}$ & c \\
\hline & $\begin{array}{l}\text { Como imunossupressão de manutenção, em associação à dose baixa de ciclosporina, sem } \\
\text { antiproliferativo, em pacientes com doença vascular do enxerto significativa; }\end{array}$ & c \\
\hline & $\begin{array}{l}\text { Como imunossupressão de manutenção associada à dose baixa } \\
\text { de ciclosporina em pacientes com deterioração da função renal; }\end{array}$ & c \\
\hline & $\begin{array}{l}\text { Como imunossupressão de manutenção na retirada da ciclosporina em pacientes com } \\
\text { deterioração progressiva da função renal a despeito da redução da dose de ciclosporina } \\
\text { (risco de rejeição). }\end{array}$ & c \\
\hline \multirow{3}{*}{ Classe llb } & $\begin{array}{l}\text { Como imunossupressão de manutenção com dose habitual } \\
\text { de ciclosporina (risco de insuficiência renal); }\end{array}$ & c \\
\hline & $\begin{array}{l}\text { Como imunossupressão de manutenção, sem inibidor } \\
\text { de calcineurina (risco de rejeição); }\end{array}$ & c \\
\hline & $\begin{array}{l}\text { No transplante precoce, antes da cicatrização da ferida operatória (risco de retardo na } \\
\text { cicatrização da ferida operatória). }\end{array}$ & C \\
\hline
\end{tabular}

em 6 graus distintos ${ }^{108}$, hoje em dia, é classificada em apenas três graus (Tabela 31$)^{106}$. O grau $1 \mathrm{R}$ (rejeição leve, baixo grau), correspondente aos antigos graus $1 \mathrm{~A}$, 1B e 2, é caracterizado por infiltrado inflamatório linfohistiocitário perivascular ou intersticial, pouco exuberante, sem agressão dos cardiomiócitos ou com apenas um foco de agressão. O grau 2R (rejeição moderada, grau intermediário), correspondente ao antigo grau 3A, é caracterizado pela presença de dois ou mais focos de agressão dos cardiomiócitos pelo infiltrado inflamatório, que é tipicamente multifocal, podendo conter alguns eosinófilos. O grau 3R (rejeição intensa, alto grau), equivalente aos antigos graus $3 \mathrm{~B}$ e 4 , é caracterizado pelo acometimento inflamatório dos vários fragmentos da biópsia, com padrão difuso em ao menos um deles, associado a múltiplas áreas de agressão celular. No grau 3R, o infiltrado inflamatório tende a ser polimórfico, contendo neutrófilos e eosinófilos, podendo ocorrer

\section{Tabela 31 - Classificação revisada da rejeição celular em enxerto} cardíaco

\begin{tabular}{lcc}
\hline $\begin{array}{l}\text { Nomenclatura } \\
\text { nova (2005) }\end{array}$ & $\begin{array}{c}\text { Nomenclatura } \\
\text { antiga (1990) }\end{array}$ & Achados histopatológicos \\
\hline Grau 0R & Grau 0 & Ausência de infiltrado inflamatório. \\
\hline Grau 1R & Grau 1B & $\begin{array}{c}\text { Infiltrado inflamatório perivascular } \\
\text { ou intersticial geralmente } \\
\text { discreto, sem dano celular ou } \\
\text { com foco único de agressão dos } \\
\text { cardiomiócitos. }\end{array}$ \\
\cline { 2 - 3 } Grau 2R & Grau 2 & $\begin{array}{c}\text { Infiltrado inflamatório multifocal } \\
\text { com dois ou mais focos de } \\
\text { agressão dos cardiomiócitos. }\end{array}$ \\
\hline Grau 3R & Grau 3B & $\begin{array}{c}\text { Infiltrado inflamatório difuso, } \\
\text { geralmente com presença } \\
\text { de neutrófilos associado a } \\
\text { múltiplos focos de agressão dos } \\
\text { cardiomiócitos. }\end{array}$ \\
\hline & Grau 4 &
\end{tabular}


Recomenda-se que toda biópsia endomiocárdica seja classificada como "negativa para rejeição aguda mediada por anticorpos (AMR 0)" ou "positiva para rejeição aguda mediada por anticorpos (AMR 1)", baseado nos achados histopatológicos e imunopatológicos ${ }^{106}$. Os primeiros correspondem basicamente à lesão da microcirculação, caracterizada por edema e proeminência das células endoteliais, com eventual desnudamento dos capilares. É descrito infiltrado inflamatório neutrofílico perivascular, edema intersticial e eventuais focos de hemorragia. Caracteristicamente, os capilares apresentam luz abarrotada por macrófagos e podem existir trombos de fibrina nos casos graves.

As características histopatológicas devem ser confirmadas pelos achados imunopatológicos, ou seja, ao menos uma das condições abaixo:

- Detecção de imunoglobulinas (IgG, IgM e/ou IgA) associada à deposição de complemento $(\mathrm{C} 3 \mathrm{~d}, \mathrm{C} 4 \mathrm{~d}$ e/ou C1q) em capilares, por imunofluorescência em material congelado;

- Detecção de macrófagos (células CD68+) na luz de capilares, por imuno-histoquímica;

- Detecção da fração C4d do complemento em capilares, por imuno-histoquímica ${ }^{109}$.

O diagnóstico "positivo para rejeição aguda mediada por anticorpos" na biópsia endomiocárdica não significa necessariamente a presença de rejeição aguda humoral significativa ou que mereça intervenção terapêutica. O diagnóstico definitivo depende da demonstração de anticorpos circulantes específicos contra o doador (geralmente anti-HLA de classe I ou II) e de quadro clínico compatível, usualmente disfunção do enxerto sem causa aparente, ou seja, sem infiltrado inflamatório significativo ${ }^{74,107}$. A avaliação da rejeição humoral pela biópsia endomiocárdica é apenas qualitativa, ou seja, inexistem critérios histopatológicos que indiquem melhora ou piora de rejeição em curso, que é classificada apenas como "presente" ou "ausente".

\section{c) Rejeição hiperaguda}

A rejeição hiperaguda é mediada por anticorpos préformados, geralmente dirigidos contra o sistema ABO ou HLA. É precoce, ocorrendo na sala cirúrgica, ou poucas horas após o transplante. O quadro histopatológico é semelhante ao da rejeição aguda humoral grave, com trombos fibrinosos na microcirculação, degeneração ou necrose da parede vascular, infiltrado inflamatório neutrofílico perivascular, acentuado edema e hemorragia intersticial.

\section{ii. Outros achados significativos da biópsia endomiocárdica, distintos da rejeição}

\section{a) Lesão isquêmica}

Caracteriza-se pela presença de microinfartos em diferentes fases evolutivas. Distingue-se da rejeição basicamente pela desproporção entre a grande intensidade das lesões celulares (necrose dos cardiomiócitos) e a relativa escassez do infiltrado inflamatório ${ }^{110}$. É achado relativamente comum no período perioperatório (até a $6^{\underline{a}}$ semana), podendo se correlacionar com disfunção precoce do enxerto. Sua presença em biópsias realizadas no seguimento a longo termo ${ }^{106}$ pode estar associada à doença vascular do enxerto.

\section{b) Efeito Quilty}

Consiste no infiltrado inflamatório mononuclear do endocárdio, caracteristicamente de aspecto nodular, constituído por linfócitos, macrófagos e plasmócitos, acompanhado de proliferação vascular e fibrose. Seu significado é incerto, não sendo atualmente considerado marcador histológico de rejeição aguda celular, da qual deve ser diferenciado.

\section{c) Local de biópsia prévia}

Tecido de granulação ou área fibrosa cicatricial no endomiocárdio, que se forma depois de repetidas biópsias. Não deve ser confundido com rejeição aguda e não é considerada área avaliável da biópsia.

\section{d) Infecção do enxerto}

É rara a detecção de agentes infecciosos na biópsia endomiocárdica. Os mais descritos são o Trypanosoma cruzi, o Toxoplasma gondii e o citomegalovírus. É excepcional esse último acarretar efeito citopático ou ser identificado por imuno-histoquímica, sendo o diagnóstico geralmente feito por PCR. No paciente chagásico, a distinção entre rejeição aguda celular e reativação da doença de Chagas é geralmente difícil, pois, nesta última condição, o parasita pode não estar representado na biópsia, que é inerentemente escassa, mesmo utilizando-se imuno-histoquímica. Nesses casos, firmamos o diagnóstico do grau da rejeição aguda celular, mas notificamos que "não se acha afastada a hipótese de reativação da doença de Chagas".

\section{e) Neoplasia linfoide}

Não é comum que a doença linfoproliferativa póstransplante acometa o coração e seu aspecto pode se confundir com rejeição aguda celular. O caráter excessivamente monomórfico do infiltrado linfocitário e seu perfil imunofenotípico monoclonal (geralmente B) permitem o diagnóstico diferencial.

\section{D) Tratamento da rejeição aguda celular e humoral}

A despeito dos grandes avanços na terapia imunossupressora, a rejeição ainda é uma das principais causas de mortalidade no primeiro ano após transplante cardíaco ${ }^{111}$. Classicamente, existem bem documentados três tipos principais de rejeição, conforme descrito acima: a rejeição hiperaguda, muito rara e geralmente fatal; a rejeição aguda celular, a mais frequente; e a rejeição humoral ou vascular, que é a menos frequente, porém é a mais grave e geralmente se acompanha de instabilidade hemodinâmica ${ }^{112}$. 


\section{Diretrizes}

Apesar de existir uma grande divulgação de novos métodos não invasivos para diagnóstico da rejeição, a biópsia endomicárdica continua sendo o "padrão-ouro" para o seu diagnóstico correto e precoce. A biópsia fundamenta a orientação terapêutica baseada no tipo e intensidade do processo inflamatório, que associado a parâmetros clínicos e à avaliação de função do enxerto com o ecocardiograma, permite-nos a abordagem com sucesso da maioria dos episódios de rejeição ${ }^{113}$.

\section{i. Rejeição aguda celular}

A rejeição aguda celular é o tipo de rejeição mais frequente e ocorre em aproximadamente $50-70 \%$ dos pacientes, nos primeiros 6 meses de evolução após o transplante cardíaco ${ }^{114}$. É caracterizada pela presença de infiltrado inflamatório predominantemente linfocitário, associado a macrófagos ativados que levam dano à fibra miocárdica.

A maioria dos episódios de rejeição celular é assintomática na sua fase inicial ou pode resultar em sintomas inespecíficos, como fadiga, astenia, anorexia e estado subfebril. Manifestações de insuficiência cardíaca com sinais de congestão, baixo débito cardíaco e disfunção sistólica no ecocardiograma são mais tardios e, geralmente, indicam rejeição grave com alto potencial para falência do enxerto. Portanto, o diagnóstico e a terapêutica dessa forma de rejeição são baseados nos achados histológicos da biópsia endomiocárdica, que deve ser realizada protocolarmente (variável nas diferentes instituições), ou diante de qualquer manifestação clínica ou sinais de disfunção do enxerto ao ecocardiograma.

Atualmente, a rejeição aguda celular é classificada histologicamente em 4 graus: OR (ausência de rejeição); $1 R$ (rejeição leve); $2 R$ (rejeição moderada) e $3 R$ (rejeição severa) ${ }^{106}$. Assim, a atitude e o tipo de mudança terapêutica são guiados pelos achados histológicos associados a dados clínicos e alterações de função sistólica e/ou diastólica no ecocardiograma (Tabela 32).

a) Biópsia OR (paciente estável e com função sistólica normal ao ecocardiograma)

Mantém-se o esquema atual de imunossupressão. b) Biópsia $1 R$ (paciente estável e função sistólica normal)

Faz-se apenas reajustes nas doses dos imunossupressores via oral (otimiza-se nível sérico de inibidor de calcineurina e dose de antiproliferativo).

\section{C) Biópsia $2 R$}

Além do ajuste nas doses dos imunossupressores orais, indica-se pulso com metilprednisolona na dose de $0,5-1 \mathrm{~g} /$ dia/ 3 dias, seguido de dose oral de $1 \mathrm{mg} / \mathrm{kg} / \mathrm{dia}$ até a nova biópsia e indica-se uma nova biópsia em 7 dias após término do tratamento. Na presença de disfunção ventricular deve ser associada terapia citolítica.

\section{d) Biópsia 3R}

Além da pulsoterapia com metilprednisolona, devese considerar a associação de terapêutica citolítica, principalmente se existir sinais de baixo débito cardíaco ou disfunção sistólica grave ao ecocardiograma. Se persistirem os sinais histológicos de rejeição (rejeição persistente), ou ocorrer recorrência frequente dos mesmos (rejeição recorrente), deve-se optar pela conversão da ciclosporina para tacrolimus, considerar medidas adicionais como a associação de metotrexate ou procedimentos extremos como irradiação linfoide total ou retransplante.

Cabe ressaltar que a decisão de tratamento mais agressivo na rejeição celular não é apenas baseada em dados histológicos. Devemos considerar fatores de risco para rejeição, dados imunológicos pré-transplante, dados clínicos, parâmetros de função sistólica e diastólica no ecocardiograma e efeitos colaterais das terapêuticas mais agressivas (Tabela 33).

\section{ii. Rejeição humoral}

Rejeição humoral ou rejeição aguda mediada por anticorpos é o termo que tem se aplicado à rejeição que agride preferentemente a microcirculação do enxerto cardíaco ${ }^{115}$. A sua atual incidência não é conhecida devido às divergências que existem a respeito dos critérios diagnósticos histológicos e imunopatológicos. Acredita-se que sua incidência esteja em torno de $15-20 \%$ no primeiro ano.-

\section{Tabela 32 - Proposta terapêutica da rejeição aguda celular baseada no grau das alterações histológicas}

\begin{tabular}{|c|c|c|}
\hline \multirow{2}{*}{$\begin{array}{l}\text { Biópsia - ISHLT } \\
2005\end{array}$} & \multicolumn{2}{|c|}{ Disfunção Ventricular } \\
\hline & Ausente & Presente \\
\hline $1 \mathrm{R}$ & Sem tratamento adicional, rever esquema imunossupressor. & Pesquisar rejeição humoral e doença vascular do enxerto. \\
\hline $2 R$ & $\begin{array}{l}\text { PO recente: Metilprednisolona 0,5 - 1,0 g IV por 3-5 dias; } \\
\text { PO tardio: Prednisona } 1 \text { mg/kg/d VO por 3-5 dias. }\end{array}$ & $\begin{array}{c}\text { Metilprednisolona 0,5-1,0 g IV por 3-5 dias } \\
+ \\
\text { ATS } 1,5 \mathrm{mg} / \mathrm{kg} / \mathrm{d} \text { por } 5-7 \text { dias; } \\
{ }^{*} \text { Pesquisar rejeição humoral. }\end{array}$ \\
\hline $3 R$ & $\begin{array}{c}\text { Metilprednisolona } 0,5 \text { - } 1,0 \mathrm{~g} \text { IV por } 3-5 \text { dias; } \\
+ \\
\text { ATS } 1,5 \mathrm{mg} / \mathrm{kg} / \mathrm{d} \text { por } 5-7 \text { dias. }\end{array}$ & $\begin{array}{c}\text { Metilprednisolona 0,5-1,0 g IV por 3- } 5 \text { dias } \\
+ \\
\text { ATS } 1,5 \mathrm{mg} / \mathrm{kg} / \mathrm{d} \text { por } 5-7 \text { dias; } \\
\text { *Pesquisar rejeição humoral. }\end{array}$ \\
\hline
\end{tabular}

ATS - timoglobulina. 


\section{Tabela 33 - Recomendações para o tratamento da rejeição aguda celular e rejeição humoral em transplante cardíaco}

\begin{tabular}{|c|c|c|}
\hline Classe de Recomendação & Indicações & Nível de Evidência \\
\hline \multirow{4}{*}{ Classe I } & Pulsoterapia com corticosteroide para rejeição de grau $\geq 2 R$; & C \\
\hline & $\begin{array}{l}\text { Conversão de ciclosporina para tacrolimus na rejeição celular } \geq 2 R \text {, } \\
\text { recorrente ou refratária e na rejeição humoral; }\end{array}$ & C \\
\hline & Plasmaférese e imunoglobulina para rejeição humoral; & $\mathrm{C}$ \\
\hline & Terapia citolítica para rejeição humoral. & C \\
\hline \multirow{3}{*}{ Classe lla } & Terapia citolítica na rejeição celular $\geq 2 R$ com disfunção ventricular; & C \\
\hline & $\begin{array}{l}\text { Associação de metotrexate na rejeição celular recorrente ou refratária com função } \\
\text { ventricular normal, após conversão de ciclosporina para tacrolimus; }\end{array}$ & C \\
\hline & Suporte circulatório para rejeição celular ou humoral refratárias. & C \\
\hline \multirow{4}{*}{ Classe Illb } & Associação de ciclofosfamida na rejeição humoral; & C \\
\hline & $\begin{array}{l}\text { Associação de irradiação linfoide total para tratamento de } \\
\text { rejeição aguda celular } \geq 2 R \text { refratária; }\end{array}$ & C \\
\hline & Rituximab como terapia de resgate na rejeição humoral; & C \\
\hline & Retransplante cardíaco para rejeição celular ou humoral refratárias. & C \\
\hline
\end{tabular}

O diagnóstico de rejeição aguda humoral é caracterizado por achados histopatológicos compatíveis, anticorpos circulantes e disfunção do enxerto. Sua apresentação clínica ocorre geralmente de forma precoce e apresenta elevadas taxas de mortalidade. O diagnóstico histológico isolado (AMR1) não permite a caracterização da rejeição humoral. A melhor estratégia é identificar os pacientes com maior potencial para desenvolver rejeição humoral e suspeitar de tal diagnóstico sempre que o episódio de rejeição ocorrer nas primeiras semanas pós-transplante e quando houver instabilidade hemodinâmica ou comprometimento significativo da função sistólica no ecocardiograma ${ }^{114}$. Dosagem de anticorpos no sangue (painel seriado) também é recomendada. Também se deve considerar rejeição humoral quando estamos diante de quadro clínico e ecocardiográfico exuberantes e biópsia sem grandes alterações histológicas.

Devido ao alto potencial para comprometimento grave da função sistólica e elevado grau de comprometimento hemodinâmico, o tratamento da rejeição humoral deve ser agressivo e instituído o mais precocemente possível, mesmo antes da confirmação histológica e da imunofluorescência. Havendo suspeita ou diagnóstico de rejeição humoral, a terapêutica deve ser iniciada precocemente, com suporte inotrópico ou circulatório mecânico e a imunossupressão agressiva com pulsoterapia de metilprednisolona na dose de 1g/dia/3 dias; conversão da ciclosporina para tacrolimus da dose de 0,1-0,3 mg/kg/dia; conversão da azatioprina para micofenolato ou substituição deste por ciclofosfamida. A terapêutica citolítica também está indicada. A plasmaférese deve ser realizada precocemente e diariamente por 3-4 dias consecutivos com o objetivo de remover anticorpos e citocinas circulantes. Recentemente, tem-se preconizado também a infusão de imunoglobulina hiperimune (IVIg) associada à plasmaférese. Rituximab também tem sido utilizado ${ }^{116}$.

Diferente da rejeição aguda celular, em que a mortalidade é baixa, próximo de 5-10\%, a mortalidade da rejeição humoral com comprometimento do estado hemodinâmico é extremamente alta, girando em torno de $30-50 \%$. Novas drogas imunossupressoras estão em avaliação, muitas ainda em níveis experimentais e são promissoras para uma melhor prevenção e controle dos diferentes tipos de rejeição (Tabela 33) ${ }^{117}$.

\section{E) Terapias de indução e terapias de resgate}

A terapia de indução tem como objetivo induzir rapidamente imunossupressão, reduzir rejeição aguda e facilitar a manutenção das drogas habituais ${ }^{118}$. Seu uso rotineiro tem sido extensamente estudado, porém sem sustentação para uso universal ${ }^{119}$.

Contudo, algumas situações merecem atenção quanto à indução: pré-sensibilização com PRA positivo, crossmatch positivo e disfunção renal prévia ou provável (idade avançada, taxa de filtração glomerular (TFG) $<40 \mathrm{ml} / \mathrm{min} / 1,73 \mathrm{~m}^{2}$, diabetes e hipertensão). Nesses grupos, a terapia de indução reduz o risco de rejeição humoral, inclusive hiperaguda, e posterga a introdução dos inibidores de calcineurina. Ainda assim, o impacto sobre a mortalidade permanece incerto bem como o risco de rejeição tardia. Entretanto, existe associação com desenvolvimento de malignidades linfoproliferativas ${ }^{120}$.

A chamada terapia de resgate refere-se ao uso de drogas ou estratégias imunossupressoras diferenciadas para controle de rejeição crônica ou aguda de difícil manejo com drogas habituais.

As drogas utilizadas na terapia de indução com suas respectivas características estão relacionadas na Tabela 34 e as recomendações para seu uso na Tabela 35.

\section{i. Anticorpos monoclonais}

OKT3 - anticorpo monoclonal citolítico. Pode levar à "síndrome de liberação de citocinas", com sintomas entre leve desconforto até choque e sintomas relacionados ao sistema nervoso central. Em estudos clínicos, apresentou resultados 


\section{Diretrizes}

conflitantes, sendo indiferente em relação à terapia padrão sem indução e em outros com redução nas rejeições, porém sem impacto na mortalidade no primeiro ano, mas com aumento tardio na incidência de doenças linfoproliferativas ${ }^{121}$.

Antagonistas dos receptores de IL2 (anticorpos monoclonais - IgG humanizados):

- Daclizumab - Quando comparado com OKT3, apresenta maior tolerância, porém, no que diz respeito à rejeição, os dados são conflitantes. Quando comparado com terapia padrão sem indução, apresentou menor incidência de rejeições nos primeiros 6 meses, com evolução limítrofe no primeiro ano ${ }^{122}$.

- Basiliximab - Em estudo comparado com OKT3, não demonstrou superioridade de efeito antirrejeição. Outros estudos sugerem dados controversos, com melhores relatos no que se refere à lesão renal e infecção ${ }^{123,124}$.

É importante ressaltar que a associação dessa classe de drogas com a terapia citolítica aumenta o risco de mortalidade por infecção ${ }^{122}$.

\section{ii. Anticorpos policlonais}

ATS - Timoglobulina - agente citolítico bem tolerado clinicamente. Em estudos comparando-se à terapia padrão sem indução, demonstrou redução nas rejeições, menor mortalidade no primeiro ano, porém com relatos de maior incidência de infecção, principalmente no primeiro mês. Em terapia de resgate por curtos períodos e até mesmo com prolongamento do uso, há diversos estudos com resposta imunossupressora positiva ${ }^{125}$.

\section{iii. Ciclofosfamida}

Agente citotóxico com efeitos supressivos da proliferação linfocitária (interfere na replicação de DNA) e na resposta das células B. Possui estudos com uso na forma de pulso como TI (4 meses) e resgate, tendo em ambos redução de rejeições, especialmente em pacientes sensibilizados, porém seu uso contínuo em substituição aos antiproliferativos não demonstrou controle sobre novos episódios ${ }^{126}$.

\section{iv. Plasmaférese}

Remoção através da separação por centrifugação ou filtragem de imunocomplexos em especial anticorpos (pré ou pós-formados) e, associadamente, redução sérica dos mediadores liberados no processo de rejeição aguda (tóxicos para a fibra miocárdica). Plasmaférese isolada ou associada à timoglobulina, ciclofosfamida e/ou imunoglobulina tem sido descrita com bom resultado, em especial em casos urgentes pré-sensibilizados, ainda que com elevação no risco de infecção ${ }^{127}$.

\section{v. Metotrexate}

Inibidor potente da dihidrofolatoredutase com atuação na imunidade celular e humoral, diminuindo anticorpos,

Tabela 35 - Recomendações para terapia de indução no transplante cardíaco

\begin{tabular}{lcc}
\hline $\begin{array}{l}\text { Classe de } \\
\text { Recomendação }\end{array}$ & Indicação & $\begin{array}{c}\text { Nível de } \\
\text { Evidência }\end{array}$ \\
\hline \multirow{3}{*}{ Classe Ila } & $\begin{array}{c}\text { Antagonistas dos receptores de IL2 } \\
\text { como terapia de indução em pacientes } \\
\text { pré-sensibilizados ou doença renal pré- } \\
\text { existente ou provável; }\end{array}$ & B \\
\cline { 2 - 3 } & $\begin{array}{c}\text { Timoglobulina como terapia de indução } \\
\text { em pacientes pré-sensibilizados ou } \\
\text { doença renal pré-existente ou provável. }\end{array}$ & B \\
\hline Terapia de indução rotineiramente \\
em todos os pacientes submetidos a \\
transplante;
\end{tabular}

IL2 - interleucina 2; OKT3 - anticorpo monoclonal citolítico.

Tabela 34 - Principais drogas para terapia de indução (i) e resgate (r)

\begin{tabular}{|c|c|c|c|c|c|}
\hline Droga & Alvo & Dose & Tempo de uso & Segurança & Tolerabilidade \\
\hline Basiliximab (i) & CD25 & 20 mg/dose. & 2 doses (D0 e D4) & +++ & Boa tolerância. \\
\hline Daclizumab (i) & CD25 & $1 \mathrm{mg} / \mathrm{kg}$ & 5 doses $/ 2$ semanas & +++ & Boa tolerância. \\
\hline Timoglobulina (i+r) & Linfócitos periféricos & $1,5 \mathrm{mg} / \mathrm{kg} / \mathrm{dia}$ & 3-7 dias & ++ & Febre, calafrios, leucopenia. \\
\hline OKT3 (i +r) & CD3 & 2,5-5 mg/dia. & 7-14 dias & + & $\begin{array}{c}\text { Síndrome de liberação de } \\
\text { citocinas. }\end{array}$ \\
\hline Ciclofosfamida (r) & Linfócitos / células B & 0,5-1,5 mg/Kg/dia. & variável & ++ & $\begin{array}{l}\text { Mielossupressão, sint. } \\
\text { Gastrointestinais. }\end{array}$ \\
\hline Metotrexate (r) & Linfócitos / citocinas & 5-15 mg/semana. & 3-12 semanas & +++ & $\begin{array}{c}\text { Mielossupressão, sintomas } \\
\text { gastrointestinais, hepato e } \\
\text { nefrotoxicidade. }\end{array}$ \\
\hline $\begin{array}{l}\text { Imunoglobulina } \\
(\mathrm{IVIg})(\mathrm{r})\end{array}$ & $\begin{array}{l}\text { Linfócitos / citocinas / } \\
\text { anticorpos }\end{array}$ & $\begin{array}{l}2 \mathrm{~g} / \mathrm{Kg} / \text { doses diárias de } 100 \\
\mathrm{mg} / \mathrm{Kg} \text { (pós plasmaférese). }\end{array}$ & variável & ++ & $\begin{array}{c}\text { Cefaleia, calafrios, artralgias, } \\
\text { febre. }\end{array}$ \\
\hline
\end{tabular}

OKT3 - anticorpo monoclonal citolítico. 
interferindo na produção de citocinas e diminuindo a proliferação linfocitária. Diversos estudos pequenos têm descrito controle de processos de rejeição refratária, principalmente se associado à ciclosporina, com efeito prolongado, mesmo após a interrupção. Seus efeitos colaterais incluem mielossupressão e hepatotoxicidade. Em doses altas, tem sido relacionado a um aumento de infecções ${ }^{128,129}$.

\section{vi. Imunoglobulina (IVIg)}

Uma grande variedade de imunoglobulinas está presente nessa preparação. Apesar de um mecanismo de ação ainda não totalmente elucidado, possui inúmeros efeitos sobre o sistema imune (redução de citocinas inflamatórias, aumento de citocinas anti-inflamatórias, bloqueio dos receptores Fc, inibição da ativação e deposição de complemento, redução da adesão endotelial de leucócitos, neutralização de antígenos microbianos e autoanticorpos). Tem sido utilizada em situações de resgate no transplante cardíaco de pacientes com rejeição aguda grave mediada por anticorpos, geralmente associada à plasmaférese ${ }^{130}$. Em pacientes sensibilizados (PRA alterado), existem protocolos utilizando IVIg como estratégia de redução de produção de anticorpos anti-HLA no pré-transplante, entretanto, são necessárias repetições de aplicação, dependendo do tempo, até a realização do transplante ${ }^{131}$.

\section{vii. Rituximab}

Apresenta anticorpo específico de alta afinidade contra o receptor $\mathrm{CD} 20^{116}$. Na literatura, existe descrição de sua utilização como terapia de indução em pacientes sensibilizados e no tratamento de resgate de rejeição humoral ${ }^{132}$

F) Seguimento pós-transplante cardíaco - avaliação de rejeição

\section{i. Biópsia endomiocárdica}

A biópsia endomiocárdica é o método diagnóstico "padrão-ouro" para monitorização de rejeição. Trata-se de um procedimento percutâneo que usualmente é guiado por fluoroscopia no laboratório de cateterismo cardíaco, mas poderá ser guiado pelo ecocardiograma ${ }^{133}$. A via de acesso percutâneo pode ocorrer por via femural ou jugular, apresentando baixa morbidade e mortalidade. Geralmente, o procedimento é realizado retirando fragmentos do septo interventricular direito ${ }^{133,134}$. A biópsia deve ser realizada com bióptomo adequado, devendo ser retirado de 5-7 fragmentos de boas dimensões, pois alguns podem não conter tecido miocárdico. Os protocolos de biópsia endomiocárdica variam de acordo com a experiência de cada serviço, porém a primeira biópsia é geralmente realizada após a primeira semana do transplante ${ }^{133}$.

A biópsia endomiocárdica deverá ser realizada sempre que houver suspeita clínica de rejeição (Tabela 36) ${ }^{14,134}$.

\section{ii. Cintilografia miocárdica}

$\mathrm{Na}$ avaliação da função ventricular após transplante cardíaco, pode ser utilizada a angiocardiografia ou ventrículografia radioisotópica. Na detecção de rejeição aguda, o Citrato de Gálio-67 apresenta elevada sensibilidade e especificidade, e também elevada sensibilidade para avaliação da gravidade da rejeição ${ }^{135}$. O acompanhamento seriado com esse método reduz significativamente a necessidade de biópsias endomiocárdicas nos pacientes (Tabela 36).

\section{iii. Ressonância magnética cardíaca}

A ressonância magnética cardíaca (RMC) apresenta elevada sensibilidade e especificidade na detecção de rejeição através do uso de gadolíneo e caracterização da alteração do tempo de relaxamento (nas fases iniciais). Por tratar-se de estratégia de alto custo, além do uso de gadolíneo, que apresenta risco em pacientes com disfunção renal, são necessários mais trabalhos para definição de seu papel no seguimento de rejeição no transplante cardíaco (Tabela 36$)^{136}$.

\section{G) Doença vascular do enxerto}

A doença vascular do enxerto (DVE) persiste sendo a principal complicação tardia após transplante cardíaco, e é responsável por grande parte dos óbitos após o primeiro ano de seguimento. Se analisarmos a evolução tardia, veremos que, ao final de 5 anos, cerca de $90 \%$ dos pacientes apresentarão hipertensão arterial, 80\% dislipidemia, 30\% diabetes e aproximadamente $50 \%$ dos pacientes apresentarão algum grau de $\mathrm{DVE}^{137}$. Uma vez que o paciente transplantado é denervado, os sintomas habituais de isquemia miocárdica podem não estar presentes, e a primeira manifestação da doença pode ser a morte súbita. Outro sinal de alerta é a presença de arritmias, sinais de IC, documentação de alterações eletrocardiográficas ou alterações evidenciadas ao ecocardiograma de repouso.

Existem diferenças claras entre a tradicional aterosclerose coronariana e a DVE. A aterosclerose é usualmente focal, com proliferação excêntrica da camada íntima do segmento proximal dos vasos, associada ao depósito de cálcio, ruptura da

Tabela 36 - Recomendações para diagnóstico e seguimento de rejeição no transplante cardíaco

\begin{tabular}{lcc}
\hline $\begin{array}{l}\text { Classe de } \\
\text { Recomendação }\end{array}$ & Indicações & $\begin{array}{c}\text { Nível de } \\
\text { Evidência }\end{array}$ \\
\hline Classse I & $\begin{array}{c}\text { Ecocardiograma para avaliação da } \\
\text { função do enxerto; }\end{array}$ & $\mathrm{C}$ \\
\cline { 2 - 3 } & $\begin{array}{c}\text { Biópsia endomiocárdica para } \\
\text { seguimento de rejeição conforme } \\
\text { protocolos institucionais e na suspeita } \\
\text { de rejeição. }\end{array}$ & $\mathrm{C}$ \\
\hline Classe Ila & $\begin{array}{c}\text { Cintilografia com Gálio-67 para } \\
\text { seguimento de rejeição em pacientes } \\
\text { estáveis. }\end{array}$ & $\mathrm{C}$ \\
\hline Classe Ilb & $\begin{array}{c}\text { Ressonância magnética cardíaca para } \\
\text { seguimento de rejeição em pacientes } \\
\text { estáveis. }\end{array}$ & $\mathrm{C}$ \\
\hline
\end{tabular}




\section{Diretrizes}

lâmina elástica interna e presença de componente gorduroso da placa. Pode apresentar sinais de inflamação e as veias não são envolvidas no processo aterosclerótico tradicional ${ }^{138}$. A DVE é tipicamente caracterizada por uma proliferação difusa, concêntrica da camada miointimal dos vasos. Os ramos intramiocárdicos são usualmente envolvidos, assim como o sistema venoso. Nas fases iniciais da DVE, o depósito de cálcio é raro, a lâmina elástica é intacta e inflamação está frequentemente presente ${ }^{139}$.

Os mecanismos envolvidos no desenvolvimento da DVE ainda não estão totalmente elucidados. Considera-se que fatores imunológicos e não imunológicos exerceriam influência conjunta na instalação do processo. Classicamente, os fatores de risco habituais da aterosclerose, tais como dislipidemia, obesidade, hipertensão, tabagismo, diabetes e sedentarismo, continuam exercendo seu papel no desenvolvimento da doença. Algumas séries documentaram a correlação entre o índice de massa corpórea dos pacientes com a maior probabilidade de desenvolver DVE, provavelmente refletindo, muito mais do que um simples dado antropométrico, um marcador de alterações metabólicas que podem ocorrer em tais pacientes, inclusive alterações relacionadas com resistência à insulina ${ }^{140}$.

Os mecanismos imunológicos também têm sido estudados, e hoje se considera que fatores, tais como a morte encefálica, preservação do enxerto, fenômenos de isquemia e reperfusão, possam influenciar as alterações endoteliais do enxerto. A resposta aloimune é caracterizada por alorreconhecimento, ativação de células T, expansão clonal, citotoxicidade e produção de anticorpos por células B, liberação de citocinas pró-inflamatórias. Esta ativação resulta em disfunção endotelial com disfunção vasomotora, estado prótrombótico, apoptose e proliferação muscular lisa, contribuindo para o complexo processo da DVE ${ }^{141,142}$.

Também é importante que se diga que infecções por citomegalovírus também têm sido descritas em algumas séries como sendo responsáveis pelo desenvolvimento de DVE, provavelmente por interferir no processo de proliferação endotelial, via mecanismo imunológico ${ }^{143}$.

\section{i. Diagnóstico}

O diagnóstico precoce de DVE é limitado pela denervação, que resulta em ausência de sintomas anginosos típicos.

Dos métodos diagnósticos não invasivos disponíveis, o ecocardiograma de estresse com dobutamina tem se mostrado o método mais aceito para diagnóstico, como também método útil em predizer pacientes com maior risco de eventos cardiovasculares, no seguimento tardio, pelo seu elevado valor preditivo negativo ${ }^{144,145}$. Os protocolos atuais utilizam ecocardiograma de estresse com dobutamina anual para triar pacientes que necessitarão de estudo angiográfico (estudo positivo para isquemia), e, consequentemente, pacientes de maior risco, que deverão ser submetidos a intervenções ou mudanças terapêuticas.

A angiotomografia de coronária com múltiplos detectores permite avaliação não invasiva da luz coronariana, da parede intimal podendo ser considerada para screening, diagnóstico, intensidade e seguimento de doença vascular do enxerto.
Como dificuldades do método, destacam-se o uso de contraste, a dificuldade para redução da frequência cardíaca no procedimento e a exposição à radiação ${ }^{146}$.

A maioria dos protocolos internacionais preconiza, após o primeiro ano, realização de estudo angiográfico anual para detecção da doença. No entanto, é importante que se diga que, após o diagnóstico realizado, poucas opções de intervenção são possíveis, devido à natureza difusa e com comprometimento distal das lesões ${ }^{147}$. A análise por ultrassonografia intravascular se mostrou mais sensível na detecção de lesões mais precoces, na análise das modificações das lesões, bem como na capacidade de testar novas drogas, aptas a bloquear o processo de proliferação miointimal.

A DVE denominada rapidamente progressiva é definida como o aumento maior ou igual a $0,5 \mathrm{~mm}$ na espessura máxima da íntima do vaso, ao final do primeiro ano após transplante ${ }^{148}$. Além do aspecto diagnóstico, a ultrassonografia intravascular é capaz de predizer e identificar pacientes com maior risco de desenvolver eventos cardiovasculares, além de ajudar na definição de estratégias terapêuticas precoces (Tabela 37) ${ }^{149}$.

\section{ii. Prevenção e tratamento}

Como descrito anteriormente, quando a DVE está estabelecida, com comprometimento multivascular, difuso e com acometimento do leito distal, muito pouco impacto terapêutico é possível nesta fase e, consequentemente, o prognóstico do paciente é ruim.

As medidas preventivas a serem adotadas devem contemplar a orientação para atividades físicas, redução de peso, controle da hipertensão e diabetes (Tabela 37).

Do ponto de vista medicamentoso, algumas estratégias são adotadas na prevenção (Tabela 37). As drogas de primeira linha para tratamento e prevenção da DVE são as estatinas. Os principais estudos são com a pravastatina, que mostrou ser efetiva ao final de um ano na redução do LDL colesterol, redução do triglicérides e aumento do HDL, associado a maior redução da proliferação miointimal e por efeito pleiotrópico na redução de rejeições graves, por bloqueio de linfócitos natural killer, quando comparados a placebo $^{150,151}$. As outras estatinas testadas são a sinvastatina e a atorvastatina, porém devem ser usadas nas menores doses possíveis, por maior chance de rabdomiólise por interação com os inibidores de calcineurina.

No controle da hipertensão, os bloqueadores do canal de cálcio (diltiazem) se mostraram efetivos na prevenção da DVE por redução da hiperplasia miointimal, além de interagirem com a ciclosporina, aumentando seu nível sérico, e, consequentemente, expondo o paciente a doses menores de inibidor de calcineurina ${ }^{152}$. Os IECA também se mostraram efetivos na melhora da disfunção endotelial da DVE, inclusive com efeito sinérgico ao diltiazem ${ }^{153}$.

Os maiores avanços no impacto medicamentoso na prevenção e tratamento da DVE foram com os inibidores do sinal de proliferação, drogas com potente ação antiproliferativa (sirolimus, everolimus). Os estudos anteriores já mostravam superioridade do micofenolato, quando comparado à azatioprina, com redução de DVE ${ }^{154}$. No entanto, os estudos 
Tabela 37 - Recomendações para diagnóstico, prevenção e tratamento da DVE

\begin{tabular}{|c|c|c|}
\hline Classe de Recomendação & Indicações & Nível de Evidência \\
\hline \multicolumn{3}{|l|}{ Diagnóstico } \\
\hline Classe I & $\begin{array}{l}\text { Ecocardiografia de estresse com dobutamina anual para identificação de pacientes } \\
\text { com maior risco de eventos cardiovasculares após transplante cardíaco. }\end{array}$ & C \\
\hline Classe Ila & $\begin{array}{l}\text { Cineangiocoronariografia anual (após primeiro ano), para diagnóstico e } \\
\text { prognóstico de pacientes submetidos a transplante cardíaco; }\end{array}$ & C \\
\hline Classe Ilb & $\begin{array}{l}\text { Teste ergométrico convencional / cintilografia miocárdica / angiotomografia } \\
\text { para diagnóstico de isquemia após transplante cardíaco. }\end{array}$ & C \\
\hline \multicolumn{3}{|l|}{ Prevenção } \\
\hline \multirow{2}{*}{ Classe I } & $\begin{array}{l}\text { Orientação dos pacientes para redução de peso, controle da HAS, } \\
\text { diabetes e para prática de atividades físicas; }\end{array}$ & C \\
\hline & Diltiazem precocemente como droga de primeira linha para controle da HAS e prevenção de DVE. & A \\
\hline \multirow[b]{2}{*}{ Classe lla } & IECA para prevenção de DVE, associado ou não ao diltiazem; & B \\
\hline & $\begin{array}{l}\text { AAS para pacientes diabéticos após transplante cardiaco, para } \\
\text { prevenção de DVE e eventos cardiovasculares. }\end{array}$ & C \\
\hline \multicolumn{3}{|l|}{ Tratamento } \\
\hline \multirow[b]{2}{*}{ Classe I } & Angioplastia com colocação de stent para lesões proximais > 70\% e com documentação de isquemia; & C \\
\hline & $\begin{array}{c}\text { Revascularização cirúrgica para pacientes triarteriais, com leito distal favorável e com documentação de } \\
\text { isquemia. }\end{array}$ & C \\
\hline Classe lla & $\begin{array}{l}\text { Retransplante para pacientes com DVE difusa multiarterial, com comprometimento do leito distal e com } \\
\text { disfunção ventricular importante, não passíveis de tratamento percutâneo ou cirúrgico. }\end{array}$ & C \\
\hline
\end{tabular}

HAS - hipertensão arterial sistêmica; DVE - doença vascular do enxerto; IECA - inibidores da enzima de conversão da angiotensina.

randomizados mais recentes mostraram que o everolimus, testado com duas dosagens (1,5 e 3 mg), comparado à azatioprina, mostrou ser mais efetivo na preservação do lúmen arterial, quando analisado por ultrassonografia intravascular. Esse benefício foi estendido no seguimento de doisea 4 anos, além de reduzir os episódios de rejeição e diminuir as infecções por citomegalovírus (CMV) ${ }^{97}$. O sirolimus também mostrou ser efetivo na prevenção da proliferação miointimal em estudos randomizados, porém com número menor de pacientes testados ${ }^{\mathbf{9 8}}$.

Para os pacientes que já apresentam a doença instalada, as opções terapêuticas são a angioplastia com colocação de stent, revascularização miocárdica ou retransplante. A decisão deve ser tomada levando-se em conta a anatomia coronariana, característica e localização das lesões e a função ventricular. No entanto, não dispomos de estudos randomizados para uma definição terapêutica com maior grau de evidência

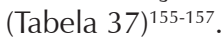

\section{Aspectos cirúrgicos do transplante cardíaco}

\section{A) Captação e preservação do enxerto}

A tolerância de até 4 horas entre a retirada do coração do doador e a sua reperfusão representa importante desafio ${ }^{158}$. Acima desse tempo, o coração apresenta alterações estruturais que podem comprometer o sucesso do procedimento ${ }^{159,160}$. Todavia, bons resultados têm sido relatados com períodos de isquemia maiores, a despeito do aumento dos gastos hospitalares e do maior período de internação $^{161}$. A preparação do doador e do receptor deve ser cuidadosamente sincronizada com o objetivo de diminuir o tempo de isquemia do órgão.

\section{i. Técnica de retirada do enxerto}

O doador deverá estar monitorado com pressão intraarterial, pressão venosa central e cateter urinário. A operação para retirada dos órgãos é realizada por uma incisão torácica e abdominal. Após a pericardiotomia, o coração é inspecionado em busca de alguma alteração que contraindique o transplante. A aorta ascendente é separada da artéria pulmonar e dissecada o mais próximo do tronco braquiocefálico. A veia cava superior é dissecada e completamente mobilizada ${ }^{162}$. Recomenda-se ligar e suturar a veia ázigos.

Após a heparinização do paciente (3-4 mg/kg), um cateter para infusão de solução de preservação é posicionado na aorta ascendente ${ }^{163}$. Com o objetivo de esvaziar o coração, realiza-se o pinçamento das veias cavas. A seguir, oclui-se a aorta e infunde-se solução cardioplégica até a parada cardíaca. Nesse momento, abre-se a cava inferior e a veia pulmonar superior direita com o intuito de evitar distensão 


\section{Diretrizes}

do coração. Uma solução fisiológica gelada é instilada no espaço pericárdico para resfriamento miocárdico. Seccionamse sucessivamente as veias cavas, inferior e superior, aorta, artéria e veias pulmonares, bem como as reflexões pericárdicas após elevação da ponta do coração ${ }^{162}$. Em situações em que a retirada dos pulmões se faz necessária para o transplante pulmonar, deixa-se um cuff de átrio esquerdo ao redor dos óstios das veias pulmonares, esquerda e direita, realizandose a incisão diretamente no átrio esquerdo e não nas veias pulmonares, como é feito convencionalmente. O coração removido é colocado na solução de preservação dentro de sacos plásticos estéreis e transportado em recipiente apropriado (Tabela 38) ${ }^{164}$.

\section{ii. Preservação do coração}

A melhor técnica de preservação miocárdica para transplante ainda não foi definida. No entanto, a infusão de soluções cardioplégicas e o armazenamento frio do órgão são os métodos comumente utilizados ${ }^{165}$. De acordo com a sua composição iônica, as soluções de preservação disponíveis no mercado são classificadas em: intracelulares (Wisconsin, Euro-Collins, HTK-Custodiol ${ }^{\circledR}$ e Soluções de Stanford) e extracelulares (Hopkins, Celsior ${ }^{\circledR}$, Krebs e St. Thomas). Demonstrou-se vantagem teórica na utilização de soluções hipopotassêmicas por diminuir dano celular ${ }^{166}$. Comparações de diferentes soluções no resultado do transplante cardíaco mostram resultados variados (Tabela 38) ${ }^{\mathbf{1 6 0 , 1 6 7}}$.

Alguns fatores, como o manejo inadequado do doador, lesões de isquemia-reperfusão e depleção dos estoques de energia por má proteção miocárdica, contribuem para a falência de enxerto e devem ser agressivamente evitados.

A ótima preservação do enxerto pode diminuir a necessidade de suporte inotrópico com melhora da morbidade e da mortalidade após o transplante cardíaco. Com isso, abre-se a possibilidade de se utilizar doadores limítrofes ou períodos prolongados de isquemia ${ }^{168}$.

Recentemente, tem-se discutido o emprego de perfusão ex vivo no sentido de ampliar perspectivas futuras para melhor proteção miocárdica ${ }^{160}$.

Tabela 38 - Recomendações para retirada e preservação do coração doador

\begin{tabular}{|c|c|c|}
\hline $\begin{array}{l}\text { Classe de } \\
\text { Recomendação }\end{array}$ & Indicações & $\begin{array}{l}\text { Nível de } \\
\text { Evidência }\end{array}$ \\
\hline \multirow{3}{*}{ Classe I } & $\begin{array}{l}\text { Transporte do coração removido em } \\
\text { solução de preservação dentro de sacos } \\
\text { plásticos estéreis e em recipientes } \\
\text { apropriados. }\end{array}$ & C \\
\hline & $\begin{array}{c}\text { Sincronização cuidadosa da preparação } \\
\text { do doador e do receptor com o objetivo } \\
\text { de diminuir a isquemia do órgão, } \\
\text { evitando-se períodos superiores a } 4 \\
\text { horas. }\end{array}$ & C \\
\hline & $\begin{array}{c}\text { Infusão de soluções cardioplégicas } \\
\text { industrializadas a } 4^{\circ} \mathrm{C} \mathrm{e} \\
\text { armazenamento frio para preservação } \\
\text { miocárdica. }\end{array}$ & C \\
\hline
\end{tabular}

\section{B) Transplante ortotópico: técnica clássica versus bicaval}

A técnica clássica ou biatrial descrita inicialmente por Shumway e cols. ${ }^{169}$. ainda tem sido empregada, devendo-se ter especial atenção com a preservação da geometria atrial, evitando-se distorções ou permanência de grandes cavidades. Suas principais complicações são: formação de trombos intraatriais, arritmias e insuficiência das valvas atrioventriculares ${ }^{170}$.

No início da década de 1970, Webb e cols. ${ }^{171}$ idealizaram a técnica bicaval, também chamada de ortotópica total. Na técnica bicaval, a secção da veia cava superior deve ser feita junto à veia ázigos; a secção da veia cava inferior deve ser feita na reflexão do diafragma; e a secção das veias pulmonares deve ser feita na inserção com o átrio esquerdo, mantendose um segmento de parede atrial entre elas. No receptor, é obrigatória a canulação direta das veias cavas. A veia cava superior é seccionada na inserção com o átrio direito e um grande segmento de átrio direito adjacente é mantido junto à veia cava inferior.

Na técnica bicaval, o átrio esquerdo é totalmente removido, permanecendo apenas dois segmentos onde se inserem as veias pulmonares, para sutura do átrio esquerdo. Essa variante tem, entre outras, algumas vantagens: preservar a geometria atrial, diminuir a incidência de arritmias no período pós-operatório e de insuficiência tricúspide ${ }^{172,173}$. Quanto ao reimplante do átrio esquerdo, parece não haver diferença de resultados quanto à técnica uniatrial ou bipulmonar.

\section{i. Anuloplastia valvar tricúspide profilática}

O transplante cardíaco ortotópico é frequentemente associado ao desenvolvimento de insuficiência tricúspide, em longo prazo, geralmente de caráter progressivo ${ }^{174}$. A técnica clássica é associada mais frequentemente ao desenvolvimento de insuficiência tricúspide que a bicaval, o que em parte deve-se a maior alteração geométrica da valva tricúspide e do átrio direito, em decorrência da anastomose entre os átrios do doador e do receptor ${ }^{175}$. A insuficiência tricúspide pode se tornar uma doença séria se progredir a um grau moderado, com insuficiência cardíaca direita, ascite, e disfunção renal ${ }^{176}$. Além disso, a sobrevida, em longo prazo, entre os pacientes com insuficiência tricúspide moderada é menor do que a dos pacientes com insuficiência tricúspide leve ${ }^{177}$, o que justificaria a realização da anuloplastia valvar tricúspide profilática no coração doador (Tabela 39).

\section{Tabela 39 - Anuloplastia valvar tricúspide profilática do enxerto}

\begin{tabular}{lcc}
\hline $\begin{array}{l}\text { Classe de } \\
\text { Recomendação }\end{array}$ & Indicações & $\begin{array}{c}\text { Nível de } \\
\text { Evidência }\end{array}$ \\
\hline Classe Ilb & $\begin{array}{c}\text { Proceder anuloplastia } \\
\text { profilática tricúspide. }\end{array}$ & B \\
\hline
\end{tabular}

\section{C) Transplante heterotópico}

O transplante heterotópico é uma alternativa ao ortotópico. Em pacientes com impossibilidade de utilização de dispositivos de assistência circulatória mecânica esta opção estaria indicada apesar do pior desempenho hemodinâmico e menor sobrevida. Pode ser considerado nas seguintes 
situações: resistência vascular pulmonar $>5$ uW, após o uso de vasodilatadores; desproporção entre o peso do doador e do receptor maior do que $20 \%$, quando houver emergência clínica; disfunção ventricular potencialmente reversível; situações imprevistas que leve ao aumento do tempo de isquemia e doadores limítrofes em situação de emergência.

\section{D) Aspectos anestésicos e monitoração perioperatória}

O anestesiologista geralmente possui pouco tempo para o manejo pré-operatório do receptor de transplante cardíaco. A avaliação pré-operatória deve incluir história clínica objetiva, exame físico com avaliação da via aérea, revisão dos dados laboratoriais e do prontuário médico. Deve-se indagar sobre a última ingesta oral, anestesias e cirurgias prévias, terapia farmacológica utilizada para compreender o tipo e a extensão da disfunção cardíaca e de outros órgãos. A RVP e a resposta à terapia vasodilatadora devem ser anotadas. Eletrocardiograma, ecocardiograma, radiografia de tórax, cateterismo, exames hematológicos, função renal, hepática e da coagulação devem ser revistos ${ }^{178,179}$.

A maioria dos pacientes que aguardam transplante cardíaco está em estágio terminal de IC com quadro clínico compensado ou não. Geralmente, recebem terapia otimizada para IC, suporte inotrópico endovenoso ou estão com algum dispositivo de assistência ventricular mecânica, como uma "ponte para transplante". Antes e após o transporte para sala cirúrgica, deve-se revisar o funcionamento de linhas de monitoração invasiva, bombas de infusão, marca-passo, desfibrilador, BIA e DAV ${ }^{180}$.

Pacientes com IC grave têm níveis elevados de catecolaminas circulantes e são pré-carga dependente. Pequenas doses de sedativos podem resultar em redução súbita do tônus simpático, vasodilatação e instabilidade hemodinâmica. Medicação pré-anestésica deve ser evitada e, se necessária, administrada preferencialmente já na sala cirúrgica. Titulação cuidadosa com benzodiazepínico endovenoso deve ser associada à administração de oxigênio suplementar e monitoração dos sinais vitais. Deve-se obter um ou mais acessos venosos periféricos de grosso calibre e acesso venoso central ${ }^{180}$

A monitoração básica necessária é similar àquela de qualquer cirurgia cardíaca: ECG com cinco derivações, pressão arterial invasiva, oxímetro de pulso, capnógrafo, pressão venosa central, débito urinário e temperatura nasofaríngea (Tabela 40) $)^{179}$.

\section{a) Cateter de artéria pulmonar}

Permite monitorar o débito cardíaco (DC) e as pressões de enchimento ventricular, bem como calcular a resistência vascular sistêmica e a resistência vascular pulmonar. Não há trabalhos que justifiquem o uso rotineiro do cateter de artéria pulmonar no transplante cardíaco ${ }^{181}$. A despeito das controvérsias envolvendo o uso de cateter de artéria pulmonar e sua influência em tomadas de decisões clínicas, ele está indicado no manejo perioperatório de pacientes com $\mathrm{HP}$, ou como monitor de resgate para pacientes em que medidas de suporte hemodinâmico de rotina falharam ${ }^{182}$. b) Ecocardiografia transesofágica

Valiosa ferramenta no manejo do receptor de transplante cardíaco. Fornece informações sobre: função de ventrículo direito (VD), função de VE, anastomoses vasculares, shunts potenciais que podem levar à hipoxemia, êmbolos intracavitários, disfunção valvar, condições do dispositivo de assistência ventricular antes da retirada do coração do receptor, pressões de artéria pulmonar e presença de aterosclerose nos locais de canulação aórtica e de pinçamento ${ }^{183}$. A ecocardiografia transesofágica serve como um importante método diagnóstico para determinar precocemente possíveis complicações tardias ${ }^{184}$.

\section{c) Monitoração com índice biespectral (BIS)}

Pacientes submetidos a cirurgias cardíacas têm maior risco de despertar no intraoperatório ${ }^{185}$. Portanto, avaliar a profundidade anestésica nesses pacientes pode ser difícil porque a resposta simpática a planos superficiais de anestesia pode estar mascarada. O uso do BIS reduz a incidência de despertar no intraoperatório, diminui o consumo de drogas anestésicas e melhora a recuperação pós-anestésica ${ }^{186,187}$.

A comunicação entre a equipe de transplante e o anestesiologista deve ser constante a fim de evitar prolongar o tempo isquêmico do coração doador. O momento para iniciar a indução anestésica do receptor deve considerar o deslocamento do órgão, a dificuldade técnica do receptor e não deve começar antes de todo o equipamento de anestesia e ventilação ser verificado e testado. O equipamento de anestesia deve estar limpo e com filtro bacteriano no sistema circular. Todos os procedimentos invasivos devem ser realizados com técnica asséptica. Antibiótico profilático de amplo espectro deve ser administrado, assim como o imunossupressor. Drogas de suporte inotrópico devem estar disponíveis e drogas de reanimação diluídas previamente ${ }^{188}$.

Tabela 40 - Métodos de monitoração perioperatória em pacientes submetidos ao transplante cardíaco

\begin{tabular}{lcc}
\hline $\begin{array}{c}\text { Classe de } \\
\text { Recomendação }\end{array}$ & Indicações & $\begin{array}{c}\text { Nível de } \\
\text { Evidência }\end{array}$ \\
\hline \multirow{2}{*}{ Classe I } & $\begin{array}{c}\text { Eletrocardiograma com 5 derivações, } \\
\text { com análise do segmento ST de DII } \\
\text { e V5; }\end{array}$ & $\mathrm{C}$ \\
\cline { 2 - 3 } & Oxímetro de pulso; & $\mathrm{C}$ \\
\cline { 2 - 3 } & Cressão arterial invasiva; & $\mathrm{C}$ \\
\cline { 2 - 3 } & Pressão venosa central; & $\mathrm{C}$ \\
\cline { 2 - 3 } & Débito urinário; & $\mathrm{C}$ \\
\cline { 2 - 3 } & Termômetro em nasofaringe. & $\mathrm{C}$ \\
\hline & Monitor de atividade cerebral (BIS); & $\mathrm{C}$ \\
\hline & Ecocardiografia transesofágica; & $\mathrm{C}$ \\
\hline & Cateter de artéria pulmonar. & $\mathrm{C}$ \\
\hline
\end{tabular}

BIS - índice biespectral. 


\section{Diretrizes}

Os objetivos durante a indução e a manutenção anestésica estão reunidos na Tabela 41.

Quando o receptor for considerado com "estômago cheio", antes da indução anestésica, devem ser administrados anti- $\mathrm{H}_{2}$ (ranitidina $50 \mathrm{mg}$ ) e metoclopramida $10 \mathrm{mg}$ por via venosa para melhorar o esvaziamento e reduzir a acidez gástrica. A indução anestésica deve ser em sequência rápida modificada com pré-oxigenação e pressão cricoide.

O receptor de transplante cardíaco possui uma reserva cardíaca diminuída e alterações fisiológicas e hemodinâmicas, durante a indução anestésica e por todo o tempo cirúrgico, devem ser evitadas ou prontamente corrigidas a fim de garantir estabilidade hemodinâmica e perfusão de órgãos-alvo.

Assim como em todo paciente com disfunção ventricular grave, a droga anestésica a ser usada é menos importante do que como ela deve ser usada. O tempo lento de circulação em pacientes com IC terminal pode retardar a resposta a agentes anestésicos administrados na indução ${ }^{188}$. Anestésicos comumente usados incluem etomidato $(0,2-$ $0,3 \mathrm{mg} / \mathrm{Kg}$ ) em combinação com fentanil $(5-10 \mathrm{mg} / \mathrm{Kg})$ ou sufentanil $(0,2-0,5 \mathrm{mg} / \mathrm{Kg})$ e succinilcolina $(1-1,5 \mathrm{mg} / \mathrm{kg})$. Não há contraindicação formal ao uso de nenhum relaxante muscular, mas, devido aos menores efeitos cardiovasculares, o vecurônio (0,08-0,1 mg/Kg) e o cisatracúrio (0,15-0,20 mg/ Kg) são os mais apropriados ${ }^{180}$.

Antes da esternotomia, deve estar disponível sangue tipado e cruzado e desfibrilador externo transcutâneo posicionado, principalmente nos casos de reoperação. Terapia antifibrinolítica deve ser iniciada logo após a indução anestésica.

\section{i. Técnicas de ventilação}

Complicações pulmonares após cirurgia cardíaca, como atelectasias e derrames pleurais (60\%), episódios de hipóxia $(10 \%)$ e pneumonias (3\%), são frequentes. A anestesia geral é uma causa bem conhecida de atelectasia e a resposta inflamatória sistêmica associada à esternotomia, hipotermia, circulação extracorpórea (CEC) e reperfusão contribuem para diferentes graus de disfunção pulmonar no pós-operatório ${ }^{189}$.

O uso de técnicas de ventilação mecânica no período intraoperatório pode reduzir essas complicações (Tabela 42) ${ }^{190}$.

Estratégias de ventilação utilizando o conceito de "pulmão aberto" ( $\mathrm{VC}=6 \mathrm{ml} / \mathrm{kg}$ e PEEP $\left.=14 \mathrm{cmH}_{2} \mathrm{O}\right)$ atenuaram a disfunção pulmonar em cirurgia cardíaca sem alterar significativamente a pós-carga de VD e a incidência de pneumotórax ${ }^{191}$. Entretanto, hiperinsuflação dos pulmões deve ser evitada no paciente com falência de VD grave, pois

Tabela 41 - Objetivos hemodinâmicos durante a indução e manutenção anestésica

\begin{tabular}{l}
\hline Manter a contratilidade e a frequência cardíaca; \\
\hline Evitar hipotensão e hipovolemia mantendo a pré-carga; \\
\hline Evitar aumento da pós-carga; \\
\hline Evitar hipoxemia e hipercarbia; \\
\hline Evitar hipertensão pulmonar. \\
\hline
\end{tabular}

aumenta significativamente a RVP. Além disso, a aplicação de altos níveis de pressão expiratória final pulmonar (PEEP) estreita os capilares em áreas bem ventiladas e desvia o fluxo para áreas piores ou não ventiladas, reduzindo a pressão arterial de oxigênio $\left(\mathrm{PaO}_{2}\right)^{192}$.

\section{ii. Suporte hemodinâmico}

Durante a indução e manutenção da anestesia, deve ser mantido o suporte hemodinâmico já em uso no préoperatório. Hipotensão deve ser tratada com infusão contínua ou intermitente de drogas alfa- 1 agonistas como a fenilefrina ou noradrenalina. A frequência cardíaca não deve sofrer grandes variações ${ }^{180}$.

Na saída de CEC, após reperfusão e reaquecimento, o ritmo sinusal normal geralmente é retomado. Diante de bradicardia ou bloqueio $\mathrm{AV}$, ritmo e frequência podem ser conseguidos com infusão de agentes cronotrópicos (dobutamina, isoproterenol) ou marca-passo. Deve-se ressaltar que o coração transplantado é desnervado e não responde à atropina.

Disfunção do enxerto após CEC é frequentemente por causa da isquemia prolongada, proteção inadequada ou relacionada às condições do doador. A função de VE geralmente encontra-se adequada, mas, no período após CEC, a falência aguda de VD e a HP respondem por $50 \%$ das complicações e 19\% das mortes após transplante cardíaco (Tabela 43) ${ }^{192,193 .}$.

Suporte hemodinâmico deve ser aplicado proativamente antes da saída de CEC, com benefícios sobre a função de VE e VD. A falência ou disfunção de ventrículo direito é a causa mais comum de dificuldade de desmame de CEC no transplante

\section{Tabela 42 - Recomendações sobre ventilação mecânica no intraoperatório na prevenção de complicações perioperatórias}

\begin{tabular}{l} 
A comparação de diferentes modalidades não demonstrou benefício de uma \\
técnica em relação à outra; \\
Volume corrente de 8-10 ml/Kg ou pico/platô de pressão suficiente para \\
manter este mesmo volume; \\
PEEP mínima de $5 \mathrm{cmH}_{2} \mathrm{O} ;$ \\
Manobras de recrutamento alveolar após reinício da ventilação mecânica; \\
$\mathrm{FiO}_{2}$ de 1 na indução anestésica e saída de $\mathrm{CEC}$ e, durante a manutenção, \\
em torno de 0,3-0,4 (ou suficiente para manter $\mathrm{SaO}_{2}>98 \%$ ). \\
\hline PEEP - pressão expiratória final pulmonar; $\mathrm{CEC}$ - circulacão extracorpórea
\end{tabular}

PEEP - pressão expiratória final pulmonar: CEC - circulação extracorpórea.

Tabela 43 - Fatores que contribuem para o desenvolvimento de falência do VD no transplante cardíaco

\begin{tabular}{l}
\hline Hipertensão pulmonar pré-existente ou adquirida; \\
\hline Tempo de isquemia prolongado e má preservação do órgão; \\
\hline Obstrução mecânica na anastomose de artéria pulmonar; \\
\hline Desproporção de tamanho doador-receptor (doador menor); \\
\hline Rejeição hiperaguda. \\
\hline VD - ventrículo direito.
\end{tabular}


cardíaco, indicado por uma pressão arterial pulmonar média frequentemente maior do que $25-30 \mathrm{mmHg}$. O manejo dessa situação envolve manutenção de adequada oxigenação e ventilação, evitando acidose, hipercarbia, hipotermia e usando vasodilatadores pulmonares (nitroglicerina, nitroprussiato de sódio, óxido nítrico) e inotrópicos (isoproterenol, dobutamina e milrinone). A falência em responder a essas medidas indica a necessidade de suporte mecânico de VD ${ }^{194}$.

Agentes inotrópicos como milrinone e dobutamina diminuem a RVP. O isoproterenol, além dessa propriedade, possui efeito cronotrópico mais significativo. Os inotrópicos com qualidades vasodilatadoras, como milrinone, facilitam o enchimento de VE e melhoram o DC, mas podem causar ou agravar hipotensão por sua ação vasodilatadora sistêmica. Drogas com ação alfa-1 agonistas, como fenilefrina ou noradrenalina, podem ser associadas para restaurar a pressão arterial e a pressão de perfusão coronariana.

Nos pacientes com disfunção de VD e hipotensão associada com um aumento na pressão arterial pulmonar agudo ou crônico, noradrenalina pode ser usada para manutenção da pressão sistêmica, aumentando o índice cardíaco e reduzindo a pressão pulmonar. Em caso de refratariedade às catecolaminas, a vasopressina pode ser útil para o tratamento de hipotensão grave ${ }^{195}$. Dobutamina ou milrinone são recomendados na disfunção de leve à moderada de VD, mas sem hipotensão grave por aumentarem o DC e diminuírem a pressão arterial pulmonar. Na disfunção de VD grave associada à falência circulatória, a adrenalina também deve ser considerada ${ }^{\mathbf{1 9 2}}$.

\section{E) Disfunção aguda do enxerto}

A disfunção ou falência aguda do enxerto após transplante cardíaco está associada a uma altíssima taxa de mortalidade e é a maior causa de morte nos primeiros 30 dias após o transplante ${ }^{196}$. Sua incidência varia na literatura de 1,4-9,7\% e as principais causas de disfunção aguda do enxerto são: rejeição aguda acelerada e rejeição hiperaguda com choque cardiogênico, HP com disfunção ventricular direita e falência primária do enxerto (erros técnicos, má proteção miocárdica ou tempo prolongado de isquemia) ${ }^{197}$. O tratamento, além do suporte clínico com drogas inotrópicas (dopamina, dobutamina, adrenalina, noradrenalina e isoproterenol), milrinone, prostaglandina e/ou óxido nítrico, pode incluir a assistência mecânica (prolongamento da CEC, BIA, bombas centrífugas, DAV e coração artificial total) e até o retransplante. Na rejeição hiperaguda ou humoral, deve ser feito tratamento de resgate intensivo.

\section{i. Disfunção aguda do ventrículo esquerdo}

Nas condições de falência ventricular, o DC é altamente dependente da frequência, já que o volume de ejeção é quase fixo. Pouco aumento na pós-carga vai determinar uma significativa diminuição do débito cardíaco, assim o isoproterenol é uma droga particularmente útil, já que, além do inotropismo positivo, vai aumentar a frequência cardíaca e promover vasodilatação periférica.

Convém lembrar que a curva de Frank-Starling é diminuída e achatada, mas as pressões máximas de enchimento precisam ainda ser mantidas para otimizar um débito cardíaco marginal. O miocárdio pode estar com baixa regulação para os receptores beta-adrenérgicos; assim, em tal situação, há necessidade de níveis mais altos de drogas inotrópicas. Um inibidor da fosfodiesterase III (por exemplo, milrinona) pode ser acrescentado, já que não depende dos betarreceptores.

Nessa situação, cuidados também devem ser dispensados aos variados graus de edema pulmonar, aumentos reversíveis ou fixos de resistência vascular pulmonar, disfunção hepática com coagulopatia e insuficiência renal. No entanto, a terapêutica clínica e medicamentosa isolada é associada a um prognóstico uniformemente desanimador (Tabela 44) ${ }^{198}$.

A assistência circulatória mecânica para que o coração possa se recuperar, ou o paciente possa ser retransplantado, oferece a única chance para a sobrevida. Entretanto, comparando-se o uso do suporte mecânico pós-cardiotomia com o da ponte para transplante, os resultados após o transplante cardíaco são muito piores ${ }^{199}$. A explicação para isso seria que, no momento de instalação do suporte, comparados aos pacientes em ponte para transplante, esses pacientes estão

Tabela 44 - Recomendações para ajuste e otimização das condições clínicas do paciente com disfunção ventricular grave no perioperatório

\begin{tabular}{|c|c|c|}
\hline $\begin{array}{l}\text { Classe de } \\
\text { Recomendação }\end{array}$ & Indicações & $\begin{array}{l}\text { Nível de } \\
\text { Evidência }\end{array}$ \\
\hline \multirow{6}{*}{ Classe I } & $\begin{array}{l}\text { Isoproterenol com ajuste da frequência } \\
\text { cardíaca para 90-120 bpm e suporte } \\
\text { inotrópico com diminuição da resistência } \\
\quad \text { vascular sistêmica e pulmonar; }\end{array}$ & C \\
\hline & $\begin{array}{l}\text { Marca-passo temporário epicárdico } \\
\text { atrial ou átrio ventricular com ajuste } \\
\text { da frequência cardíaca para } 90-120 \\
\text { bpm visando obter um débito cardíaco } \\
\text { adequado; }\end{array}$ & C \\
\hline & $\begin{array}{l}\text { Agonistas beta-adrenérgicos } \\
\text { (dobutamina, dopamina adrenalina e } \\
\text { noradrenalina) como suporte inotrópico, } \\
\text { associados ou não ao isoproterenol, de } \\
\text { acordo com os parâmetros monitorados; }\end{array}$ & $C$ \\
\hline & $\begin{array}{l}\text { Vasodilatadores intravenosos } \\
\text { (nitroprussiato ou nitroglicerina), } \\
\text { associados ou não a inotrópicos, com } \\
\text { monitoração hemodinâmica invasiva } \\
\text { demonstrando resistência vascular } \\
\text { sistêmica aumentada; }\end{array}$ & $C$ \\
\hline & $\begin{array}{l}\text { Diurético de alça endovenoso (bolus } \\
\text { ou infusão contínua) em dose } \\
\text { suficiente para o estímulo da diurese, } \\
\text { principalmente em situações de } \\
\text { hipervolemia; }\end{array}$ & C \\
\hline & $\begin{array}{l}\text { Inibidores da fosfodiesterase III } \\
\text { (milrinona) nos pacientes com muita } \\
\text { impregnação por betabloqueadores } \\
\text { no pré-operatório, e hiperresistência } \\
\text { vascular pulmonar. }\end{array}$ & $C$ \\
\hline Classe Ila & $\begin{array}{l}\text { Ultrafiltração adaptada ao circuito } \\
\text { de circulação extracorpórea para } \\
\text { redução da sobrecarga de volume ou } \\
\text { na dificuldade da reposição do volume } \\
\text { extracorpóreo. }\end{array}$ & C \\
\hline
\end{tabular}




\section{Diretrizes}

geralmente em condições desastrosas e não há tempo para compensar a deterioração hemodinâmica. Assim também a indicação de assistência mecânica deve ser a mais precoce possível para obter melhores resultados ${ }^{200}$.

Infelizmente, a maioria das publicações da literatura sobre assistência circulatória mecânica em disfunção cardíaca pós-transplante consiste em relatos de casos esporádicos, frequentemente descrevendo o uso de uma variedade de dispositivos numa amostra pequena de pacientes com uma variedade grande de indicações ${ }^{201}$, a qual justifica as referências nível $\mathrm{C}$ citadas no texto.

O BIA, por sua simplicidade, disponibilidade e preço, é frequentemente o primeiro dispositivo a ser usado, e apesar de sua utilidade, há pouco benefício nos pacientes muito comprometidos. Além disso, atualmente em nosso país, temos poucos DAV mais complexos disponíveis: bombas centrífugas (Terumo, Medtronic e Jostra), bombas pulsáteis paracorpóreas (AB 5000 da Abiomed $^{\circledR}$ e Excor da BerlinHeart ${ }^{\circledR}$ ) e bombas axiais (Incor da Berlin-Heart ${ }^{\circledR}$ e Impella 2.5, por via percutânea, e Impella 5.0, por via transesternal da Abiomed ${ }^{\circledR}$ ) (Tabela 45).

As bombas centrífugas têm sido usadas em alguns grupos $^{201,202}$ e apresentam como limitação fornecer apenas suporte cardiopulmonar parcial, o qual pode ser insuficiente em pacientes com função cardíaca muito precária, não sendo indicadas no estágio final da lesão de órgãos. Não podem ser empregadas também em casos de sangramento incontrolável e de arritmias ventriculares incontroláveis. O uso de resina heparinizada revestindo a superfície interna dos tubos do circuito (Carmeda Bioactive - Medtronic) reduz a necessidade do uso de heparina, minimizando o risco de sangramento ${ }^{203}$.

Tabela 45 - Uso de dispositivos de assistência ventricular na disfunção aguda de ventrículo esquerdo no pós-transplante

\begin{tabular}{|c|c|c|}
\hline $\begin{array}{l}\text { Classe de } \\
\text { Recomendação }\end{array}$ & Indicações & $\begin{array}{l}\text { Nível de } \\
\text { evidência }\end{array}$ \\
\hline \multirow{3}{*}{ Classe I } & $\begin{array}{c}\text { BIA como medida de suporte inicial em } \\
\text { disfunção refratária a drogas, desde que a } \\
\text { deterioração do VE não seja ainda muito } \\
\text { avançada; }\end{array}$ & C \\
\hline & $\begin{array}{l}\text { Bomba centrífuga para suporte uni ou } \\
\text { biventricular com ou sem membrana de } \\
\text { oxigenação (ECMO) para pacientes com } \\
\text { dificuldade de saída de CEC (apesar } \\
\text { de inotrópicos e BIA), com tempo de } \\
\text { permanência máximo de 7-14 dias; }\end{array}$ & C \\
\hline & $\begin{array}{l}\text { DAV do tipo bomba pulsátil ou bomba } \\
\text { axial (paracorpórea ou intracorpórea) } \\
\text { como ponte para recuperação ou ponte } \\
\text { para retransplante. }\end{array}$ & C \\
\hline \multirow{3}{*}{ Classe III } & Sangramento incontrolável; & C \\
\hline & Disfunção múltipla irreversível de órgãos; & C \\
\hline & $\begin{array}{l}\text { Comprometimento neurológico grave com } \\
\text { prognóstico ruim. }\end{array}$ & C \\
\hline
\end{tabular}

BIA - balão intra-aórtico; DAV - dispositivo de assistência ventricular; CEC circulação extracorpórea.
Com relação aos DAV mais complexos disponíveis em nosso meio, vale a pena ressaltar que as bombas pulsáteis podem dar assistência uni ou biventricular. Lembramos que, geralmente, as falências primárias de enxerto são disfunções biventriculares, havendo então necessidade de assistência dupla ${ }^{198}$.

\section{ii. Disfunção aguda do ventrículo direito}

A falência do VD é um problema comum na fase aguda do transplante e sua etiologia é multifatorial. Receptores com RVP fixa acima de 6-8 uW ou gradiente transpulmonar acima de 15 apresentam alto risco de falência do VD. O VD do doador não funciona efetivamente nessas circunstâncias, que podem ser agravadas com o desenvolvimento de hipoxemia e acidose. Outros fatores agravantes podem ser: tempo de isquemia prolongado (mais de 4 horas), má preservação miocárdica, ou até mesmo contusão do VD do doador. Pode ainda haver dilatação do VD e insuficiência tricúspide secundária, o que agrava ainda mais a situação com congestão hepática e edema periférico.

No intraoperatório, é importante afastar causas "mecânicas"204, tais como problemas na anastomose da artéria pulmonar (torsão ou angulação). Deve-se também estar atento à saída de CEC, à embolia aérea de coronária direita e ainda à reação à protamina com vasoconstrição pulmonar. Ainda considerando-se outros diagnósticos diferenciais, lembrar de eventual embolia pulmonar que poderia ter ocorrido desde a última avaliação do receptor.

Uma vez corrigidas as causas removíveis, o tratamento da disfunção do VD envolve a diminuição da RVP e o aumento da contratilidade miocárdica. Os agentes inotrópicos mais usados e que tendem a diminuir a RVP são: o isoproterenol, a dobutamina e a milrinona. Para pacientes com RVP fixa, são necessários vasodilatadores mais potentes como a prostaglandina E1 (PGE1), cuja dose inicial deve ser $25 \mathrm{ng} /$ $\mathrm{kg} / \mathrm{min}$, chegando até $100-200 \mathrm{ng} / \mathrm{kg} / \mathrm{min}^{205}$. A PGE1, que é um vasodilatador pulmonar com menos efeito sistêmico que a nitroglicerina, pode ser associada à epinefrina $(25 \mathrm{ng} / \mathrm{kg} /$ min), sendo esta última infundida preferencialmente na via do átrio esquerdo. Esse suporte farmacológico comumente é satisfatório para a maioria dos casos de falência do VD do doador.

Outra alternativa terapêutica bastante útil na fase aguda da disfunção é o uso do óxido nítrico, que age basicamente na circulação pulmonar sem efeito sistêmico e que pode ser usado enquanto o paciente estiver intubado ${ }^{206}$.

O óxido nítrico produz vasodilatação pulmonar sem causar vasodilatação sistêmica, aumenta o fluxo sanguíneo somente nas áreas ventiladas do pulmão, melhorando a relação ventilação/perfusão e aumentando a $\mathrm{PaO}_{2}{ }^{207}$. Recentemente, tem-se discutido, para condicionamento do leito vascular pulmonar, iniciar a administração do óxido nítrico antes da CEC, e manter até o pós-operatório imediato ${ }^{192,208,209}$.

O BIA é útil na falência de VD por melhorar a perfusão coronariana tanto do VE como do VD e oferecer o suporte necessário até a melhora da função do VD. Pode ser benéfico em pacientes com disfunção de VD resultante de isquemia, má preservação ou lesão de reperfusão ${ }^{193}$. Quando o aumento 
do suporte inotrópico não mantém DC aceitável, o tratamento com BIA melhora a perfusão tecidual periférica e diminui a necessidade de drogas inotrópicas ${ }^{210}$. Nos casos em que não há resposta adequada a esses tratamentos anteriores, a assistência circulatória mecânica deve ser considerada, porém com resultados pouco animadores se a RVP não diminuir (Tabela 46 e 47) $)^{211-213}$.

\section{Tabela 46 - Recomendações na disfunção ventricular direita no pós-transplante}

\begin{tabular}{lcc}
\hline $\begin{array}{l}\text { Classe de } \\
\text { Recomendação }\end{array}$ & \multicolumn{1}{c}{ Indicações } & $\begin{array}{c}\text { Nível de } \\
\text { Evidência }\end{array}$ \\
\hline & $\begin{array}{c}\text { Tratamento da hipoxemia e acidose } \\
\text { e exclusão de causas mecânicas na } \\
\text { anastomose da artéria pulmonar; }\end{array}$ & $\mathrm{C}$ \\
\cline { 2 - 3 } & $\begin{array}{c}\text { Considerar embolia aérea coronária, } \\
\text { pulmonar ou reação à protamina; }\end{array}$ & $\mathrm{C}$ \\
\cline { 2 - 3 } Classe | & Medidas de GTP e RVP; & $\mathrm{C}$ \\
\cline { 2 - 3 } & $\begin{array}{c}\text { Inotrópicos para melhorar a } \\
\text { contratilidade do VD e infundir volume } \\
\text { se RVP normal; }\end{array}$ & $\mathrm{C}$ \\
\cline { 2 - 3 } & $\begin{array}{c}\text { Dispositivo de assistência ventricular } \\
\text { direita se as orientações acima } \\
\text { falharem. }\end{array}$ & $\mathrm{C}$ \\
\hline
\end{tabular}

GTP - gradiente transpulmonar; RVP - resistência vascular pulmonar; VD - ventrículo direito.

Tabela 47 - Recomendações na RVP elevada no pós-transplante

\begin{tabular}{|c|c|c|}
\hline $\begin{array}{l}\text { Classe de } \\
\text { Recomendação }\end{array}$ & Indicações & $\begin{array}{l}\text { Nível de } \\
\text { Evidência }\end{array}$ \\
\hline \multirow{5}{*}{ Classe I } & Hiperventilação e pH > 7,5; & C \\
\hline & Manter $\mathrm{pO}_{2}>100$ mmHg; & C \\
\hline & $\begin{array}{c}\text { Adicionar vasodilatadores pulmonares } \\
\text { (nitroprussiato de sódio, nitroglicerina } \\
\text { ou milrinona) e inotrópicos } \\
\text { (dopamina, dobutamina, epinefrina ou } \\
\text { norepinefrina); }\end{array}$ & C \\
\hline & $\begin{array}{c}\text { Óxido nítrico contínuo pela } \\
\text { cânula de intubação. Controle da } \\
\text { metahemoglobinemia, } \mathrm{NO}_{2} \text { ou ambos; }\end{array}$ & C \\
\hline & Prostaglandina E1 ou Prostaciclina. & C \\
\hline
\end{tabular}

$R V P$ - resistência vascular pulmonar.

F) Uso de hemoderivados e controle de sangramento no perioperatório do transplante cardíaco

\section{i. Risco de sangramento em transplante cardíaco}

Cerca de $10-25 \%$ das transfusões de hemoderivados ocorrem em pacientes submetidos à cirurgia cardíaca e os fatores relacionados ao sangramento no pós-operatório dividem-se em cirúrgicos e não cirúrgicos.

Entre os fatores cirúrgicos, destacam-se as operações cardíacas prévias e a utilização da CEC. A utilização da CEC pode levar à redução do número e função das plaquetas, à queda dos fatores de coagulação pela diluição com as soluções de preenchimento (prime) e a exacerbação da fibrinólise pela ativação endotelial e a liberação do ativador do plasminogênio tecidual.

Quanto aos fatores não cirúrgicos, podemos destacar o uso de medicamentos anticoagulantes, antiagregantes plaquetários e trombolíticos e as coagulopatias adquiridas, como aquelas secundárias à uremia, doença hepática e má absorção ${ }^{214}$.

\section{ii. Reversão de terapias anticoagulante e antiagregante plaquetária}

Sendo o transplante cardíaco uma cirurgia não eletiva, a suspensão prévia de medicação anticoagulante ou antitrombótica é impraticável, restando-se como opção a reversão de seus efeitos no momento da convocação do pacientes para o procedimento (Tabela 48).

\section{a) Antagonistas da vitamina K (varfarina)}

O uso de varfarina provoca a redução nos fatores de coagulação da vitamina K-dependentes. A reversão desse efeito pode ser alcançada com duas alternativas: administração de vitamina $\mathrm{K}$ e a reposição de fatores de coagulação usando plasma fresco congelado (PFC) ou concentrado do complexo protrombínico (CCP).

A reversão da anticoagulação com administração de vitamina $\mathrm{K}$ requer um tempo prolongado para ser obtida (12-16 horas) e, em um cenário de cirurgia de emergência, o seu uso isolado é insuficiente. Mesmo assim, a administração de vitamina K (5-10 mg, via endovenosa), simultaneamente à reposição dos fatores de coagulação, evita o rebote dos efeitos da varfarina, após o consumo dos fatores de coagulação infundidos.

Quando se usa PFC para a reposição de fatores de coagulação, a dose preconizada é $15 \mathrm{ml} / \mathrm{kg}$, o que acarreta em sobrecarga de volume ao paciente e tempo prolongado para infusão, além do potencial risco de transmissão de infecções.

No caso do CCP, a concentração de fatores de coagulação da vitamina K-dependentes é 25 vezes maior do que no PFCe, portanto, o volume a ser administrado é bem menor, a reversão é obtida rapidamente (10-15 minutos) e o risco de transmissão de infecções é mínimo. Tais características tornam a CCP a primeira escolha para a reversão da anticoagulação oral.

Uma opção para o uso de CCP é administrar uma dose fixa de $500 \mathrm{UI}$ (suficiente para corrigir $\mathrm{RNI}<5,0$ ), repetindo-se o RNI após 15 minutos para avaliar a necessidade de uma dose subsequente se $\mathrm{RNI}>1,5$. Outra opção é uma dose calculada conforme o peso e o RNI do paciente (RNI 2-4: 25 $\mathrm{U} / \mathrm{kg}$; RNI 4-6: $35 \mathrm{U} / \mathrm{kg}$; RNI > 6: $50 \mathrm{U} / \mathrm{kg}$ ).

\section{b) Heparinas}

A heparina não fracionada (HNF) tem uma meia vida curta de 60-90 minutos e, portanto, o seu efeito é eliminado após 3-4 horas da cessação da administração endovenosa. O sulfato de protamina reverte completamente o efeito da HNF.

Altas doses de heparina são usadas na CEC. Ao final do procedimento cirúrgico, sulfato de protamina é administrado 


\section{Diretrizes}

\section{Tabela 48 - Antídotos para reversão de urgência de anticoagulantes e antitrombóticos}

\begin{tabular}{|c|c|c|c|c|}
\hline Fármaco & Antídoto & Dose & Uso & Tempo para Reversão \\
\hline HNF & Sulfato de protamina & $\begin{array}{l}1 \text { mg para cada } 100 \text { U HNF administradas } \\
\text { nas últimas 2-3 horas }(20-30 \mathrm{mg}) \text {. }\end{array}$ & EV & Imediata. \\
\hline HBPM & Sulfato de protamina & $\begin{array}{c}1 \mathrm{mg} \text { para cada } 100 \mathrm{U} \text { anti } \mathrm{Xa} \text { administradas } \\
\text { nas últimas } 8 \text { horas }(25-50 \mathrm{mg})\end{array}$ & EV & Imediata (parcial). \\
\hline \multirow{3}{*}{$\begin{array}{l}\text { Antagonistas da } \\
\text { Vitamina K }\end{array}$} & PFC & $15 \mathrm{ml} / \mathrm{kg}$ & EV & Horas \\
\hline & & $\begin{array}{l}\text { Opção 1: } \\
500 \text { Ul }\end{array}$ & EV & $\begin{array}{l}\text { Imediata (repetir RNI após } 15 \text { minutos e } \\
\text { avaliar necessidade de nova dose). }\end{array}$ \\
\hline & $\mathrm{CCP}$ & $\begin{array}{c}\text { Opção 2: } \\
\text { RNI 2-4: } 25 \mathrm{U} / \mathrm{kg} \\
\text { RNI 4-6: } 35 \mathrm{U} / \mathrm{kg} \\
\text { RNI > 6: } 50 \mathrm{U} / \mathrm{kg}\end{array}$ & EV & Imediata (repetir INR após 15 minutos). \\
\hline \multirow[b]{2}{*}{ Clopidogrel } & Concentrado de Plaquetas & & EV & \\
\hline & $\begin{array}{l}\text { DDAVP (combinado com } \\
\text { Conc. Plaquetas) }\end{array}$ & $0,3-0,4 \mu \mathrm{g} / \mathrm{kg}$ & EV & De $15-30$ minutos. \\
\hline
\end{tabular}

HNF - heparina não fracionada; HBPM - heparina de baixo peso molecular; PFC - plasma fresco congelado; CCP - complexo protrombínico ativado; DDAVP - 1-deamino-8$D$-arginina vasopressina.

para neutralizar a heparina remanescente. Em geral, após a CEC emprega-se $1 \mathrm{mg}$ de sulfato de protamina para neutralizar 100 unidades de HNF, sob o controle do tempo de coagulação ativado (TCA). Como a meia-vida da protamina é menor que a da heparina, pode ocorrer rebote do efeito da heparina e ser necessária nova dose de sulfato de protamina.

No caso da heparina de baixo peso molecular (HBPM), o efeito do sulfato de protamina é parcial, já que ele neutraliza a atividade do antifator Ila, porém tem efeito nulo ou mínimo sobre a atividade do fator antiXa. Uma abordagem prática é administrar um mg de sulfato de protamina para cada 100 unidades de fator antiXa da HBPM administradas nas últimas 8 horas (onde um mg de enoxaparina equivale a 100 unidades de fator antiXa) ${ }^{215}$.

\section{c) Antiagregantes plaquetários}

Em geral, não é necessário suspender a aspirina para procedimentos invasivos, porém, deve-se redobrar a atenção na hemostasia local. No caso da associação de aspirina e de clopidogrel, o risco de sangramento é alto. A reversão do efeito do clopidogrel é obtida com a transfusão de plaquetas e, eventualmente, na subsequente administração de 1-deamino-8-D-arginina vasopressina (DDAVP) que aumenta significativamente a concentração de fator de von Willebrand ${ }^{215}$

\section{iii. Uso de hemoderivados e controle de sangramento pós-operatório}

Em geral, o uso de hemoderivados no pós-operatório de cirurgia cardíaca não segue uma diretriz universal e depende, principalmente, das padronizações e disponibilidades de cada instituição, bem como da experiência pessoal das equipes envolvidas (Tabela 49).
No caso particular do transplante cardíaco, para se evitar a sensibilização do receptor, deve-se proceder ao processo de leucorredução de um componente sanguíneo celular (glóbulos vermelhos ou plaquetas) e a irradiação de todos os hemocomponentes.

A decisão quanto à transfusão de concentrado de hemácias $(\mathrm{CH})$ é complexa. Vários fatores, como o estado volêmico, cardíaco, neurológico, extensão da cirurgia e risco de sangramento, devem ser considerados. Em geral, para hemoglobina $<7,0 \mathrm{~g} / \mathrm{l}$ está indicada a transfusão de $\mathrm{CH}$.

A transfusão de plaquetas deve ser considerada em pacientes com sangramento microvascular se a contagem de plaquetas for menor do que $50.000 / \mu \mathrm{L}$. Não é necessária para contagem superior a $100.000 / \mu \mathrm{L}$.

O PFC e o CCP devem ser utilizados para repor fatores de coagulação. O crioprecipitado, produto derivado de plasma descongelado, contém predominantemente fibrinogênio, fator VIII e fator de von Willebrand. No cenário de pós-CEC, o crioprecipitado deve ser usado apenas para correção desses fatores e não como um agente hemostático inespecífico.

O rFVIla foi originalmente idealizado para uso em pacientes com hemofilia hereditária ou adquirida (única indicação aprovada pelos órgãos competentes). No entanto, o rFVIla tem sido utilizado com sucesso em circunstâncias "fora da bula", como para reversão de anticoagulação. A posologia preconizada varia de $15-120 \mu \mathrm{g} / \mathrm{kg}$, infundidos por via endovenosa, em bolo, a cada 2-6 horas 215-217. $^{2}$

O rFVIla tem sido usado em situação de sangramento incontrolável no pós-operatório de cirurgia cardíaca, uso "fora da bula", devido a sua capacidade de promover a hemostasia em sítios de sangramento com mínima ativação sistêmica. Já o DDAVP, por ser utilizado para atenuar sangramento excessivo em pacientes com disfunção plaquetária secundária à $\mathrm{CEC}^{214,218}$. 
Tabela 49 - Uso de hemoderivados e controle de sangramento no perioperatório de transplante cardíaco

\begin{tabular}{|c|c|c|}
\hline Classe de Recomendação & Indicações & Nível de Evidência \\
\hline \multirow{3}{*}{ Classe I } & CCP para reversão da anticoagulação por antagonistas da vitamina K; & B \\
\hline & $\begin{array}{l}\text { Transfusão de } \mathrm{CH} \text { depende das condições clínicas do paciente } \\
\text { (em geral para nível de hemoglobina inferior a 7,0-10 g/dl); }\end{array}$ & C \\
\hline & Transfusão de plaquetas na presença de sangramento difuso e plaquetas $<50.000 / \mu \mathrm{L}$. & \\
\hline \multirow{6}{*}{ Classe Ila } & Tromboelastograma para avaliação dos distúrbios de coagulação no perioperatório; & C \\
\hline & PFC para reversão da anticoagulação por antagonistas da vitamina K; & B \\
\hline & $\begin{array}{l}\text { Leucorredução de componente sanguíneo celular (glóbulos vermelhos ou plaquetas) e irradiação de todos } \\
\text { os hemocomponentes administrados em receptores de transplante cardíaco para evitar sensibilização; }\end{array}$ & C \\
\hline & $\begin{array}{l}\text { CCP ou PFC para reposição de fatores de coagulação no perioperatório } \\
\text { quando há evidência de déficit dos fatores de coagulação; }\end{array}$ & C \\
\hline & $\begin{array}{l}\text { Crioprecipitado para reposição de fibrinogênio, fator VIII e fator de von Willebrand } \\
\text { no perioperatório quando há evidência de déficit destes fatores; }\end{array}$ & C \\
\hline & $\begin{array}{l}\text { DDAVP para atenuar sangramento excessivo no pós-operatório } \\
\text { quando há evidência de disfunção plaquetária. }\end{array}$ & C \\
\hline Classe Ilb & $\begin{array}{l}\text { rFVIla para o manuseio de sangramento pós-operatório intratável, } \\
\text { secundário a coagulopatia e não responsivo a terapia hemostática convencional. }\end{array}$ & C \\
\hline Classe III & $\begin{array}{l}\text { Uso indiscriminado de hemoderivados para controle de sangramento } \\
\text { pós-operatório sem evidência laboratorial de sua deficiência. }\end{array}$ & C \\
\hline
\end{tabular}

CCP - complexo protrombínico ativado; PFC - plasma fresco congelado; DDAVP -1-deamino-8-D-arginina vasopressina; $r F V I l a$ - fator VII ativado recombinante.

\section{Complicações pós-transplante}

A) Condutas em complicações infecciosas pós-transplante cardíaco

\section{i. Introdução}

As complicações infecciosas pós-transplante podem ser de natureza diversa, tanto no que diz respeito ao agente etiológico quanto em relação ao sítio de infecção. Além das imunizações, aspectos preventivos, diagnósticos e terapêuticos de infecções de ferida operatória, toxoplasmose e CMV têm papel destacado após o transplante.

\section{ii. Profilaxia}

a) Profilaxia para infecções de sítio cirúrgico
As infecções de sítio cirúrgico, tanto aquelas superficiais como profundas (abrangendo mediastinites, osteomielite de esterno, e excetuando endocardite), ocorrem com frequência variável, mas com profilaxia adequada e técnica operatória otimizada, em geral, acometem menos de $5 \%$ dos pacientes, embora a mortalidade possa ser elevada (até $14 \%$ nos casos de mediastinite) (Tabela 50) ${ }^{219}$. Como um grupo, os estafilococos são os agentes mais importantes, sendo gram-negativos e espécies de cândida menos prevalentes. O conceito de utilização de profilaxia antibacteriana em cirurgias é o da prevenção exclusivamente de colonização da ferida operatória no ato operatório, reduzindo o inóculo a um mínimo possível. Embora as taxas de infecção não sejam altas e não haja estudos randomizados, preconiza-se a antibioticoprofilaxia pré-operatória ${ }^{220}$.

Embora as recomendações sejam para uma dose antes da indução anestésica e apenas mais uma dose ao final da

\section{Tabela 50 - Recomendações de profilaxia bacteriana do sítio cirúrgico}

\begin{tabular}{|c|c|c|}
\hline Classe da recomendação & Indicações & Nível de evidência \\
\hline \multirow[b]{2}{*}{ Classe I } & $\begin{array}{l}\text { Antibiótico iniciando imediatamente antes do procedimento até no máximo após } 24 \mathrm{~h} \text {, utilizando } \\
\text { cefalosporinas de primeira ou segunda geração (cefuroxime, cefazolina) preferencialmente. }\end{array}$ & C \\
\hline & $\begin{array}{l}\text { Individualizar a profilaxia antibacteriana para pacientes infectados ou colonizados } \\
\text { por agentes intra-hospitalares isolados e para aqueles cujo doador tenha } \\
\text { infecção com repercussão sistêmica cujo agente foi isolado. }\end{array}$ & C \\
\hline \multirow[b]{2}{*}{ Classe Ila } & $\begin{array}{l}\text { Antibiótico iniciando imediatamente antes do procedimento até no máximo após } 48 \mathrm{~h} \text {, utilizando } \\
\text { cefalosporinas de primeira ou segunda geração (cefuroxime, cefazolina) preferencialmente. }\end{array}$ & C \\
\hline & $\begin{array}{l}\text { Individualizar a profilaxia antibacteriana para pacientes colonizados por agentes } \\
\text { intra-hospitalares e para aqueles cujo doador tenha infecção documentada em } \\
\text { sítios com repercussão sistêmica e sem isolamento do agente. }\end{array}$ & C \\
\hline Classe Ilb & $\begin{array}{c}\text { Promover descolonização nasal de Staphylococcus aureus previamente } \\
\text { à cirurgia com antibacterianos sistêmicos ou tópicos. }\end{array}$ & C \\
\hline
\end{tabular}




\section{Diretrizes}

operação em não imunodeprimidos, há dúvidas sobre o benefício de extensão dessa profilaxia por mais tempo em função do grau da imunodepressão induzida. A extensão da profilaxia, além de 24-48 horas, pode ser aceitável, embora seja cada vez mais claro que o uso por períodos mais breves reduz o custo e a toxicidade e não aumenta os riscos.

A droga a ser escolhida deve prover cobertura para estafilococos e bactérias gram-negativas e doses intraoperatórias devem ser administradas, caso haja sangramento relevante ou prolongamento da cirurgia além da meia-vida da droga.

Embora haja clara correlação entre colonização nasal por Staphylococcus aureus e infecção de sítio cirúrgico subsequente, estudos de descolonização não mostraram impacto na redução destas infecções ${ }^{221}$.

Em pacientes colonizados por bactérias multirresistentes (principalmente aqueles internados por períodos prolongados em UTIs antes do transplante), a profilaxia pode ser individualizada de acordo com o perfil de colonização ou com a vigência de infecções no momento do transplante.

Para doadores onde houver isolamento de agentes infecciosos em materiais como sangue ou secreções respiratórias (quando na vigência de pneumonia clinicamente documentada), a profilaxia também deve ser individualizada de acordo e pode ser prolongada configurando terapia preemptiva.

\section{b) Profilaxia para toxoplasmose}

A toxoplasmose pode assumir curso grave e letal após o transplante cardíaco, manifestando-se como miocardite ou doença sistêmica. A quase totalidade dos casos ocorre como decorrência de doença aguda, transmitida pelo órgão transplantado de doador soropositivo para receptor soronegativo, embora possa haver reativação de doença latente.

Não está claro o esquema profilático ideal. Estudos não controlados mostram resultados positivos com sulfametoxazol trimetoprin isoladamente, ao passo que alguns centros adicionam a pirimetamina ao esquema, por período de pelo menos três meses (Tabela 51) 222-224.

\section{C) Profilaxia para Pneumocystis jirovecii (carinii)}

A pneumonia por $P$. jirovecii ocorre com frequência variável após o transplante cardíaco, podendo esta taxa estar sujeita a variações regionais. Entretanto, ocorrendo pneumonia, há alta mortalidade associada. Pelo menos um estudo randomizado em centro único mostra sensível redução da ocorrência de pneumonia por $P$. jiroveccii com o uso de sulfametoxazol trimetoprim profilático, por pelo menos três meses após o transplante (Tabela 52) 225,226 .

Há evidência insuficiente mostrando proteção contra $P$. jirovecii com uso de micofenolato mofetil.

\section{d) Profilaxia para citomegalovírus (CMV)}

A infecção ativa por CMV é altamente prevalente após transplante cardíaco, sendo frequentemente assintomática, pode, entretanto, causar febre e depressão medular, doença invasiva de trato gastrointestinal, SNC, pulmão e retina. Além de efeitos diretos, há evidência de dano indireto relacionado à replicação viral, como rejeição aguda e redução da sobrevida do enxerto em longo prazo, possivelmente associado à coronariopatia pós-transplante. Embora a taxa de infecção seja similar em receptores soropositivos ou soronegativos que recebem enxerto de doador soropositivo, há maior gravidade clínica e aparentemente efeitos deletérios indiretos, em longo prazo, mais frequentes neste último grupo de pacientes.

Estudos apontam um maior benefício para profilaxia de infecção precoce em receptores soronegativos de doadores soropositivos, em relação à redução dos efeitos indiretos (aumento da sobrevida do enxerto em longo prazo) e não há redução da ocorrência de doença clínica ${ }^{227}$, uma vez que estudos com transplante em órgãos sólidos demonstram que há a mesma taxa de doença tardiamente (Tabela 53).

As medicações utilizadas para a profilaxia de CMV são: aciclovir 3,2 g vo ao dia, valaciclovir $8 \mathrm{~g}$ vo ao dia e

\section{Tabela 52 - Recomendações de profilaxia para Pneumocystis jirovecii (carinii)}

\begin{tabular}{lcc}
\hline $\begin{array}{l}\text { Classe da } \\
\text { Recomendação }\end{array}$ & Indicações & $\begin{array}{c}\text { Nível de } \\
\text { Evidência }\end{array}$ \\
\hline Classe I & $\begin{array}{c}\text { Sulfametoxazol trimetoprin }(160 / 800 \mathrm{mg} \\
\text { pelo menos três vezes por semana) } \\
\text { ou }=3 \text { meses. }\end{array}$ & B \\
\hline Classe Ilb & $\begin{array}{c}\text { Não usar profilaxia em centros } \\
\text { com taxas baixas de infecção com } \\
\text { investigação adequada. }\end{array}$ & C \\
\hline
\end{tabular}

Tabela 51 - Recomendações de profilaxia para toxoplasmose

\begin{tabular}{lcc}
\hline Classe da recomendação & Indicações & Nivel de evidência \\
\hline Classe I & $\begin{array}{r}\text { Receptores soronegativos de doadores soropositivos por pelo menos } \\
\text { três meses após transplante com sulfametoxazol trimetoprin. }\end{array}$ & B \\
\hline Classe Ila & $\begin{array}{r}\text { Receptores soronegativos de doadores soropositivos após transplante com sulfametoxazol } \\
\text { trimetoprin (160/800 mg) isoladamente, pelo menos três vezes por semana. }\end{array}$ & B \\
\hline Classe IIb & $\begin{array}{r}\text { Associar pirimetamina a pacientes de maior risco (tratamento prévio de eventos } \\
\text { de rejeição, uso de anticorpos mono ou policlonais antilinfócitos). }\end{array}$ & $\mathrm{C}$ \\
\cline { 2 - 4 } & $\begin{array}{c}\text { Sulfametoxazol trimetoprin para receptores soropositivos de maior risco (tratamento } \\
\text { prévio de eventos de rejeição, uso de anticorpos mono ou policlonais antilinfócitos). }\end{array}$ & $\mathrm{C}$ \\
\hline Classe III & Usar isoladamente pirimetamina para profilaxia. & $\mathrm{C}$ \\
\hline
\end{tabular}


Tabela 53 - Recomendações de profilaxia para citomegalovirose

\begin{tabular}{lcc}
\hline $\begin{array}{l}\text { Classe da } \\
\text { recomendação }\end{array}$ & Indicação & $\begin{array}{c}\text { Nível de } \\
\text { evidência }\end{array}$ \\
\hline Classe I & $\begin{array}{c}\text { Vigilância da infecção por CMV, após } \\
\text { profilaxia por pelo menos três meses } \\
\text { pelo risco de doença tardia para } \\
\text { receptores soronegativos de doadores } \\
\text { soropositivos. }\end{array}$ & C \\
\hline & Profilaxia para CMV para receptores \\
& soronegativos de doadores \\
& soropositivos por pelo menos três & B meses. \\
\cline { 2 - 3 } Classe lla & $\begin{array}{c}\text { Pode-se oferecer profilaxia por período } \\
\text { de pelo menos um mês para pacientes } \\
\text { soropositivos submetidos a grau }\end{array}$ & C \\
& intenso de imunodepressão (tratamento \\
& de rejeição ou uso de anticorpos & \\
& antilinfócitos/timócitos). & \\
\hline
\end{tabular}

CMV - citomegalovírus.

valganciclovir 450 mg vo de 12-12 horas, que é mais prático e permite maior adesão ${ }^{228,229}$.

\section{iii. Diagnóstico e tratamento}

\section{a) Infecção pelo citomegalovírus}

Os dois métodos mais importantes e eficientes para o diagnóstico de infecção pelo CMV são a antigenemia e o PCR (Tabela 54). Comparativamente, o PCR apresenta maior sensibilidade, sendo a antigenemia positiva para cargas virais maiores. Em 30\% dos casos de doença do trato gastrointestinal, a antigenemia pode resultar negativa, ao passo que o PCR em geral é positivo. De maneira geral, os métodos equivalem-se na prática clínica, podendo o método a ser escolhido basear-se em custo e rapidez no fornecimento de resultados. Entretanto, é importante ter em mente que para pacientes de maior risco, em que é necessário detectar cargas virais muito baixas (como quando há transplante coração-pulmão concomitante; situações de extrema imunodepressão e doença do trato gastrointestinal), o PCR é preferível. Não há níveis de corte que possam ser padronizáveis para todas as populações, sendo necessário usar o método de maneira qualitativa ou então de forma sequencial.

Com relação ao tratamento, para o caso de doença estabelecida em qualquer forma (invasiva ou síndrome por CMV), a droga de escolha é o ganciclovir, por via venosa nos casos de maior gravidade (doença invasiva), podendo utilizarse o valganciclovir via oral para casos mais leves (900 mg 2 x dia por 21 dias e, a seguir, $900 \mathrm{mg} /$ dia como manutenção) (Tabela 54). O tempo de tratamento não é definido, mas deve ser usado por pelo menos 15 dias, ou uma semana após a negativação da antigenemia ou PCR.

A terapia preemptiva pressupõe o tratamento quando da positivação da antigenemia ou do PCR. Em função da potencial gravidade da doença no transplante cardíaco, e principalmente no transplante coração-pulmão, sugere-se, pelo menos quinzenal, a realização da vigilância da infecção com PCR ou antigenemia e tratamento quando da positivação do teste, em
Tabela 54 - Recomendações para diagnóstico e tratamento da citomegalovirose

\begin{tabular}{lcc}
\hline $\begin{array}{c}\text { Classe da } \\
\text { recomendação }\end{array}$ & Indicações & $\begin{array}{c}\text { Nível de } \\
\text { evidência }\end{array}$ \\
\hline & $\begin{array}{c}\text { Antigenemia ou PCR para o diagnóstico } \\
\text { de infecção pelo CMV; }\end{array}$ & B \\
\cline { 2 - 3 } Classe I & $\begin{array}{c}\text { Ganciclovir ou valganciclovir para o } \\
\text { tratamento da infecção e doença por } \\
\text { CMV; }\end{array}$ & B \\
\cline { 2 - 3 } & Foscarnet para resistência ao \\
ganciclovir ou valganciclovir. & C \\
\hline Classe lla & $\begin{array}{c}\text { Vigilância para detectar infecção } \\
\text { semanal, ou pelo menos quinzenal, para } \\
\text { todos os pacientes por pelo menos três } \\
\text { meses pós-transplante. }\end{array}$ & B \\
\hline
\end{tabular}

CMV - citomegalovírus.

particular em pacientes excessivamente imunossuprimidos.

Quando da suspeita da resistência ao ganciclovir, a genotipagem deve ser solicitada, sendo o foscarnet (180 mg/dia, IV) a droga de escolha nos casos de resistência. $\mathrm{Na}$ impossibilidade de realizar genotipagem, a suspeita de resistência se faz pela não negativação de antigenemia ou PCR, na vigência de terapia com ganciclovir em dose adequada.

\section{b) Toxoplasmose}

Para o diagnóstico da toxoplasmose aguda, o método diagnóstico disponível é a sorologia, usando como referência a positivação de IgM. Como muitas vezes a soro-conversão é tardia em relação à apresentação clínica, deve-se tentar identificar o agente em tecido. Por exemplo, na suspeita de miocardite aguda, a biópsia endomiocárdica deve ser indicada, o mesmo ocorrendo para a pneumonia.

Para o diagnóstico de doença reativada, a escolha é a variação de títulos de IgG (por, pelo menos, 4 vezes em relação ao basal ou repositivação de lgM).

O tratamento de escolha para a doença aguda ou reativada é a associação de sulfadiazina (6-8 g vo/dia) e pirimetamina (50-75 mg vo/dia), com uso concomitante de ácido folínico (15 $\mathrm{mg} / \mathrm{dia}$ ) para prevenção da depressão medular. Em situações de extrema gravidade, a sulfadiazina pode ser substituída por sulfametoxazol trimetoprin endovenoso. Nos casos de alergia ou intolerância às sulfas, clindamicina $(2,4 \mathrm{~g} / \mathrm{dia})$ é a droga de escolha (Tabela 55).

\section{c) Pneumocystis jirovecii (carinii)}

Embora o diagnóstico em escarro possa ser feito, a amostra de material nem sempre é suficiente. Além do mais, como muitas vezes o quadro clínico pode ser confundido com outras patologias, o método de escolha é invasivo, tanto com broncoscopia como com biópsia a céu aberto.

A droga de escolha para o tratamento é o sulfametoxazol trimetoprin (100 mg/kg divididas em 4 doses ao dia) por via endovenosa por 14-21 dias. A pentamidina (5 mg/kg/dia por 14-21 dias) por via venosa é a alternativa terapêutica em casos de intolerância à sulfa (Tabela 56). 


\section{Diretrizes}

Tabela 55 - Recomendações para diagnóstico e tratamento da toxoplasmose

\begin{tabular}{lcc}
\hline $\begin{array}{l}\text { Classe da } \\
\text { recomendação }\end{array}$ & Indicações & $\begin{array}{c}\text { Nível de } \\
\text { evidência }\end{array}$ \\
\hline \multirow{2}{*}{ Classe I } & $\begin{array}{c}\text { Sorologia para o diagnóstico da } \\
\text { toxoplasmose aguda; }\end{array}$ & $\mathrm{C}$ \\
\cline { 2 - 3 } & $\begin{array}{c}\text { Sulfadiazina e pirimetamina, associado } \\
\text { a ácido folínico para toxoplasmose } \\
\text { aguda; }\end{array}$ & $\mathrm{C}$ \\
\cline { 2 - 3 } & $\begin{array}{c}\text { Clindamicina na alergia ou intolerância } \\
\text { às sulfas. }\end{array}$ & $\mathrm{C}$ \\
\hline Classe lla & $\begin{array}{c}\text { Sulfametoxazol trimetropim intravenoso } \\
\text { nos casos de extrema gravidade. }\end{array}$ & $\mathrm{C}$ \\
\hline
\end{tabular}

Tabela 56 - Recomendações para diagnóstico e tratamento Pneumocystis jirovecii

\begin{tabular}{lcc}
\hline $\begin{array}{l}\text { Classe da } \\
\text { recomendação }\end{array}$ & Indicação & $\begin{array}{c}\text { Nível de } \\
\text { evidência }\end{array}$ \\
\hline \multirow{2}{*}{ Classe I } & Sulfametoxazol trimetoprin. & $\mathrm{C}$ \\
\cline { 2 - 3 } & Pentamidina na intolerância à sulfa. & $\mathrm{C}$ \\
\hline
\end{tabular}

\section{iv. Imunização em adultos}

A atualização do calendário vacinal de adultos deve ser feita antes do transplante em virtude de maiores taxas de soro-conversão. Após o transplante, embora os dados sejam controversos, nos primeiros seis meses após o transplante, deve-se evitar a vacinação pelo risco de potencializar eventos de rejeição. Também após o transplante, deve-se evitar o uso de vacinas com vírus vivos atenuados, como, por exemplo, as vacinas para febre amarela e para sarampo, rubéola e caxumba.

Na atualização do calendário vacinal em adultos, atenção especial deve ser dada à imunização para difteria e tétano (atualização necessária a cada 10 anos). Recomenda-se vacinação para hepatites A e B para os suscetíveis, bem como imunização para influenza eS. pneumoniae. A vacinação para influenza deve ser anual. Pacientes suscetíveis à varicela, sarampo, rubéola e caxumba (se necessário, confirmar com sorologia) devem receber a vacina antes do transplante (Tabela 57).

\section{B) Reativação da doença de Chagas}

Em pacientes com doença de Chagas, a persistência do Trypanosoma cruzi no coração e outros órgãos tem sido demonstrada ${ }^{230}$. A reativação da infecção por Trypanosoma cruzi pode ocorrer em pacientes após transplante cardíaco devido à imunodepressão de 27-90\%, podendo ser repetitiva ${ }^{231-233}$. Reativação ou infecção pode ocorrer com doador portador de infecção pelo Trypanosoma cruzi ${ }^{234}$. Apesar da frequente reativação, em longo prazo, a sobrevida é boa e sem desenvolvimento de miocardiopatia ${ }^{235,236}$.

\section{i. Profilaxia}

Profilaxia inespecífica dever incluir manutenção de doses de medicações imunossupressoras cronicamente
Tabela 57 - Recomendações para imunização

\begin{tabular}{lcc}
\hline $\begin{array}{c}\text { Classe da } \\
\text { Recomendação }\end{array}$ & Indicações & $\begin{array}{c}\text { Nível de } \\
\text { evidência }\end{array}$ \\
\hline \multirow{2}{*}{ Classe I } & $\begin{array}{c}\text { Atualizar o calendário vacinal de adultos } \\
\text { antes do transplante, com especial } \\
\text { atenção para as vacinas dupla adulto, } \\
\text { influenza, S. pneumoniae; }\end{array}$ & $\mathrm{C}$ \\
\cline { 2 - 3 } & $\begin{array}{c}\text { Imunizar pacientes suscetíveis para } \\
\text { hepatites B e A, varicela (confirmar com } \\
\text { sorologia, se necessário), sarampo, } \\
\text { caxumba e rubéola (confirmar com } \\
\text { sorologia, se necessário); }\end{array}$ & $\mathrm{C}$ \\
\cline { 2 - 3 } & $\begin{array}{c}\text { Não usar vírus vivos atenuados após o } \\
\text { transplante. }\end{array}$ & $\mathrm{C}$ \\
\hline Classe III & Vacinação nos primeiros seis meses \\
após o transplante. & $\mathrm{C}$ \\
\hline
\end{tabular}

tão baixas quanto toleradas livres de rejeição. Na prática clínica, as doses de imunossupressores devem ser lentamente reduzidas e a possibilidade de rejeição monitorada. Redução da utilização de corticosteroides foi associada à incidência menor de reativação ${ }^{237}$. Medicações imunossupressoras associadas a uma maior frequência de reativação, como o micofenolato em dose plena, devem ser evitadas $^{93}$. Fatores, como número de episódios de rejeição, desenvolvimento de neoplasias e micofenolato, foram associados com reativação ${ }^{238}$. Esquema imunossupressor com inibidores do sinal de proliferação não tem sido testado no transplante para miocardiopatia chagásica, mas haveria potencial uso em situações de aumento de risco de neoplasia ${ }^{96}$. Cepas do Trypanosoma cruzi não parecem ser o elemento principal da reativação ${ }^{239}$. Suporte mecânico prétransplante cardíaco não parece ser risco para reativação da infecção por Trypanosoma cruzi ${ }^{240}$.

A profilaxia específica com utilização de medicações com ação anti Trypanosoma cruzi, antes e depois do transplante tem sido motivo de debate, incluindo uso ou não de medicação, medicação a ser utilizada e a dose e tempo de uso (Tabela 58). A maior parte dos centros não utiliza profilaticamente, dentro do princípio de que é difícil erradicar o Trypanosoma cruzi do receptor. Estudo com controle histórico com benzonidazol não demonstrou benefício do tratamento profilático antes ou após transplante sem reativação, havendo chance de efeitos colaterais com a medicação ${ }^{231}$.

\section{ii. Diagnóstico}

A monitoração da infecção por Trypanosoma cruzi deve ser realizada através de pesquisa rotineira na biópsia endomiocárdica de receptores com doença de Chagas. Na suspeita de reativação, devem-se buscar a detecção em tecidos (imunoperoxidade com anticorpo anti Trypanosoma cruzi, PCR, etc.) e a utilização de esfregaço, xenodiagnóstico ou hemocultura. A hipótese diagnóstica de reativação deve ser considerada em pacientes com miocardiopatia chagásica prévia quando na presença isolada ou conjunta de febre indeterminada, nódulos subcutâneos, manifestação neurológica, pancitopenia, 
lesões cutâneas não esclarecidas, persistência de rejeição apesar do tratamento, comprometimento agudo de função ventricular, arritmias de recente começo, fragmentos de biópsia miocárdica com detecção do Trypanosoma cruzi através de imunohistoquímica.

As manifestações mais frequentes são miocardite e paniculite. O diagnóstico deve ser confirmado pela detecção de Trypanosoma cruzi, em locais tais como pele, miocárdio, líquido raquidiano e medula óssea. O isolamento do Trypanosoma cruzi no sangue não necessariamente indica doença, mas pode ser uma manifestação precoce, e, quando associado a quadro clínico, é forte evidência para reativação. O diagnóstico diferencial da reativação com rejeição diante de um quadro de IC aguda ainda sem resultado de biópsia endomiocárdica, ou de infiltrado persistente sem resposta ao tratamento imunodepressor sem detecção do Trypanosoma cruzi são desafios no diagnóstico da infecção. Além da detecção direta do parasita, outros achados da biópsia endomiocárdica poderão vir a ser úteis para o diagnóstico diferencial entre rejeição e reativação da doença de Chagas, a exemplo da diferente relação CD4+/CD8+ e maior expressão de CD4+ na rejeição, quando comparada à miocardite chagásica crônica ${ }^{241}$. Nesse sentido, a técnica do PCR para Trypanosoma cruzi nos fragmentos da biópsia tem sido realizada, com resultados promissores ${ }^{242,243}$.

\section{iii. Tratamento}

A mortalidade diretamente relacionada à reativação pelo Trypanosoma cruzi tratada é reduzida, com adequada sobrevida em longo prazo ${ }^{13,244}$. A redução da imunodepressão, quando possível, deve ser preconizada diante do diagnóstico ou da suspeita de reativação. As medicações que foram utilizadas para o tratamento específico da reativação com sucesso foram o benzonidazol (10 mg/ $/ \mathrm{kg} /$ dia por 60 dias) e o alopurinol (600-900 mg/dia por 60 dias) (Tabela 58).

\section{C) Neoplasias após transplante cardíaco}

Após o transplante, existe aumento da incidência de neoplasias malignas, principalmente de pele e sistema hematopoiético ${ }^{245}$. A maior incidência de neoplasias após transplante de órgãos está relacionada ao uso de drogas imunossupressoras e infecções. Na doença de Chagas, foi descrita incidência elevada de neoplasias, que reduziu após utilização de menores doses de drogas imunossupressoras ${ }^{246}$. A doença linfoproliferativa pós- transplante (DLPT) pode ser intra ou extragânglio, localizada ou disseminada. No diagnóstico de DLPT, é necessário estadiamento, sendo que a DLPT é diretamente relacionada com a infecção primária por Ebstein-Baar vírus (EBV), que é considerado o fator de risco mais importante. O risco também aumenta com a utilização de anticorpos monoclonais ou policlonais, além de infecção por CMV. Em relação aos tumores sólidos, em publicação recente, foi descrita a incidência de 8,6\%, com $83 \%$ no sexo masculino, sendo que os tumores mais comuns foram os de próstata, pulmão e mama. A idade e o retransplante foram fatores associados ao aumento da incidência de malignidade ${ }^{247}$.
Na Tabela 59, estão incluídas as recomendações para prevenção e tratamento de neoplasia. Salienta-se que efeitos antitumorais têm sido relatados com inibidores do sinal de proliferação. Foi demonstrado que o everolimus pode ter ação antitumoral, bloqueando o seu crescimento, retardando a progressão do ciclo celular e inibindo a angiogênese. Em recente estudo de fase II, foi demonstrado que o everolimus tem ação antitumoral contra câncer renal metastático ${ }^{248}$. O uso de sirolimus em baixas doses inibiu o crescimento de linhagens celulares de carcinoma hepatocelular in vitro. Altas doses de sirolimus impediram o crescimento de células tumorais ${ }^{249}$.

Tabela 58 - Recomendações na reativação da infecção por Trypanosoma cruzi

\begin{tabular}{|c|c|c|}
\hline $\begin{array}{l}\text { Classe de } \\
\text { Recomendação }\end{array}$ & Indicação & $\begin{array}{l}\text { Nível de } \\
\text { Evidência }\end{array}$ \\
\hline \multicolumn{3}{|c|}{ Profilaxia inespecífica } \\
\hline \multirow{3}{*}{ Classe lla } & $\begin{array}{l}\text { Menor imunossupressão tolerada sem } \\
\text { rejeição; }\end{array}$ & $C$ \\
\hline & $\begin{array}{l}\text { Evitar corticosteroides sem aumentar o } \\
\text { risco de rejeição; }\end{array}$ & C \\
\hline & Evitar micofenolato em dose plena. & C \\
\hline Classe Ilb & $\begin{array}{l}\text { Azatioprina como imunossupressão de } \\
\text { manutenção em pacientes chagásicos } \\
\text { visando a redução da incidência de } \\
\text { reativação da doença de Chagas. }\end{array}$ & C \\
\hline \multicolumn{3}{|c|}{ Profilaxia específica } \\
\hline \multirow[t]{2}{*}{ Classe Ilb } & $\begin{array}{l}\text { Benzonidazol ou alopurinol após } \\
\text { transplante cardíaco em situações de } \\
\text { elevada imunodepressão; }\end{array}$ & C \\
\hline & $\begin{array}{l}\text { Benzonidazol ou alopurinol pré- } \\
\text { transplante de rotina. }\end{array}$ & C \\
\hline Classe III & $\begin{array}{l}\text { Benzonidazol ou alopurinol após } \\
\text { transplante de rotina. }\end{array}$ & $C$ \\
\hline \multicolumn{3}{|c|}{ Diagnóstico } \\
\hline \multirow[t]{2}{*}{ Classe I } & $\begin{array}{c}\text { Monitoração rotineira da infecção por } \\
\text { Trypanosoma cruzi após transplante } \\
\text { cardíaco; }\end{array}$ & C \\
\hline & $\begin{array}{l}\text { Pesquisa específica do Trypanosoma } \\
\text { cruzi para confirmação do diagnóstico. }\end{array}$ & C \\
\hline \multicolumn{3}{|c|}{ Tratamento } \\
\hline \multirow{2}{*}{ Classe I } & $\begin{array}{c}\text { Tratamento específico com } \\
\text { benzonidazol nos casos comprovados } \\
\text { de reativação da infecção por } \\
\text { Trypanosoma cruzi. }\end{array}$ & C \\
\hline & $\begin{array}{l}\text { Tratamento específico com } \\
\text { benzonidazol nos casos suspeitos de } \\
\text { reativação da infecção por Trypanosoma } \\
\text { cruzi com repercussão clínica. }\end{array}$ & C \\
\hline \multirow[b]{2}{*}{ Classe Ila } & $\begin{array}{l}\text { Tratamento específico com alopurinol } \\
\text { nos casos comprovados de reativação } \\
\text { da infecção por Trypanosoma cruzi. }\end{array}$ & C \\
\hline & $\begin{array}{l}\text { Tratamento específico com alopurinol } \\
\text { nos casos suspeitos de reativação da } \\
\text { infecção por Trypanosoma cruzi com } \\
\text { repercussão clínica. }\end{array}$ & C \\
\hline
\end{tabular}




\section{Diretrizes}

Tabela 59 - Recomendações para prevenção e tratamento de neoplasia maligna

\begin{tabular}{|c|c|c|}
\hline $\begin{array}{l}\text { Classe de } \\
\text { Recomendação }\end{array}$ & Indicação & $\begin{array}{l}\text { Nível de } \\
\text { Evidência }\end{array}$ \\
\hline & Prevenção & \\
\hline \multirow{12}{*}{ Classe I } & Medidas gerais & \\
\hline & $\begin{array}{l}\text { Utilizar a menor dose possível de } \\
\text { imunossupressores; }\end{array}$ & C \\
\hline & Cessar tabagismo; & C \\
\hline & $\begin{array}{l}\text { Ênfase para avaliação periódica: } \\
\text { câncer de mama, próstata, útero, } \\
\text { cólon, pulmão; }\end{array}$ & C \\
\hline & Dosagens periódicas; PSA, CEA. & C \\
\hline & Pele & \\
\hline & Evitar exposição ao sol; & C \\
\hline & Protetor solar; & C \\
\hline & $\begin{array}{l}\text { Exame físico e educação para } \\
\text { autoexame da pele. }\end{array}$ & C \\
\hline & DLPT: & \\
\hline & $\begin{array}{l}\text { Evitar anticorpos monoclonal ou } \\
\text { policlonal; }\end{array}$ & C \\
\hline & $\begin{array}{l}\text { Monitorizar carga viral de EBV se } \\
\text { disponível e considerar possível } \\
\text { tratamento antiviral, se redução da } \\
\text { imunossupressão não é efetiva. }\end{array}$ & C \\
\hline Classe lla & $\begin{array}{c}\text { Uso de aciclovir ou ganciclovir para } \\
\text { profilaxia antiviral. }\end{array}$ & C \\
\hline \multicolumn{3}{|c|}{ Tratamento } \\
\hline \multirow{4}{*}{ Classe I } & Medidas usuais, se indicado & \\
\hline & $\begin{array}{l}\text { Ressecção cirúrgica, quimioterapia e } \\
\text { radioterapia. }\end{array}$ & c \\
\hline & Medidas inespecíficas & \\
\hline & Redução de imunossupressão. & C \\
\hline \multirow{5}{*}{ Classe lla } & Medidas inespecíficas & \\
\hline & Retirada da imunossupressão. & C \\
\hline & $\begin{array}{l}\text { Conversão de imunossupressão para } \\
\text { inibidores de sinal de proliferação. }\end{array}$ & C \\
\hline & Medidas específicas - DLPT & \\
\hline & Agentes antivirais (rituximab) & C \\
\hline
\end{tabular}

CEA - antígeno carcinoembrionário; DLPT - doença linfoproliferativa póstransplante; $E B V$ - Epstein BAAR virus.

\section{D) Retransplante cardíaco}

O primeiro retransplante foi realizado em $1968{ }^{250}$ e atualmente representa algo em torno de 2,05\% dos transplantes cardíacos. As principais indicações para retrasplante são a falência precoce e tardia do enxerto e a doença vascular do enxerto (Tabela 60) ${ }^{251}$.

A evolução pós-retransplante cardíaco é inferior à evolução dos transplantes "de novo"251,252. Os resultados ainda são mais comprometidos quando realizados em situação "de resgate" de emergência, em geral no pós-operatório imediato. A

\section{Tabela 60 - Recomendações para retransplante}

\begin{tabular}{|c|c|c|}
\hline $\begin{array}{l}\text { Classe de } \\
\text { Recomendação }\end{array}$ & Indicação & $\begin{array}{l}\text { Nível de } \\
\text { Evidência }\end{array}$ \\
\hline \multirow[t]{2}{*}{ Classe I } & $\begin{array}{l}\text { Doença vascular do enxerto associada } \\
\text { à insuficiência cardíaca ou manifestação } \\
\text { isquêmica refratárias sem possibilidade } \\
\text { de outro tratamento; }\end{array}$ & C \\
\hline & $\begin{array}{l}\text { Insuficiência cardíaca classes III-IV sem } \\
\text { doença vascular do enxerto ou rejeição } \\
\text { ativa tardiamente pós-transplante. }\end{array}$ & C \\
\hline Classe Ila & $\begin{array}{c}\text { Doença coronariana crônica grave } \\
\text { do aloenxerto sem possibilidade de } \\
\text { outro tratamento, assintomática com } \\
\text { disfunção importante. }\end{array}$ & C \\
\hline Classe Ilb & $\begin{array}{l}\text { Disfunção aguda do enxerto após } \\
\text { transplante cardíaco. }\end{array}$ & C \\
\hline \multirow[t]{2}{*}{ Classe III } & $\begin{array}{l}\text { Doença vascular do enxerto sem } \\
\text { insuficiência cardiaca, sem isquemia } \\
\text { demonstrável ou com outra opção de } \\
\text { tratamento. }\end{array}$ & C \\
\hline & Receptor não ideal. & C \\
\hline
\end{tabular}

sobrevida nos pacientes retransplantados por rejeição cardíaca aguda é de $32 \%$ e $8 \%$, aos um e 5 anos, e nos retransplantados por falência precoce do enxerto é de $50 \%$ e $39 \%$, aos um e 5 anos. Os retransplantados por doença vascular do enxerto ou realizados tardiamente apresentam sobrevida de $74 \%$ em um $\mathrm{ano}^{251}$. O risco de óbito após retransplante está associado à indicação por rejeição aguda $(p=0,0005)$, por falência precoce do enxerto $(p=0,03)$ e uso de doador feminino ( $p$ $=0,005)$. A sobrevivência após o retransplante para doença vascular do enxerto tem melhorado ${ }^{252}$.

Quando o tempo entre os transplantes é inferior a dois anos, a sobrevida de um ano é de cerca de $60 \%$, enquanto que, quando o tempo é maior do que dois anos, a sobrevida é de $74 \%{ }^{253}$.

Os retransplantes pediátricos têm apresentado resultados melhores que os em adultos, com sobrevida de um ano de $30 \%$ quando realizado precocemente ${ }^{254}$, enquanto que, quando indicado tardiamente, a sobrevida foi semelhante a do primeiro transplante cardíaco ${ }^{255}$.

As principais limitações para o retransplante são: a inferioridade dos resultados e a indisponibilidade de doadores em número suficiente para suprir a demanda de transplante cardíaco "de novo". Salienta-se que devido a estas limitações, o receptor para retransplante deve ter características de receptor ideal.

\section{E) Comorbidades - prevenção e tratamento}

A prevalência em 5 anos pós-transplante foi de 94\% para hipertensão arterial sistêmica (HAS), 85\% para dislipidemia (DLP) e 33\% para diabetes melito (DM) ${ }^{253}$.

\section{i. Diabetes Melito}

A ciclosporina e o tacrolimus têm impacto negativo sobre a função pancreática, sendo o tacrolimus mais diabetogênico ${ }^{256}$. 
Os hipoglicemiantes orais são problemáticos no pósoperatório precoce. A redução da dose de prednisona reduz a incidência de DM. O manejo do DM em longo prazo é similar ao de não transplantados. Agentes hipoglicemiantes orais são efetivos mesmo em uso de corticosteroides, ciclosporina ou tacrolimus. Terapia com insulina pode ser necessária, particularmente no período pós-transplante imediato ${ }^{257}$. As principais classes de antidiabéticos orais disponíveis estão na Tabela 61.

A metformina é um agente de referência para pacientes com sobrepeso, porém, deve ser evitado em disfunção de enxerto e em risco de acidose láctica. Os derivados da sulfonilureia em pacientes com disfunção de enxerto ou idosos aumentam o risco de hipoglicemia. As meglitinidas "não sulfonilureias" são secretadoras de insulina com mecanismo de ação semelhante ao das sulfonilureias. Esses agentes são bem tolerados em idosos e em disfunção de enxerto. Os derivados tiazolidínicos são sensibilizadores da insulina que podem ser necessários quando há indicação de insulina ${ }^{258}$. Pacientes utilizando metformina, rosiglitazona ou pioglitazona apresentam maior incidência de fraturas 259,260 . O uso de gemfibrozil, um inibidor da 3A4 CYP, e de repaglinida em terapia combinada, tem sido associado a aumento de hipoglicemia. Coadministração de ciclosporina e repaglinida aumenta o risco de hipoglicemia ${ }^{261}$. Em contraste, a rifampicina, um forte indutor da 3A4 CYP, diminui as concentrações e o efeito da repaglinida ${ }^{262}$.

O manejo do DM está descrito nas Tabelas 62 e 63. Os níveis de $\mathrm{HbA1C}$ não refletem a realidade do perfil de glicemia nos primeiros três meses pós-transplante devido a vários fatores, como transfusão de sangue, anemia, disfunção renal ou de enxerto ${ }^{263}$.

$\mathrm{Na}$ presença de enxerto com função normal, pode-se utilizar secretagogos e biguanidas, enquanto que na disfunção de enxerto, sugere-se evitar a utilização de metiglinidas e biguanidas e contraindica-se o uso de sulfonilureias e glitazonas.

\section{Tabela 61 - Antidiabéticos orais}

\begin{tabular}{|c|c|}
\hline \multirow{7}{*}{$\begin{array}{l}\text { Aumentam a } \\
\text { disponibilidade } \\
\text { de insulina } \\
\text { (Secretagogos). }\end{array}$} & Sulfonilureias \\
\hline & $1^{\text {a }}$ geração: clorpropamida; \\
\hline & 2a geração: glibenclamida, glipizida, gliclazida; \\
\hline & $3^{\mathrm{a}}$ geração: glimepirida. \\
\hline & Meglitinidas \\
\hline & Repaglinida; \\
\hline & Nateglinida. \\
\hline \multirow{2}{*}{$\begin{array}{l}\text { Suprimem a produção } \\
\text { hepática de glicose. }\end{array}$} & Biguanidas \\
\hline & Metformina. \\
\hline \multirow{3}{*}{$\begin{array}{l}\text { Aumentam a } \\
\text { sensibilidade à } \\
\text { insulina. }\end{array}$} & Glitazonas \\
\hline & Rosiglitazona; \\
\hline & Pioglitazona. \\
\hline \multirow{2}{*}{$\begin{array}{l}\text { Reduzem a absorção } \\
\text { gastrointestinal de } \\
\text { glicose. }\end{array}$} & Inibidor da $\alpha$-glicosidase \\
\hline & Acarbose. \\
\hline
\end{tabular}

Tabela 62 - Manejo geral do diabetes melito

\begin{tabular}{|c|c|c|}
\hline $\begin{array}{l}\text { Classe de } \\
\text { Recomendação }\end{array}$ & Indicações & $\begin{array}{l}\text { Nível de } \\
\text { Evidência }\end{array}$ \\
\hline \multirow{6}{*}{ Classe I } & Modificação da dieta & \\
\hline & $\begin{array}{l}\text { Dieta pobre em gorduras saturadas } \\
\text { e colesterol e rica em fibras e } \\
\text { carboidratos complexos. }\end{array}$ & C \\
\hline & Modificação no estilo de vida & \\
\hline & $\begin{array}{l}\text { Exercício, reduzir ou evitar o ganho de } \\
\text { peso, não fumar, cuidado com MMIl; }\end{array}$ & C \\
\hline & $\begin{array}{l}\text { Pesquisar HbA1C, microalbuminúria, } \\
\text { alterações oftalmológicas, dislipidemia; }\end{array}$ & C \\
\hline & $\begin{array}{l}\text { Tratar agressivamente HAS e } \\
\text { dislipidemia. }\end{array}$ & C \\
\hline \multirow[t]{2}{*}{ Classe lla } & $\begin{array}{l}\text { Modificação ou ajuste dos medicamentos } \\
\text { imunossupressores }\end{array}$ & \\
\hline & Converter tacrolimus por ciclosporina. & C \\
\hline
\end{tabular}

MMII - membros inferiores; HbA1C - hemoglobina glicada; HAS - hipertensão arterial sistêmica.

Tabela 63 - Manejo medicamentoso do diabetes melito pós-transplante

\begin{tabular}{llc}
\hline $\begin{array}{l}\text { Classe de } \\
\text { Recomendação }\end{array}$ & Indicações & $\begin{array}{c}\text { Nível de } \\
\text { Evidência }\end{array}$ \\
\hline & \begin{tabular}{l} 
Marcada hiperglicemia aguda \\
\cline { 2 - 3 } Classe I
\end{tabular} & $\mathrm{C}$ \\
\cline { 2 - 3 } & $\begin{array}{l}\text { Hiperglicemia crônica (Alvo = HbA1C } \\
<6.5-7 \% \text { ) }\end{array}$ & \\
\cline { 2 - 2 } & $\begin{array}{l}\text { Hipoglicemiante oral em monoterapia } \\
\text { ou terapia combinada com ou sem } \\
\text { insulina. }\end{array}$ & $\mathrm{C}$ \\
\hline
\end{tabular}

HbA1C - hemoglobina glicada.

\section{ii. Hipertensão arterial sistêmica}

A principal causa de HAS é o uso de inibidores de calcineurina (ciclosporina e tacrolimus) e corticosteroides ${ }^{264}$. O tacrolimus apresenta menor incidência de HAS do que a ciclosporina. Micofenolato mofetil e azatioprina não estão associados à HAS. Os esquemas tacrolimus e micofenolato mofetil versus ciclosporina e micofenolato mofetil têm uma incidência de HAS de $12 \%$ e 30,3\% respectivamente ${ }^{256}$. As medidas não farmacológicas e farmacológicas estão relacionadas na Tabela 64. A preferência é pelo uso de antagonistas do cálcio ${ }^{265}$ e inibidores da enzima conversora da angiotensina (IECA). Os antagonistas do cálcio, particularmente o diltiazem, contribuem para a redução da pressão arterial e da doença vascular do enxerto, permitindo redução das doses de ciclosporina.

\section{iii. Dislipidemias}

As alterações no perfil lipídico, após transplante cardíaco ${ }^{266-269}$, podem ser devido a múltiplos fatores, 


\section{Diretrizes}

Tabela 64 - Medidas não farmacológicas e farmacológicas preventivas e terapêuticas da hipertensão arterial

\begin{tabular}{|c|c|c|}
\hline $\begin{array}{l}\text { Classe de } \\
\text { Recomendação }\end{array}$ & Indicações & $\begin{array}{l}\text { Nível de } \\
\text { Evidência }\end{array}$ \\
\hline \multirow{6}{*}{ Classe I } & Medidas não farmacológicas & \\
\hline & $\begin{array}{l}\text { Dieta hipossódica, exercício, controle } \\
\text { de peso e estresse. }\end{array}$ & C \\
\hline & Tratamento farmacológico & \\
\hline & $\begin{array}{l}\text { Minimizar doses de ciclosporina, se } \\
\text { possível; }\end{array}$ & C \\
\hline & $\begin{array}{l}\text { Antagonistas do cálcio } \\
\text { (dihidroperidínicos); }\end{array}$ & C \\
\hline & IECA. & C \\
\hline \multirow{4}{*}{ Classe lla } & Outros anti-hipertensivos & \\
\hline & $\begin{array}{l}\text { Bloqueadores dos receptores da } \\
\text { angiotensina II; }\end{array}$ & C \\
\hline & Diuréticos; & C \\
\hline & Clonidina. & C \\
\hline Classe Ilb & Betabloqueadores. & C \\
\hline
\end{tabular}

como aumento da ingestão, perfusão gastrointestinal, absorção de alimentos, ganho de peso ${ }^{266-271}$, uso de antihipertensivos (tiazídicos, furosemida e betabloqueadores) ${ }^{272}$ e, principalmente, secundária aos imunossupressores, especialmente os corticosteroides e a ciclosporina ${ }^{273,274}$. Adicionalmente, disfunção renal e DM são fatores de risco de dislipidemia em transplantados. Os inibidores do sinal da proliferação estão relacionados à importante elevação de colesterol e triglicérides. O tacrolimus causa menor incidência de hiperlipidemia, enquanto que o micofenolato e a azatioprina não estão associados à dislipidemia ${ }^{275-276}$.

Os transplantados devem ser considerados como portadores de risco equivalente à doença coronariana, sendo alvos de perfil lipídicos: LDL $<100$ mg/dl (ótimo $<70$ mg/ $\mathrm{dl}$, para pacientes de alto risco), TG $<200 \mathrm{mg} / \mathrm{dl}, \mathrm{HDL}>$ $45 \mathrm{mg} / \mathrm{dl}^{277-278}$.

O uso de inibidores da HMG-CoA redutase reduz a incidência e a progressão da doença vascular do enxerto, independente da redução do colesterol, além de ser associado à redução de rejeição ${ }^{279-280}$. As estatinas são a primeira escolha (Tabela 65) e, dentre elas, a pravastatina, por ser hidrofílica, liga-se pouco aos tecidos musculares e tem pouca interação com a ciclosporina, sendo a preferência no pós-transplante. Além disso, tem efeito imunossupressor (efeitos na modulação imunológica e na função endotelial) mais bem documentado. As outras estatinas testadas são a sinvastatina e a atorvastatina, porém, devem ser usadas nas menores doses possíveis, por maior a chance de rabdomiólise através da interação com os inibidores de calcineurina. Se o alvo de LDL não é alcançado com monoterapia com estatinas, considerar a combinação de estatina com inibidores da absorção do colesterol. Sequestradores de ácidos biliares não devem ser utilizados associados à ciclosporina. Quando necessário, utilizar, com cuidado, terapia combinada de estatina e fibrato.
Tabela 65 - Prevenção e tratamento da dislipidemia

\begin{tabular}{|c|c|c|}
\hline $\begin{array}{l}\text { Classe de } \\
\text { Recomendação }\end{array}$ & Indicações & $\begin{array}{l}\text { Nível de } \\
\text { Evidência }\end{array}$ \\
\hline \multirow{4}{*}{ Classe I } & Medidas não farmacológicas & \\
\hline & $\begin{array}{l}\text { Dieta pobre em gorduras saturadas, } \\
\text { colesterol e triglicerídeos, exercício, } \\
\text { controle de peso. }\end{array}$ & C \\
\hline & Tratamento farmacológico & \\
\hline & Pravastatina, sinvastatina. & $\mathrm{B}$ \\
\hline \multirow{3}{*}{ Classe Ila } & Tratamento farmacológico & \\
\hline & Atorvastatina, rosuvastatina; & C \\
\hline & Ezetimibe. & C \\
\hline
\end{tabular}

\section{iv. Insuficiência renal}

A insuficiência renal é uma complicação comum após transplante cardíaco, podendo atingir $21,4 \%$ dos pacientes após 5 anos do transplante, sendo que aproximadamente $2,5 \%$ dos pacientes necessitam de diálise, o que resulta em aumento da morbidade e diminuição da sobrevida destes pacientes $^{\mathbf{7 6}}$.

O aparecimento da insuficiência renal deve-se principalmente ao uso de inibidores da calcineurina, que possuem nefrotoxidade aguda (vasoconstrição da arteríola aferente do nefrón) e crônica (nefroesclerose). Algumas estratégias podem ser usadas para poupar ou melhorar a função renal (Tabela 66) ${ }^{281,282}$. A utilização de minimização da dose de ciclosporina, ou conversão para inibidores do sinal de proliferação, deve ser efetuada somente em pacientes com mais de 6 meses de transplante e sobre monitoração rigorosa (ecocardiográfica e biópsia endomiocárdica).

\section{v. Osteoporose}

Os pacientes submetidos a transplante de órgãos são uma população de alto risco para osteoporose, sendo que esta doença desenvolve-se nos pacientes com sobrevida maior que

\section{Tabela 66 - Recomendações para o manejo da insuficiência renal}

\begin{tabular}{lcc}
\hline $\begin{array}{l}\text { Classe de } \\
\text { recomendação }\end{array}$ & Indicações & $\begin{array}{c}\text { Nível de } \\
\text { evidência }\end{array}$ \\
\hline Classe I & $\begin{array}{c}\text { Dosagem de ciclosporina sérica para } \\
\text { utilização da menor dose efetiva para } \\
\text { imunossupressão segura. }\end{array}$ & C \\
\hline & $\begin{array}{c}\text { Minimização da dose de ciclosporina: } \\
\text { níveis de ciclosporina plasmática entre } \\
50-70 \text { ng/ml com dose máxima de } \\
\text { micofenolato (3 g) e prednisona 7,5 } \\
\text { mg/d; }\end{array}$ & C \\
\cline { 2 - 3 } Classe Ila & $\begin{array}{c}\text { Conversão do inibidor da calcineurina } \\
\text { por inibidor do sinal de proliferação, } \\
\text { mantendo dose máxima de micofenolato } \\
\text { e mantendo ou não prednisona na } \\
\text { terapia de imunossupressão. }\end{array}$ & C \\
\hline & $\begin{array}{l}\text { Manutenção da dose plena de } \\
\text { ciclosporina em pacientes com } \\
\text { creatinina > 2,5 mg/dl. }\end{array}$ & C \\
\hline
\end{tabular}


um ano após o transplante cardíaco. Sua ocorrência deve-se ao emprego dos corticosteroides e inibidores de calcineurina na terapêutica imunossupressora e a fatores inerentes à IC avançada (deficiência nutricional de cálcio e vitamina D, sedentarismo, hipogonadismo, uso de anticoagulantes e diuréticos de alça), além do tabagismo e alcoolismo ${ }^{283,284}$.

Estima-se que a perda óssea no primeiro ano varie entre $2-20 \%$ e que $10-30 \%$ dos pacientes apresentem fraturas vertebrais nos três primeiros anos após o transplante cardíaco.

O tratamento da osteoporose encontra-se na Tabela $67^{285}$, sendo que para monitoração da osteoporose devemos realizar densitometria óssea antes do transplante e periodicamente após a cirurgia, por pelo menos dois anos .

\section{vi. Depressão}

Depressão é uma ocorrência comum em pacientes transplantados e pode acometer até $25 \%$ dos pacientes entre um e três anos após a cirurgia, sendo mais comum no primeiro ano. A depressão impacta negativamente na qualidade de vida do paciente e é um fator de risco para a não aderência terapêutica. Seguem algumas recomendações para prevenção e tratamento da depressão em pacientes transplantados cardíacos $^{286,287}$. No tratamento medicamentoso, a fluoxetina e norfluoxetina podem alterar os níveis plasmáticos de ciclosporina. Não há relatos de interações medicamentosas com citalopram, sertralina e paroxetina (Tabela 68).

\section{Tabela 67 - Recomendações para o tratamento da osteoporose}

\begin{tabular}{lcc}
\hline $\begin{array}{l}\text { Classe de } \\
\text { recomendação }\end{array}$ & Indicações & $\begin{array}{c}\text { Níveis de } \\
\text { evidência }\end{array}$ \\
\hline \multirow{2}{*}{ Classe I } & $\begin{array}{c}\text { Bisfosfonados (Alendronato 10 mg/dia } \\
\text { vo) ou Calcitriol 0,25 mcg duas vezes ao } \\
\text { dia, no mínimo por um ano. }\end{array}$ & B \\
\hline \multirow{3}{*}{ Classe lla } & Exercício físico; & B \\
\cline { 2 - 3 } & $\begin{array}{c}\text { Vitamina D 400 Ul e um grama de cálcio } \\
\text { elementar ao dia. }\end{array}$ & C \\
\hline
\end{tabular}

Tabela 68 - Recomendações para a prevenção e para o tratamento da depressão

\begin{tabular}{lcc}
\hline $\begin{array}{l}\text { Classe de } \\
\text { recomendação }\end{array}$ & Indicações & $\begin{array}{c}\text { Nível de } \\
\text { evidência }\end{array}$ \\
\hline Classe I & $\begin{array}{c}\text { Monitoração dos níveis séricos } \\
\text { dos imunossupressores durante a } \\
\text { administração conjunta desses com } \\
\text { antidepressivos. }\end{array}$ & $\mathrm{C}$ \\
\hline Classe Ila & Inibidores da recaptação da serotonina. & $\mathrm{C}$ \\
\hline Classe Ilb & $\begin{array}{c}\text { Inibidores da MAO, antidepressivos } \\
\text { tricíclicos, litium e eletroconvulsoterapia. }\end{array}$ & $\mathrm{C}$ \\
\hline
\end{tabular}

F) Orientações equipe multiprofissional

\section{i. Dieta}

A orientação dietética após transplante visa reduzir a incidência de síndrome metabólica e doença vascular do enxerto, fatores relacionados à perda de função do enxerto.

Dieta associada a um programa de atividade física deve ser estimulada de maneira compreensível e educacional para a modificação de hábitos de vida ${ }^{288}$.

\section{ii. Aderência}

Os motivos para não aderência ao tratamento incluem os efeitos colaterais dos medicamentos; instruções inadequadas; relação médico-paciente inadequada; baixo nível cognitivo e desconhecimento do paciente sobre a necessidade do tratamento.

A manutenção da aderência em longo prazo é fundamental. Para manutenção da aderência, sugere-se a combinação de aconselhamento e instruções detalhadas e individualizadas de acordo com as necessidades ${ }^{289}$.

\section{iii. Reinserção social}

O suporte profissional deve ser na estimulação ao retorno às atividades sociais e laborativas. Evitar induzir o paciente à aposentadoria definitiva, e estimular o retorno ao mercado de trabalho, exercendo as suas funções originais ou uma nova função compatível com suas possibilidades atuais ${ }^{290}$.

A reinserção social e ocupacional do transplantado contribui para a melhoria da sua qualidade de vida.

\section{iv. Atividade física}

A inatividade física é frequente no pós-transplante e devese ao desconhecimento a respeito dos potenciais benefícios e da eficácia, medo, falta de ajuda e suporte de familiares. Dados confirmam que sintomas exacerbados, falta de afeto e depressão são inversamente proporcionais à atividade física.

A atividade física regular com duração de 30 minutos nos dias da semana deve ser estimulada ${ }^{291}$.

\section{v. Atividade sexual}

Dúvidas sobre a atividade sexual são comumente relatadas antes e após o transplante. A disfunção sexual geralmente é originada por fatores orgânicos, afetivos e de relacionamento. A disfunção sexual mais relatada no homem é a impotência sexual, mesmo com o relatado aumento da libido. A estratégia de tratamento deve incluir o casal ${ }^{292}$. O acompanhamento psicológico do comportamento sexual por longo período de tempo pode ser necessário.

\section{Transplante cardíaco em crianças}

\section{A) Indicações e contraindicações}

Existem três grupos de cardiopatias pediátricas que podem ser consideradas para transplante cardíaco: cardiomiopatias desde o período neonatal até os 18 anos de idade; cardiopatias congênitas, corrigidas ou não, desde o período neonatal até a vida adulta; e pacientes submetidos a transplante desde o período neonatal até os 18 anos de idade ${ }^{293-295}$. 


\section{Diretrizes}

O transplante cardíaco é considerado quando a expectativa de sobrevida é inferior a dois anos, esgotadas as terapêuticas conservadoras, quando existe uma qualidade de vida inaceitável ou ambos.

Alguns aspectos peculiares desse grupo devem ser considerados. Aproximadamente um quarto dos receptores é lactente abaixo de um ano de idade, dos quais dois terços possuem cardiopatias congênitas complexas que necessitam de reconstrução especializada durante o transplante. É importante salientar que o receptor deve ter idade gestacional maior que 36 semanas e peso acima de 2000 g ${ }^{296}$. Além disso, as comorbidades em tais receptores diferem dos adultos.
Existe uma minoria com síndromes genéticas, retardo de desenvolvimento e malformações extracardíacas, que devem ser consideradas do ponto de vista ético ${ }^{295}$.

Apesar dos resultados em longo prazo e dos benefícios que o transplante oferece a pacientes com cardiomiopatia, o objetivo da terapêutica nas cardiomiopatias em pediatria é minimizar e retardar a necessidade de transplante cardíaco em lactentes, crianças e adolescentes ${ }^{297}$.

Na Tabela 69, estão resumidas as recomendações para transplante cardíaco em pacientes pediátricos com cardiomiopatia e cardiopatia congênita ${ }^{293}$.

\section{Tabela 69 - Recomendações para indicação de transplante cardíaco em pacientes pediátricos}

\begin{tabular}{|c|c|c|}
\hline Classe de Recomendação & Indicações & Nível de Evidência \\
\hline \multirow{5}{*}{ Classe I } & $\begin{array}{l}\text { IC estágio D associada à disfunção do ventrículo sistêmico em cardiomiopatia ou cardiopatia congênita, } \\
\text { previamente corrigida ou paliada; }\end{array}$ & $\mathrm{B}$ \\
\hline & $\begin{array}{l}\text { IC estágio C associada à disfunção do ventrículo sistêmico em cardiomiopatia ou cardiopatia congênita, } \\
\text { previamente corrigida ou paliada, quando houver importante retardo de crescimento atribuível à IC; }\end{array}$ & C \\
\hline & $\begin{array}{l}\text { IC associada à morte súbita ressuscitada e/ou arritmias com risco de morte súbita não responsivas à } \\
\text { terapêutica medicamentosa ou CDI; }\end{array}$ & C \\
\hline & IC estágio C em cardiomiopatia restritiva associada à HP reversível; & C \\
\hline & $\begin{array}{l}\text { Quando houver indicação de transplante cardíaco, este é factível em pacientes com IRVP }>6 \text { UWood/m² el } \\
\text { ou gradiente transpulmonar }>15 \mathrm{mmHg} \text {, se a administração de inotrópicos ou vasodilatadores pulmonares } \\
\text { reduzir a IRVP para }<6 \text { UWood } / \mathrm{m}^{2} \text { elou o gradiente transpulmonar } a<15 \mathrm{mmHg} \text {. }\end{array}$ & B \\
\hline \multirow{10}{*}{ Classe lla } & IC estágio C em cardiopatias associadas à HAP reversivel com risco de desenvolver elevação da RVP fixa. & C \\
\hline & $\begin{array}{l}\text { Condições anatômicas e fisiológicas que possam piorar a história natural das cardiopatias congênitas com } \\
\text { ventrículo único funcional como: }\end{array}$ & \multirow{4}{*}{ C } \\
\hline & Estenoses ou anomalias complexas de anomalias de coronárias; & \\
\hline & Estenose ou regurgitação de moderada a grave das valvas atrioventriculares ou semilunares; & \\
\hline & Disfunção ventricular grave. & \\
\hline & $\begin{array}{l}\text { Condições anatômicas e fisiológicas que pioram a história natural das cardiopatias congênitas previamente } \\
\text { corrigidas ou paliadas e IC estágio C: }\end{array}$ & \multirow{5}{*}{ C } \\
\hline & HAP e risco de desenvolver elevação da RVP fixa e irreversível contraindicando transplante no futuro; & \\
\hline & $\begin{array}{l}\text { Regurgitação aórtica ou de valva atrioventricular sistêmica importantes não passíveis de correção } \\
\text { cirúrgica; }\end{array}$ & \\
\hline & Dessaturação arterial não passível de correção cirúrgica; & \\
\hline & Enteropatia perdedora de proteína apesar da terapêutica otimizada. & \\
\hline \multirow{4}{*}{ Classe Ilb } & História de uso recente de drogas ilícitas, tabaco ou abuso de bebidas alcoólicas; & $\mathrm{B}$ \\
\hline & $\begin{array}{l}\text { História de distúrbios psicológicos, comportamentais ou cognitivos, inadequado suporte da estrutura familiar, } \\
\text { não aderência a terapêuticas prévias podendo comprometer o resultado do tratamento após o transplante, } \\
\text { desde que haja cuidador responsável; }\end{array}$ & $\mathrm{B}$ \\
\hline & Retransplante nos primeiros 6 meses após primeiro transplante. & B \\
\hline & Infecções prévias por Hepatite B ou C ou HIV. & B \\
\hline \multirow{4}{*}{ Classe III } & $\begin{array}{l}\text { Doença cardíaca associada à doença irreversível em outros órgãos ou quando for parte de doença } \\
\text { multissistêmica irreversível; }\end{array}$ & C \\
\hline & Cardiopatia associada à elevação fixa, severa e irreversível da RVP após testes farmacológicos; & C \\
\hline & Presença de hipoplasia grave das artérias pulmonares centrais ou veias pulmonares; & C \\
\hline & Terapêutica de rotina para qualquer cardiopatia congênita passível de correção cirúrgica convencional. & $\mathrm{B}$ \\
\hline
\end{tabular}

IC - insuficiência cardíaca; RVP - resistência Vascular Pulmonar; HP - hipertensão pulmonar; IRVP - índice de resistência vascular pulmonar. 
Na Tabela 70, estão resumidas as recomendações para transplante cardíaco em adultos com cardiopatia congênita corrigida.

$\mathrm{Na}$ Tabela 71, encontram-se as contraindicações de transplante cardíaco em pacientes pediátricos ${ }^{298,299}$.

B) Acompanhamento ambulatorial pré e pós-transplante cardíaco pediátrico

\section{i. Acompanhamento ambulatorial pré-transplante cardíaco}

A seleção da criança candidata ao transplante cardíaco, a técnica cirúrgica e o manuseio pós-operatório têm possibilitado melhora na sobrevida em curto e longo prazos ${ }^{300,301}$.

A mortalidade em crianças aguardando o transplante tem diminuído na lista de transplante, porém ainda é significativa, especialmente entre crianças dependentes de drogas vasoativas ou suporte mecânico.

O acompanhamento ambulatorial consiste no manuseio da insuficiência cardíaca congestiva, que é possível nos pacientes estáveis e inclui o uso de diuréticos, drogas que diminuam a pós-carga (inibidores da enzima conversora de angiotensina) e betabloqueadores, como succinato de metoprolol e carvedilol, para melhora dos sintomas e função cardíaca em pacientes selecionados ${ }^{302}$. Esses pacientes devem realizar visitas ambulatoriais frequentes para otimização de drogas e para monitoração da função ventricular (Tabela 72 e 73).

Crianças candidatas ao transplante cardíaco que apresentam índice de resistência vascular pulmonar elevada devem considerar o uso de vasodilatadores pulmonares, como oxigênio nasal, sildenafil ou bosentan.

\section{Tabela 70 - Recomendações para transplante cardíaco em adultos com cardiopatia congênita corrigida}

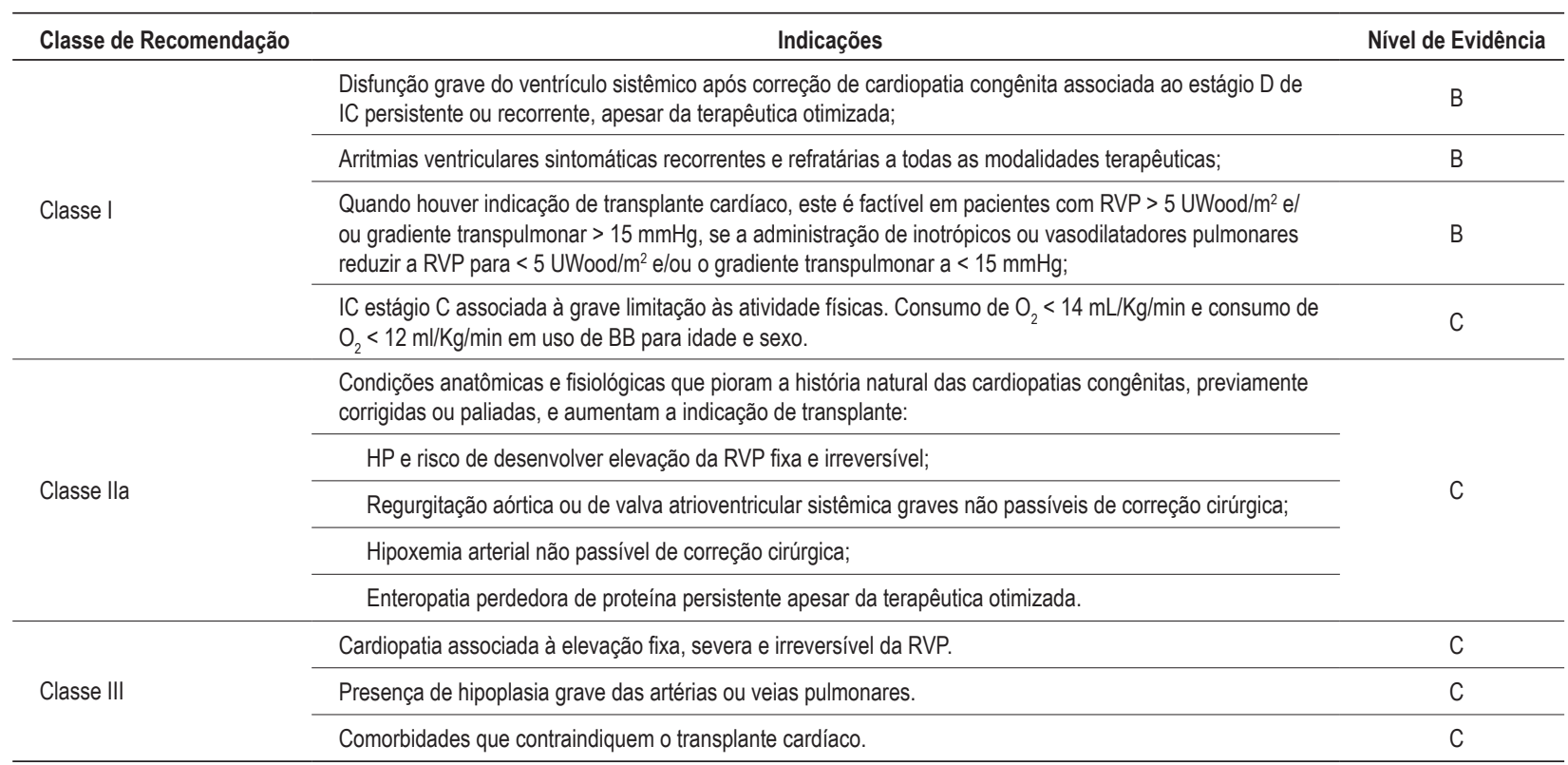

IC - insuficiência cardiaca; RVP - resistência vascular pulmonar; BB - betabloqueador; HP - hipertensão pulmonar; IRVP - índice de resistência vascular pulmonar.

Tabela 71 - Contraindicações para transplante cardíaco em pacientes pediátricos

\begin{tabular}{l}
\hline Sepsis ou outra infecção generalizada não controlada; \\
\hline Hipertensão pulmonar irreversível; \\
\hline Falência de outros órgãos ou de múltiplos órgãos; \\
\hline Síndromes genéticas complexas; \\
\hline Anormalidade significativa do sistema nervoso central; \\
\hline Distúrbio psiquiátrico; \\
\hline Evidência de não aderência ao tratamento; \\
\hline Evidência de impedimento psicossocial familiar intransponível; \\
\hline Prematuridade (<36 semanas de IG); \\
\hline Doença maligna não controlada. \\
\hline
\end{tabular}

Tabela 72 - Terapêutica dietética e medicamentosa nos candidatos a transplante cardíaco

\begin{tabular}{lcc}
\hline $\begin{array}{c}\text { Classe de } \\
\text { Recomendação }\end{array}$ & Indicações & $\begin{array}{c}\text { Nível de } \\
\text { Evidência }\end{array}$ \\
\hline & $\begin{array}{c}\text { Terapêutica otimizada com diuréticos, } \\
\text { IECA e betabloqueadores; }\end{array}$ & B \\
\cline { 2 - 3 } Classe I & Visitas ambulatoriais periódicas; & $\mathrm{C}$ \\
\cline { 2 - 3 } & $\begin{array}{c}\text { Suporte nutricional adequado, restrição } \\
\text { de líquidos e de sódio, correção da } \\
\text { anemia, suplementação de potássio e } \\
\text { magnésio. }\end{array}$ & $\mathrm{C}$ \\
\hline
\end{tabular}

IECA - inibidores da enzima de conversão da angiotensina. 


\section{Diretrizes}

Tabela 73 - Doses de medicamentos para os candidatos ao transplante cardíaco

\begin{tabular}{|c|c|}
\hline Medicamentos & Doses \\
\hline \multicolumn{2}{|c|}{ Inibidores da enzima de conversão da angiotensina } \\
\hline Captopril & $\begin{array}{c}\text { Inicial: 0,1-0,3 mg/kg/dose VO a cada } 8 \text { horas; } \\
\text { Manutenção: } 1-6 \mathrm{mg} / \mathrm{kg} / \mathrm{dia} ; \\
\text { Corrigir para insuficiência renal. }\end{array}$ \\
\hline Enalapril & $\begin{array}{l}0,1 \mathrm{mg} / \mathrm{kg} / \mathrm{dia} \text { VO dose única ou duas vezes ao dia. } \\
\text { Corrigir para insuficiência renal moderada e importante. }\end{array}$ \\
\hline \multicolumn{2}{|r|}{ Betabloqueadores } \\
\hline Carvedilol & $\begin{array}{l}\text { 0,01-2 mg/kg/dia VO dependendo da resposta clínica } \\
\text { e da idade. Menores de } 4 \text { anos, até 0,8-1 mg/kg/dia; } \\
\text { Maiores de } 4 \text { anos, até } 2 \mathrm{mg} / \mathrm{kg} / \mathrm{dia} \text {. } \\
\text { Dose limite: } 50 \mathrm{mg} \text { VO, de } 12 / 12 \text { horas. } \\
\text { Reduzir a dose da digoxina pela metade. }\end{array}$ \\
\hline $\begin{array}{l}\text { Succinato de } \\
\text { Metoprolol }\end{array}$ & $1-5$ mg/kg/dia VO. \\
\hline
\end{tabular}

A monitoração da pressão pulmonar é recomendada em tal situação e pode ser realizada de forma seriada durante o acompanhamento para avaliação do índice de resistência vascular pulmonar ${ }^{303}$.

Outro aspecto importante no acompanhamento dessas crianças é o suporte nutricional que deve ser realizado para que o paciente possa estar preparado para o procedimento cirúrgico e sua recuperação. A restrição de líquidos e de sódio faz parte das recomendações no tratamento da IC. A reposição de sódio é raramente necessária. O potássio deve ser mantido com níveis acima de $3,5 \mathrm{mmol} / \mathrm{L}$ pelo risco de arritmias e fraqueza muscular. $\mathrm{O}$ suplemento de magnésio pode ser necessário (Tabela 72 ). Um regime de reabilitação física deve também fazer parte do tratamento dessas crianças em nível ambulatorial. Em crianças com disfunção ventricular importante, que apresentem risco de embolização, deve ser considerada a anticoagulação.

Em decorrência da caquexia, essas crianças podem apresentar anemia grave, que é normalmente tolerável, sendo que o uso profilático de eritropoetina pode reduzir a necessidade de hemoderivados. Quando a transfusão não pode ser evitada, os derivados de sangue a serem administrados devem ser lavados e irradiados. Em crianças com IC avançada, pode ocorrer deterioração de outros órgãos como fígado e rins. As enzimas hepáticas e os níveis de ureia e creatinina plasmáticos irão refletir o grau de comprometimento desses órgãos em consequência do quadro clínico avançado.

As imunizações devem ser realizadas de acordo com o calendário de imunizações (Tabela 74). A imunização para varicela não é recomendada para crianças menores de um ano de idade devido ao risco potencial da doença com manifestações clínicas graves nesta faixa etária ${ }^{304}$.

A avaliação específica pré-transplante deve incluir ecocardiograma, radiologia de tórax, eletrocardiograma, medida de $\mathrm{VO}_{2}$ por ergoespirometria quando possível, exames laboratoriais incluindo hemograma completo, bioquímica, perfil hepático e renal, perfil lipídico, urina I,
Tabela 74 - Imunizações pré e pós-transplante cardíaco

\begin{tabular}{|c|c|c|}
\hline $\begin{array}{l}\text { Classe de } \\
\text { Recomendação }\end{array}$ & Indicação & $\begin{array}{l}\text { Nível de } \\
\text { Evidência }\end{array}$ \\
\hline \multirow{3}{*}{ Classe I } & $\begin{array}{l}\text { Pré-transplante: calendário vacinal } \\
\text { do ministério da Saúde acrescido } \\
\text { das vacinas para H. influenza, } \\
\text { S.pneumoniae, influenza e varicela. }\end{array}$ & B \\
\hline & $\begin{array}{l}\text { Pós-transplante: difteria, tétano, } \\
\text { poliomielite (salk), hemofilos, } \\
\text { pneumococos. Não imunizar com } \\
\text { vacinas com agentes vivos ou } \\
\text { atenuados e evitar vacinas nos } \\
\text { primeiros } 6 \text { meses. }\end{array}$ & C \\
\hline & $\begin{array}{c}\text { Contactantes e familiares imediatos não } \\
\text { devem receber vacina para pólio VO e } \\
\text { devem receber vacina Salk. }\end{array}$ & C \\
\hline Classe Ila & $\begin{array}{l}\text { MMR e varicela para familiares } \\
\text { imediatos e contactantes. }\end{array}$ & $C$ \\
\hline Classe III & $\begin{array}{l}\text { Imunização nas seguintes situações: } \\
\text { febre, episódios de rejeição, convulsões, } \\
\text { reações alérgicas cutâneas e } \\
\text { imunização por MMR, sarampo, varicela } \\
\text { e vacina Sabin. }\end{array}$ & C \\
\hline
\end{tabular}

exame parasitológico de fezes, sorologias para infecções como hepatites, HIV, STORCH, EBV, Chagas, além de tipagem sanguínea e a determinação da magnitude da sensibilização do paciente pré-transplante.

Anticorpos circulantes contra o doador podem resultar em rejeição celular e humoral, bem como falência precoce do enxerto. Nível de anticorpos HLA maior do que 10\% é considerado elevado e compromete os resultados de sobrevida em curto e médio prazos após o transplante. Os pacientes mais suscetíveis a apresentarem painel elevado são aqueles que receberam transfusão prévia, realizaram cirurgia e adolescentes com história de gestação anterior.

A avaliação psicossocial fornece informações sobre a adequação da família frente ao transplante como procedimento. O suporte psicossocial é vital quando a criança torna-se candidata ao transplante cardíaco, pois há uma necessidade de reestruturação da rotina familiar em decorrência do acompanhamento ambulatorial.

\section{ii. Acompanhamento ambulatorial pós-transplante cardíaco}

Os pacientes submetidos ao transplante cardíaco devem ser avaliados conforme critério médico, visitas ambulatoriais, ecocardiograma, eletrocardiograma, radiografia de tórax, dosagem de inibidor de calcineurina (ciclosporina ou tacrolimus), dosagem de eletrólitos, enzimas hepáticas e hemograma. Realiza-se também a monitoração da sorologia para toxoplasmose, citomegalovírus, sorologia para Epsteinbarr, clearance de creatinina, ultrassonografia de abdome, holter, ecocardiograma com dobutamina, cateterismo cardíaco e biópsia endomiocárdica, quando indicada. Essa monitoração se faz necessária em decorrência das potenciais co-morbidades do transplante propriamente dito, que são: rejeição, infecção, doença coronariana, neoplasia 
e das complicações relacionadas à imunossupressão, que são: nefrotoxicidade, hipertensão arterial sistêmica, hiperlipidemia e litíase biliar. A periodicidade das avaliações ambulatoriais e biópsias endomiocárdicas estão relacionadas na Tabela 75.

Tabela 75 - Periodicidade das revisões ambulatoriais e biópsias

\begin{tabular}{lcc}
\hline Período & Revisão Ambulatorial & Biópsias \\
\hline 0-4 semanas & Semanal com revisão completa*. & $\begin{array}{c}\text { 2 biópsias: com } \\
7 \text { dias e 30 dias }\end{array}$ \\
\hline 4-12 semanas & $\begin{array}{c}\text { Semanal com laboratório/Quinzenal } \\
\text { com revisão completa* }\end{array}$ & Mensais. \\
\hline 3-6 meses & $\begin{array}{c}\text { Quinzenal/Mensal com revisão } \\
\text { completa. }\end{array}$ & Trimestral. \\
\hline 6-12 meses & Mensal com revisão completa*. & Trimestral. \\
\hline$>12$ meses & Trimestral com revisão completa*. & Anual. \\
\hline
\end{tabular}

*Revisão completa: ECG, ecocardiograma, hemograma, leucograma, eletrólitos, niveis séricos de imunossupressor.

C) Rejeição

\section{i. Diagnóstico}

A rejeição é uma das principais complicações do transplante cardíaco pediátrico, tendo sido relatada como a principal causa de óbito nos primeiros cinco anos após o transplante ${ }^{305}$. O seu diagnóstico precoce e o manuseio adequado são fundamentais para uma evolução clínica favorável. Na população pediátrica, o diagnóstico de rejeição tem sido feito por uma combinação de sinais e sintomas clínicos, testes não invasivos e/ou biópsia endomiocárdica, utilizando os critérios da Sociedade Internacional de Transplante Cardíaco e Pulmonar (ISHLT) (Tabela 76) ${ }^{296}$.

\section{ii. Tratamento}

O tratamento da rejeição deve ser direcionado para a etiologia subjacente, assim como para a gravidade do quadro baseado nos achados clínicos e patológicos. De uma maneira geral, rejeições agudas celulares leves, assintomáticas (ISHLT

\section{Tabela 76 - Métodos para avaliação de rejeição na faixa etária} pediátrica

Sinais clínicos: alterações de comportamento, febre, anorexia, arritmias, IC.
ECG: percentagem de queda do somatório do complexo QRS em todas as
derivações.
Ecocardiograma: aumento da espessura do septo e parede posterior,
aumento das dimensões, aparecimento de derrame pericárdico, insuficiência
de valvas atrioventriculares e disfunção ventricular.
Cintilografia Miocárdica com Gálio 67.
Dosagem de BNP.
Biópsia Endomiocárdica $\geq 2 R$ pelos critérios da ISHL.

ISHLT - Sociedade Internacional de Transplante Cardíaco e Pulmonar.
- 1R) não requerem tratamento pela alta taxa de resolução espontânea e pela ausência de associação com sobrevida em longo prazo e doença vascular do enxerto ${ }^{306}$.

Entretanto, biópsias evidenciando rejeição celular moderada (ISHLT $\geq 2 \mathrm{R}$ ) devem ser tratadas com intensificação da imunossupressão (Tabela 77) ${ }^{306}$. O tratamento da rejeição humoral inclui os mesmos esquemas utilizados para tratamento da rejeição celular, com doses elevadas de corticoides e agentes linfocitolíticos (Tabela 78). Adicionalmente, utiliza-se imunoglobulina endovenosa e/ou plasmaférese para remoção dos anticorpos circulantes ${ }^{127,307}$. Terapias específicas para atingir células B, incluindo ciclofosfamida, micofenolato e rituximab têm sido utilizadas ${ }^{116}$. Episódios de rejeição com comprometimento hemodinâmico têm sido associados a prognósticos desfavoráveis ${ }^{308}$ e requerem imunossupressão ampla, incluindo os tratamentos para rejeição celular e humoral.

\section{Tabela 77 - Terapia da rejeição celular aguda na faixa etária pediátrica}

\begin{tabular}{|c|c|c|}
\hline $\begin{array}{l}\text { Classe de } \\
\text { Recomendação }\end{array}$ & Indicações & $\begin{array}{l}\text { Nível de } \\
\text { Evidência }\end{array}$ \\
\hline \multirow{5}{*}{ Classe I } & Pulsoterapia com metilprednisolona; & C \\
\hline & $\begin{array}{l}\text { Globulina antitimocitária em casos de } \\
\text { alteração hemodinâmica ou rejeição } \\
\text { refratária*; }\end{array}$ & C \\
\hline & $\begin{array}{l}\text { Terapia citolítica em casos de alteração } \\
\text { hemodinâmica ou rejeição refratária; }\end{array}$ & C \\
\hline & $\begin{array}{l}\text { Conversão de ciclosporina por } \\
\text { tacrolimus na rejeição refratária, } \\
\text { recorrente ou persistente; }\end{array}$ & c \\
\hline & $\begin{array}{l}\text { Conversão de azatioprina por } \\
\text { micofenolato na rejeição refratária, } \\
\text { recorrente ou persistente. }\end{array}$ & C \\
\hline \multirow{2}{*}{ Classe Ilb } & $\begin{array}{l}\text { Metotrexate em rejeições persistentes } \\
\text { ou recorrentes; }\end{array}$ & C \\
\hline & $\begin{array}{l}\text { Irradiação linfoide total (rejeições } \\
\text { refratárias extremas). }\end{array}$ & C \\
\hline
\end{tabular}

*Rejeição refratária é definida pela presença de rejeição após dois ou três episódios consecutivos tratados com corticosteroides.

Tabela 78 - Terapia da rejeição humoral aguda na faixa etária pediátrica

\begin{tabular}{lcc}
\hline \multirow{2}{*}{$\begin{array}{c}\text { Classe de } \\
\text { Recomendação }\end{array}$} & Indicações & $\begin{array}{c}\text { Nível de } \\
\text { Evidência }\end{array}$ \\
\hline & Pulsoterapia com metilprednisolona; & $\mathrm{C}$ \\
\cline { 2 - 3 } Classe I & Globulina antitimocitária; & $\mathrm{C}$ \\
\cline { 2 - 3 } & Plasmaférese; & $\mathrm{C}$ \\
\cline { 2 - 3 } & Ciclofosfamida; & $\mathrm{C}$ \\
\cline { 2 - 3 } & Micofenolato; & $\mathrm{C}$ \\
\hline Classe Ila & Imunoglobulina intravenosa. & $\mathrm{C}$ \\
\hline
\end{tabular}




\section{Diretrizes}

\section{iii. Imunossupressão}

Os esquemas de imunossupressão são geralmente definidos como de indução, manutenção e rejeição. A indução terapêutica moderna pode ser definida como terapia imunossupressora profilática no período perioperatório que não é utilizada no regime de imunossupressão de manutenção ${ }^{296,309}$. Dados obtidos de transplantes cardíacos pediátricos e de outros órgãos sólidos apoiam o uso da terapia de indução com agentes citolíticos para diminuir a incidência de rejeição precoce

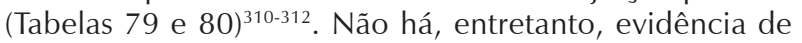
seu efeito na sobrevida ou na incidência de doença vascular do enxerto. O relatório do registro da ISHLT mostra que a proporção de pacientes com transplante cardíaco na faixa etária pediátrica que recebeu terapia de indução vem aumentando nos últimos 6 anos, e encontra-se atualmente em mais de $60 \%{ }^{305}$.

Diferentes classes de drogas são utilizadas para imunossupressão inicial e de manutenção em crianças (Tabela 81 e 82). Os esquemas iniciais mais utilizados são compostos pela associação de corticosteroides, inibidores da calcineurina e agentes antiproliferativos ${ }^{313}$. Entretanto, o papel do corticosteroide associado ao esquema de imunossupressão, principalmente em transplante pediátrico, ainda não está bem esclarecido. A sua administração em longo prazo pode

\section{Tabela 79 - Terapia de indução com agentes citolíticos na faixa} etária pediátrica

\begin{tabular}{|c|c|c|}
\hline $\begin{array}{l}\text { Classe de } \\
\text { Recomendação }\end{array}$ & Indicações & $\begin{array}{l}\text { Nível de } \\
\text { Evidência }\end{array}$ \\
\hline \multirow[b]{2}{*}{ Classe Ila } & Anticorpos Policlonais & \multirow[b]{2}{*}{ C } \\
\hline & $\begin{array}{l}\text { Globulina antitimocitária coelho } \\
\text { (Timoglobulina). }\end{array}$ & \\
\hline \multirow{5}{*}{ Classe Illb } & $\begin{array}{l}\text { Anticorpos Anti-receptores de Citocinas } \\
\text { - Anti-IL-2R: }\end{array}$ & \multirow{3}{*}{ C } \\
\hline & Basiliximab; & \\
\hline & Daclizumab. & \\
\hline & Anticorpos Monoclonais: Anti-CD3. & \multirow{2}{*}{ C } \\
\hline & OKT3. & \\
\hline
\end{tabular}

Tabela 80 - Doses de imunossupressores utilizados para terapia de indução na faixa etária pediátrica

\begin{tabular}{|c|c|}
\hline \multicolumn{2}{|l|}{ Anticorpos policlonais } \\
\hline $\begin{array}{l}\text { Globulina antitimocitária coelho } \\
\text { (Timoglobulina) }\end{array}$ & 1,5 mg/kg/dia por 3-7 dias PO. \\
\hline \multicolumn{2}{|c|}{ Anticorpos anti-receptores de citocinas - Anti-IL-2R } \\
\hline Basiliximab & $12 \mathrm{mg} / \mathrm{m}^{2} /$ dose no dia 0 e $4 \mathrm{PO}$. \\
\hline Daclizumab & $\begin{array}{c}1 \mathrm{mg} / \mathrm{kg} / \mathrm{dose} 5 \text { doses em intervalos } \\
\text { de } 14 \mathrm{~d} \text { - iniciar dia } 0 \text { PO. }\end{array}$ \\
\hline \multicolumn{2}{|l|}{ Anticorpos Monoclonais - Anti-CD3 } \\
\hline OKT3 & $\begin{array}{c}0,2 \mathrm{mg} / \mathrm{kg} / \mathrm{dia} \text { por } 7-14 \mathrm{dias} \\
\text { Maiores de } 12 \text { anos - } 5 \mathrm{mg} / \mathrm{dia} \text {. }\end{array}$ \\
\hline
\end{tabular}

Tabela 81 - Drogas imunossupressoras utilizadas para terapia de manutenção na faixa etária pediátrica

\begin{tabular}{llc}
\hline \multirow{2}{*}{$\begin{array}{l}\text { Classe de } \\
\text { Recomendação }\end{array}$} & \multicolumn{1}{c}{ Indicações } & $\begin{array}{c}\text { Nível de } \\
\text { Evidência }\end{array}$ \\
\cline { 1 - 2 } Classe I & Inibidores da Calcineurina: & C \\
\cline { 2 - 3 } & Ciclosporina; & \\
\cline { 2 - 3 } Classe I & Tacrolimus. & $\mathrm{C}$ \\
\cline { 2 - 3 } & Agentes Antiproliferativos: & $\mathrm{C}$ \\
\hline Classe Ila & Corticosteroides. & $\mathrm{C}$ \\
\hline Classe IIb & Inibidores do sinal de proliferação. & \\
\hline
\end{tabular}

Tabela 82 - Doses das drogas imunossupressoras utilizadas para terapia de manutenção na faixa etária pediátrica

\begin{tabular}{|c|c|}
\hline \multicolumn{2}{|c|}{ Inibidores da Calcineurina } \\
\hline \multirow[b]{2}{*}{ Ciclosporina } & $\begin{array}{c}\text { 0,1-0,2 mg/kg/dia EV contínua no PO imediato até } \\
\text { transição para via oral. }\end{array}$ \\
\hline & $\begin{array}{l}\text { 10-20 } \mathrm{mg} / \mathrm{kg} / \mathrm{dia} 12 / 12 \mathrm{~h} \text { e de } 8 / 8 \mathrm{~h} \text { em lactentes, nível } \\
\text { sérico entre } 300-400 \mathrm{ng} / \mathrm{ml} \text { até o } 1^{\circ} \text { ano, e, depois, } \\
\text { entre } 150-200 \mathrm{ng} / \mathrm{ml} \text {, conforme os episódios de rejeição } \\
\text { e avaliação dos efeitos colaterais da droga. }\end{array}$ \\
\hline Tacrolimus & $\begin{array}{c}\text { 0,1-0,3 } \mathrm{mg} / \mathrm{kg} / \mathrm{dia} 12 / 12 \mathrm{~h} \text { e de } 8 / 8 \mathrm{~h} \text { em lactentes, } \\
\text { mantendo-se nível sérico entre } 10-15 \mathrm{ng} / \mathrm{ml} \text { no primeiro } \\
\text { ano e } 5-10 \mathrm{ng} / \mathrm{ml} \text { após. }\end{array}$ \\
\hline \multicolumn{2}{|c|}{ Agentes Antiproliferativos } \\
\hline $\begin{array}{l}\text { Micofenolato } \\
\text { mofetil }\end{array}$ & $20-40$ mg/kg/dia 12/12h. \\
\hline Azatioprina & $\begin{array}{c}3 \mathrm{mg} / \mathrm{kg} / \mathrm{dia} \text { no } 1^{\circ} \text { ano e } 1 \mathrm{mg} / \mathrm{kg} / \mathrm{dia} \text { após, mantendo-se } \\
\text { leucócitos maior do que } 4.000 \text {. }\end{array}$ \\
\hline \multicolumn{2}{|l|}{ Corticosteroides } \\
\hline Prednisona & $\begin{array}{l}1 \mathrm{mg} / \mathrm{kg} / \mathrm{dia} \text { com diminuição progressiva até } 0,1 \mathrm{mg} / \\
\mathrm{kg} / \mathrm{dia} .\end{array}$ \\
\hline \multicolumn{2}{|c|}{ Inibidores do sinal de proliferação } \\
\hline Sirolimus & $1 \mathrm{mg} / \mathrm{m}^{2} / \mathrm{dia}$, nível sérico 4-10 ng/ml. \\
\hline
\end{tabular}

levar a efeitos adversos graves, como atraso no crescimento e risco aumentado de processos infecciosos, levando a um crescente interesse na redução progressiva da dose ou sua completa suspensão ${ }^{314-316}$. O aumento do uso de tacrolimus como inibidor da calcineurina e a substituição da azatioprina como agente antiproliferativo pelo micofenolato é a tendência atual na maioria dos centros mundiais. Os inibidores do sinal de proliferação (everolimus e sirolimus) ainda são pouco utilizados nessa população ${ }^{305}$.

Um dos principais desafios no transplante cardíaco consiste na busca de modelos ideais de imunossupressão. Embora muitos pesquisadores estejam empenhados no desenvolvimento de novas drogas, os esquemas de imunossupressão atuais ainda apresentam sérias limitações, que incluem: falta de especificidade, dificuldade na redução da frequência da doença coronariana, presença de toxicidade significativa, 
aumento do risco de infecções por agentes oportunistas e aparecimento de tumores ${ }^{317}$. Tais fatores devem levar à progressiva individualização do tratamento imunossupresor.

\section{D) Técnicas cirúrgicas - particularidades na criança}

\section{i. Técnica cirúrgica}

Nos casos de cardiomiopatia, a técnica utilizada se assemelha aos casos de transplante em adultos, podendo ser utilizada a técnica convencional, descrita por Shumway e cols. ${ }^{318}$, ou a técnica bicaval, descrita por Webb e cols. ${ }^{171}$. Em ambas as técnicas, há necessidade de extremo cuidado na adequação e compatibilização das estruturas do coração doador em relação às estruturas do receptor, pelo fato de que, na maioria dos casos, o peso do doador é maior que o do receptor (até três vezes), e comumente há diferenças entre as dimensões e calibres dos vasos a serem anastomosados (Tabela 83).

Alguns casos de cardiopatias congênitas necessitam de programação prévia com relação à técnica a ser empregada na captação, como nos casos de distorções e estenoses das artérias pulmonares do receptor, em que o coração doador deve ser preparado com extensos segmentos de artérias pulmonares. Nos casos de operações prévias tipo Fontan, o coração doador deve conter longos segmentos de veia cava superior, bem como de artéria pulmonar direita, para facilitar a reconstrução destas estruturas durante o transplante ${ }^{319}$.

Outra situação peculiar são casos de situs inversus, em que o coração doador deve conter longos segmentos de aorta, artérias pulmonares, e, sobretudo, veia cava superior e veia inominada, para que se criem prolongamentos dos vasos a fim de facilitar as anastomoses com estruturas contralaterais ${ }^{320}$. Nos casos de hipoplasia do coração esquerdo, longo segmento de aorta, contendo o arco e seus ramos, deve ser preparado para que se possa realizar a reconstrução da aorta no receptor ${ }^{320}$. Outra situação peculiar se refere a casos de anomalias de retorno venoso, tanto sistêmico como pulmonar, em que se deve individualizar o reparo a ser feito. Cuidado adicional precisa ser tomado nos casos de presença de shunt sistêmico pulmonar ou canal arterial persistente, que precisam

\section{Tabela 83 - Recomendações técnicas para transplante em cardiopatias congênitas}

\begin{tabular}{lc}
\hline Característica do receptor & Técnica para o doador \\
\hline $\begin{array}{l}\text { Estenose ou hipoplasia de tronco e } \\
\text { ramos arteriais pulmonares. }\end{array}$ & $\begin{array}{c}\text { Captar o coração doador com } \\
\text { segmentos longos de tronco e } \\
\text { artérias pulmonares. }\end{array}$ \\
\hline $\begin{array}{l}\text { Pós-operatório de operações tipo } \\
\text { Fontan. }\end{array}$ & $\begin{array}{c}\text { Captar coração com veia cava } \\
\text { superior e artéria pulmonar direita. }\end{array}$ \\
\hline $\begin{array}{l}\text { Situs ambíguos, com anomalias de } \\
\text { drenagem venosa. }\end{array}$ & $\begin{array}{c}\text { Captar coração com átrio esquerdo } \\
\text { e veias cava superior, inferior e veia } \\
\text { inominada. }\end{array}$ \\
\hline $\begin{array}{l}\text { Situs inversus. } \\
\text { Cardiopatia congênita complexa coração doador com } \\
\text { com hipoplasia do arco aórtico. }\end{array}$ & $\begin{array}{c}\text { segmentos mais longos de aorta, } \\
\text { artérias pulmonares e veias cava } \\
\text { superior e inferior e veia inominada. }\end{array}$ \\
\hline
\end{tabular}

ser ligados, antes do início da CEC, para evitar desvio e roubo de sangue para os pulmões.

A preservação miocárdica é feita mediante injeção de solução cardioplégica cristaloide hipotérmica injetada na aorta ascendente, com infusão por gravidade, com pressão baixa após descompressão das câmaras direitas e esquerdas. Para os transportes de longa distância, com tempo de isquemia prolongado, novas doses de solução cardioplégica (solução cristaloide ou sanguínea) podem ser infundidas durante o implante do coração (Tabela 84).

A captação simultânea de coração e pulmão deve ser realizada seguindo critérios anatômicos pré-estabelecidos entre as equipes captadoras, evitando-se problemas relacionados à falta de tecido atrial ou vascular para algum dos grupos.

\section{E) 0 doador para crianças}

Como os receptores de transplante cardíaco pediátricos variam desde neonatos até adultos jovens, o doador também deverá ter características apropriadas para cada faixa etária.

A avaliação do doador deve incluir tipagem sanguínea, peso e altura, determinação da causa da morte, do tempo desde o diagnóstico de morte cerebral e a retirada dos órgãos, história médica pregressa, eletrocardiograma, ecocardiograma, história de infecções prévias e atuais, utilização de outros órgãos, principalmente os pulmões, quando houver necessidade de reconstruções mais complexas ${ }^{321}$. Na Tabela 85, encontram-se os critérios para utilização do doador pediátrico ${ }^{296,321 .}$

\section{Tabela 84 - Recomendações para retirada e preservação do órgão transplantado}

O coração removido deve ser colocado dentro de sacos plásticos estéreis em solução salina gelada e transportado em recipiente térmico com gelo;

A preparação do doador e do receptor deve ser cuidadosamente sincronizada com o objetivo de diminuir isquemia fria do órgão, considerando adequada logística de transporte para cada caso;

Infusão de soluções cardioplégicas e armazenamento frio para preservação miocárdica para o transplante;

Evitar tempo de isquemia fria superior a 4 horas.

\section{Tabela 85 - Critérios para utilização de doador pediátrico}

Preencher critérios de morte encefálica de acordo com a idade;

Compatibilidade ABO;

Doador com peso até três vezes maior do que o receptor;

Ecocardiograma para avaliar função ventricular e para excluir anomalias estruturais;

Cardiopatia estrutural de mínima repercussão não desqualifica o doador

Estável hemodinamicamente com:

Dopamina $<10 \mu \mathrm{g} / \mathrm{Kg} / \mathrm{min}$;

Adrenalina ou Noradrenalina $<0,1 \mu \mathrm{g} / \mathrm{Kg} / \mathrm{min}$;

Vasopressina 0,5-4 U/h.

Peso do doador abaixo de $20 \%$ do receptor com RVP aumentada pode ser desfavorável.

$R V P$ - resistência vascular pulmonar. 


\section{Diretrizes}

\section{O papel das centrais de captação e avaliação do doador}

\section{A) Estratégias para confirmação do potencial doador}

\section{i. Critérios de morte encefálica}

Todo o processo de doação e alocação de órgãos humanos deve atender integralmente às determinações da Portaria n. 3.407, de 05/08/1998, do Ministério da Saúde, que regulamenta as disposições da Lei n. 9.434, de 04/02/1997, e do Decreto n. 2.268, de 30/07/1997. O Conselho Federal de Medicina, no uso das atribuições conferidas pela Lei n. 3.268, de 30/09/1957, regulamentada pelo Decreto n. 44.045, de 19/07/1958 e, considerando que a lei n. 9.434, de 04/02/1997, determina em seu artigo 3o que compete ao CFM definir os critérios para diagnóstico de morte encefálica.

Os critérios de morte encefálica evoluíram (Tabela 86). Mollaret e Goulon ${ }^{322}$ introduziram o termo coma dépassé em pacientes inconscientes, sem reflexos de tronco cerebral ou respiratório e sem atividade eletroncefalográfica. Em 1968, uma comissão da Harvard Medical Schoo/ ${ }^{323}$ redefiniu esses critérios, ressaltando danos ao tronco cerebral como componente crítico.

Exame clínico deve se prender à confirmação do coma, à ausência de reflexos do tronco cerebral e apneia, com intervalo de 6 horas de observação, entre os dois exames. $\mathrm{O}$ exame clínico em crianças segue os mesmos princípios que o nos adultos ${ }^{324}$.

A confirmação de morte encefálica exige, além de cuidadoso exame neurológico, o reconhecimento da causa do coma, da sua irreversibilidade, o afastamento de sinais clínicos neurológicos inconclusivos, reconhecimento de possíveis fatores de confusão: distúrbio hidroeletrolítico, metabólico, hipotermia grave $\left(<32^{\circ} \mathrm{C}\right)$, hipotensão, sinais

\section{Tabela 86 - Critérios clínicos de morte encefálica em adultos e} crianças

\begin{tabular}{l}
\hline Determinação da etiologia do coma; \\
\hline Ausência de respostas motoras; \\
\hline Pupilas sem resposta a estímulo luminoso, médio-fixas e dilatadas (4-6 mm); \\
\hline Ausência de reflexos córneo-palpebral; \\
\hline Ausência de resposta a estímulo calórico; \\
Ausência de reflexo de tosse; \\
\hline Ausência de reflexo óculo-cefálico; \\
Ausência de drive respiratório com PaCO 2 de $60 \mathrm{~mm} \mathrm{Hg} \mathrm{ou} 20 \mathrm{mmHg}$ acima \\
do valor basal; \\
\hline Intervalo mínimo entre duas avaliações clínicas, de acordo com a idade do \\
potencial doador: \\
7d-2m de idade - $48 \mathrm{~h} ;$ \\
2m-1a de idade - $24 \mathrm{~h} ;$ \\
1a-2a de idade - $12 \mathrm{~h} ;$ \\
$>$ 2a de idade - $6 \mathrm{~h}$.
\end{tabular}

de intoxicação por fármacos, drogas ou bloqueadores neuromusculares ${ }^{324-326}$.

\section{ii. Exames de avaliação}

Os testes confirmatórios de morte encefálica são essenciais quando existe dúvida sobre os achados clínicos, podendo estabelecer que o paciente não tenha perfusão cerebral. Embora o diagnóstico de morte encefálica continue sendo clínico, os testes confirmatórios são obrigatórios em qualquer faixa etária (Tabela 87).

Abaixo, seguem os testes realizados para confirmação de morte encefálica ${ }^{324,326}$.

\section{a) Angiografia cerebral}

Ausência de fluxo intracerebral bilateral nas artérias carótidas e vertebrais. O fluxo nas carótidas externas pode estar patente.

\section{b) Eletroencefalograma}

Deve demonstrar falta de reatividade a estímulos somatossensitivos ou audiovisuais.

\section{c) Doppler transcraniano}

Deve demonstrar falta de fluxo diastólico ou sistólico reverberantes, ou pequenos picos no início da sístole.

\section{d) Cintilografia cerebral (tecnécio 99m Tc hexametazime)}

Ausência de penetração no parênquima cerebral. Enchimento tardio do seio sagital superior pode ocorrer. Uma imagem estática de 500.000 contagens deve ser obtida em vários momentos: imediatamente, entre 30-60 minutos mais tarde, e com duas horas.

A avaliação do doador deve incluir história médica pregressa, eletrocardiograma e ecocardiograma. A realização de cinecoronariografia com ventriculografia está recomendada em doadores do sexo masculino acima de 45 anos e do sexo feminino acima de 50 anos, principalmente quando a causa do coma encefálico for acidente vascular cerebral.

\section{Tabela 87 - Recomendações de número e intervalo dos testes confirmatórios}

\begin{tabular}{l}
\hline Testes confirmatórios: \\
\hline 7d-2m de idade - 2 EEG (Intervalo 48h); \\
\hline 2m-1ano de idade - 2 EEG (Intervalo 24h); \\
\hline$>1-2$ ano de idade - 1 teste opcional; \\
\hline$>2$ ano de idade - 1 teste. \\
\hline
\end{tabular}

\section{B) Manutenção do doador}

Após a morte encefálica ocorre deficiência de hormônio antidiurético e como resultado o diabetes insipidus. Outras 
alterações como disfunção tireoidiana e hiperglicemia também são descritas. Na presença de diabetes insipidus, é recomendada a administração de desmopressina intranasal 10-20 mcg/dia ${ }^{327}$.

Distúrbios hidroeletrolíticos são comuns, especialmente a hipernatremia. O tratamento da hipernatremia consiste na infusão de volume com solução hipotônica. A infusão de grandes quantidades de soro glicosado pode precipitar hiperglicemia e diurese osmótica. Os níveis glicêmicos devem ser mantidos entre $80-150 \mathrm{mg} / \mathrm{dl}$, às custas de insulina em infusão contínua. Todo fluído deve ser aquecido a $37^{\circ} \mathrm{C}$ para reduzir o risco de hipotermia ${ }^{328}$.

Em vigência de acidose metabólica, deve-se assegurar adequada reposição de volume e hemoderivados, além do controle de temperatura e parâmetros gasimétricos. Deve-se manter $\mathrm{PaO}_{2}>100$ mmHg, $\mathrm{PaCO}_{2}<40 \mathrm{mmHg}$, pH arterial entre 7,35-7,45, hemoglobina $>10 \mathrm{~g} / \mathrm{dl}$. A manutenção da temperatura entre $36-37^{\circ} \mathrm{C}$ pode ser obtida com uso de cobertores térmicos ${ }^{329}$.

Em pacientes euvolêmicos, não responsivos ao uso de drogas vasoativas em altas doses e $\mathrm{FE}<45 \%$, deve-se considerar a presença de disfunção do eixo hipotálamohipófise-adrenal/tireoide e iniciar terapia de reposição de hormônios tireoidianos. Altos níveis de hormônio tireoidiano parecem melhorar a função mitocondrial e reduzir a necessidade de drogas vasoativas (Tabela 88). O esquema proposto consiste em metilpredinisolona $15 \mathrm{mg} / \mathrm{Kg}$ in bolus, triiodotironina $4 \mathrm{mg}$ in bolus e infusão contínua de $3 \mathrm{mg} / \mathrm{h}$, vasopressina-arginina 1 UI in bolus e infusão contínua de 0,5-4 $\mathrm{U} / \mathrm{h}$, ajustado para manter resistência vascular sistêmica (RVS) entre 800-1200 dynes/seg-cm e insulina $10 \mathrm{U}$ (dextrose 50\%) para manter glicemia entre 80-150 mg/dl ${ }^{\mathbf{3 2 7}, \mathbf{3 2 8}}$.

A identificação das causas da hipovolemia e sua adequada correção são cruciais. Em modelos experimentais de morte encefálica, a isquemia medular resulta em desativação do sistema nervoso simpático, cursando com vasodilatação, baixos níveis séricos de catecolaminas e consequente hipotensão ${ }^{328}$.

Ringer com lactato ou solução salina $(0,45 \%)$ devem ser usados como primeira escolha, a fim de evitar a hipernatremia ${ }^{328}$. A hipotensão também pode ser corrigida com reposição de volume. Evita-se que a PVC exceda valores

Tabela 88 - Recomendações para o uso de hormônio tireoidiano no potencial doador

\begin{tabular}{lcc}
\hline $\begin{array}{l}\text { Classe de } \\
\text { Recomendação }\end{array}$ & Indicações & $\begin{array}{c}\text { Nível de } \\
\text { Evidência }\end{array}$ \\
\hline Classe Ila & $\begin{array}{c}\text { Quando volemia e uso de drogas } \\
\text { vasoativas otimizadas por cateter } \\
\text { pulmonar falham em manter } \\
\text { estabilidade hemodinâmica. }\end{array}$ & $\mathrm{C}$ \\
\hline Classe IIb & $\begin{array}{c}\text { Instabilidade hemodinâmica persistente, } \\
\text { apesar de otimização de PVC e drogas } \\
\text { vasoativas. }\end{array}$ & $\mathrm{C}$ \\
\hline Classe III & $\begin{array}{c}\text { Como tratamento inicial em pacientes } \\
\text { com instabilidade hemodinâmica } \\
\text { persistente. }\end{array}$ & $\mathrm{C}$ \\
\hline
\end{tabular}

acima de $12 \mathrm{mmHg}$ para que possa ser mantida adequada oxigenação do paciente ${ }^{329}$. Em geral, pressão arterial sistêmica média (PAM) entre 60-70 mmHg é suficiente, mas o melhor parâmetro para demonstrar que a pressão de perfusão é adequada é a presença de diurese entre 1,5-3 $\mathrm{ml} / \mathrm{kg} / \mathrm{h}^{330}$. Se a diurese for menor do que $1,5 \mathrm{ml} / \mathrm{Kg} / \mathrm{h}$ e a PAM $\geq 80 \mathrm{mmHg}$, deve-se primeiro corrigir a temperatura corporal, a hemoglobina e os parâmetros gasimétricos antes de estimular a diurese ${ }^{329}$. Em pacientes que apresentam PAM $<60 \mathrm{mmHg}$, débito urinário $<1 \mathrm{ml} / \mathrm{Kg} / \mathrm{h}$ e fração de ejeção $<45 \%$ e estão em uso de altas doses de drogas vasoativas, deve-se considerar o uso de cateter da artéria pulmonar para monitoração invasiva (Swan-Ganz). O objetivo é manter a PVC entre 8-10 mmHg, capilar pulmonar entre 8-12 mmHg e PAM > $60 \mathrm{mmHg}$. Nos pacientes com RVS menor do que 800 dyn.seg.cm-5, recomenda-se o uso de vasopressor (Tabela 89) ${ }^{328}$.

Distúrbios da coagulação sanguínea são comuns e hemoderivados sanguíneos são necessários para manter INR $<2$, plaquetas $>80.000 / \mathrm{cm}^{3}$ e hematócrito $>30 \%{ }^{331}$.

Suporte com drogas vasoativas é necessário quando a instabilidade hemodinâmica persiste, apesar de adequado aporte de volume. Entre $70-90 \%$ dos pacientes podem ser manejados com reposição volêmica e baixas doses de vasopressores ${ }^{327}$, porém, quando necessária, a droga vasoativa de escolha é a dopamina ${ }^{328}$. A dopamina mantém a PAM aumentando a frequência cardíaca, a contratilidade cardíaca e, quando utilizada em baixas doses $(2-10 \mu \mathrm{cg} /$ $\mathrm{kg} / \mathrm{min})$, aumenta o fluxo sanguíneo mesentérico ${ }^{327,331}$. A dopamina está contraindicada em pacientes com índice cardíaco normal ou elevado e RVS baixa ${ }^{332}$. Necessidade de doses de dopamina acima de $10 \mu \mathrm{g} / \mathrm{kg} / \mathrm{min}$ indica a associação de outra classe de catecolamina, a escolha aceita é a noradrenalina. Idealmente, deve-se tentar manter doses inferiores a $0,1 \mu \mathrm{g} / \mathrm{kg} / \mathrm{min}$ de noradrenalina e entre $5-10 \mu \mathrm{g} /$ $\mathrm{kg} / \mathrm{min}$ de dopamina ${ }^{328}$.

Estudos sugerem que a manutenção de vasopressor possibilita a redução de infusão da dopamina para 2-3 $\mu \mathrm{g} /$ $\mathrm{kg} / \min ^{329}$. O uso de vasopressor não só melhora a função hemodinâmica, mas também mantém a perfusão renal e a contratilidade cardíaca. No entanto, altas doses de agentes alfa-adrenérgicos devem ser evitadas, pois há evidência

Tabela 89 - Recomendações para cateterização da artéria pulmonar (Swan Ganz) no potencial doador

\begin{tabular}{lcc}
\hline $\begin{array}{l}\text { Classe de } \\
\text { recomendação }\end{array}$ & Indicações & $\begin{array}{c}\text { Nível de } \\
\text { Evidência }\end{array}$ \\
\hline Classe Ila & $\begin{array}{c}\text { Pacientes com } \mathrm{PAM}<60 \mathrm{mmHg} \text { ou } \\
\text { débito urinário }<1 \mathrm{ml} / \mathrm{Kg} / \mathrm{h} \text { ou } \mathrm{FE}<45 \% \\
\text { e em uso de altas doses de drogas } \\
\text { vasoativas. }\end{array}$ & B \\
\hline Classe IIb & $\begin{array}{c}\text { Pacientes com instabilidade } \\
\text { hemodinâmica, para otimização de } \\
\text { volume e uso de drogas vasoativas. }\end{array}$ & $\mathrm{C}$ \\
\hline Classe III & $\begin{array}{c}\text { Pacientes estáveis hemodinamicamente } \\
\text { para otimizar uso de volume. }\end{array}$ & $\mathrm{C}$ \\
\hline
\end{tabular}




\section{Diretrizes}

de que concentrações elevadas de catecolaminas estão relacionadas a dano miocárdico ${ }^{328,331,333}$. As catecolaminas podem reduzir a concentração de ATP na mitocôndria das células musculares, levando a alterações estruturais irreversíveis ${ }^{332}$.

O uso de vasopressina em doses baixas ( $1 \mathrm{U}$ in bolus, $0,5-$ $4 \mathrm{U} / \mathrm{h}$ ) pode ser considerado quando houver instabilidade hemodinâmica apesar de doses de dopamina $>10 \mu \mathrm{g} / \mathrm{kg} / \mathrm{min}$ e noradrenalina $>0,05 \mu \mathrm{g} / \mathrm{kg} / \mathrm{min}^{328,332}$. Além de potencializar a ação vasopressora das catecolaminas, a vasopressina também apresenta um importante papel na manutenção do tônus vasomotor e possibilita a redução de infusão de dopamina e de adrenalina (Tabela 90) ${ }^{332}$.

Infecções graves geralmente contraindicam a doação, no entanto bacteremia não é contraindicação absoluta. Órgãos transplantados de doadores com bacteremia raramente transmitem infecção ${ }^{328,333,334}$. Contraindicação absoluta para o transplante cardíaco deve ser considerada em pacientes portadores de HIV, vírus humano da leucemia de células T (HTLV-1), infecção viral sistêmica (exemplos: rubéola, raiva, adenovírus, enterovírus e parvovírus) e meningoencefalite viral. Citomegalovírus (CMV) não contraindica o transplante cardíaco.

Órgãos de doadores com hepatite B ou C não são aceitos, apesar da exclusão ter sido contestada, uma vez que o risco de contaminação não é sempre o mesmo e está relacionado ao tipo de marcador viral encontrado ${ }^{335}$. Quando HBsAg é positivo no doador, a única possibilidade para o transplante é estado de emergência. Em torno de $50 \%$ dos pacientes positivos para anticorpos para HCV transmitem a doença, no entanto, se os doadores forem HCV PCR positivos, a infecção ocorre em $100 \%^{335}$. Embora estudos sugiram que órgãos de pacientes infectados com hepatite $\mathrm{B}$ ou $\mathrm{C}$ possam ser usados em receptores com o mesmo vírus, existem relatos de superinfecção e reinfecção ${ }^{327,335}$. Pacientes com sorologia positiva para Chagas devem ser excluídos como doadores.

A avaliação sorológica no doador ${ }^{335}$ deve incluir: HIV I e II; vírus humano da leucemia de células T (HTLV-I e II); HBsAg e HBcAg. Se o AntiHBc for positivo solicitar AntiHBc IgM e AntiHBsAb; HCV se positivo, solicitar PCR-HCV; citomegalovírus e Epstein-Barr vírus IgG; toxoplasmose; sorologia para Chagas e VDRL.

\section{Tabela 90 - Recomendações para o uso de vasopressina}

\begin{tabular}{|c|c|c|}
\hline $\begin{array}{l}\text { Classe de } \\
\text { recomendação }\end{array}$ & Indicações & $\begin{array}{l}\text { Nível de } \\
\text { Evidência }\end{array}$ \\
\hline \multirow[t]{2}{*}{ Classe lla } & $\begin{array}{c}\text { Instabilidade hemodinâmica, em } \\
\text { pacientes com FE > 45\% e dopamina }> \\
10 \mu \mathrm{g} / \mathrm{kg} / \text { min e noradrenalina }>0,05 \mu \mathrm{g} / \\
\mathrm{kg} / \mathrm{min} \text { e RVS inferior a } 800 \mathrm{dyn} / \mathrm{min} \text {. }\end{array}$ & C \\
\hline & $\begin{array}{c}\text { Pacientes com FE }<45 \% \text { e dopamina }> \\
10 \mu \mathrm{g} / \mathrm{kg} / \mathrm{min} \text { e adrenalina/noradrenalina } \\
>0,1 \mu \mathrm{g} / \mathrm{kg} / \mathrm{min} .\end{array}$ & C \\
\hline Classe III & $\begin{array}{l}\text { Pacientes com baixas doses de drogas } \\
\text { vasoativas independente da fração de } \\
\text { ejeção. }\end{array}$ & C \\
\hline
\end{tabular}

C) Atuação das organizações de procura de órgãos (OPO) e alocação de órgãos

O Sistema Nacional de Transplante (SNT) centraliza a atividade de Captação e Transplantação de Órgãos, tendo, em cada estado, as Centrais de Notificação, Captação e Distribuição de Órgãos (CNCDO), as quais, por sua vez, coordenam as atividades da Organização de Procura de Órgãos (OPO), sendo esta responsável pela identificação, captação e viabilização de doadores para transplante de órgãos, em áreas geográficas pré-estabelecidas ${ }^{336}$.

Estão envolvidas as etapas de confirmação de potencial doador, estado clínico como doador de coração, manutenção adequada das condições hemodinâmicas e metabólicas e estabelecimento de logística para realização de transplante ${ }^{337}$.

As vias de identificação de potenciais doadores pela OPO são: a notificação passiva pelo médico assistente e a busca ativa pela visita de representantes da OPO às UTIs, procurando identificar o paciente em coma encefálico, devendo ter estrutura administrativa completa em funcionamento integral ${ }^{338}$. Sua atuação se faz presente: na confirmação de morte encefálica, compatibilidade $\mathrm{ABO}$, determinação do estado clínico do doador, notadamente do coração, descartando as contraindicações; na manutenção das condições hemodinâmicas do ponto de vista clínicolaboratorial; na remoção e alocação do órgão levando em conta as variáveis logísticas pertinentes, e que o coração é o mais sensível dos órgãos sólidos, não permitindo períodos isquêmicos prolongados, por isso devendo ser o primeiro a ser retirado ${ }^{339}$.

\section{D) Abordagem multidisciplinar do potencial doador}

Define-se processo de doação-transplante como o conjunto de ações que são capazes de transformar um potencial doador (PD) em doador efetivo até a realização do transplante: identificação, avaliação e manutenção do $\mathrm{PD}$, entrevista familiar, envio de informações à Central de Notificação, Captação e Distribuição de Órgãos (CNCDO), retirada de órgãos/tecidos e entrega do corpo à família do $\mathrm{PD}^{340,341}$

Em 2005, a Portaria n. 1752/GM determinou a constituição das Comissões Intrahospitalares de Doação de Órgãos e Tecidos para Transplante (CIHDOTT) em hospitais públicos, privados e filantrópicos com mais de 80 leitos e, desde então, passaram a ter papel importante no processo doação-transplante.

Em 2006, foi aprovado Regulamento Técnico para estabelecer as atribuições e deveres das CIHDOTT, bem como a obrigatoriedade do coordenador da comissão possuir certificação, com mínimo de 24 horas, através de curso ministrado pelo Sistema Nacional de Transplantes (SNT) ou pelas $\mathrm{CNCDOs}^{342}$.

Assim, preconiza-se que membros da equipe multiprofissional (médicos, enfermeiros, psicólogos, assistentes sociais, fisioterapeutas e nutricionistas) executores das etapas do processo, devam possuir a referida certificação ou pós-graduação Lato Sensu que contemple as diretrizes já mencionadas. 


\section{i. Identificação de potencial doador}

Define-se potencial doador como o indivíduo em morte encefálica, excluídas contraindicações que possam representar algum risco aos receptores ${ }^{343}$.

A identificação de potenciais doadores deve ser feita através da busca ativa: visitas a Unidades de Terapia Intensiva, pronto-socorros e centros cirúrgicos (recuperação pósanestésica $)^{343,344}$. Considerar pacientes em morte encefálica como possíveis doadores de órgãos e tecidos e pacientes que evoluíram com parada cardíaca irreversível como possíveis doadores de tecidos. Para tal, recomenda-se visita diária aos setores que possam informar o número de óbitos ocorridos.

\section{ii. Avaliação do potencial doador}

O prontuário médico deve ser criteriosamente avaliado e, quando corretamente preenchido, deve fornecer dados de extrema relevância como: história do paciente, antecedentes familiares e exames complementares. Deve-se também solicitar parecer clínico do médico que acompanha o paciente ${ }^{345}$.

Verificar se o Termo de Declaração de Morte Encefálica está corretamente preenchido, sem rasuras, atentando para a causa do coma e ausência de hipotermia, bem como uso de drogas depressoras do Sistema Nervoso Central.

\section{iii. Entrevista familiar}

Consiste em reunião entre os familiares do PD e um ou mais profissionais pertencentes à CIHDOTT ou Organização de Procura de Órgãos (OPO), com a finalidade de esclarecer dúvidas e fornecer subsídios para a decisão familiar ${ }^{343}$. A entrevista deve constar de conteúdo e direção.

Conteúdo: consiste em informações essenciais sobre o processo da doação como: o diagnóstico de morte encefálica (estabelecido por médicos não pertencentes às equipes de captação); a doação só pode ocorrer com autorização familiar e o tempo médio para o término do processo ser de 24-36 horas não havendo custos em decorrência da doação dos órgãos, esclarecendo que o corpo não será deformado 343,346 .

Direção: o entrevistador deve apresentar-se pelo nome e na medida do possível realizar o contato em ambiente isolado. Lembrar sempre que a doação é opção; a família precisa de tempo para aceitar a perda e entender a morte encefálica como morte ${ }^{343}$.

Verificar se os exames clínicos, assim como o complementar, foram realizados e corretamente preenchidos conforme as Diretrizes do Conselho Federal de Medicina.

A retirada de órgãos e tecidos, ou partes do corpo humano de pessoas falecidas para transplante ou outra finalidade terapêutica, dependerá do cônjuge ou parente maior de idade, obedecida a linha sucessória, reta ou colateral, até o segundo grau inclusive, firmada em documento subscrito por duas testemunhas.

\section{iv. Retirada de órgãos e tecidos ${ }^{341,347}$}

Definir o horário de retirada do(s) órgão(s)/tecido(s) - mínimo de 06 horas após o envio das informações do PD à CNCDO.
Receber as equipes e coordenar a retirada dos órgãos indicados para transplante, bem como providenciar a retirada dos rins, fazendo cumprir o acordado no termo de doação.

\section{v. Entrega do corpo à família ${ }^{347}$}

Acompanhar e supervisionar a entrega do corpo à família.

\section{Organização do centro transplantador}

\section{A) Critérios para habilitação e estrutura do centro transplantador}

Os estabelecimentos de saúde e as equipes médicas interessadas em desenvolver Programa de Transplante de Coração deverão observar integralmente as determinações da Portaria n. 3.407, de 05/08/1998, do Ministério da Saúde, que regulamenta as disposições da Lei n. 9.434, de 04/02/1997, com as alterações de dispositivos através da Lei n. 10.211, de 23/03/2001, e do decreto n. 2.268, de 30/07/1997. Deverão também observar a Portaria MS n. 270 de 24/06/1999, as Portarias GM n. 901 e n. 905 de 16/08/2000, n. 91 de 23/01/2001, n. 783 de 12/04/2006 e Portaria SAS n. 284 de 25/06/2004.

A estrutura hospitalar mínima necessária para credenciamento de um centro transplantador está demonstrada na Tabela 91. A estrutura hospitalar deveria estar preparada não só para o transplante, mas também para o implante de dispositivos de assistência ventricular mecânica.-

A equipe médica deverá ter experiência comprovada em cirurgia cardíaca e ter disponibilidade a qualquer hora, para a realização do transplante, assim como para o atendimento

Tabela 91 - Estrutura hospitalar exigida para credenciamento de um centro para transplante de coração

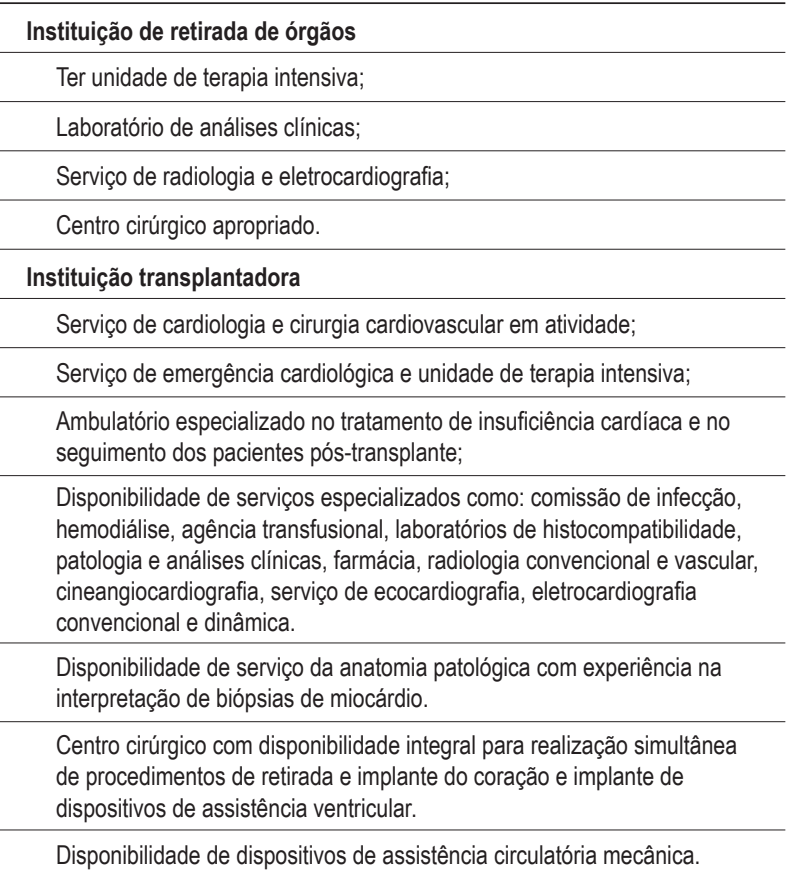




\section{Diretrizes}

ao paciente no período pré e pós-transplante, em curto e longo prazos. Toda a equipe de transplante cardíaco deverá ter seu protocolo de condutas aprovado pelo comitê de ética local e este deve ficar disponibilizado para conhecimento da comunidade científica, sendo revisado e atualizado periodicamente. Deve haver um coordenador clínico e um coordenador cirúrgico ${ }^{14}$. A equipe médica da instituição transplantadora deverá satisfazer as recomendações expostas na Tabela 92.

\section{B) Aspectos éticos do transplante cardíaco}

\section{i. Introdução}

O transplante cardíaco representa hoje uma opção de extraordinário valor para os pacientes em estado avançado

\section{Tabela 92 - Equipe médica da instituição transplantadora}

\begin{tabular}{|c|c|}
\hline Especialistas & Objetivos \\
\hline $\begin{array}{l}\text { Dois cirurgiões } \\
\text { cardiovasculares em } \\
\text { atividade }\end{array}$ & $\begin{array}{l}\text { Estar familiarizados com os protocolos de seleção, } \\
\text { retirada e preservação do coração do doador, } \\
\text { diferentes técnicas de transplante, complicações } \\
\text { pós-operatórias e a instalação de assistência } \\
\text { circulatória mecânica. }\end{array}$ \\
\hline Dois cardiologistas & $\begin{array}{l}\text { Ter experiência no tratamento da insuficiência } \\
\text { cardiaca aguda e crônica; na interpretação dos } \\
\text { exames anatomopatológicos, no manuseio da } \\
\text { terapia imunossupressora, no tratamento das } \\
\text { infecções e de outras complicações pós-operatórias } \\
\text { imediatas e tardias. }\end{array}$ \\
\hline Dois anestesistas & Ter experiência comprovada em cirurgia cardíaca. \\
\hline Ecocardiografista & $\begin{array}{l}\text { Realizar e interpretar o ecocardiograma do receptor } \\
\text { no seguimento pós-operatório. }\end{array}$ \\
\hline Hemodinamicista & $\begin{array}{l}\text { Realizar as biópsias endomiocárdicas e estudos } \\
\text { invasivos após o transplante. }\end{array}$ \\
\hline Patologista & $\begin{array}{c}\text { Ser capaz de avaliar as biópsias e diagnosticar } \\
\text { rejeições. }\end{array}$ \\
\hline Infectologista & $\begin{array}{l}\text { Ter experiência no diagnóstico e tratamento das } \\
\text { patologias relacionadas ao transplante }\end{array}$ \\
\hline Imunologista & $\begin{array}{l}\text { Apto em terapia imunossupressora e suas } \\
\text { complicações. O imunologista poderia dar } \\
\text { consultoria à distância. }\end{array}$ \\
\hline $\begin{array}{l}\text { Especialista em } \\
\text { saúde mental }\end{array}$ & $\begin{array}{l}\text { Para avaliação de candidatos a transplante, quando } \\
\text { necessário. }\end{array}$ \\
\hline
\end{tabular}

\section{Referências}

1. Luckraz H, Sharples L, Charman S, Tsui S, Wallwork J, Parameshwar J, et al. Does heart transplantation confer survival benefit in all risk groups? J Heart Lung Transplant. 2005; 24 (9): 1231-4.

2. Dickstein K, Cohen-Solal A, Filippatos G, McMurray J, Ponikowski P, PooleWilson $\mathrm{P}$, et al. ESC guidelines for the diagnosis and treatment of acute and chronic heart failure 2008: the Task Force for the diagnosis and treatment of acute and chronic heart failure 2008 of the European Society of Cardiology. Developed in collaboration with the Heart Failure Association of the ESC e irreversível de IC e de máxima importância em nosso meio com uma relação custo e benefício muito favorável. Sobrevida de mais de 20 anos é frequente em inúmeros grupos brasileiros, com qualidade de vida a custo seguramente inferior do que o demandado pelas custosas internações que tais pacientes invariavelmente necessitariam.

Dessa forma, podemos considerar o transplante cardíaco uma opção ética por excelência e que precisa receber das autoridades públicas de saúde, todo o estímulo para que os centros credenciados possam realizar este procedimento em todo o Brasil ${ }^{348}$.

A única observação preocupante que faríamos é o pequeno número de transplantes realizados por ano. Profunda análise é necessária para verificar quais medidas seriam necessárias para reverter tal situação.

\section{ii. Algumas questões de importância}

\section{a) Retransplante cardíaco}

O retransplante cardíaco foi considerado uma opção questionável do ponto de vista ético, porém, hoje, face aos melhores resultados, pode-se entender como procedimento justificável em casos selecionados ${ }^{349,350}$.

\section{b) Transplante cardiopulmonar}

O transplante cardiopulmonar, pela utilização de 3 órgãos vitais em um único paciente, constitui-se em opção eticamente controversa, principalmente em virtude da limitada sobrevida. A melhora dos esquemas de imunossupressão e as indicações absolutamente precisas podem pontualmente justificar a indicação ${ }^{351-353}$.

\section{C) Papel da Secretaria de Saúde na organização do sistema de transplante cardíaco}

Os centros de transplantes organizados pelas Secretarias de Saúde dos Estados têm auxiliado muito na racionalização da busca e distribuição de órgãos de forma ética e eficaz. Entretanto, é consenso desta diretriz que uma ação de Estado para melhorar a qualificação e o treinamento dos médicos de pronto-socorro e unidade de terapia intensiva seja necessária no reconhecimento e manuseio de pacientes em morte encefálica, assim como a promoção de ações para viabilizar a doação.
(HFA) and endorsed by the European Society of Intensive Care Medicine (ESICM). Eur J Heart Fail. 2008; 10 (10): 933-89.

3. Sociedade Brasileira de Cardiologia. III Diretriz brasileira de insuficiência cardíaca crônica. Arq Bras Cardiol. 2009; 93 (1 supl.1): 1-71.

4. Mehra M, Kobashigawa J, Starling R, Russell S, Uber P, Parameshwar J, et al. Listing criteria for heart transplantation: International Society for Heart and Lung Transplantation guidelines for the care of cardiac transplant 
candidates--2006. J Heart Lung Transplant. 2006; 25 (9): 1024-42.

5. Jessup M, Banner N, Brozena S, Campana C, Costard-Jäckle A, Dengler T, et al. Optimal pharmacologic and non-pharmacologic management of cardiac transplant candidates: approaches to be considered prior to transplant evaluation: International Society for Heart and Lung Transplantation guidelines for the care of cardiac transplant candidates-2006. J Heart Lung Transplant. 2006; 25 (9): 1003-23.

6. Weiss E, Nwakanma L, Patel N, Yuh D. Outcomes in patients older than 60 years of age undergoing orthotopic heart transplantation: an analysis of the UNOS database. J Heart Lung Transplant. 2008; 27 (2): 184-91.

7. Cahalin L, Mathier M, Semigran M, Dec G, DiSalvo T. The six-minute walk test predicts peak oxygen uptake and survival in patients with advanced heart failure. Chest. 1996; 110 (2): 325-32.

8. Arena R, Myers J, Abella J, Peberdy M, Bensimhon D, Chase P, et al. Development of a ventilatory classification system in patients with heart failure. Circulation. 2007; 115 (18): 2410-7.

9. Myers J, Arena R, Dewey F, Bensimhon D, Abella J, Hsu L, et al. A cardiopulmonary exercise testing score for predicting outcomes in patients with heart failure. Am Heart J. 2008; 156 (6): 1177-83.

10. Guimarães G, Silva M, d'Avila V, Ayub-Ferreira S, Silva C, Bocchi E. VO pico e inclinação $\mathrm{VE} / \mathrm{VCO}_{2}$ na era dos betabloqueadores na insuficiência cardíaca: uma experiência brasileira. Arq Bras Cardiol. 2008; 91 (1): 42-8.

11. Chiribiri A, Anselmino M, Del Grosso A, Trevi G, Bobbio M. Long-term followup of patients eligible, deferred, or ineligible for heart transplantation. J Heart Lung Transplant. 2008; 27 (4): 380-6.

12. Odim J, Wheat J, Laks H, Kobashigawa J, Gjertson D, Osugi A, et al. Perioperative renal function and outcome after orthotopic heart transplantation. J Heart Lung Transplant. 2006; 25 (2): 162-6.

13. Bocchi E, Fiorelli A. The paradox of survival results after heart transplantation for cardiomyopathy caused by Trypanosoma cruzi. First Guidelines Group for Heart Transplantation of the Brazilian Society of Cardiology. Ann Thorac Surg. 2001; 71 (6): 1833-8.

14. Sociedade Brasileira de Cardiologia. I Diretriz para transplante cardíaco. Arq Bras Cardiol. 1999; 73 (supl. 5): 1-55.

15. Mancini D, Eisen H, Kussmaul W, Mull R, Edmunds LJ, Wilson J. Value of peak exercise oxygen consumption for optimal timing of cardiac transplantation in ambulatory patients with heart failure. Circulation. 1991; 83 (3): 778-86.

16. Aaronson K, Schwartz J, Chen T, Wong K, Goin J, Mancini D. Development and prospective validation of a clinical index to predict survival in ambulatory patients referred for cardiac transplant evaluation. Circulation. 1997; 95 (12): 2660-7.

17. Peterson L, Schechtman K, Ewald G, Geltman E, Meyer T, Krekeler P, et al. The effect of beta-adrenergic blockers on the prognostic value of peak exercise oxygen uptake in patients with heart failure. J Heart Lung Transplant. 2003; 22 (1): 70-7.

18. Pohwani A, Murali S, Mathier M, Tokarczyk T, Kormos R, McNamara D, et al. Impact of beta-blocker therapy on functional capacity criteria for heart transplant listing. J Heart Lung Transplant. 2003; 22 (1): 78-86.

19. Deng M, De Meester J, Smits J, Heinecke J, Scheld H. Effect of receiving a heart transplant: analysis of a national cohort entered on to a waiting list, stratified by heart failure severity. Comparative Outcome and Clinical Profiles in Transplantation (COCPIT) Study Group. BMJ. 2000; 321 (7260): 540-5.

20. Levy WC, Mozaffarian D, Linker DT, Sutradhar SC, Anker SD, Cropp AB, et al. The Seattle Heart Failure Model: prediction of survival in heart failure. Circulation. 2006; 113: 1424-33.

21. Sociedade Brasileira de Cardiologia. Diretriz brasileira de insuficiência cardíaca aguda. Arq Bras Cardiol. 2009; 93 (3 supl.3): 1-65.

22. Ezekowitz J, Hernandez A, Starling R, Yancy C, Massie B, Hill J, et al. Standardizing care for acute decompensated heart failure in a large megatrial: the approach for the Acute Studies of Clinical Effectiveness of Nesiritide in Subjects with Decompensated Heart Failure (ASCEND-HF). Am Heart J. 2009; 157 (2): 219-28.

23. Jessup M, Abraham W, Casey D, Feldman A, Francis G, Ganiats T, et al. 2009 focused update: ACCF/AHA Guidelines for the Diagnosis and Management of Heart Failure in Adults: a report of the American College of Cardiology
Foundation/American Heart Association Task Force on Practice Guidelines: developed in collaboration with the International Society for Heart and Lung Transplantation. Circulation. 2009; 119 (14): 1977-2016.

24. Connors AJ, Speroff T, Dawson N, Thomas C, Harrell FJ, Wagner D, et al. The effectiveness of right heart catheterization in the initial care of critically ill patients. SUPPORT Investigators. JAMA. 1996; 276 (11): 889-97.

25. Petersen J, Felker G. Inotropes in the management of acute heart failure. Crit Care Med. 2008; 36 (1 Suppl): S106-11.

26. Stahl M, Richards N. Update on ventricular assist device technology. AACN Adv Crit Care. 2009; 1: 26-34.

27. Stevenson L, Kormos R. Mechanical Cardiac Support 2000: current applications and future trial design. J Thorac Cardiovasc Surg. 2001; 121 (3): 418-24

28. Goldstein D, Oz M, Rose E. Implantable left ventricular assist devices. N Engl J Med. 1998; 339 (21): 1522-33.

29. Delgado D, Rao V, Ross H, Verma S, Smedira N. Mechanical circulatory assistance: state of art. Circulation. 2002; 106 (16): 2046-50.

30. Hochman J, Sleeper L, Webb J, Sanborn T, White H, Talley J, et al. Early revascularization in acute myocardial infarction complicated by cardiogenic shock. SHOCK Investigators. Should We Emergently Revascularize Occluded Coronaries for Cardiogenic Shock. N Engl J Med. 1999; 341 (9): 625-34.

31. Louis Lt, Sun B. Advances in mechanical circulatory support. Curr Opin Organ Transplant. 2008; 13 (5): 522-5

32. Renlund D, Taylor D, Kfoury A, Shaddy R. New UNOS rules: historical background and implications for transplantation management. United Network for Organ Sharing. J Heart Lung Transplant. 1999; 18 (11): 1065-70.

33. Norkiene I, Ringaitiene D, Rucinskas K, Samalavicius R, Baublys A Miniauskas S, et al. Intra-aortic balloon counterpulsation in decompensated cardiomyopathy patients: bridge to transplantation or assist device. Interact Cardiovasc Thorac Surg. 2007; 6 (1): 66-70.

34. Jessup M, Banner N, Brozena S, Campana C, Costard-Jäckle A, Dengler T, et al. Optimal pharmacologic and non-pharmacologic management of cardiac transplant candidates: approaches to be considered prior to transplant evaluation: International Society for Heart and Lung Transplantation guidelines for the care of cardiac transplant candidates--2006. J Heart Lung Transplant. 2006; 25 (9): 1003-23.

35. Gronda E, Bourge R, Costanzo M, Deng M, Mancini D, Martinelli L, et al. Heart rhythm considerations in heart transplant candidates and considerations for ventricular assist devices: International Society for Heart and Lung Transplantation guidelines for the care of cardiac transplant candidates--2006. J Heart Lung Transplant. 2006; 25 (9): 1043-56.

36. Drakos S, Kfoury A, Gilbert E, Horne B, Long J, Stringham J, et al. Effect of reversible pulmonary hypertension on outcomes after heart transplantation. J Heart Lung Transplant. 2007; 26 (4): 319-23.

37. Shah R, Semigran M. Pulmonary hypertension secondary to left ventricular systolic dysfunction: contemporary diagnosis and management. Curr Heart Fail Rep. 2008; 5(4): 226-32.

38. Chang P, Longenecker J, Wang N, Baughman K, Conte J, Hare J, et al. Mild vs severe pulmonary hypertension before heart transplantation: different effects on posttransplantation pulmonary hypertension and mortality. J Heart Lung Transplant. 2005; 24 (8): 998-1007.

39. Butler J, Stankewicz M, Wu J, Chomsky D, Howser R, Khadim G, et al. Pretransplant reversible pulmonary hypertension predicts higher risk for mortality after cardiac transplantation. J Heart Lung Transplant. 2005; 24 (2):170-7.

40. Craig M, Pereira N. Right heart catheterization and risk stratification in advanced heart failure. Curr Heart Fail Rep. 2006; 3 (3): 143-52.

41. Goland S, Czer L, Kass R, De Robertis M, Mirocha J, Coleman B, et al. Preexisting pulmonary hypertension in patients with end-stage heart failure: impact on clinical outcome and hemodynamic follow-up after orthotopic heart transplantation. J Heart Lung Transplant. 2007; 26 (4): 312-8.

42. Wade C, Reith K, Sikora J, Augustine S. Postoperative nursing care of the cardiac transplant recipient. Crit Care Nurs Q. 2004; 27(1): 17-28.

43. Pereira W. Manual de transplantes de órgãos e tecidos. $3^{a}$ ed. Rio de Janeiro: 


\section{Diretrizes}

Guanabara Koogan; 2004.

44. Hoffman F. Outcomes and complications after heart transplantation: a review. J Cardiovasc Nurs. 2005; 20 (5 Suppl): S31-42.

45. Roza B, Duarte M, Luz R, Mendes K, Lima A, Nunes C, et al. Protocolo de assistência de enfermagem ao paciente submetido ao transplante cardíaco. Protocolo de cuidados de enfermagem em Transplante Órgãos: ABTO; 2008.

46. Lemos C, Neves N. Métodos de avaliação social em programa de transplante cardíaco. Rev Soc. Cardiol Estado de São Paulo. 2000; 10 (1 supl. A): 11-20.

47. Moreira M, Alvarenga R. O parecer social. CFESS - Estudo social em perícias, laudos e pareceres técnicos: contribuição ao debate no judiciário, no penitenciário e na previdência social / Conselho Federal de Serviço Social. 6⿳a ed. São Paulo: Cortez; 2006.

48. Anker S, Negassa A, Coats A, Afzal R, Poole-Wilson P, Cohn J, et al. Prognostic importance of weight loss in chronic heart failure and the effect of treatment with angiotensin-converting-enzyme inhibitors: an observational study. Lancet. 2003; 361: 1077-83.

49. von Haehling S, Lainscak M, Springer J, Anker S. Cardiac cachexia: a systematic overview. Pharmacol Ther. 2009; 121 (3): 227-52.

50. Meltzer J, Moitra V. The nutritional and metabolic support of heart failure in the intensive care unit. Curr Opin Clin Nutr Metab Care. 2008; 11 (2): 140-6.

51. Kamimura M, Baxmann A, Sampaio LLC. Avaliação nutricional. In: Cuppar L. (editor). Guias de medicina ambulatorial e hospitalar: nutrição clínica no adulto. 2a ed. São Paulo: Manole; 2005. p. 89-127.

52. Gray G, Gray L. Anthropometric measurements and their interpretation: principles, practices, and problems. J Am Diet Assoc. 1980; 77 (5): 534-9.

53. Frisancho A. Antropometrics standards for the assessment of growth and nutritional status. Michigan: Michigan University; 1990.

54. da Costa H. Avaliação nutricional de pacientes portadores de insuficiência cardíaca no período pré-transplante cardíaco [dissertação]. São Paulo: Universidade de São Paulo; 2008.

55. Nicol S, Carroll D, Homeyer C, Zamagni C. The identification of malnutrition in heart failure patients. Eur J Cardiovasc Nurs. 2002; 1 (2): 139-47.

56. Hauptman P, Rich M, Heidenreich P, Chin J, Cummings N, Dunlap M, et al. The heart failure clinic: a consensus statement of the Heart Failure Society of America. J Card Fail. 2008; 14 (10): 801-15

57. Kreymann K, Berger M, Deutz N, Hiesmayr M, JollietP, Kazandjiev G, et al. ESPEN Guidelines on Enteral Nutrition: Intensive care. Clin Nutr. 2006; 25 (2): 210-23.

58. Aquilani R, Opasich C, Verri M, Boschi F, Febo O, Pasini E, et al. Is nutritional intake adequate in chronic heart failure patients? J Am Coll Cardiol. 2003 $42(7): 1218-23$

59. Strassburg S, Anker S. Metabolic and immunologic derangements in cardiac cachexia: where to from here? Heart Fail Rev. 2006; 11 (1): 57-64.

60. Nakasato M. Efeitos agudos do sal de adição na dieta de pacientes estávei com insuficiência cardíaca crônica [dissertação]. São Paulo: Universidade de São Paulo; 2003.

61. American Psychiatric Association. Diagnostic and statistical manual. 4th ed Michigan: APA Publications; 2000.

62. Denollet J, Sys S, Brutsaert D. Personality and mortality after myocardial infarction. Psychosom Med. 1995; 57 (6): 582-91.

63. Denollet J. DS14: standard assessment of negative affectivity, social inhibition, and Type D personality. Psychosom Med. 2005; 67(1):89-97.

64. Pereira A, Rosa J, Haddad N. Adaptação psicológica, fatores de risco e probabilidade de sobrevida em transplante cardíaco. Mudanças. 2002; 10 (1): 41-61.

65. Brandwin M, Trask P, Schwartz S, Clifford M. Personality predictors of mortality in cardiac transplant candidates and recipients. J Psychosom Res. 2000; 49 (2): 141-7.

66. Levenson J, Olbrisch M. Psychosocial evaluation of organ transplant candidates: a comparative survey of process, criteria, and outcomes in heart, liver, and kidney transplantation. Psychosomatics. 1993; 34 (4): 314-23.

67. Smith J, Danskine A, Laylor R, Rose M, Yacoub M. The effect of panel reactive antibodies and the donor specific crossmatch on graft survival after heart and heart-lung transplantation. Transpl Immunol. 1993; 1(1): 60-5.

68. Loh E, Bergin J, Couper G, Mudge GJ. Role of panel-reactive antibody crossreactivity in predicting survival after orthotopic heart transplantation. J Heart Lung Transplant. 1994; 13(2): 194-201.

69. Lavee J, Kormos R, Duquesnoy R, Zerbe T, Armitage J, Vanek M, et al. Influence of panel-reactive antibody and lymphocytotoxic crossmatch on survival after heart transplantation. J Heart Lung Transplant. 1991; 10 (6): 921-9; discussion 929-30.

70. Zangwill S, Ellis T, Zlotocha J, Jaquiss R, Tweddell J, Mussatto K, et al. The virtual crossmatch--a screening tool for sensitized pediatric heart transplant recipients. Pediatr Transplant. 2006; 10 (1): 38-41.

71. Zangwill S, Ellis T, Stendahl G, Zahn A, Berger S, Tweddell J. Practical application of the virtual crossmatch. Pediatr Transplant. 2007; 11 (6): 650-4.

72. Vaidya S. Clinical importance of anti-human leukocyte antigen-specific antibody concentration in performing calculated panel reactive antibody and virtual crossmatches. Transplantation. 2008; 85 (7): 1046-50.

73. Michaels P, Espejo M, Kobashigawa J, Alejos J, Burch C, Takemoto S, et al. Humoral rejection in cardiac transplantation: risk factors, hemodynamic consequences and relationship to transplant coronary artery disease. J Heart Lung Transplant. 2003; 22 (1): 58-69.

74. Reed E, Demetris A, Hammond E, Itescu S, Kobashigawa J, Reinsmoen N, et al. Acute antibody-mediated rejection of cardiac transplants. J Heart Lung Transplant. 2006; 25 (2): 153-9.

75. Ho E, Vasilescu E, Colovai A, Stokes M, Hallar M, Markowitz G, et al. Sensitivity, specificity and clinical relevance of different cross-matching assays in deceased-donor renal transplantation. Transpl Immunol. 2008; 20 (1-2): 61-7.

76. Taylor D, Edwards L, Aurora P, Christie J, Dobbels F, Kirk R, et al. Registry of the International Society for Heart and Lung Transplantation: twenty-fifth official adult heart transplant report--2008. J Heart Lung Transplant. 2008; 27 (9): 943-56

77. Opelz G, Döhler B, Laux G. Long-term prospective study of steroid withdrawal in kidney and heart transplant recipients. Am J Transplant. 2005; 5 (4 Pt 1): 720-8.

78. Crespo-Leiro M. Calcineurin inhibitors in heart transplantation. Transplant Proc. $2005 ; 37$ (9): 4018-20.

79. Knight S, Morris P. The clinical benefits of cyclosporine C2-level monitoring: a systematic review. Transplantation. 2007; 83 (12): 1525-35

80. Taylor D, Barr M, Radovancevic B, Renlund D, Mentzer RJ, Smart F, et al. A randomized, multicenter comparison of tacrolimus and cyclosporine immunosuppressive regimens in cardiac transplantation: decreased hyperlipidemia and hypertension with tacrolimus. J Heart Lung Transplant. 1999; 18 (4): 336-45.

81. Reichart B, Meiser B, Viganò M, Rinaldi M, Yacoub M, Banner N, et al. European multicenter tacrolimus heart pilot study: three year follow-up. J Heart Lung Transplant. 2001;20(2):249-50.

82. Kobashigawa JA, Miller LW, Russell SD, Ewald GA, Zucker MJ, Goldberg LR, et al. Tacrolimus with mycophenolate mofetil (MMF) or sirolimus vs. cyclosporine with MMF in cardiac transplant patients: 1-year report. Am J Transplant. 2006; 6: 1243-5

83. Grimm M, Rinaldi M, Yonan NA, Arpesella G, Arizón Del Prado JM Pulpón LA, et al. Superior prevention of acute rejection by tacrolimus vs. cyclosporine in heart transplant recipients--a large European trial. Am J Transplant. 2006; 6: 1387-97

84. Mentz RM Jr, Jahania MS, Lasley RD. Tacrolimus as a rescue immunosuppressant after heart and lung transplantation. The US multicenter FK506 Study group. Transplantation. 1998; 65: 109-13.

85. Kobashigawa JA, Meiser BM. Review of major clinical trials with mycophenolate mofetil in cardiac transplantation. Transplantation. 2005; 80: S235-S243.

86. Kobashigawa JA, Renlund DG, Gerosa G, Almenar L, Eisen HJ, Keogh AM, et al. Similar efficacy and safety of enteric-coated Mycophenolate Sodium (ECMPS, Myfortic) compared With Mycophenolate Mofetil (MMF) in de novo 
heart transplant recipients: results of a 12-Month, single-blind, randomized, parallel-group, multicenter study. J Heart Lung Transplant. 2006; 25: 935-41.

87. Staatz CE, Tett SE. Clinical pharmacokinetics and pharmacodynamics of mycophenolate in solid organ transplant recipients. Clin Pharmacokinet. 2007; 46: 13-58.

88. Kobashigawa J, Miller L, Renlund D, Mentzer R, Alderman E, Bourge R, et al. A randomized active-controlled trial of mycophenolate mofetil in heart transplant recipients. Mycophenolate Mofetil Investigators. Transplantation. 1998; 66 (4): 507-15

89. Hosenpud JD, Bennett LE. Mycophenolate mofetil versus azathioprine in patients surviving the initial cardiac transplant hospitalization: an analysis of the Joint UNOS/ISHLT Thoracic Registry. Transplantation. 2001; 74: 1662-5.

90. Keogh A. Long-term benefits of mycophenolate mofetil after heart transplantation. Transplantation. 2005; 79: S45-S46.

91. O'Neill JO, Edwards LB, Taylor DO. Mycophenolate mofetil and risk of developing malignancy after orthotopic heart transplantation: analysis of the transplant registry of the ISHLT. J Heart Lung Transplant. 2006; 25: 1186-91.

92. Eisen HJ, Kobashigawa JA, Keogh A, Bourge R, Renlund D, Mentzer R. Threeyear results of a randomized, double-blind, controlled trial of mycophenolate mofetil versus azathioprine in cardiac transplant recipients. J Heart Lung Transplant. 2005; 24: 517-25.

93. Bacal F, Silva CP, Bocchi EA, Pires PV, Moreira LF, Issa VS, et al. Mycophenolate mofetil increased Chagas' disease reactivation in heart transplanted patients: comparison between two different protocols. Am J Transplant. 2005; 5: 2017-21

94. Bestetti RB, Souza TR, Lima MF, Theodoropoulos TAD. Effects of a mycophenolate mofetil-based immunosuppressive regimen in Chagas' heart transplant recipients. Transplantation. 2007; 84: 441-2.

95. Raichlin E, Kushwaha SS. Proliferation signal inhibitors and cardiac allograft vasculopathy. Curr Opin Organ Transplant. 2008; 13: 543-50.

96. Bocchi EA, Ahualli L, Amuchastegui M, Boullon F, Cerutti B, Colque R, et al. Recommendations for use of everolimus after heart transplantation: results from a Latin-American consensus meeting. Transplant Proc. 2006; 38: $937-42$.

97. Eisen HJ, Tuzcu EM, Dorent R, Kobashigawa JA, Mancini D, Valantine-von Kaeppler $\mathrm{HA}$, et al. Everolimus for the prevention of allograft rejection and vasculopathy in cardiac-transplant recipients. N Engl J Med. 2003; 349: $847-58$.

98. Keogh A, Richardson M, Ruygrok P, Spratt B, Galbraith A, O'Driscoll G, et al. Sirolimus in de novo heart transplant recipients reduces acute rejection and prevents coronary artery disease at 2 years: a randomized clinical trial. Circulation. 2004; 110: 2694-700

99. Mancini D, Pinney S, Burkhoff D, LaManca J, Itescu S, Burke E, et al. Use of rapamycin slows progression of cardiac transplantation vasculopathy. Circulation 2003; 108: 48-53.

100. Gustafsson F, Ross HI. Proliferation signal inhibitors in cardiac transplantation. Curr Opin Cardiol. 2007; 22: 111-6.

101. Chapman R, Valantine H, Albanell J, Arns WA, Campistol JM, Eisen H, et al. Proliferation signal inhibitors in transplantation: questions at the cutting edge of everolimus therapy. Transplant Proc. 2007; 39: 2937-50.

102. Zuckerman A, Aliabadi AZ. Calcineurin-inhibitor minimization protocols in heart transplantation, Transplant Int. 2009; 22: 78-89.

103.Zakliczynski M, Nozynski J, Kocher A, Lizak MK, Zakliczynska H, Przybylski $\mathrm{R}$, et al. Surgical wound-healing complications in heart transplant recipients treated with rapamycin. Wound Rep Reg. 2007; 15: 316-21.

104. Bestetti R, Theodoropoulos TA, Burdmann EA, Abbud Filho M, Cordeiro JA, Villafanha D. Switch from calcineurin inhibitors to sirolimus-induced renal recovery in heart transplant recipients in the midterm follow-up. Transplantation. 2006; 81 (5): 692-6

105. Rothenburger M, Zuckermann A, Bara C, Hummel M, Strüber M, Hirt S. Recommendations for the use of everolimus (certican) in heart transplantation: results from the second German-Austrian certican consensus conference. J Heart Lung Transplant. 2007; 26: 305-11.
106. Stewart S, Winters GL, Fishbein MC, Tazelaar HD, Kobashigawa J, Abrams I, et al. Revision of the 1990 working formulation for the standardization of nomenclature in the diagnosis of heart rejection. J Heart Lung Transplant. 2005; 24: 1710-20.

107. Tan C, Baldwin W, Rodriguez E. Update on cardiac transplantation pathology. Arch Pathol Lab Med. 2007; 131 (8): 1169-91.

108. Billingham M, Cary N, Hammond M, Kemnitz J, Marboe C, McCallister $\mathrm{H}$, et al. A working formulation for the standardization of nomenclature in the diagnosis of heart and lung rejection: Heart Rejection Study Group. The International Society for Heart Transplantation. J Heart Transplant. 1990 (6): 587-93.

109. Chantranuwat C, Qiao J, Kobashigawa J, Hong L, Shintaku P, Fishbein M. Immunoperoxidase staining for $\mathrm{C} 4 \mathrm{~d}$ on paraffin-embedded tissue in cardiac allograft endomyocardial biopsies: comparison to frozen tissue immunofluorescence. Appl Immunohistochem Mol Morphol. 2004; 12 (2): 166-71.

110.Fyfe B, Loh E, Winters G, Couper G, Kartashov A, Schoen F. Heart transplantation-associated perioperative ischemic myocardial injury: morphological features and clinical significance. Circulation. 1996; 93 (6): 1133-40.

111. Chan M, Pearson G. New advances in antirejection therapy. Curr Opin Cardiol. 2007; 22 (2): 117-22.

112. Lindenfeld J, Miller G, Shakar S, Zolty R, Lowes B, Wolfel E, et al. Drug therapy in the heart transplant recipient: part II: immunosuppressive drugs. Circulation. 2004; 110 (25): 3858-65.

113. Hunt S, Haddad F. The changing face of heart transplantation. J Am Col Cardiol. 2008; 52 (8): 587-98.

114. Bourke R, Rodriguez R, Tan C. Cardiac allograft rejection. In: Kirklin J. (editor). Heart transplantation. Philadelphia: Churchill Livingstone; 2002. p. $464-520$.

115. Hamond E, Renlund D. Cardiac allograft vascular (micro vascular) rejection. Curr Opin Organ Transplant. 2002; 7: 233-9

116. Garrett HJ, Duvall-Seaman D, Helsley B, Groshart K. Treatment of vascular rejection with rituximab in cardiac transplantation. J Heart Lung Transplant. 2005; 24 (9): 1337-42.

117.Eisen H. Immunosuppression on the horizon. Heart Fail Clin. 2007; 3 (1): 43-9.

118. Baran D. Induction therapy in cardiac transplantation: when and why? Heart Fail Clin. 2007; 3 (1): 31-41.

119. Tan H, Smaldone M, Shapiro R. Immunosuppressive preconditioning or induction regimens: evidence to date. Drugs. 2006; 66 (12): 1535-45.

120. Uber P, Mehra M. Induction therapy in heart transplantation: is there a role? J Heart Lung Transplant. 2007; 26 (3): 205-9.

121. Starnes V, Oyer P, Stinson E, Dein J, Shumway N. Prophylactic OKT3 used as induction therapy for heart transplantation. Circulation. 1989; 80 (5 Pt 2): $11179-83$

122. Hershberger R, Starling R, Eisen H, Bergh C, Kormos R, Love R, et al Daclizumab to prevent rejection after cardiac transplantation. N Engl J Med. 2005; 352 (26): 2705-13

123. Møller C, Gustafsson F, Gluud C, Steinbrüchel D. Interleukin-2 receptor antagonists as induction therapy after heart transplantation: systematic review with meta-analysis of randomized trials. J Heart Lung Transplant. 2008; 27 (8): 835-42.

124. Mehra M, Zucker M, Wagoner L, Michler R, Boehmer J, Kovarik J, et al. A multicenter, prospective, randomized, double-blind trial of basiliximab in heart transplantation. J Heart Lung Transplant. 2005; 24 (9): 1297-304

125. Carrier M, White M, Perrault L, Pelletier G, Pellerin M, Robitaille D, et al. A 10-year experience with intravenous thymoglobuline in induction of immunosuppression following heart transplantation. J Heart Lung Transplant. 1999; 18 (12): 1218-23.

126. Itescu S, Burke E, Lietz K, John R, Mancini D, Michler R, et al. Intravenous pulse administration of cyclophosphamide is an effective and safe treatment for sensitized cardiac allograft recipients. Circulation. 2002; 


\section{Diretrizes}

\section{5 (10): 1214-9}

127.Grauhan O, Knosalla C, Ewert R, Hummel M, Loebe M, Weng YG, et al. Plasmapheresis and cyclophosphamide in the treatment of humoral rejection after heart transplantation. J Heart Lung Transplant. 2001; 20 (3): 316-21.

128. Costanzo M, Koch D, Fisher S, Heroux A, Kao W, Johnson M. Effects of methotrexate on acute rejection and cardiac allograft vasculopathy in heart transplant recipients. J Heart Lung Transplant. 1997; 16 (2): 169-78.

129. Bacal F, Veiga V, Fiorelli A, Bellotti G, Bocchi E, Stolf N, et al. Treatment of persistent rejection with methotrexate in stable patients submitted to heart transplantation. Arq Bras Cardiol. 2000; 74 (2): 141-8.

130. Udi N, Yehuda S. Intravenous immunoglobulin - indications and mechanisms in cardiovascular diseases. Autoimmun Rev. 2008; 7 (6): 445-52.

131. Jordan S, Vo A, Peng A, Toyoda M, Tyan D. Intravenous gammaglobulin (IVIG): a novel approach to improve transplant rates and outcomes in highly HLA-sensitized patients. Am J Transplant. 2006; 6 (3): 459-66.

132. Singh N, Pirsch J, Samaniego M. Antibody-mediated rejection: treatment alternatives and outcomes. Transplant Rev (Orlando). 2009; 23 (1): 34-46.

133. Ross H, Hendry P, Dipchand A, Giannetti N, Hirsch G, Isaac D, et al. Canadian Cardiovascular Society Consensus Conference on cardiac transplantation. Can J Cardiol. 2001; 11: 1135-58.

134. Adult heart transplantation. Protocol Revised June 2002: Loma Linda (CA): Loma Linda University Medical Center; 2002.

135. Bocchi E, Mocelin A, de Moraes A, Menegheti C, Higuchi ML, Bacal F, et al. Comparison between two strategies for rejection detection after heart transplantation: routine endomyocardial biopsy versus gallium-67 cardiac imaging. Transplant Proc. 1997; 29: 586-8.

136. Butler C, Thompson R, Haykowsky M, Toma M, Paterson I. Cardiovascular magnetic resonance in the diagnosis of acute heart transplant rejection: review. J Cardiovasc Magn Reson. 2009; 11 (1): 7.

137. Taylor D, Edwards L, Mohacsi P, Boucek M, Trulock E, Keck B, et al. The registry of the International Society for Heart and Lung Transplantation: twentieth official adult heart transplant report--2003. J Heart Lung Transplant. $2003 ; 22$ (6): 616-24.

138. Aranda JJ, Hill J. Cardiac transplant vasculopathy. Chest. 2000; 118 (6): 1792-800.

139. Johnson D, Gao S, Schroeder J, DeCampli W, Billingham M. The spectrum of coronary artery pathologic findings in human cardiac allografts. J Heart Transplant. 1989; 8 (5): 349-59.

140. Bacal F, Veiga V, Fiorelli A, Bellotti G, Bocchi E, Stolf N, et al. Analysis of the risk factors for allograft vasculopathy in asymptomatic patients after cardiac transplantation. Arq Bras Cardiol. 2000; 75 (5): 421-8.

141. Schmauss D, Weis M. Cardiac allograft vasculopathy: recent developments. Circulation. 2008; 117 (16): 2131-41

142. Rogers N, Lechler R. Allorecognition. Am J Transplant. 2001; 1 (2): 97-102.

143.Smyth L, Herrera O, Golshayan D, Lombardi G, Lechler R. A novel pathway of antigen presentation by dendritic and endothelial cells: Implications for allorecognition and infectious diseases. Transplantation. 2006; 82 (1 Suppl): S15-8.

144. Bacal F, Stolf N, Veiga V, Chalela W, Grupi C, Rodrigues A, et al. Noninvasive diagnosis of allograft vascular disease after heart transplantation. Arq Bras Cardiol. 2001; 76 (1): 29-42.

145. Bacal F, Moreira L, Souza G, Rodrigues A, Fiorelli A, Stolf N, et al. Dobutamine stress echocardiography predicts cardiac events or death in asymptomatic patients long-term after heart transplantation: 4-year prospective evaluation. J Heart Lung Transplant. 2004; 23 (11): 1238-44.

146. Bogot N, Durst R, Shaham D, Admon D. Cardiac CT of the transplanted heart: indications, technique, appearance, and complications. Radiographics. 2007; 27 (5): 1297-309.

147. Weis $\mathrm{M}$, von Scheidt W. Coronary artery disease in the transplanted heart. Annu Rev Med. 2000; 51: 81-100.

148. Kobashigawa J, Tobis J, Starling R, Tuzcu E, Smith A, Valantine H, et al
Multicenter intravascular ultrasound validation study among heart transplant recipients: outcomes after five years. J Am Coll Cardiol. 2005; 45 (9): 1532-7.

149. Tuzcu E, Kapadia S, Sachar R, Ziada K, Crowe T, Feng J, et al. Intravascular ultrasound evidence of angiographically silent progression in coronary atherosclerosis predicts long-term morbidity and mortality after cardiac transplantation. J Am Coll Cardiol. 2005; 45 (9): 1538-42.

150. Kobashigawa J, Katznelson S, Laks H, Johnson J, Yeatman L, Wang X, et al. Effect of pravastatin on outcomes after cardiac transplantation. N Engl J Med. 1995; 333 (10): 621-7.

151. Keogh A, Macdonald P, Kaan A, Aboyoun C, Spratt P, Mundy J. Efficacy and safety of pravastatin vs simvastatin after cardiac transplantation. J Heart Lung Transplant. 2000; 19 (6): 529-37.

152. Schroeder J, Gao S, Alderman E, Hunt S, Johnstone I, Boothroyd D, et al. A preliminary study of diltiazem in the prevention of coronary artery disease in heart-transplant recipients. N Engl J Med. 1993; 328 (3): 164-70.

153. Erinc K, Yamani M, Starling R, Crowe T, Hobbs R, Bott-Silverman C, et al. The effect of combined Angiotensin-converting enzyme inhibition and calcium antagonism on allograft coronary vasculopathy validated by intravascular ultrasound. J Heart Lung Transplant. 2005; 24 (8): 1033-8.

154. Kobashigawa J, Tobis J, Mentzer R, Valantine H, Bourge R, Mehra M, et al. Mycophenolate mofetil reduces intimal thickness by intravascular ultrasound after heart transplant: reanalysis of the multicenter trial. Am J Transplant. 2006; 6 (5 Pt 1): 993-7.

155. Redonnet M, Tron C, Koning R, Bouchart F, Cribier A, Soyer R, et al. Coronary angioplasty and stenting in cardiac allograft vasculopathy following heart transplantation. Transplant Proc. 2000; 32 (2): 463-5.

156. Patel V, Radovancevic B, Springer W, Frazier O, Massin E, Benrey J, et al. Revascularization procedures in patients with transplant coronary artery disease. Eur J Cardiothorac Surg. 1997; 11 (5): 895-901.

157. Musci M, Loebe M, Wellnhofer E, Meyer R, Pasic M, Hummel M, et al. Coronary angioplasty, bypass surgery, and retransplantation in cardiac transplant patients with graft coronary disease. Thorac Cardiovasc Surg. 1998; 46 (5): 268-74

158. Ackemann J, Gross W, Mory M, Schaefer M, Gebhard M. Celsior versus custodiol: early postischemic recovery after cardioplegia and ischemia at 5 degrees C. Ann Thorac Surg. 2002; 74 (2): 522-9.

159. Bourge R, Naftel D, Costanzo-Nordin M, Kirklin J, Young J, Kubo S, et al. Pretransplantation risk factors for death after heart transplantation: a multiinstitutional study. The Transplant Cardiologists Research Database Group. J Heart Lung Transplant. 1993; 12 (4): 549-62.

160. McCrystal G, Pepe S, Esmore D, Rosenfeldt F. The challenge of improving donor heart preservation. Heart Lung Circ. 2004; 13 (1): 74-83.

161. Marasco S, Esmore D, Richardson M, Bailey M, Negri J, Rowland M, et al. Prolonged cardiac allograft ischemic time--no impact on long-term survival but at what cost? Clin Transplant. 2007; 21 (3): 321-9.

162. Nwakanma L, Shah A, Conte J, Baumgartner W. Heart transplantation. In: Cohn L. (editor). Cardiac surgery in the adult. 3rd ed. New York: McGrawHill; 2008. p. 1539-78.

163. Vega J, Ochsner J, Jeevanandam V, McGiffin D, McCurry K, Mentzer RJ, etal. A multicenter, randomized, controlled trial of Celsior for flush and hypothermic storage of cardiac allografts. Ann Thorac Surg. 2001; 71 (5): 1442-7.

164. Keon W, Hendry P, Taichman G, Mainwood G. Cardiac transplantation: the ideal myocardial temperature for graft transport. Ann Thorac Surg. 1988; 46 (3): $337-41$

165. Boku N, Tanoue Y, Kajihara N, Eto M, Masuda M, Morita S. A comparative study of cardiac preservation with Celsior or University of Wisconsin solution with or without prior administration of cardioplegia. J Heart Lung Transplant. 2006; 25 (2): 219-25.

166. Llosa J, Rodriguez Lambert J, Naya J, Gosalbez F, Valle J. Celsior, a novel cardioplegic solution for arrest and storage in heart transplantation. Transplant Proc. 2000; 32 (8): 2589-90.

167.Pereda D, Castella M, Pomar J, Cartaña R, Josa M, Barriuso C, et al. Elective cardiac surgery using Celsior or St. Thomas No. 2 solution: a prospective, single-center, randomized pilot study. Eur J Cardiothorac 
Surg. 2007; 32 (3): 501-6.

168. Conte J, Baumgartner W. Overview and future practice patterns in cardiac and pulmonary preservation. J Card Surg. 2000; 15 (2): 91-107.

169. Shumway N, Lower R, Stofer R. Transplantation of the heart. Adv Surg. 1966; 2: $265-84$.

170. Chaccur P, Dinkhuysen I, Nina V, Abdulmassih C, Arnoni A, Souza L, et al. Transplante cardíaco ortotópico pela técnica bicaval. Rev Bras Cir Cardiovasc. 1997; 12 (2): 145-52.

171. Webb W, Howard H, Neely W. Practical methods of homologous cardiac transplantation. J Thorac Surg. 1959; 37 (3): 361-6.

172. Forni A, Faggian G, Chiominto B, Perini G, Bertolini P, Zanini M, et al. Avoidance of atrioventricular valve incompetence following orthotopic heart transplantation using direct bicaval anastomosis. Transplant Proc. 1995; 27 (6): 3478-82.

173. Aziz T, Burgess M, Khafagy R, Wynn Hann A, Campbell C, Rahman A, et al. Bicaval and standard techniques in orthotopic heart transplantation: medium-term experience in cardiac performance and survival. J Thorac Cardiovasc Surg. 1999; 118 (1): 115-22.

174. Ichikawa S, Takeuchi Y, Suda Y, Ban T, Nunoda S. Tricuspid valve replacement after cardiac transplantation. Jpn J Thorac Cardiovasc Surg. 2000; 48 (10): 659-62.

175. Chan M, Giannetti N, Kato T, Kornbluth M, Oyer P, Valantine H, et al. Severe tricuspid regurgitation after heart transplantation. J Heart Lung Transplant. 2001; 20 (7): 709-17.

176. Jeevanandam V, Russell H, Mather P, Furukawa S, Anderson A, Grzywacz F, et al. A one-year comparison of prophylactic donor tricuspid annuloplasty in heart transplantation. Ann Thorac Surg. 2004; 78 (3): 759-66.

177. Jeevanandam V, Russell H, Mather P, Furukawa S, Anderson A, Raman J. Donor tricuspid annuloplasty during orthotopic heart transplantation: long-term results of a prospective controlled study. Ann Thorac Surg. 2006; 82 (6): 2089-95

178. Quinlan J, Murray A, Casta A. Anesthesia for heart, lung and heartlung transplantation. In: Kaplan J. (editor). Cardiac anesthesia. 5th ed. Philadelphia: WB Saunders Co; 2006. p. 845-65.

179. Rother A, Collard C. Anesthetic management for cardiac transplantation. In: Hensley Jr F, Martin D, Gravlee G. (editors). A practical approach to cardiac anesthesia. 3rd ed. Philadelphia: Lippincott Williams \& Wilkins; 2003. p. 425-47.

180. Baker J, Yost C, Niemann C. Organ transplantation. In: Miller R. (editor). Miller's anesthesia. 6th ed. Philadelphia: Churchill Livingstone; 2005

181. Consenso Brasileiro de Monitorização e suporte hemodinâmico. Parte II: Monitorização hemodinâmica básica e cateter de artéria pulmonar. Rev bras ter intensiva. 2006; 18(1):63-77.

182. Leibowitz A, Oropello J. The pulmonary artery catheter in anesthesia practice in 2007: an historical overview with emphasis on the past 6 years. Semin Cardiothorac Vasc Anesth. 2007; 11 (3): 162-76.

183. Thys D, Abel M, Bollen B, Cahalan MK, Curling P, Dean RJ, et al. Practice guidelines for perioperative transesophageal echocardiography: a report by the American Society of Anesthesiologists and the Society of Cardiovascular Anesthesiologists Task Force on Transesophageal Echocardiography. Anesthesiology. 1996; 84: 986-1006

184. Romano P, Mangion J. The role of intraoperative transesophageal echocardiography in heart transplantation. Echocardiography. 2002; 19 (7Pt 1): 599-604.

185. Phillips A, McLean R, Devitt J, Harrington E. Recall of intraoperative events after general anaesthesia and cardiopulmonary bypass. Can J Anaesth. 1993; 40 (10): $922-6$.

186. Bowdle T. Depth of anesthesia monitoring. Anesthesiol Clin. 2006; 24 (4): 793-822.

187. Vretzakis G, Ferdi E, Argiriadou H, Papaziogas B, Mikroulis D, Lazarides M, et al. Influence of bispectral index monitoring on decision making during cardiac anesthesia. J Clin Anesth. 2005; 17 (7): 509-16.

188. Shanewise J. Cardiac transplantation. Anesthesiol Clin North America. 2004,
22 (4): 753-65.

189. Raikhelkar J. Mechanical ventilation for cardiac support. Crit Care Clin. 2007; 23 (2): 291-8.

190. Auler Junior J, Galas F, Hajjar L, Franca S. Ventilação mecânica no intraoperatório. Rev bras ter intensiva. 2007; 19 (3): 393-8.

191. Miranda D, Gommers D, Papadakos P, Lachmann B. Mechanical ventilation affects pulmonary inflammation in cardiac surgery patients: the role of the open-lung concept. J Cardiothorac Vasc Anesth. 2007; 21 (2): 279-84.

192. Haddad F, Couture P, Tousignant C, Denault A. The right ventricle in cardiac surgery, a perioperative perspective: II. Pathophysiology, clinical importance, and management. Anesth Analg. 2009; 108 (2): 422-33.

193. Stobierska-Dzierzek B, Awad H, Michler R. The evolving management of acute right-sided heart failure in cardiac transplant recipients. J Am Coll Cardiol. 2001; 38 (4): 923-31.

194. Ramakrishna H, Jaroszewski D, Arabia F. Adult cardiac transplantation: a review of perioperative management (part-II). Ann Card Anaesth. 2009; 12 (2): 155-65.

195. Gold J, Cullinane S, Chen J, Seo S, Oz M, Oliver J, et al. Vasopressin in the treatment of milrinone-induced hypotension in severe heart failure. Am Cardiol. 2000; 85 (4): 506-8, A11.

196. Luckraz H, Goddard M, Charman S, Wallwork J, Parameshwar J, Large S. Early mortality after cardiac transplantation: should we do better? J Heart Lung Transplant. 2005; 24 (4): 401-5.

197. Hauptman P, Aranki S, Mudge G), Couper G, Loh E. Early cardiac allograft failure after orthotopic heart transplantation. Am Heart J. 1994; 127 (1): 179-86.

198. Kavarana M, Sinha P, Naka Y, Oz M, Edwards N. Mechanical support for the failing cardiac allograft: a single-center experience. J Heart Lung Transplant. 2003; 22 (5): 542-7.

199. Ibrahim M, Hendry P, Masters R, Rubens F, Lam B, Ruel M, et al. Management of acute severe perioperative failure of cardiac allografts: a single-centre experience with a review of the literature. Can J Cardiol. 2007; 23 (5): 363-7.

200. Petrofski J, Patel V, Russell S, Milano C. BVS5000 support after cardiac transplantation. J Thorac Cardiovasc Surg. 2003; 126 (2): 442-7.

201. Miniati DN, Robbins RC. Mechanical support for acutely failed heart or lung grafts. J Card Surg. 2000; 15 (2): 129-35

202. Ko W, Lin C, Chen R, Wang S, Lin F, Chen Y. Extracorporeal membrane oxygenation support for adult postcardiotomy cardiogenic shock. Ann Thorac Surg. 2002; 73 (2): 538-45.

203. Aranki S, Adams D, Rizzo R, Couper G, DeCamp M, Fitzgerald D, et al. Femoral veno-arterial extracorporeal life support with minimal or no heparin. Ann Thorac Surg. 1993; 56 (1): 149-55.

204. de Marchena E, Futterman L, Wozniak P, Madrid W, Mitrani A, Myerburg R, e al. Pulmonary artery torsion: a potentially lethal complication after orthotopic heart transplantation. J Heart Transplant. 1989; 8 (6): 499-502.

205. Esmore D, Spratt P, Branch J, Keogh A, Lee R, Farnsworth A, et al. Right ventricular assist and prostacyclin infusion for allograft failure in the presence of high pulmonary vascular resistance. J Heart Transplant. 1990; 9 (2): 136-41.

206. Mejia JAC, Souza Neto JD, Carvalho Jr W, Cavalcante Pinto Jr V, Mesquita F, Brasil HB, et al. Uso do óxido nítrico inalatório no tratamento da crise hipertensiva pulmonar no pós-operatório de transplante cardíaco. Rev Bras Cir Cardiovasc. 2002; 17 (3): 230-5

207. Subramaniam K, Yared J. Management of pulmonary hypertension in the operating room. Semin Cardiothorac Vasc Anesth. 2007; 11 (2): 119-36.

208. Germann P, Braschi A, Della Rocca G, Dinh-Xuan A, Falke K, Frostell C, et al Inhaled nitric oxide therapy in adults: European expert recommendations. Intensive Care Med. 2005; 31 (8): 1029-41.

209. Rajek A, Pernerstorfer T, Kastner J, Mares P, Grabenwöger M, Sessler D, et al. Inhaled nitric oxide reduces pulmonary vascular resistance more than prostaglandin E(1) during heart transplantation. Anesth Analg. 2000; 90 (3): 523-30.

210. George I, Xydas S, Topkara V, Ferdinando C, Barnwell E, Gableman L, et al 


\section{Diretrizes}

Clinical indication for use and outcomes after inhaled nitric oxide therapy. Ann Thorac Surg. 2006; 82 (6): 2161-9.

211. Arafa O, Geiran O, Andersen K, Fosse E, Simonsen S, Svennevig J. Intraaortic balloon pumping for predominantly right ventricular failure after heart transplantation. Ann Thorac Surg. 2000; 70 (5): 1587-93.

212. Yerebakan C, Buz S, Huebler M, Weng Y, Lehmkuhl H, Hetzer R. Right ventricular failure following heart transplantation--recovery after extended mechanical support. J Card Surg. 2008; 23 (5): 578-80.

213. Bajona P, Salizzoni S, Brann SH, Coyne J, Bermudez C, Kormos R, et al. Prolonged use of right ventricular assist device for refractory graft failure following orthotopic heart transplantation. J Thorac Cardiovasc Surg. 2009. [Epub ahead of print].

214. Whitlock R, Crowther M, Ng H. Bleeding in cardiac surgery: its prevention and treatment--an evidence-based review. Crit Care Clin. 2005; 21 (3): 589-610.

215. Levi M. Emergency reversal of antithrombotic treatment. Intern Emerg Med. 2009; 4 (2): 137-45

216. Schulman S, Bijsterveld N. Anticoagulants and their reversal. Transfus Med Rev. 2007; 21 (1): 37-48.

217. Cavalheiro Filho C, Rached R. Reversão da anticoagulação oral em situação de risco. Rev Soc Cardiol Estado de São Paulo. 2006; 4: 287-94.

218. Ferraris V, Ferraris S, Saha S, Hessel EN, Haan C, Royston B, et al. Perioperative blood transfusion and blood conservation in cardiac surgery: the Society of Thoracic Surgeons and The Society of Cardiovascular Anesthesiologists clinical practice guideline. Ann Thorac Surg. 2007; 83 (5 Suppl): S27-86

219. Ramos A, Asensio A, Muñez E, Torre-Cisneros J, Blanes M, Carratalá J, et al. Incisional surgical infection in heart transplantation. Transpl Infect Dis. 2008 10 (4): 298-302.

220. Mattner F, Kola A, Fischer S, Becker T, Haverich A, Simon A, et al. Impact of bacterial and fungal donor organ contamination in lung, heart-lung, heart and liver transplantation. Infection. 2008; 36 (3): 207-12.

221. Konvalinka A, Errett L, Fong I. Impact of treating Staphylococcus aureus nasal carriers on wound infections in cardiac surgery. J Hosp Infect. 2006; 64 (2): $162-8$

222.Baran D, Alwarshetty M, Alvi S, Arroyo L, Lubitz S, Pinney S, et al. Is toxoplasmosis prophylaxis necessary in cardiac transplantation? Longterm follow-up at two transplant centers. J Heart Lung Transplant. 2006; 25 (11): 1380-2.

223. Baden L, Katz J, Franck L, Tsang S, Hall M, Rubin R, et al. Successful toxoplasmosis prophylaxis after orthotopic cardiac transplantation with trimethoprim-sulfamethoxazole. Transplantation. 2003; 75 (3): 339-43.

224. Derouin F, Pelloux H. Prevention of toxoplasmosis in transplant patients. Clin Microbiol Infect. 2008; 14 (12): 1089-101.

225. Olsen S, Renlund D, O'Connell J, Taylor D, Lassetter J, Eastburn T, et al. Prevention of pneumocystis carinii pneumonia in cardiac transplant recipients by trimethoprim sulfamethoxazole. Transplantation. 1993; 56 (2): 359-62

226. Kramer M, Stoehr C, Lewiston N, Starnes V, Theodore J. Trimethoprimsulfamethoxazole prophylaxis for Pneumocystis carinii infections in heart-lung and lung transplantation--how effective and for how long? Transplantation. 1992; 53 (3): 586-9.

227. Opelz G, Döhler B, Ruhenstroth A. Cytomegalovirus prophylaxis and graft outcome in solid organ transplantation: a collaborative transplant study report. Am J Transplant. 2004; 4 (6): 928-36.

228. Moro J, Almenar L, Martinez-Dolz L, Blanes M, Aguero J, Sanchez-Lázaro I, et al. Utility of oral valgancicclovir for cytomegalovirus prophylaxis: does it improve treatment compliance? Transpl Proc. 2008; 40 (9): 3063-4.

229. Gupta S, Mitchell J, Markham D, Mammen P, Patel P, Kaiser P, et al. High incidence of cytomegalovirus disease in $\mathrm{D}+/ \mathrm{R}$ - heart transplant recipient shortly after completion of 3 months of valganciclovir prophylaxis. J Heart Lung Transplant. 2008; 27 (5): 536-9.

230. Bellotti G, Bocchi E, de Moraes A, Higuchi M L, Barbero-Marcial M, Sosa
E, et al. In vivo detection of Trypanosoma cruzi antigens in hearts of patients with chronic Chagas' heart disease. Am Heart J. 1996; 131 (2): 301-7.

231. Bocchi E, Bellotti G, Mocelin A, Uip D, Bacal F, Higuchi M, et al. Heart transplantation for chronic Chagas' heart disease. Ann Thorac Surg. 1996; 61 (6): 1727-33.

232. Stolf N, Higushi L, Bocchi E, Bellotti G, Auler J, Uip D, et al. Heart transplantation in patients with Chagas' disease cardiomyopathy. J Heart Transplant. 1987; 6 (5): 307-12.

233. Bestetti R, Theodoropoulos T. A systematic review of studies on heart transplantation for patients with end-stage Chagas' heart disease. J Card Fail. 2009; 15 (3): 249-55.

234. Amato Neto V, Matsubara L, Uip D, Strabelli T, Bocchi E, Stolf N, et al. Heart transplantation: donor with Chagas' disease and clinical course of the receptor. Rev Hosp Clin Fac Med São Paulo. 1992; 47: 92-4.

235. Bocchi E, Bellotti G, Uip D, Kalil J, Higuchi ML, Fiorelli A, et al. Long-term follow-up after heart transplantation in Chagas' disease. Transplant Proc. 1993; 25 (1 Pt 2): 1329-30.

236. Fiorelli A, Stolf N, Honorato R, Bocchi E, Bacal F, Uip D, et al. Later evolution after cardiac transplantation in Chagas' disease. Transplant Proc. 2005; 37 (6): 2793-8.

237. Bestetti R, Castilho O, Teno L, Freitas O. Absence of Trypanosoma cruzi myocardial infection reactivation in Chagas' heart transplant. Cardiovasc Pathol $1994 \cdot 3 \cdot 257-9$

238. Campos S, Strabelli T, Amato Neto V, Silva C, Bacal F, Bocchi E, et al. Risk factors for Chagas' disease reactivation after heart transplantation J Heart Lung Transplant. 2008; 27(6): 597-602.

239. Lahura P, Matsubara L, Amato Neto V, Okumura M, Bocchi E. Characterization of Trypanosoma cruzi strains isolated from patients with heart transplantation. Rev Hosp Clin Fac Med Sao Paulo. 1995; 50 (2): 97-100.

240. Bocchi E, Vieira M, Fiorelli A, Hayashida S, Mayzato M, Leirner A, et al. Hemodynamic and neurohormonal profile during assisted circulation with heterotopic artificial ventricle followed by heart transplantation. Arq Bras Cardiol. 1994; 62 (1): 23-7.

241. Higuchi ML, Gutierrez P, Aiello V, Palomino S, Bocchi E, Kalil J, et al. Immunohistochemical characterization of infiltrating cells in human chronic chagasic myocarditis: comparison with myocardial rejection process. Virchows Arch A Pathol Anat Histopathol. 1993; 423 (3): 157-60.

242. Benvenuti LA, Roggério A, Sambiase NV, Fiorelli A, Higuchi ML. Polymerase chain reaction in endomyocardial biopsies for monitoring reactivation of Chagas' disease in heart transplantation: a case report and review of the literature. Cardiovasc Pathol. 2005; 14 (5): 265-8.

243.Diez M, Favaloro L, Bertolotti A, Burgos JM, Vigliano C, Lastra MP, et al. Usefulness of PCR strategies for early diagnosis of Chagas' disease reactivation and treatment follow-up in heart transplantation. Am J Transplant. 2007; 7(6):1633-40

244. Bocchi E, Fiorelli A. The Brazilian experience with heart transplantation: a multicenter report. J Heart Lung Transplant. 2001; 20 (6): 637-45.

245. Feuerstein I, Geller A. Skin cancer education in transplant recipients. Prog Transplant. 2008; 18 (4): 232-41.

246. Bocchi E, Higuchi M, Vieira M, Stolf N, Bellotti G, Fiorelli A, et al. Higher incidence of malignant neoplasms after heart transplantation for treatment of chronic Chagas' heart disease. J Heart Lung Transplant. 1998; 17 (4) :399-405.

247. Kellerman L, Neugut A, Burke B, Mancini D. Comparison of the incidence of de novo solid malignancies after heart transplantation to that in the general population. Am J Cardiol. 2009; 103 (4): 562-6.

248. Amato R, Jac J, Giessinger S, Saxena S, Willis J. A phase 2 study with a daily regimen of the oral mTOR inhibitor RAD001 (everolimus) in patients with metastatic clear cell renal cell cancer. Cancer. 2009; 115 (11): 2438-46.

249. Heuer M, Benkö T, Cicinnati V, Kaiser G, Sotiropoulos G, Baba H, et al. Effect of low-dose rapamycin on tumor growth in two human hepatocellular cancer cell lines. Transplant Proc. 2009; 41 (1): 359-65.

250. Copeland J, Griepp R, Bieber C, Billingham M, Schroeder J, Hunt S, et al. 
Successful retransplantation of the human heart. J Thorac Cardiovasc Surg. 1977; 73 (2): 242-7.

251. Trulock E, Christie J, Edwards L, Boucek M, Aurora P, Taylor D, et al. Registry of the International Society for Heart and Lung Transplantation: twenty-fourth official adult lung and heart-lung transplantation report-2007. J Heart Lung Transplant. 2007; 26 (8): 782-95.

252. Magee J, Barr M, Basadonna G, Johnson M, Mahadevan S, McBride M, et al. Repeat organ transplantation in the United States, 1996-2005. Am J Transplant. 2007; 7 (5 Pt 2): 1424-33.

253. Taylor D, Edwards L, Boucek M, Trulock E, Deng M, Keck B, et al. Registry of the International Society for Heart and Lung Transplantation: twenty-second official adult heart transplant report--2005. J Heart Lung Transplant. 2005; 24 (8): 945-55.

254. Chin C, Naftel D, Pahl E, Shankel T, Clark M, Gamberg P, et al. Cardiac re-transplantation in pediatrics: a multi-institutional study. J Heart Lung Transplant. 2006; 25 (12): 1420-4.

255. Mahle W, Vincent R, Kanter K. Cardiac retransplantation in childhood: analysis of data from the United Network for Organ Sharing. J Thorac Cardiovasc Surg. 2005; 130 (2): 542-6.

256. Miller L. Cardiovascular toxicities of immunosuppressive agents. Am J Transplant. 2002; 2 (9): 807-18.

257. Jindal R, Hjelmesaeth J. Impact and management of posttransplant diabetes mellitus. Transplantation. 2000; 70 (11 Suppl): SS58-63.

258. Cheng AY, Fantus IG. Oral antihyperglycemic therapy for type 2 diabetes mellitus. CMAJ. 2005; 172 (2): 213-26.

259. Kahn S, Haffner S, Heise M, Herman W, Holman R, Jones N, et al. Glycemic durability of rosiglitazone, metformin, or glyburide monotherapy. $\mathrm{N} \mathrm{Engl} \mathrm{J}$ Med. 2006; 355 (23): 2427-43.

260. Hampton T. Diabetes drugs tied to fractures in women. JAMA. 2007; 297 (15): 1645

261. Hatorp V, Hansen K, Thomsen M. Influence of drugs interacting with CYP3A4 on the pharmacokinetics, pharmacodynamics, and safety of the prandial glucose regulator repaglinide. J Clin Pharmacol. 2003; 43 (6): 649-60.

262. Niemi M, Backman JT, Neuvonen M, Neuvonen PJ, Kivistö KT. Rifampin decreases the plasma concentrations and effects of repaglinide. Clin Pharmacol Ther. 2000; 68 (5): 495-500.

263. Pham PT, Pham PC, Lipshutz GS, Wilkinson AH. New onset diabetes mellitus after solid organ transplantation. Endocrinol Metab Clin North Am. 2007; 36 (4):873-90.

264. Bortolotto L, Silva H, Bocchi E, Bellotti G, Stolf N, Jatene A. Long-term course and complications of arterial hypertension after heart transplantation. Arq Bras Cardiol. 1997; 69 (5): 317-21.

265.Leenen F, Coletta E, Davies R. Prevention of renal dysfunction and hypertension by amlodipine after heart transplant. Am J Cardiol. 2007; 100 (3): 531-5.

266. Subramanian S, Trence D. Immunosuppressive agents: effects on glucose and lipid metabolism. Endocrinol Metab Clin North Am. 2007; 36 (4): 891-905.

267. Bellotti G, Bocchi E, Goiato M, Bacal F, Stolf N, Pileggi F, et al. Lipid profile changes during the late follow-up after heart transplantation. Arq Bras Cardiol. 1996; 66 (5): 263-6.

268. Ballantyne C, Radovancevic B, Farmer J, Frazier O, Chandler L, PaytonRoss C, et al. Hyperlipidemia after heart transplantation: report of a 6-year experience, with treatment recommendations. J Am Coll Cardiol. 1992; 19 (6): 1315-21.

269. Keogh A, Simons L, Spratt P, Esmore D, Chang V, Hickie J, etal. Hyperlipidemia after heart transplantation. J Heart Transplant. 1988; 7 (3): 171-5.

270. Stamler J, Vaughan D, Rudd M, Mudge G, Kirshenbaum J, Young P, et al. Frequency of hypercholesterolemia after cardiac transplantation. Am J Cardiol. 1988; 62 (17): 1268-72

271. Kubo S, Peters J, Knutson K, Hertz M, Olivari M, Bolman R, et al. Factors influencing the development of hypercholesterolemia after cardiac transplantation. Am J Cardiol. 1992; 70 (4): 520-6.
272. Lardinois C, Neuman S. The effects of antihypertensive agents on serum lipids and lipoproteins. Arch Intern Med. 1988; 148 (6): 1280-8.

273. Renlund D, Bristow M, Crandall B, Burton N, Doty D, Karwande S, et al. Hypercholesterolemia after heart transplantation: amelioration by corticosteroid-free maintenance immunosuppression. J Heart Transplant. 1989; 8 (3): 214-9.

274. Ballantyne C, Podet E, Patsch W, Harati Y, Appel V, Gotto AJ, et al. Effects of cyclosporine therapy on plasma lipoprotein levels. JAMA. 1989; 262 (1): 53-6.

275. Atkins D, Psaty B, Koepsell T, Longstreth WJ, Larson E. Cholesterol reduction and the risk for stroke in men: a meta-analysis of randomized, controlled trials. Ann Intern Med. 1993; 119 (2): 136-45.

276. Uretsky B, Murali S, Reddy P, Rabin B, Lee A, Griffith B, et al. Development of coronary artery disease in cardiac transplant patients receiving immunosuppressive therapy with cyclosporine and prednisone. Circulation. 1987; 76 (4): 827-34.

277. Bilodeau M, Fitchett D, Guerraty A, Sniderman A. Dyslipoproteinemias afte heart and heart-lung transplantation: potential relation to accelerated graft arteriosclerosis. J Heart Transplant. 1989; 8 (6): 454-9.

278. Kuo P, Kirshenbaum J, Gordon J, Laffel G, Young P, DiSesa V, et al. Lovastatin therapy for hypercholesterolemia in cardiac transplant recipients. Am J Cardiol. 1989; 64 (10): 631-5.

279. Pham PT, Pham PC, Danovitch GM. Cardiovascular disease posttransplant. Semin Nephrol. 2007; 27 (4): 430-44.

280. Groetzner J, Kaczmarek I, Mueller M, Huber S, Deutsch A, Daebritz S, et al. Freedom from graft vessel disease in heart and combined heart- and kidneytransplanted patients treated with tacrolimus-based immunosuppression. Heart Lung Transplant. 2005; 24 (11): 1787-92.

281. Angermann CE, Störk S, Costard-Jäckle A, Dengler TJ, Siebert U, Tenderich $\mathrm{G}$, et al. Reduction of cyclosporine after introduction of mycophenolate mofetil improves chronic renal dysfunction in heart transplant recipients--the IMPROVED multi-centre study. Eur Heart J. 2004; 25 (18): 1626-34.

282. Cantarovich M. Renal protective strategies in heart transplant patients. Curr Opin Cardiol. 2007; 22 (2): 133-8.

283. Kulak CA, Borba VZ, Kulak Junior J, Shane E. Transplantation osteoporosis. Arq Bras Endocrinol Metabol. 2006; 50 (4): 783-92.

284. Maalouf N, Shane E. Osteoporosis after solid organ transplantation. J Clin Endocrinol Metab. 2005; 90 (4): 2456-65.

285. Shane E, Addesso V, Namerow P, McMahon D, Lo S, Staron R, et al. Alendronate versus calcitriol for the prevention of bone loss after cardiac transplantation. N Engl J Med. 2004; 350 (8): 767-76.

286. Fusar-Poli P, Picchioni M, Martinelli V, Bhattacharyya S, Cortesi M, Barale $\mathrm{F}$, et al. Anti-depressive therapies after heart transplantation. J Heart Lung Transplant. 2006; 25 (7): 785-93.

287. Lindenfeld J, Page Rn, Zolty R, Shakar S, Levi M, Lowes B, et al. Drug therapy in the heart transplant recipient: Part III: common medical problems. Circulation. 2005; 111 (1): 113-7.

288. Guida B, Perrino N, Laccetti R, Trio R, Nastasi A, Pesola D, et al. Role of dietary intervention and nutritional follow-up in heart transplant recipients. Clin Transplant. 2009; 23 (1): 101-7.

289. Haynes R, Ackloo E, Sahota N, McDonald H, Yao X. Interventions for enhancing medication adherence (Cochrane Review). Cochrane Database Syst Rev. 2008(2): CD 000011.

290. Cupples S, Dew M, Grady K, De Geest S, Dobbels F, Lanuza D, et al. Report of the Psychosocial Outcomes Workgroup of the Nursing and Social Sciences Council of the International Society for Heart and Lung Transplantation: present status of research on psychosocial outcomes in cardiothoracic transplantation: review and recommendations for the field. J Heart Lung Transplant. 2006; 25 (6): 716-25.

291. Evangelista L, Dracup K, Doering L, Moser D, Kobashigawa J. Physical activity patterns in heart transplant women. J Cardiovasc Nurs. 2005; 20 (5): 334-9.

292. Basile A, Maccherini M, Diciolla F, Balistreri A, Bouklas D, Lisi G, et al. Sexual disorders after heart transplantation. Transplant Proc. 2001; 33 (1-2): 1917-9. 


\section{Diretrizes}

293. Canter C, Shaddy R, Bernstein D, Hsu D, Chrisant M, Kirklin J, et al. Indications for heart transplantation in pediatric heart disease: a scientific statement from the American Heart Association Council on Cardiovascular Disease in the Young; the Councils on Clinical Cardiology, Cardiovascular Nursing, and Cardiovascular Surgery and Anesthesia; and the Quality of Care and Outcomes Research Interdisciplinary Working Group. Circulation. 2007; 115 (5): 658-76

294. Boucek M, Aurora P, Edwards L, Taylor D, Trulock E, Christie J, et al. Registry of the International Society for Heart and Lung Transplantation: tenth official pediatric heart transplantation report--2007. J Heart Lung Transplant. 2007; 26 (8): 796-807.

295. Webber SA, McCurry K, Zeevi A. Heart and lung transplantation in children Lancet. 2006; 368 : 53-69.

296. Pediatric Heart Transplantation Protocol. Loma Linda (CA): University Medical Loma Linda Center and Children's Hospital/Transplantation Institute/ Cardiac Transplant Program; 2002.

297. Canter CE, Kantor PF. Heart transplant for pediatric cardiomyopathy. Progres in Pediatric Cardiology. 2007; 23 (1-2): 67-72.

298. Huddleston C. Indications for heart transplantation in children. Progress in Pediatric Cardiology. 2009;26(1):3-9.

299. Tjang Y, Stenlund H, Tenderich G, Hornik L, Körfer R. Pediatric heart transplantation: current clinical review. J Card Surg. 2008; 23 (1): 87-91.

300. Azeka E, Marcial MB, Jatene M, Auler JO Jr, Ramires JA. Eight-yea experience of pediatric heart transplantation: clinical outcome using noninvasive methods for the evaluation of acute rejection. Pediatr Transplant. 2002; 6 (3): 208-13.

301. Azeka E, Auler JO Jr, Marcial MB, Fumagalli F, Ramires JA. Heart transplantation in children: clinical outcome during the early postoperative period. Pediatr Transplant. 2005; 9 (4): 491-7.

302. Azeka E, Franchini Ramires J, Valler C, Alcides Bocchi E. Delisting of infants and children from the heart transplantation waiting list after carvedilol treatment. J Am Coll Cardiol. 2002; 40 (11): 2034-8.

303. Duncan B, Burch M, Kirklin J, Price J. Management of patients awaiting transplantation: medical, immunologic and mechanical support. In: Cante CE, Kirklin J. (editors). Pediatric heart transplantation. Philadelphia: Elsevier ; 2007. p. 33-54

304. Showengerdt K, Azeka E. Infection following pediatric heart transplantation. In: Canter CE, Kirklin J. (editors). Pediatric heart transplantation. Philadelphia: Elsevier; 2007. p. 157-71.

305. Kirk R, Edwards L, Aurora P, Taylor D, Christie J, Dobbels F, et al. Registry of the International Society for Heart and Lung Transplantation: eleventh official pediatric heart transplantation report--2008. J Heart Lung Transplant. 2008; 27 (9): 970-7.

306. Ameduri R, Canter CE. Current practice in immunosuppression in pediatric cardiac transplantation. Progress in Pediatric Cardiology. 2009;26(1):31-7.

307. Jordan S, Quartel A, Czer L, Admon D, Chen G, Fishbein M, et al. Posttransplant therapy using high-dose human immunoglobulin (intravenous gammaglobulin) to control acute humoral rejection in renal and cardiac allograft recipients and potential mechanism of action. Transplantation. 1998; 66 (6): 800-5.

308. Webber S, Naftel D, Parker J, Mulla N, Balfour I, Kirklin J, et al. Late rejection episodes more than 1 year after pediatric heart transplantation: risk factors and outcomes. J Heart Lung Transplant. 2003; 22 (8): 869-75.

309. Huddleston C, Alejos J, Thul J. Postoperative management: early graft failure, pulmonary hypertension, and initial immunosuppression strategies. In: Canter CE, Kirklin J. (editors). Pediatric heart transplantation. Baltimore: ISHLT; 2007. p. 103-22.

310. Boucek RJ, Naftel D, Boucek M, Chinnock R, Morrow R, Pahl E, et al. Induction immunotherapy in pediatric heart transplant recipients: a multicenter study. J Heart Lung Transplant. 1999; 18 (5): 460-9.

311. Di Filippo S, Boissonnat P, Sassolas F, Robin J, Ninet J, Champsaur G, et al . Rabbit antithymocyte globulin as induction immunotherapy in pediatric heart transplantation. Transplantation. 2003; 75 (3): 354-8.

312. Parisi F, Danesi H, Squitieri C, Di Chiara L, Ravà L, Di Donato R.
Thymoglobuline use in pediatric heart transplantation. J Heart Lung Transplant. 2003; 22 (5): 591-3.

313. Reddy SC, Laughlin K, Webber SA. Immunosuppression in Pediatric Heart Transplantation: 2003 and Beyond. Curr Treat Options Cardiovasc Med. 2003; 5 (5): 417-28.

314. Canter CE, Moorhead S, Saffitz J, Huddleston C, Spray T. Steroid withdrawal in the pediatric heart transplant recipient initially treated with triple immunosuppression. J Heart Lung Transplant. 1994; 13 (1 Pt 1): 74-9.

315. Lee K, Pierce J, Hess M, Hastillo A, Wechsler A, Guerraty A. Cardiac transplantation with corticosteroid-free immunosuppression: long-term results. Ann Thorac Surg. 1991; 52 (2): 211-7.

316. Au J, Gregory J, Colquhoun I, Scott C, Hilton C, Hunter S, et al. Paediatric cardiac transplantation with steroid-sparing maintenance immunosuppression. Arch Dis Child. 1992; 67 (10): 1262-6.

317. Russo L, Webber S. Pediatric heart transplantation: immunosuppression and its complications. Curr Opin Cardiol. 2004; 19 (2): 104-9.

318. Shumway NE, Lower RR, Stofer RC. Transplantation of the heart. Adv Surg. $1966 ; 2: 265-84$

319. Vouhé PR, Tamisier D, Le Bidois J, Sidi D, Mauriat P, Pouard P, et al. Pediatric cardiac transplantation for congenital heart defects: surgical considerations and results. Ann Thorac Surg. 1993; 56: 1239-47.

320. Allard M, Assaad A, Bailey L, Marcelletti C, Mavroudis C, Rose E, et al. Session IV: Surgical techniques in pediatric heart transplantation. J Heart Lung Transplant. 1991; 10 (5 Pt 2): 808-27.

321. Dipchand A, Cecere R, Delgado D, Dore A, Giannetti N, Haddad H, et al. Canadian Consensus on cardiac transplantation in pediatric and adult congenital heart disease patients. Can J Cardiol. 2005; 21 (13): 1145-7.

322. Mollaret P, Goulon M. The depassed coma (preliminary memoir). Rev Neurol (Paris). 1959; 101: 3-15.

323. A definition of irreversible coma. Report of the Ad Hoc Committee of the Harvard Medical School to Examine the Definition of Brain Death. JAMA. 1968; 205 (6): 337-40.

324. Wijdicks E. The diagnosis of brain death. N Engl J Med. 2001; 344 (16): 1215-21

325. Bernat J. How can we achieve uniformity in brain death determinations? Neurology. 2008; 70 (4): 252-3.

326. Morenski J, Oro J, Tobias J, Singh A. Determination of death by neurological criteria. J Intensive Care Med 2003; 18(4): 211-21.

327. Costa P, Machado M, Traesel M. Cuidados em UTI com o potencial doador de múltiplos órgãos. Acta Méd. 2005; 26: 406-22.

328. Wood K, Becker B, McCartney J, D'Alessandro A, Coursin D. Care of the potential organ donor. N Engl J Med. 2004; 351 (26): 2730-9.

329. Lopez-Navidad A, Caballero F. For a rational approach to the critical points of the cadaveric donation process. Transplant Proc. 2001; 33 (1-2): 795-805.

330. Chamorro C, Silva J, Romera M. Cardiac donor management: another point of view. Transplant Proc. 2003; 35 (5): 1935-7.

331. Ueno T, Zhi-Li C, Itoh T. Unique circulatory responses to exogenous catecholamines after brain death. Transplantation. 2000; 70 (3): 436-40.

332.Pennefather S, Bullock R, Mantle D, Dark J. Use of low dose arginine vasopressin to support brain-dead organ donors. Transplantation. 1995; 59 (1): 58-62.

333. Novitzky D, Horak A, Cooper D, Rose A. Electrocardiographic and histopathologic changes developing during experimental brain death in the baboon. Transplant Proc. 1989; 21 (1 Pt 3): 2567-9

334. Jeevanandam V, Furukawa S, Prendergast T, Todd B, Eisen H, McClurken J. Standard criteria for an acceptable donor heart are restricting heart transplantation. Ann Thorac Surg. 1996; 62 (5): 1268-75.

335. Sarmento A, Freitas F, Tavares A, Machado D. Organ donor viral screening and its implications in transplantation; an overview. Transplant Proc. 2000; 32 (8): 2571-6.

336. Bramstedt K, Young J. Use of the internet by United States heart transplant 
centers to promote transparency in the process of patient selection. Telemed J Health. 2006; 12 (3): 359-62.

337. Schnuelle P, Berger S, de Boer J, Persijn G, van der Woude F. Donor employment of vasopressors and its impact on allograft survival after transplantation. Transplant Proc. 2001; 33 (1-2): 1282-3

338. Sasso-Mendes K, Curvo P, Silveira R, Galvão C. Organ donation: acceptance and refusal among users of the public health system from Brazil. Transplant Proc. 2008; 40 (3): 660-2.

339.Smith M. Physiologic changes during brain stem death: lessons for management of the organs donor. J Heart Lung Transplant. 2004; 23: S217-22.

340. Roza B, Odiema M, Glezer M, Sá J. Captação de órgãos para transplante. In: Knobel E. (editor). Condutas no paciente grave. São Paulo: Atheneu; 2006. p. 1753-64.

341. Secretaria de Estado da Saúde de São Paulo. Resolução n ${ }^{\circ}$ 94. Dispõe sobre a estrutura organizacional e operacional do Sistema Estadual de Transplantes de São Paulo. In: Diário Oficial do Estado de São Paulo: São Paulo; 115 (122): 1 을 de julho de 2005.

342. Instituto de Direito Sanitário Aplicado. IDISA. Portaria n 1262. Aprovacão do Regulamento Técnico para estabelecer as atribuições, deveres e indicadores de eficiência e do potencial de doação de órgãos e tecidos relativos às Comissões Intra Hospitalares de Doação de Órgãos e Tecidos para Transplante (CIH-DOTT). In: Diário Oficial da União: Brasília; 2006.

343. Secretaria de Estado da Saúde. Doação de órgãos e tecidos. São Paulo; 2002.

344. Razek T, Olthoff K, Reilly P. Issues in potential organ donor management. Surg Clin North Am. 2000; 80 (3): 1021-32.

345. Karcioğlu O, Ayrik C, Erbil B. The brain-dead patient or a flower in the vase? The emergency department approach to the preservation of the organ donor.
Eur J Emerg Med. 2003; 10 (1): 52-7.

346. Brasil. Lei no 10.211. Alteração dos dispositivos da Lei no 9.434, de 4 de fevereiro de 1997, que dispõe sobre a remoção de órgãos, tecidos e partes do corpo humano para fins de transplante e tratamento. In: Diário Oficial da União: Brasília; 1997. p. 2191-3.

347. COFEN. RESOLUÇÃO COFEN № 292/2004. Normatiza a atuação do enfermeiro na captação e transplante de órgãos e tecidos. Reunião ordinária № 318, realizada em 2/5/2004. In: Conselho Federal de Medicina. Critérios do diagnóstico de morte encefálica. Brasília; 2004.

348. Vila JHA. Transplante cardíaco. In: Tratado de cardiologia da SOCESP. São Paulo: Manole; 2008.

349. Tjang Y, Tenderich G, Hornik L, Körfer R. Cardiac retransplantation in adults: an evidence-based systematic review. Thorac Cardiovasc Surg. 2008; 56 (6): 323-7.

350. Goerler H, Simon A, Gohrbandt B, Hagl C, Oppelt P, Haverich A, et al. Cardiac retransplantation: is it justified in times of critical donor organ shortage? Long-term single-center experience. Eur J Cardiothorac Surg. 2008; 34 (6): $1185-90$

351. Silva JP, Vila JHA, Cascudo MM, Baumgratz JF, Gauze Filho T, Deininger MO, et al. The heart-lung transplant: initial clinical experience. Rev Port Cardiol. 1993; $12(1): 51-5$.

352. Silva JP, Vila JHA, Cascudo MM, Baumgratz JF, Saraiva PA, Netto CD. Heart and unilateral lung transplantation for cardiomyopathy with high pulmonary vascular resistance. Ann Thorac Surg. 1992; 53 (4): 700-2.

353.Görler H, Strüber M, Ballmann M, Müller C, Gottlieb J, Warnecke G, et al. Lung and heart-lung transplantation in children and adolescents: a long-term single-center experience. J Heart Lung Transplant. 2009; 28 (3): 243-8. 